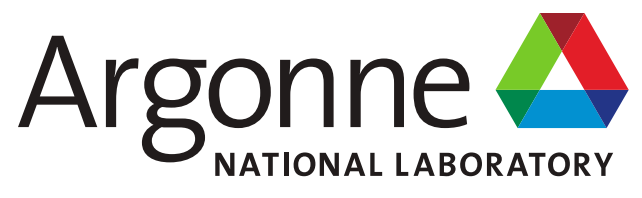

\title{
Involute Working Group - Development and Validation of the Finite Element Models of the Cheverton-Kelley Experiments
}

Nuclear Science \& Engineering Division 


\begin{abstract}
About Argonne National Laboratory
Argonne is a U.S. Department of Energy laboratory managed by UChicago Argonne, LLC under contract DE-AC02-06CH11357. The Laboratory's main facility is outside Chicago, at 9700 South Cass Avenue, Argonne, Illinois 60439. For information about Argonne and its pioneering science and technology programs, see www.anl.gov.
\end{abstract}

\title{
DOCUMENT AVAILABILITY
}

Online Access: U.S. Department of Energy (DOE) reports produced after 1991 and a growing number of pre-1991 documents are available free at OSTI.GOV (http://www.osti.gov/), a service of the U.S. Dept. of Energy's Office of Scientific and Technical Information.

\author{
Reports not in digital format may be purchased by the public from the \\ National Technical Information Service (NTIS): \\ U.S. Department of Commerce \\ National Technical Information Service \\ 5301 Shawnee Rd \\ Alexandria, VA 22312 \\ www.ntis.gov \\ Phone: (800) 553-NTIS (6847) or (703) \\ 605-6000 Fax: (703) 605-6900 \\ Email: orders@ntis.gov
}

Reports not in digital format are available to DOE and DOE contractors from the Office of Scientific and Technical Information (OSTI):

U.S. Department of Energy

Office of Scientific and Technical Information

P.O. Box 62

Oak Ridge, TN 37831-0062

www.osti.gov

Phone: (865) 576-8401

Fax: (865) 576-5728

Email: reports@osti.gov

Disclaimer

\section{Disclaimer}

This report was prepared as an account of work sponsored by an agency of the United States Government. Neither the United States Government nor any agency thereof, nor UChicago Argonne, LLC, nor any of their employees or officers, makes any warranty, express or implied, or assumes any legal liability or responsibility for the accuracy, completeness, or usefulness of any information, apparatus, product, or process disclosed, or represents that its use would not infringe privately owned rights. Reference herein to any specific commercial product, process, or service by trade name, trademark, manufacturer, or otherwise, does not necessarily constitute or imply its endorsement, recommendation, or favoring by the United States Government or any agency thereof. The views and opinions of document authors expressed herein do not necessarily state or reflect those of the United States Government or any agency thereof, Argonne National Laboratory, or UChicago Argonne, LLC. 


\section{Involute Working Group - Development and Validation of the Finite Element Models of the Cheverton-Kelley Experiments}

prepared by

M. Sitek, A. Bergeron, C. Bojanowski, Y. Yu, J. Licht

Nuclear Science \& Engineering Division, Argonne National Laboratory

September 2020 
(This page left intentionally blank) 


\section{Executive Summary}

There are three research reactors in the world with fuel plates curved as circle-involute (a spiral generated around a circle):

- The Oak Ridge National Laboratory (ORNL) High Flux Isotope Reactor (HFIR) located in Tennessee, U.S.A.,

- The Laue-Langevin Institute (ILL) High Flux Reactor (RHF) located in Grenoble, France, and

- The Technical University of Munich (TUM) Research Neutron Source Heinz Maier-Leibnitz (FRM II) located in Garching, Germany.

All three reactors are currently using Highly Enriched Uranium (HEU, ${ }^{235} \mathrm{U} / \mathrm{U} \geq 20 \mathrm{wt}$. \%) as fuel and all three are actively engaged in non-proliferation activities to convert to Low Enriched Uranium (LEU, $235 \mathrm{U} / \mathrm{U}<20$ wt. \%) fuel.

Conversion of these reactors to LEU fuel requires internal and/or external changes to the fuel plate dimensions. In the early design stage, it is important to verify that the proposed LEU fuel plates will conserve their mechanical integrity during operation using computational fluid dynamics (CFD) and finite element method (FEM) modeling.

In an involute-plate reactor, the fuel plates and side-plates are subjected to a non-uniform distribution of loads. Temperature variation derives from a variation in power distribution throughout the core. Due to small imperfections in the channel thickness, the coolant flowing in between the plates produces pressure differentials with a non-uniform distribution on the plate surface. The main goal of the analysis presented in this technical report is to investigate the ability of the commercial software STAR-CCM+ to model deformation of involute plates subjected to mechanical and thermal loads, representative of involute reactor operation conditions.

An experiment performed by R. D. Cheverton and W. H. Kelley on HFIR reactor plates was selected for validation of STAR-CCM+. The researchers investigated experimentally the deflections and tendency to buckling of a single involute plate under various thermal loads and pressure differentials. Cheverton and Kelley performed a series of tests with simplified conditions. The tests involved subjecting the plate to thermal loads with uniform temperatures up to $600{ }^{\circ} \mathrm{F}(589 \mathrm{~K})$, as well as applying a range of uniform pressure loads to the surfaces of the plate at room temperature of $80^{\circ} \mathrm{F}$ $(300 \mathrm{~K})$, or in combination with a thermal load. It was stated that the plate was subjected to pressures three times greater, and temperature $200^{\circ} \mathrm{F}$ higher $(111 \mathrm{~K})$, than the ones occurring in HFIR operating conditions.

The maximum plate temperature is relatively similar for all three involute reactors but the operating pressure of HFIR is considerably larger than RHF or FRM II. The experimental conditions used in this experiment are therefore largely encompassing the nominal operating conditions of the three involute reactors.

The computational simulations were performed based on a chosen set of tests that cover a wide variety of boundary and load conditions, which makes it possible to test multiple features available in STAR-CCM+. Numerical models of the Cheverton \& Kelley experiment were created, and the computed plate deflections were compared to the experimental measurements, and computational deflections obtained in a previous study, performed with the software COMSOL.

Involute Working Group - Development and Validation of the Finite Element Models of the Cheverton-Kelley Experiments 
A partial Verification \& Validation effort has been performed to assess the credibility of the physical models used in the analysis. In addition, a substantial number of checks and sensitivity analysis have been performed to reinforce the credibility of the numerical models of the experiment. The effort included verification of the sensitivity of the results (i.e. stresses, deflections) to variation in material properties, meshing, type of temperature load model and boundary conditions. This exercise allowed for gaining a better comprehension of the key variables and phenomena likely to influence the simulation results.

Several tests performed were then chosen for validation of the finite element model developed in the current study. They differ with the type of load: surface pressure, temperature, and combination of both. Models of a single plate with constrained edges, as well as a more complex models of a plate clamped in a base were developed and the simulation results were compared with the experimental measurements.

The comparison between experimental data and numerical ones shows that most of the models give results with deviation less than $\pm 20 \%$, irrespectively of the simulation input parameters.

There are noticeable outliers. Firstly, the proposed computational models of a plate with every other tab clamped under a pressure load of $207 \mathrm{kPa}$ were not able to reproduce accurately the deflection of the plate. They either underestimate or overestimate the experimental measurement. It is worth noting, that the same model used for lower pressure values, gave a better accuracy of results. The reason for this deviation could be that the model cannot represent well the plastic deformations that occurred in the plate during the experiment. Cheverton and Kelley mentioned that such deformations occurred, i.e. plastic flow at the foot of the tabs. The elastoplastic material model used in this study is not complex enough to capture this behavior.

Secondly, it can be noticed that the various computational models proposed to represent the deflection of a plate constrained along the long edge in an Invar base and with free ends, subjected to $477 \mathrm{~K}$ temperature load, produce a wide range of deflection values. This indicates that the deflection of the free end in this test case is very sensitive to the side boundary condition as well as the material properties. The experimental measurements confirm this finding. The deformation of the two ends of the plate was somewhat different, which may suggest that the constraints were not symmetric with respect to the midspan.

Two models that give the best accuracy of results were identified. For test cases in which the relative displacement of the plate side edges is negligible, i.e. in which the deformation of the base does not influence the deformation of the plate, the best results were obtained with the model in which contact was defined between the plate and rigid planes tangent to the involute. It is computationally more efficient than the full model of a plate clamped in a base and makes it possible to model the variations of the tab constraints proposed by Cheverton and Kelley. For the test cases in which the deformation of the base had an impact on the deformation of the plate, such as the model of a split Invar base, or a solid Monel base under thermal loads, it is recommended to use a complex model of a plate in a deformable base. Only this model can account for the interaction between the parts of the assembly.

If the plate response is within, or close to, the elastic range, the computational results show a very good accuracy. Discrepancies occur when the loads are large enough to result in an elastoplastic response. Based on these findings, it is concluded that, within the elastic domain, the commercial software Star-CCM+ can provide accurate estimation of the magnitude of deflections susceptible to occur in an involute plate reactor. 


\section{Table of Contents}

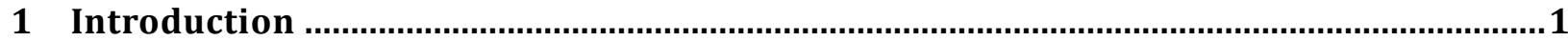

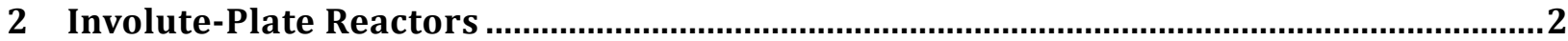

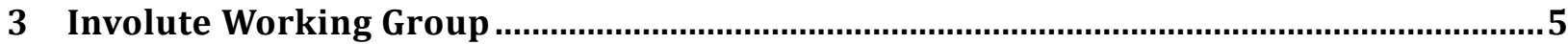

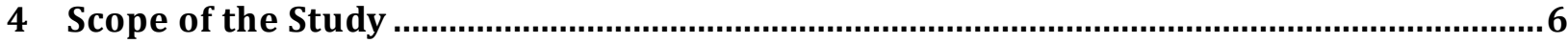

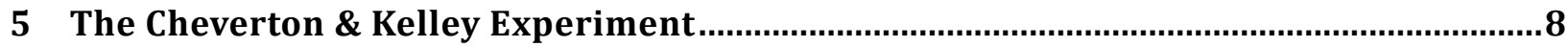

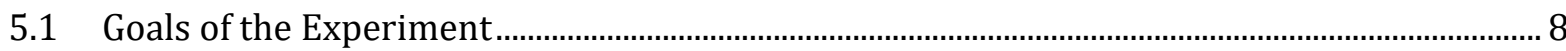

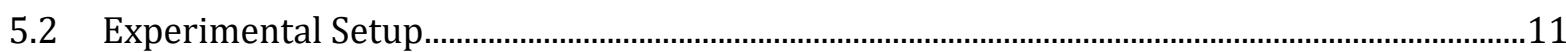

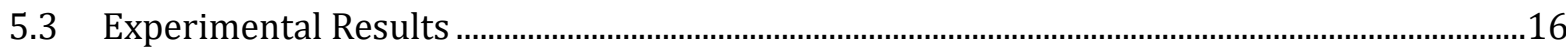

6 Finite Element Modeling of the Cheverton and Kelley Experiment .............................. 27

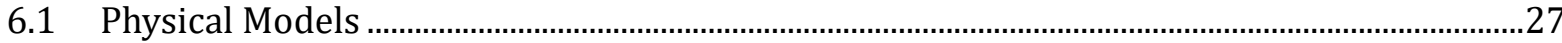

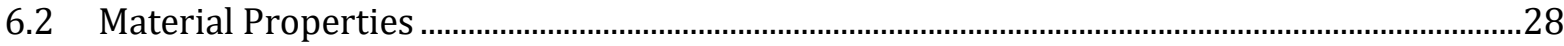

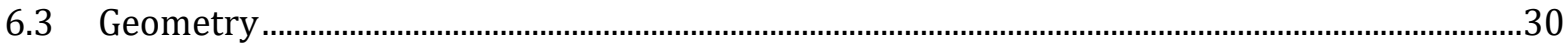

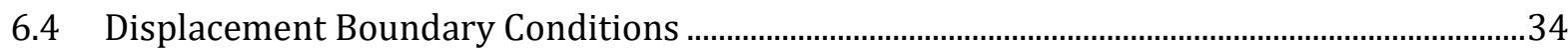

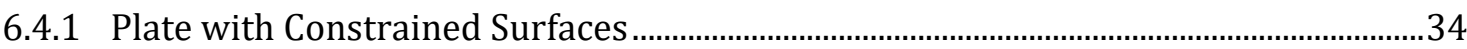

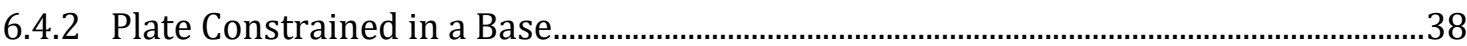

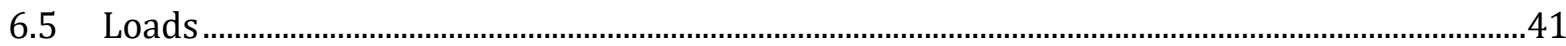

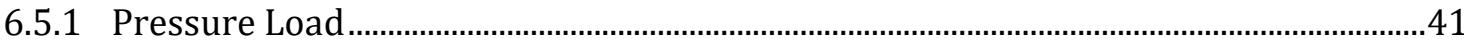

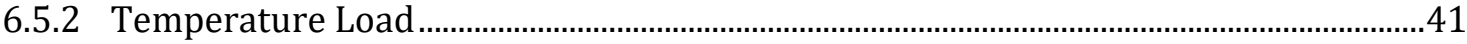

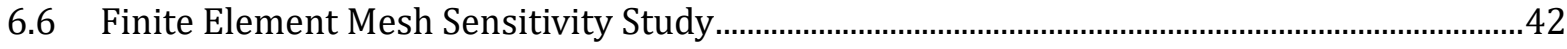

6.7 Discussion on the Selected Models .....................................................................................................

7 Cheverton \& Kelley Experiment Finite Element Modeling Results ............................... 47

7.1 Pressure Tests. Model of a Plate with Varying Edge Constraints ...............................................48

7.1.1 Every 1/4-inch-wide Tab Clamped, with Clamp Bars Tight Against the Plate and

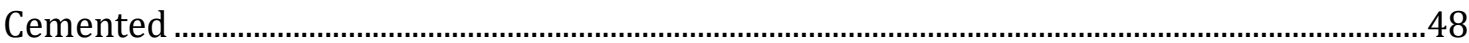

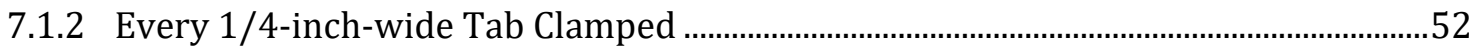

7.1.3 Every 1/8-inch-wide Tab Clamped ......................................................................................59

7.1.4 Every Other 1/4-inch-wide Tab Clamped...........................................................................66

7.2 Temperature Load Test. Model with a Solid Base............................................................................72

7.2.1 Model of a Plate with Constrained Edges..................................................................................72

7.2.2 Model of a Plate with a Base ..............................................................................................

7.2.3 Comparison of Results of the Simulations with Temperature Load...............................75

7.3 Temperature Load Test. Model with a Split Base............................................................................

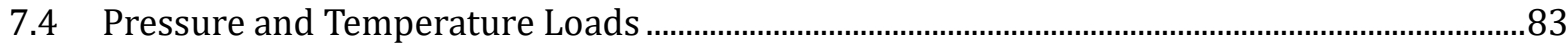

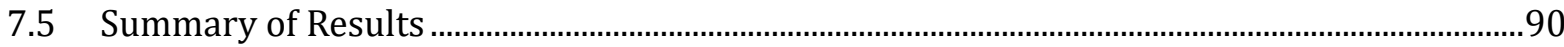




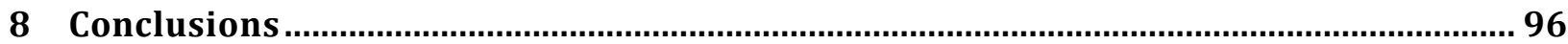

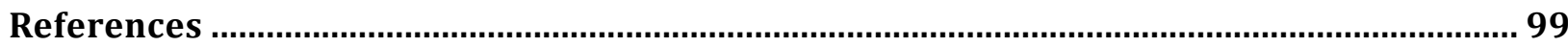

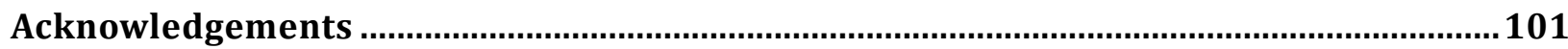

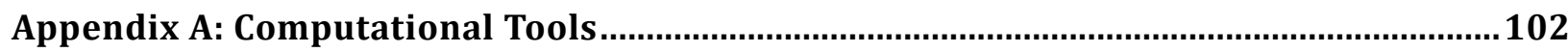

A.1 Computational Software Evaluation ................................................................................................. 102

A.2 STAR-CCM+ History and Pedigree ......................................................................................................... 103

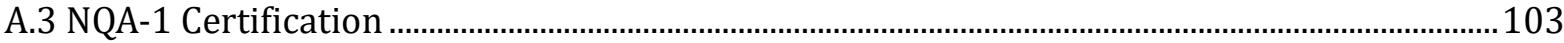

A.4 Theoretical Basis .................................................................................................................................. 104

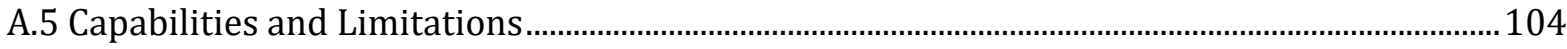

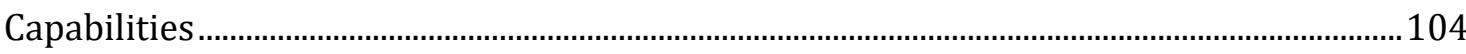

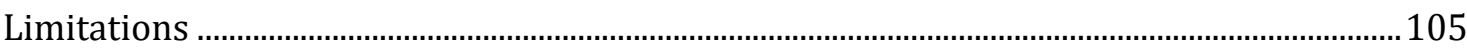

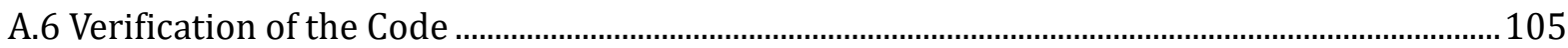

SM-1 Finite Element Bending of a Cantilever Beam......................................................................... 106

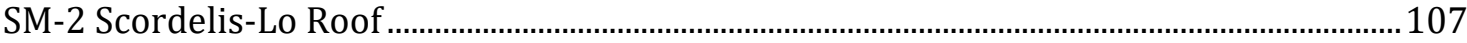

A.7 Mechanical Models Available for the Stress Analysis......................................................................... 109

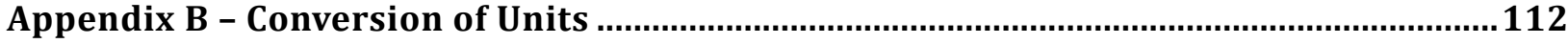

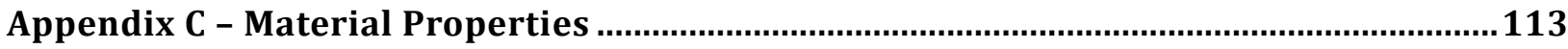

Appendix D - Digitized Experimental Data ...................................................................... 122 


\section{List of Figures}

Figure 2.1. From left to right, top view of the HFIR, RHF and FRM II fuel elements (close to true proportionality)

Figure 2.2. Detailed view of RHF fuel plates curved as involute and welded between the two annular side-plates (picture taken from a mockup and not a real element; the finish is not representative of a real element)

Figure 5.1 General view of the HFIR assembly (dimensions in inch). Source: [5] .................................... 9

Figure 5.2 Dimensions of the fuel plates (dimensions in inch). Source: [5] ................................................10

Figure 5.3. Geometry and dimensions of the test plates (dimensions in inch). Source: [5] ..................13

Figure 5.4. Clamping area in the experiment (dimensions in inch). Source: [5] .....................................14

Figure 5.5. End view of the plate clamped in the base (dimensions in inch). Source: [5] ......................14

Figure 5.6. The components of the testing assembly. Source: [5] .............................................................15

Figure 5.7. Test assembly with theoretical positions of the measurement points along the arc length. Source: [5]

Figure 5.8. Experimental test case matrix that covers 55 tests with varying load and support conditions. See Figure 5.9 for the explanation on the experimental setup. Source: [5].

Figure 5.9. Experimental test case matrix, cont'd. Description of the conditions in experiments listed in Figure 5.8. Source: [5]

Figure 5.10. Experimental results: typical plate deflection curves for change in temperature from $80^{\circ} \mathrm{F}$ to $400^{\circ}$ F. Source: [5].

Figure 5.11. Experimental results: comparison of deflections with split and non-split Invar base. Source: [5]

Figure 5.12. Experimental results: deflection for initial pressurization versus type edge attachment. Source: [5]

Figure 5.13. Experimental results: plate deflections caused by temperature $400^{\circ} \mathrm{F}$ and pressure up to 30 psi. Source: [5]

Figure 5.14. Experimental results: deflection vs. end restraint for all 1/4" tabs clamped in a split steel

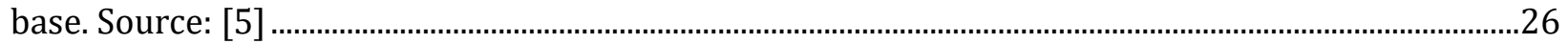

Figure 6.1. Front view of the geometry of the involute plate model.............................................................30

Figure 6.2. Top view of the geometry of the involute plate models, (a) model with $1 / 8$-inch-wide tabs, (b) model with $1 / 4$-inch-wide tabs.

Figure 6.3. Perspective view of the involute plate (marked in steel grey) and the base (a) solid base,

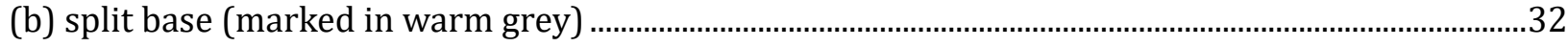

Figure 6.4. Drawing of the base geometry. Source: [17] ................................................................................33

Figure 6.5. Boundary conditions of the plate sides used in the simulations. The highlighted surfaces have components of displacement vector constrained (a) fixed all components of displacement vector of the tabs and groove-wide strips on both sides, (b) fixed displacements of the tabs, (c) fixed all components of displacement vector of the tabs and zero displacement component normal to the surface of the thin strips on concave side, (d) fixed all components of displacement vector of the tabs 
and groove-wide strips on the concave surface along the length of the plate in contact with rigid planes tangent to the involute.

Figure 6.6. Two variants of the boundary conditions: (a) every tab is constrained, (b) every other tab is constrained (surfaces highlighted in orange are constrained)

Figure 6.7. Perspective view of the involute plate and the (a) solid, (b) split base. Displacement boundary conditions are assigned to the surfaces highlighted in orange.

Figure 6.8. Perspective view of the involute plate and the solid base (a) non-transparent base surfaces, (b) opacity of the base surfaces is set to 0.5 to show the tabs. 40

Figure 6.9. A sketch of the pressure load acting on the involute plate. 41

Figure 6.10. Contour plot of normal displacement magnitude on the convex surface of an involute plate under thermal loading obtained with the use of the Specified Temperature Load model .......... 42

Figure 6.11. Maximum normal displacement on the midspan of the plate. Number of finite elements was increased across thickness, length, and width of the plate.

Figure 6.12. Midspan normal displacements for varying mesh density across plate thickness: 2, 4, and 8 finite elements..

Figure 6.13. Close up of the FEM mesh used in the simulations 45

Figure 7.1. Displacement contour plots for a plate with every tab (1/4 in) clamped, clamp bars tightly against the plate, edges sealed, and pressure on the concave surface: (a) $69 \mathrm{kPa}$, (b) $138 \mathrm{kPa}$, (c) 207 $\mathrm{kPa}$. The white arrow in figure (a) indicates the outward radial direction.

Figure 7.2. Midspan deflection of a plate with every 1/4" (6.35 $\mathrm{mm})$ tab and bars clamped under various pressure loads applied to the concave surface of the involute. Error bars were estimated by the authors of this technical report .50

Figure 7.3. Experimental and computational normal displacements at sensor locations \#2 and \#5 for a plate with every $1 / 4$-inch $(6.35 \mathrm{~mm})$ tab and bars clamped under various pressure loads. Error bars were estimated by the authors of this technical report. 51

Figure 7.4. Von Mises stress contour plots for a plate with every 1/4-inch (6.35 $\mathrm{mm}$ ) tab clamped, clamp bars tightly against the plate, edges sealed, and pressure on the concave surface: (a) $69 \mathrm{kPa}$, (b) $138 \mathrm{kPa}$, (c) $207 \mathrm{kPa}$ .52

Figure 7.5. Midspan deflection of a plate with every 1/4-inch $(6.35 \mathrm{~mm})$ tab clamped under pressure load $69 \mathrm{kPa}$. Error bars were estimated by the authors of this technical report. ....................................54

Figure 7.6. Midspan deflection of a plate with every 1/4-inch $(6.35 \mathrm{~mm})$ tab clamped under pressure load $138 \mathrm{kPa}$. Error bars were estimated by the authors of this technical report.....................................55

Figure 7.7. Midspan deflection of a plate with every 1/4-inch ( $6.35 \mathrm{~mm})$ tab clamped under pressure load $207 \mathrm{kPa}$. Error bars were estimated by the authors of this technical report. .56

Figure 7.8. Displacement contour plots for a plate with every $1 / 4$-inch $(6.35 \mathrm{~mm})$ tab clamped, edges sealed, and pressure on the concave surface: (a) $69 \mathrm{kPa}$, (b) $138 \mathrm{kPa}$, (c) $207 \mathrm{kPa}$. Model with zero displacements of the tabs and zero displacement component normal to the surface of the thin strips on concave side. .57

Figure 7.9. Experimental and computational normal displacements at sensor locations \#2 and \#5 for a plate with every 1/4-inch $(6.35 \mathrm{~mm})$ tab clamped. Error bars were estimated by the authors of this technical report. . .58

Figure 7.10. Von Mises stress contour plots for a plate with every 1/4-inch (6.35 mm) tab clamped, edges sealed, and pressure on the concave surface: (a) $69 \mathrm{kPa}$, (b) $138 \mathrm{kPa}$, (c) $207 \mathrm{kPa}$. Model with 
zero displacements of the tabs and zero displacement component normal to the surface of the thin strips on concave side. 59

Figure 7.11. Midspan deflection of a plate with every $1 / 8$-inch $(3.18 \mathrm{~mm})$ tab clamped under pressure load $69 \mathrm{kPa}$.

Figure 7.12. Midspan deflection of a plate with every 1/8-inch $(3.18 \mathrm{~mm})$ tab clamped under pressure load $138 \mathrm{kPa}$. Error bars were estimated by the authors of this technical report. 62

Figure 7.13. Midspan deflection of a plate with every $1 / 8$-inch $(3.18 \mathrm{~mm})$ tab clamped under pressure load $207 \mathrm{kPa}$. 63

Figure 7.14. Displacement contour plots for a plate with every 1/8-inch tab clamped, .64

Figure 7.15. Experimental and computational normal displacements at sensor locations \#2 and \#5 for a plate with every $1 / 8$-inch-tab clamped .

Figure 7.16. Von Mises stress contour plots for a plate with every 1/8-inch tab clamped, edges sealed, and pressure on the concave surface: (a) $69 \mathrm{kPa}$, (b) $138 \mathrm{kPa}$, (c) $207 \mathrm{kPa}$. Model with zero displacements of the tabs and zero displacement component normal to the surface of the thin strips on concave side.

Figure 7.17. Midspan deflection of a plate with every other 1/4-inch $(6.35 \mathrm{~mm})$ tab clamped under pressure load $69 \mathrm{kPa}$.

Figure 7.18 Midspan deflection of a plate with every other 1/4-inch $(6.35 \mathrm{~mm})$ tab clamped under pressure load $138 \mathrm{kPa}$. Error bars were estimated by the authors of this technical report. 68

Figure 7.19 Midspan deflection of a plate with every other 1/4-inch (6.35 $\mathrm{mm})$ tab clamped under pressure load $207 \mathrm{kPa}$. Error bars were estimated by the authors of this technical report.

Figure 7.20. Displacement contour plots for a plate with every other 1/4-inch tab clamped, edges sealed, and pressure on the concave surface: (a) $69 \mathrm{kPa}$, (b) $138 \mathrm{kPa}$, (c) $207 \mathrm{kPa}$. Model with zero displacements of the tabs and zero displacement component normal to the surface of the thin strips on concave side. . .70

Figure 7.21 Experimental and computational normal displacements at sensor locations \#2 and \#5 for a plate with every other 1/4-inch tab clamped. Error bars were estimated by the authors of this technical report.

Figure 7.22. Von Mises stress contour plots for a plate with every other $1 / 4$-inch tab clamped,........72

Figure 7.23. Displacement contour plot for a plate made of elastic material, under $477 \mathrm{~K}$ temperature load (reference temperature $300 \mathrm{~K}$ ), with free ends, and varying level of side constraint: (a) fixed displacements of the tabs, (b) fixed displacements of the tabs and zero normal displacements of the thin strips on bottom side of the plate, (c) fixed all components of displacement vector of the tabs and groove-wide strips on the concave surface along the length of the plate in contact with rigid planes tangent to the involute. . .73

Figure 7.24. von Mises stress contour plot for a plate under $477 \mathrm{~K}$ temperature load, with free ends, and varying level of side constraint: (a) fixed displacements of the tabs, (b) fixed displacements of the tabs and zero normal displacements of the thin strips on bottom side of the plate, (c) fixed all components of displacement vector of the tabs and groove-wide strips on the concave surface along the length of the plate in contact with rigid planes tangent to the involute. 74

Figure 7.25. Displacement contour plot on the convex surface of an involute plate made of elastic material, under $477 \mathrm{~K}$ temperature load (reference temperature $300 \mathrm{~K}$ ) with free ends, (a) the plate is bonded with a solid base, (b) the plate is in sliding contact with the base, and the tabs are bonded with the base 75 
Figure 7.26. Comparison of computational and experimental normal displacements of the plate ends (short edges). Error bars were estimated by the authors of this technical report. . .77

Figure 7.27. Comparison of computational and experimental normal displacements of the plate midspan. Error bars were estimated by the authors of this technical report. . .78

Figure 7.28 Displacement contour plot on the convex surface of an involute plate made of elastic material, under $477 \mathrm{~K}$ temperature load (reference temperature $300 \mathrm{~K}$ ) with free ends, (a) the plate is bonded with the split base, (b) the plate is in sliding contact with the base, and the tabs are bonded with the base .80

Figure 7.29 Normal displacements of the plate ends. Error bars were estimated by the authors of this technical report. . .81

Figure 7.30 Normal displacements of the plate midspan. Error bars were estimated by the authors of this technical report. . .82

Figure 7.31 Contour plots of normal displacement for a combination of temperature load and pressure load on the concave surface (a) $0 \mathrm{kPa}$, (b) $103 \mathrm{kPa}$, (c) $207 \mathrm{kPa}$.. . .84

Figure 7.32 Horizontal displacement along the involute arch length at the midspan of the plate......85

Figure 7.33 Normal displacements of the plate midspan for a $400^{\circ} \mathrm{F}$ temperature load.. .86

Figure 7.34 Normal displacements of the plate midspan for a combination of $400^{\circ} \mathrm{F}$ temperature load and pressure load on the concave surface $103 \mathrm{kPa}$. . .86

Figure 7.35 Normal displacements of the plate midspan for a combination of $400^{\circ} \mathrm{F}$ temperature load and pressure load on the concave surface $207 \mathrm{kPa}$. 87

Figure 7.36 Normal displacements of the plate midspan for a $400^{\circ} \mathrm{F}$ temperature load normalized with the vertical expansion of the base.

Figure 7.37 Normal displacements of the plate midspan for a combination of $400^{\circ} \mathrm{F}$ temperature load and pressure load on the concave surface $103 \mathrm{kPa}$, normalized with the vertical expansion of the base

Figure 7.38 Normal displacements of the plate midspan for a combination of $400^{\circ} \mathrm{F}$ temperature load and pressure load on the concave surface $207 \mathrm{kPa}$, normalized with the vertical expansion of the base

Figure 7.39 Comparison of computational and experimental displacements under a range of pressure and temperature loads and with varying boundary conditions and material models . .91

Figure 7.40 The best fit of the computational results to the experimental data points obtained with the model of a plate in contact with rigid planes for test cases with pressure load and elastic material model.

Figure 7.41 The best fit of the computational results to the experimental data points obtained with the model of a plate in contact with rigid planes for test cases with pressure load and elastoplastic material model.

Figure 7.42 The best fit of the computational results to the experimental data points obtained with the model of a plate clamped in a base for test cases with temperature load and a combination of pressure and temperature load, and elastic material model. . .94

Figure 7.43 The best fit of the computational results to the experimental data points obtained with the model of a plate clamped in a base for test cases with temperature load and a combination of pressure and temperature load, and elastoplastic material model. . .95 


\section{List of Tables}

Table 2.1. Key parameters of fuel elements in involute reactors …….......................................................... 3

Table 2.2. Key thermal-hydraulic parameters in involute reactors.................................................................. 4

Table 6.1. Material properties of the plate and base at room temperature. Source: [17] ......................28

Table 6.2. Sensitivity study of the mechanical properties of aluminum on the plate deflections ........29

Table 7.1. Experimental conditions in pressure tests............................................................................................47

Table 7.2. Experimental conditions in temperature tests ...............................................................................47

Table 7.3. Experimental conditions in pressure and temperature tests ......................................................47 
(This page left intentionally blank) 


\section{Introduction}

There are three research reactors in the world with fuel plates curved as circle-involute (a spiral generated around a circle):

- The Oak Ridge National Laboratory (ORNL) High Flux Isotope Reactor (HFIR) located in Tennessee, U.S.A. [1],

- The Laue-Langevin Institute (ILL) High Flux Reactor (RHF) located in Grenoble, France [2], and

- The Technical University of Munich (TUM) Research Neutron Source Heinz Maier-Leibnitz (FRM II) located in Garching, Germany [3].

All three reactors are currently using Highly Enriched Uranium (HEU, ${ }^{235} \mathrm{U} / \mathrm{U} \geq 20 \mathrm{wt}$. \%) as fuel and all three are actively engaged in non-proliferation activities to convert to Low Enriched Uranium (LEU, $235 \mathrm{U} / \mathrm{U}<20 \mathrm{wt}$ \%) fuel. More information on these reactors can be found in Section 2.

Conversion of these reactors to LEU fuel requires internal and/or external changes to the fuel plate dimensions. In the early design stage, it is important to verify that the proposed LEU fuel plates will conserve their mechanical integrity during operation using computational fluid dynamics (CFD) and finite element method (FEM) modeling. However, solid justifications on the appropriateness of the codes and methods is required. To accomplish this, Argonne National Laboratory (ANL or simply Argonne) and the three involute reactor operators formed an informal group - the Involute Working Group (IWG). Activities include benchmarking, code-to-code comparison, Verification and Validation (V\&V) as well as technical support. More information on the IWG can be found in Section 3.

The main goal of the analysis presented in this technical report is to investigate the ability of the commercial software STAR-CCM+ [4] to model deformation of involute plates subjected to mechanical and thermal loads, representative of involute reactor operation conditions. The features of this computational tool are presented and discussed in Section 0 . The experiment selected for validation of STAR-CCM+ was performed by R. D. Cheverton and W. H. Kelley [5] on HFIR reactor plates. This experiment is particularly well suited for the involute reactors as it was designed to study the deflection of the HFIR plates due to pressure and/or thermal loads. A detailed description of the experimental setup can be found in Section 5.

The validation of the computational simulations was performed based on a chosen set of tests that cover a wide variety of boundary and load conditions, which makes it possible to test multiple features available in STAR-CCM+. Numerical models of the Cheverton \& Kelley experiment were created, and the computed plate deflections were compared to the experimental ones and the ones obtained with an equivalent software, COMSOL. A description of the computational models is presented in Section 6. Key results and findings from the research are discussed in Section 7 and the conclusions from the study are presented in Section 8. 


\section{Involute-Plate Reactors}

As explained in reference [6], the fuel elements of involute-plate reactors have an annular shape as depicted in Figure 2.1, which shows a top view, from left to right, of the HFIR, RHF and FRM II fuel elements. HFIR has two elements while RHF and FRM II have only one. The fuel element of these reactors is located at the center of a larger vessel that contains the reflector (heavy water for RHF and FRM II, beryllium for HFIR) and experimental and safety devices. The cylindrical volume located at the center of the annular fuel elements is often referred to as the central cavity. FRM II and RHF use this space for the control elements, which move vertically to control the reactivity during the cycle. HFIR uses this central cavity for isotope production. HFIR reactivity control is assured by an inner and outer shroud located near the outer edge of the outer element. Fuel elements must be replaced at every new cycle (i.e. once through core).
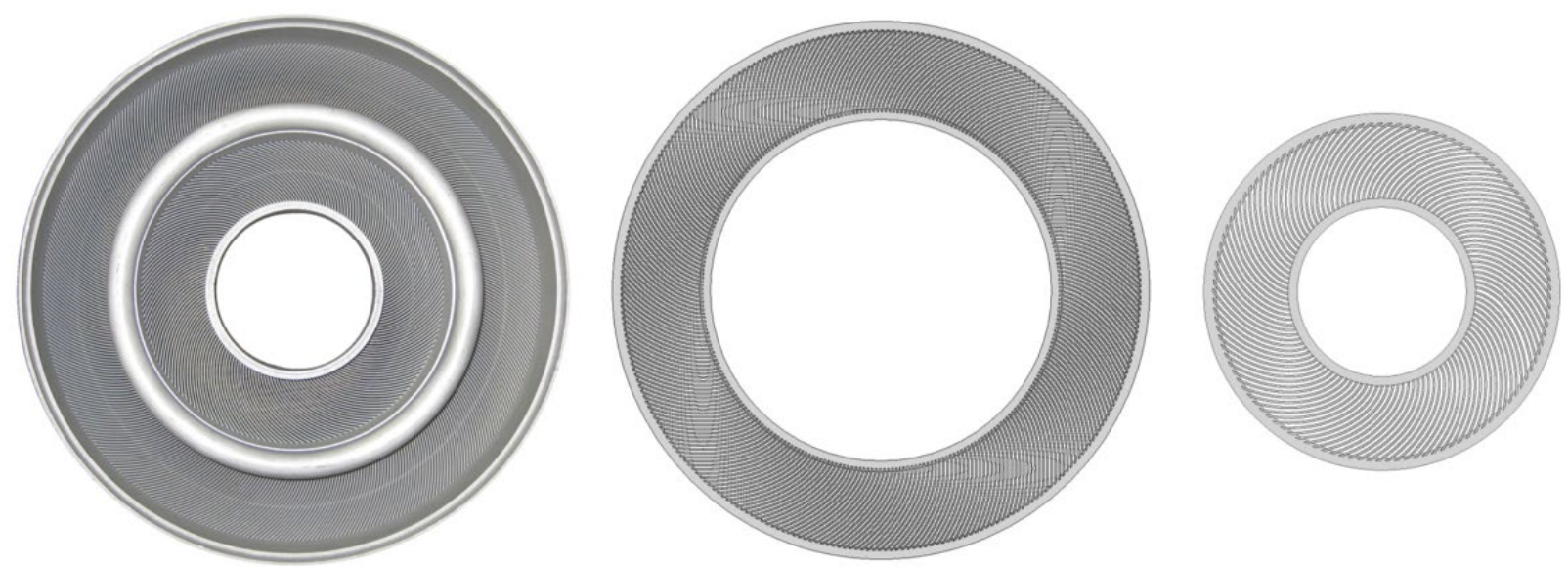

Figure 2.1. From left to right, top view of the HFIR, RHF and FRM II fuel elements (close to true proportionality)

Figure 2.2 provides a more detailed view of the RHF involute plates and channels. The involute shape allows for:

- the thickness of a coolant channel to be constant from the inner to the outer edge of the element,

- all channels to be identical (granted some local deviations due to imperfections in the manufacturing process),

- all fuel plates to experience very similar irradiation conditions (granted some possible local azimuthal variations induced by the presence of safety or experimental components located at the vicinity of the fuel elements).

As presented in the figure, the fuel plates curved as involute are attached to two concentric plates (commonly referred to as side-plates). Vertical grooves are machined in the side-plates to allow insertion of the fuel plates which are then welded to the side-plates at multiple, about 25, locations along the axis. The fuel plates are very thin (from $1.27 \mathrm{~mm}$ to $1.36 \mathrm{~mm}$ ) and have a sandwich-like structure. The fuel is made of highly enriched uranium (93 wt. \%) mixed with aluminum. This socalled "meat" is cladded on each side by aluminum alloy foils. More design information on these fuel elements can be found in Table 2.1. 


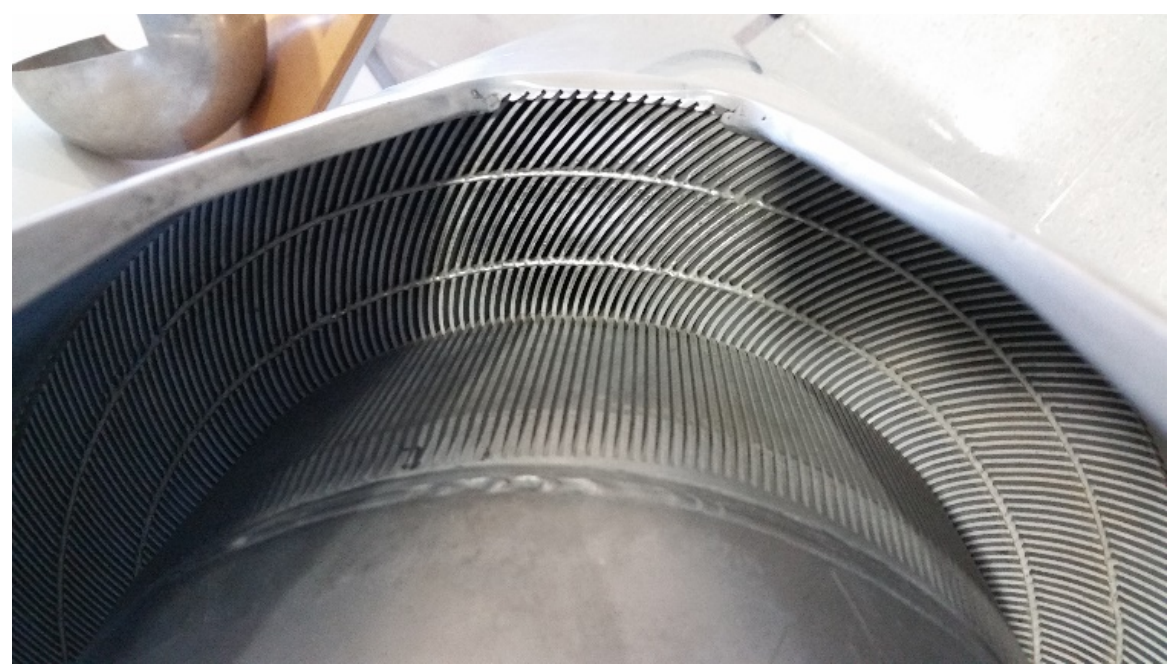

Figure 2.2. Detailed view of RHF fuel plates curved as involute and welded between the two annular side-plates (picture taken from a mockup and not a real element; the finish is not representative of a real element)

Table 2.1. Key parameters of fuel elements in involute reactors

\begin{tabular}{|l|c|c|c|}
\hline \multicolumn{1}{|c|}{ Parameters } & $\begin{array}{c}\text { HFIR } \\
{[7]}\end{array}$ & $\begin{array}{c}\text { RHF } \\
{[8]}\end{array}$ & $\begin{array}{c}\text { FRM II } \\
{[9]}\end{array}$ \\
\hline Fuel type & $\mathrm{U}_{3} \mathrm{O}_{8} / \mathrm{Al}$ & $\mathrm{UAlx} / \mathrm{Al}$ & $\mathrm{U}_{3} \mathrm{Si}_{2} / \mathrm{Al}$ \\
\hline Cladding material & $\mathrm{Al}-6061$ & $\mathrm{AlFeNi}$ & $\mathrm{AlFeNi}$ \\
\hline Number of elements & 2 & 1 & 1 \\
\hline Number of plates & $540(171+369)$ & 280 & 113 \\
\hline Plate thickness (mm) & 1.27 & 1.27 & 1.36 \\
\hline Plate length (cm) & 60.96 & 90.30 & 72.00 \\
\hline Channel width between side plates (cm) & $8.548 / 7.679$ & 7.594 & 6.940 \\
\hline Channel thickness (mm) & 1.27 & 1.80 & 2.20 \\
\hline Cladding thickness (mm) & 0.254 & 0.380 & 0.380 \\
\hline Meat thickness (mm) & $\begin{array}{c}\text { Varies along } \\
\text { width, } \\
\text { Max: } 0.693\end{array}$ & 0.51 & 0.60 \\
\hline Meat width (cm) & $7.798 / 7.087$ & 6.734 & 6.240 \\
\hline $\begin{array}{l}\text { Width inner unfueled region (from outer } \\
\text { radius of inner side-plate to inner fuel radius, } \\
\text { cm) }\end{array}$ & $0.234 / 0.218$ & 0.314 & 0.259 \\
\hline $\begin{array}{l}\text { Width outer unfueled region (from outer fuel } \\
\text { radius to inner radius of outer side-plate, cm) }\end{array}$ & $0.516 / 0.374$ & 0.547 & 0.441 \\
\hline
\end{tabular}

Table 2.2 provides some key thermal hydraulic parameters for the HEU fuel elements used in the involute reactors. RHF uses heavy water as coolant while FRM II and HFIR use light water. The coolant flows from top to bottom for all three reactors. The space between two adjacent fuel plates forms a coolant channel in which water passes at very high speed, up to $\approx 17 \mathrm{~m} / \mathrm{s}$, to evacuate the heat generated in the fuel plate by nuclear reactions. All of these reactors operate with coolant at relatively low pressure and temperature which leads to cladding temperatures on the order of $100{ }^{\circ} \mathrm{C}(373 \mathrm{~K})$ and, because of the high thermal conductivity of the cladding and fuel meat, nominal (without uncertainties) fuel temperature does not exceed $150^{\circ} \mathrm{C}(423 \mathrm{~K})$. 
Table 2.2. Key thermal-hydraulic parameters in involute reactors

\begin{tabular}{|l|c|c|c|}
\hline \multicolumn{1}{|c|}{ Parameters } & $\begin{array}{c}\text { HFIR } \\
\text { [7] }\end{array}$ & $\begin{array}{c}\text { RHF } \\
\text { [8] }\end{array}$ & $\begin{array}{c}\text { FRM II } \\
\text { [9] }\end{array}$ \\
\hline Coolant type & Light water & Heavy water & Light water \\
\hline Average coolant velocity (m/s) & 15.5 & 17 & 15.9 \\
\hline $\begin{array}{l}\text { Nominal inlet / outlet bulk coolant } \\
\text { temperature (Celsius) }\end{array}$ & $49 / 69$ & $30 / 50$ & $38 / 59$ \\
\hline Nominal inlet / outlet pressure (Pax 105) & $33.3 / 25.72$ & $14 / 4$ & $8.8 / 2.3$ \\
\hline
\end{tabular}




\section{Involute Working Group}

In the framework of its non-proliferation policies, the international community aims at eliminating the use of Highly Enriched Uranium (HEU, ${ }^{235 U} / \mathrm{U} \geq 20 \mathrm{wt}$. \%) fuel in civilian facilities (such as research reactors) [9]. Many organizations worldwide are developing high density, Low Enriched Uranium (LEU, ${ }^{235} \mathrm{U} / \mathrm{U}<20 \mathrm{wt}$. \%) fuel to replace the HEU fuel. All three involute-reactor operators, ONRL, ILL, and TUM, are actively engaged in conversion to LEU activities.

Conversion to LEU implies changing the fuel and therefore changing its material properties, which influences the thermal and thermal-mechanical behavior of the elements. In many cases, it also implies making geometric modifications, such as changing plate length, channel thickness, and others, which may also affect the thermal-mechanical performance of the elements.

To understand the effect of these changes, Argonne National Laboratory and the involute reactors formed an informal group working on the validation of numerical models and software. This socalled Involute Working Group (IWG) aims, among other things, to support the qualification of highfidelity numerical tools for thermal-hydraulic safety calculations [10], [12] and thermal-mechanical analysis. Activities include benchmarking, code-to-code comparison, Verification and Validation of the computational methods, as well as technical support.

The key goals of the analysis presented in this technical report are:

- quality assessment of the Cheverton and Kelley experiments to serve as benchmark for validation of the computational software,

- assessment of STAR-CCM+ as a suitable computational tool for structural analysis of the reactor plates,

- foundational work before performing the LEU design mechanical analysis. 


\section{Scope of the Study}

The variables of interest in this study are the deflections of the fuel plates and the resulting stresses in the plates under loads that exist in the reactors. Although the determination of specific failure criteria is beyond the scope of this work, the analysts will evaluate the results relative to the following:

- maximum deflections of the fuel plates, to ensure that the gap between the neighboring plates is not reduced excessively, which in turn could challenge the cooling of the core,

- maximum stresses in the fuel plates, to ensure existence of margin to reported yield stress of the materials due to thermal and pressure differential loads,

- the influence of missing or failing local welds acting as attachments between the fuel plate and side plates on safety of the design.

The identified variables of interest depend on various physical phenomena:

- Level of restraint. For a given type of load, the type of constraints imposed on a deformable body influences its response to external loads. If the supports offer a high level of constraint, the deformations of the plate are smaller, in turn if the attachments do not provide much constraint, the plate is free to deform.

- Type of load. Loads acting on a structure can be of various types, e.g. pressure or temperature; static or dynamic. The pressure load may result from different coolant speeds in the neighboring channels, which in turn is caused by a difference in the coolant channel thickness. The involute plate is subjected to different pressure magnitude and distribution on the concave and convex surfaces and this pressure differential causes the plate to bend. Thermal loads are a result of the nuclear reactions occurring in the fuel and cause the plate to expand. Static response occurs when the load does not change or changes slowly in time. In turn the dynamic response occurs when the load is time dependent, it acts as an impulse load for a very short time or changes the direction and/or amplitude in time. An example of a dynamic load on an involute plate is vortex shedding from the leading edge or elements of the reactor upstream of the fuel element.

- Material response: elastic or elastoplastic. A plate subjected to loads that produce stresses higher than the material yield strength, undergoes plastic deformations. In opposition to elastic deformations, plastic deformations are permanent and can cause damage of the plate, which is immediate or caused by an accumulation of the deformations over time. Mechanical characteristics of materials vary due to the change in temperature. For instance, the elastic modulus of aluminum 6061-T0 decreases with increasing temperature: at room temperature is about $69 \mathrm{GPa}$ and at $477 \mathrm{~K}$ drops by $14 \%$ to about $59 \mathrm{GPa}$.

- Manufacturing imperfections in the plate and supports. Imperfections in the plate shape can change its response to loading. Improperly manufactured or missing attachments may lead to higher than expected deflections of the plate.

It was assumed that the finite element method is the most suitable for the purposes of this study. It is one of two methods available in STAR-CCM+, with the other being the finite volume method which was tested previously by ANL researchers [16] and is currently considered as obsolete. The simulation input parameters that influence the physical phenomena identified above are:

- Finite element formulation and mesh density. The product documentation specifies if a formulation is of general purpose or is suitable to be used only in specific applications. The documentation provides the general information about the finite element implementation,

Involute Working Group - Development and Validation of the Finite Element Models of the Cheverton-Kelley Experiments 
but the detailed formulation is seldom available to the user community. The choice of the mesh density for a given displacement-based finite element formulation affects the solution. The mesh needs to be dense enough to capture the deformations of the structure under the external loads. A mesh density study is usually performed to establish the convergence of the discretization.

- Displacement boundary conditions. In the displacement based finite element method, the primary variables are displacements at finite element nodes. A body defined in three dimensions has 6 rigid body modes that must be constrained. Additionally, constraints are applied to the nodes to simulate the supports, such as welds or contact with grooves in the side plates. It is up to the modeler to choose the best representation of the real-life conditions, which may not be known in detail or may be difficult to simulate. In some cases, a sensitivity study is required where several models are proposed and the most adequate selected for modeling.

- Load models. The software provides a selection of standard load models, such as pressure, force, temperature loads, that can be used to represent the influence of the conditions on the plate deformations. If the deformations of the plate are such that they change the outside conditions and therefore loading applied to the plate, a fluid-structure interaction simulation needs to be performed. STAR-CCM+ makes it possible to perform this type of simulations. The FEM-CFD modeling is outside of the scope of the study presented in this technical report but will be the topic of future considerations.

- Material models. A deformable body in a solid stress analysis must be assigned a material model along with its properties to bind the strains exerted by the external loads with the internal stresses. In structural analysis, aluminum is usually modeled as an isotropic, linear elastic, or elastoplastic material, and this assumption is held in the current study. Material orthotropy and anisotropy, as well as various types of plastic behavior can also be modeled, as well as temperature dependence of the material properties.

As a part of the verification of the code, to determine whether the equations are solved correctly, test cases from the STAR-CCM+ Verification Suite [4] were simulated. The computational results were compared with analytical solutions and showed a good agreement. The description of the tests, and analysis of the computational and analytical results are presented in Appendix A: Computational Tools .

Validation consists of ensuring that the computational tool can represent the physical phenomena in a way that fulfills the expectations within the validation range, i.e. within the variation range for the characteristic geometrical or physical variables for which the results are considered acceptable. In the current study, the finite element formulations available in STAR-CCM+ are evaluated based on comparing the computational results with experimental measurements performed by Cheverton and Kelley [5]. The validation cases encompass an analysis of the separate effects of the physical phenomena, as well as their combinations. A sensitivity analysis of the computational results to the variation of selected input parameters is also performed. For a few of the validation cases, computational results obtained with other equivalent software are available [17] and therefore the validation can be carried out based on a cross-evaluation. The various uncertainties resulting from the validation of separate effects and integral are also evaluated. 


\section{The Cheverton \& Kelley Experiment}

In this section, the main goals, analysis methods, and results of the experiments performed by Cheverton and Kelley [5] are discussed. Note that Cheverton and Kelley used English units throughout their report. In this technical report, units are given in both U.S. customary units (English unit system) and the metric system (SI unit system). The conversion of basic units is given in Appendix B.

\subsection{Goals of the Experiment}

Cheverton and Kelley investigated experimentally the deflections and tendency to buckling of a single involute plate under various thermal loads and pressure differentials. In an involute-plate reactor, the fuel plates and side-plates are subjected to a non-uniform distribution of loads. Temperature variation derives from a variation in power distribution throughout the core. Due to small imperfections in the channel thickness, the coolant flowing in between the plates produces pressure differentials with a non-uniform distribution on the plate surface. Cheverton and Kelley performed a series of tests with simplified conditions. The tests involved: subjecting the plate to thermal loads with uniform temperatures up to $600^{\circ} \mathrm{F}(589 \mathrm{~K})$, as well as applying a range of uniform pressure loads to the surfaces of the plate at room temperature of $80^{\circ} \mathrm{F}(300 \mathrm{~K})$, or in combination with a thermal load. It was stated that the plate was subjected to pressures three times greater, and temperature $200^{\circ} \mathrm{F}$ higher $(111 \mathrm{~K})$, than the ones occurring in HFIR operating conditions. Note that the plate temperature is relatively similar for all three involute reactors but the operating pressure of HFIR is considerably larger than RHF or FRM II. The experimental conditions used in this experiment are therefore largely encompassing the nominal operating conditions of the three involute reactors.

A general view of the HFIR assembly and the shape and dimensions of the plates are presented in Figure 5.1 and Figure 5.2, respectively. As can be seen on these figures, the HFIR core is made of two concentric fuel elements. The shape of the plates forming the HFIR core is based on an involute of a circle curve. The plates are installed between side-plates, forming two annuli with a different radius. As shown in Figure 5.1, only the inner side-plate of the inner element and the outer side-plate of the outer element are supported and the common side plate, between the inner and outer annulus, is not. The fuel plates are installed within grooves cut in the side-plates and welded to them. Additionally, combs are included on both ends of the plates to further restrain their motion.

As the generating circles for the two elements of plates differ, their shape also varies. The inner plates are wider and, because the generating circle has a smaller radius, they are more curved (radius of curvature is smaller) than the outer plates. The outer plates are flatter and even though their width is smaller than the inner ones, the researchers decided to test them as they are more susceptible to buckling. 


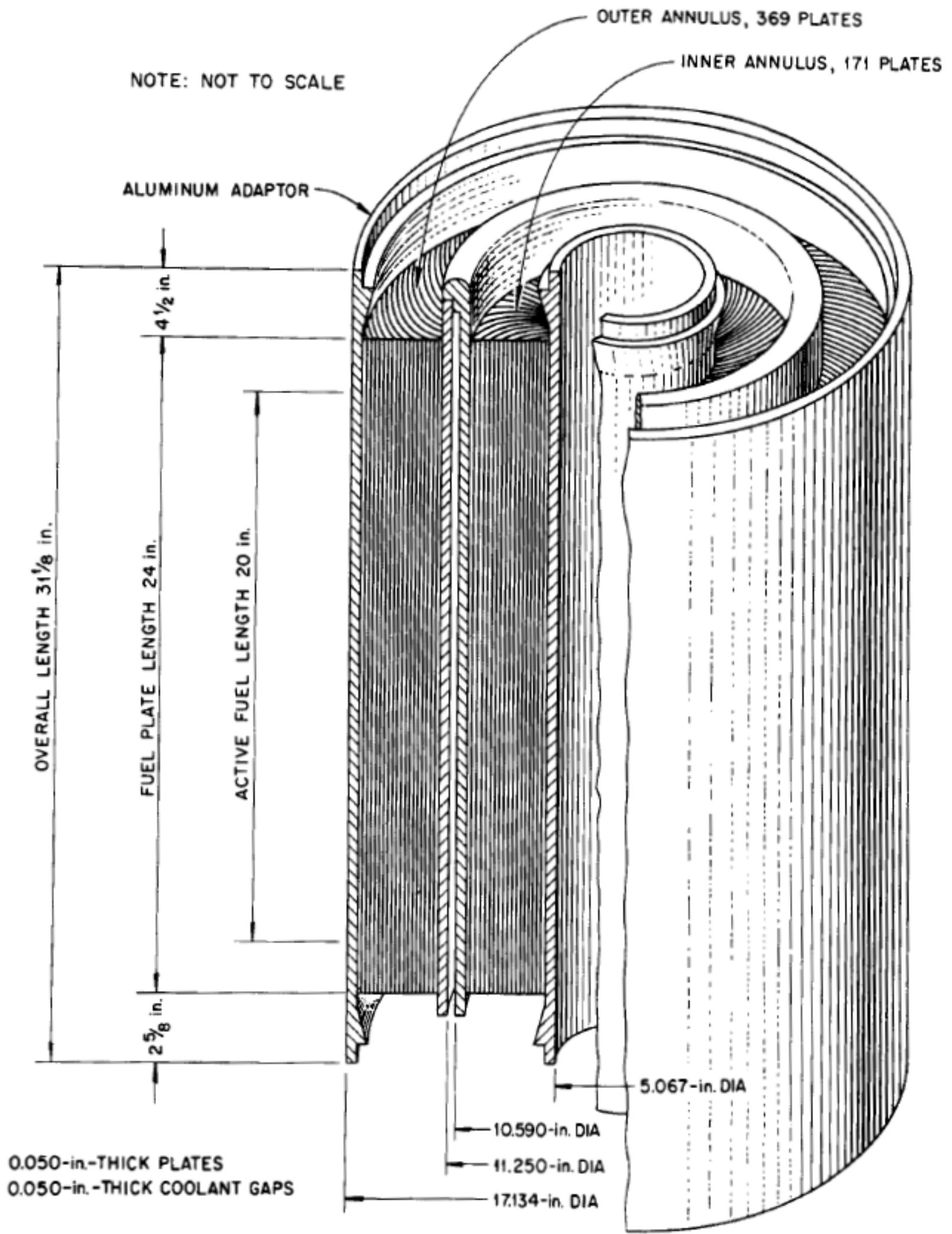

Figure 5.1 General view of the HFIR assembly (dimensions in inch). Source: [5] 


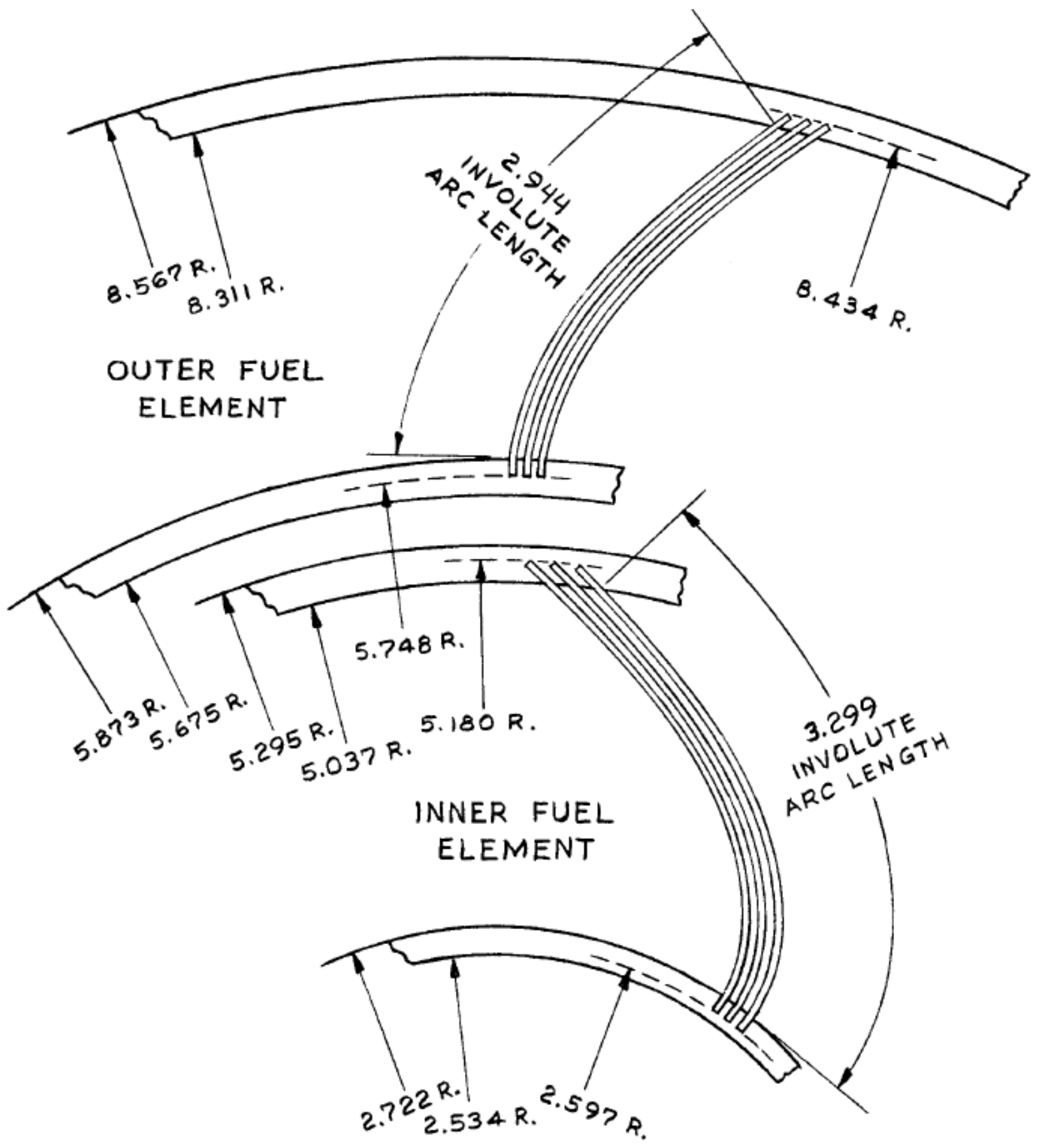

Figure 5.2 Dimensions of the fuel plates (dimensions in inch). Source: [5] 


\subsection{Experimental Setup}

The experimental setup consisted of several parts: a base, a measuring device, and an oven to heat up the assembly.

The experiments were performed on plates with shape and dimensions identical to the HFIR fuel plates. Two types of plates were used: the actual fuel plates containing fuel, and sheet stock 6061-T0 aluminum alloy plates. All outer plates have the same theoretical shape of an involute curve and dimensions: length of 24 inch $(0.6096 \mathrm{~m})$, and thickness that may vary from 0.049 inch to 0.051 inch $(1.2446 \mathrm{~mm} \div 1.2954 \mathrm{~mm})$. The distance between two consecutive plates is nominally 0.050 inch (1.27 $\mathrm{mm})$.

In the HFIR core, the ends of the plates are installed in combs that restrain their movement. The long edges are positioned in the side-plate grooves and then welded to it at 1-inch $(25.4 \mathrm{~mm})$ intervals, with 0.12 -inch-long welds (3.05 $\mathrm{mm})$. The groove on the inner side is $0.125 \mathrm{in}(3.18 \mathrm{~mm}) \mathrm{deep}$, and the groove on the outer side is 0.144 in $(3.66 \mathrm{~mm})$ deep, which leaves 2.944 in $(74.78 \mathrm{~mm})$ of the plate arc length exposed to the coolant.

In the experiment, the combs were not present. Instead, the level of end constraint was varied from free, when the displacement was not constrained, to fixed, when all displacement vector components were constrained, to analyze its influence on the plate deflections. The constraints on the long edges of the plate were created, as shown in Figure 5.3, by modifying the plate by an addition of tabs on both sides with the width and spacing approximately corresponding to the location and size of the spot welds. These tabs were then clamped in a base of the assembly, as a surrogate to welding. Most of the experiments were performed with $1 / 4$-inch-wide tabs $(6.35 \mathrm{~mm})$, with spacing between centers of 1 inch $(25.4 \mathrm{~mm})$. A few of the experiments were performed using 1/8-inch-wide tabs (3.18 $\mathrm{mm})$, to better represent the actual weld size. The corner between the outside edge and the tabs was rounded, with a radius of $1 / 32$ to $1 / 16$ inch $(0.8 \mathrm{~mm}$ to $1.59 \mathrm{~mm})$.

The clamping area on the tabs is shown in Figure 5.4. In some experiments, thin strips of the plate along the edges, 0.125 -inch $(3.18 \mathrm{~mm}$ ) wide (left side), and 0.144-inch (3.66 mm) wide (right side), also shown in Figure 5.3, were clamped in the base, to represent the restraint caused by the grooves in the side plates. In most of the tests however, the edge was not tightly clamped, and the plate was placed in the grooves that partially limited the displacements. Figure 5.5 shows the end view of the plate clamped in the base.

The base was used in the experiments as a single piece, referred to later in the text as 'solid base', and as two separate pieces, referred to as 'split base'. After all experiments with a solid base were performed, the base was cut into two pieces along the length and held together with aluminum end plates. This way, the plate had the possibility to expand in the transverse direction, which simulated the rotation of the side plate.

The displacement measurements were performed with the use of seven differential transformers, mounted on a bridge that moved along the length of the plate. Each transformer ended with a stylus that was positioned in the normal direction to the theoretical involute surface, with a spring attached to ensure contact with the plate. Therefore, the measured distance was representative of a change in the coolant channel thickness. The setup allowed for simultaneous readings from the transformers and to produce continuous plots along the plate. The upper limit of the temperature at which the

Involute Working Group - Development and Validation of the Finite Element Models of the Cheverton-Kelley Experiments 
transformers could operate was $400^{\circ} \mathrm{F}$. This was the temperature used in most of the experiments, except for one, when the assembly was heated up to $600^{\circ} \mathrm{F}$.

The components of the test apparatus are presented in Figure 5.6 and the testing assembly as well as the numbering and positioning of the transformers can be seen in Figure 5.7. During an experiment, the entire assembly was heated up slowly to the desired temperature. Thermocouples were used to monitor the temperature change.

In a real core, the coolant flowing in the channels in between the fuel plates subjects them to a nonuniform distribution of pressure differentials and the hydrodynamic forces are usually the greatest on the leading edge. In the experiments, the real conditions were simplified. A uniform pressure was applied to the surfaces of the involute plate by means of pumping vacuum or pressurizing the sealed volume with bottled gas. 


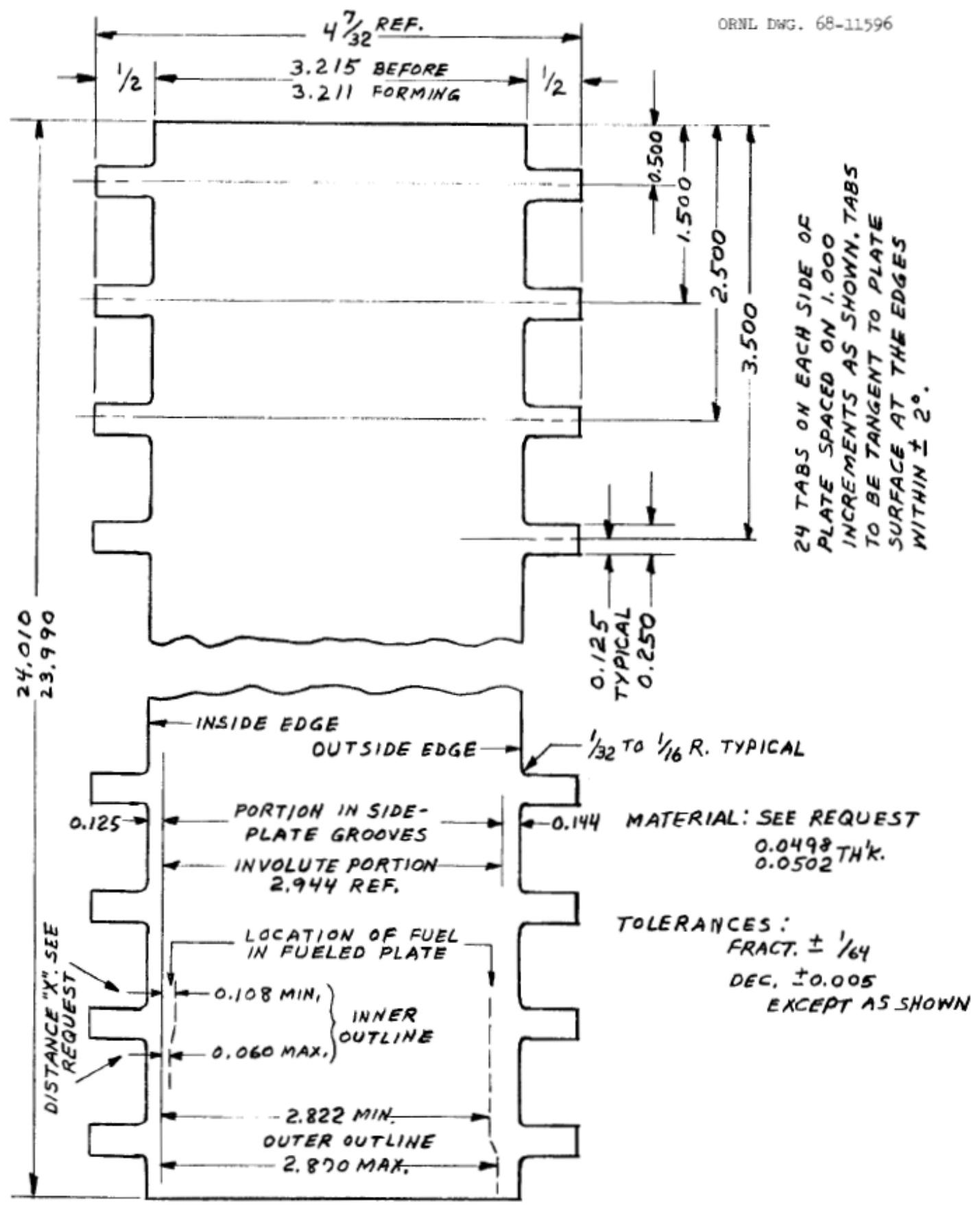

Figure 5.3. Geometry and dimensions of the test plates (dimensions in inch). Source: [5] 


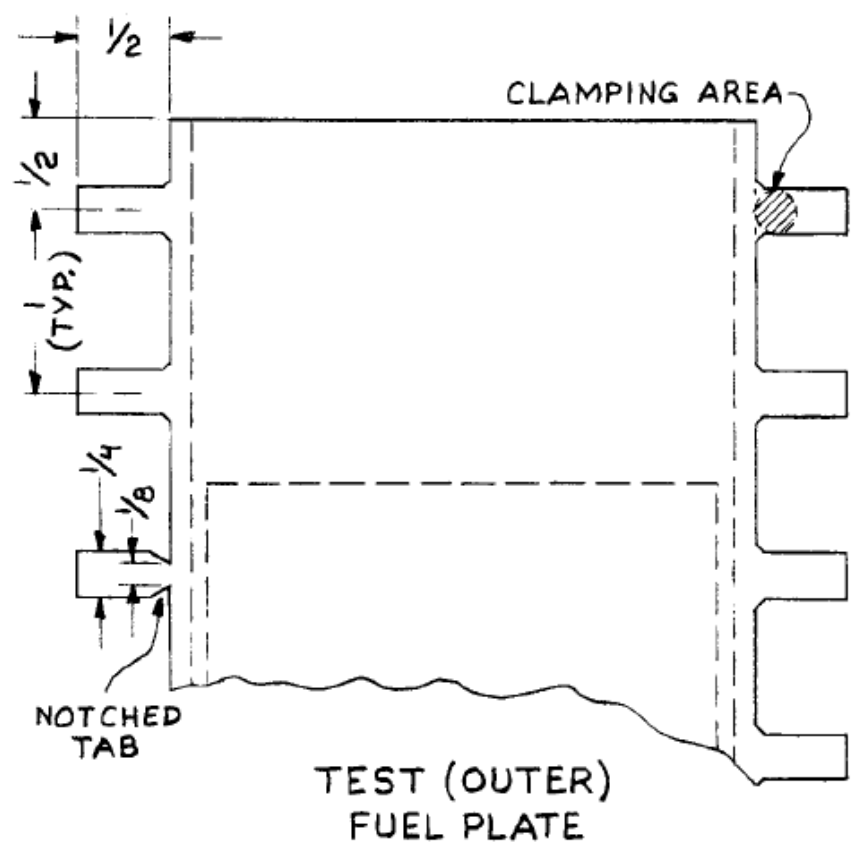

Figure 5.4. Clamping area in the experiment (dimensions in inch). Source: [5]

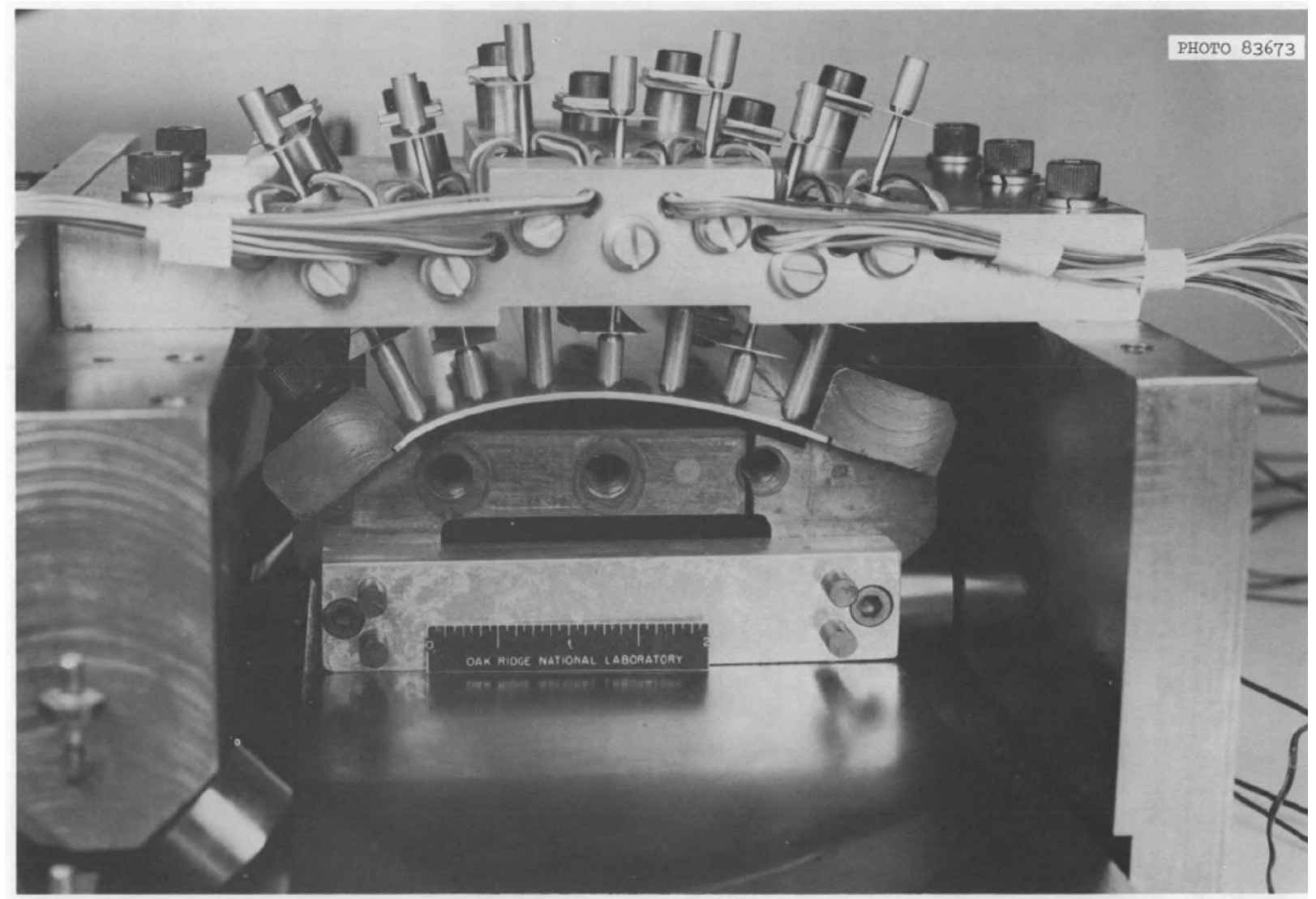

Figure 5.5. End view of the plate clamped in the base (dimensions in inch). Source: [5] 


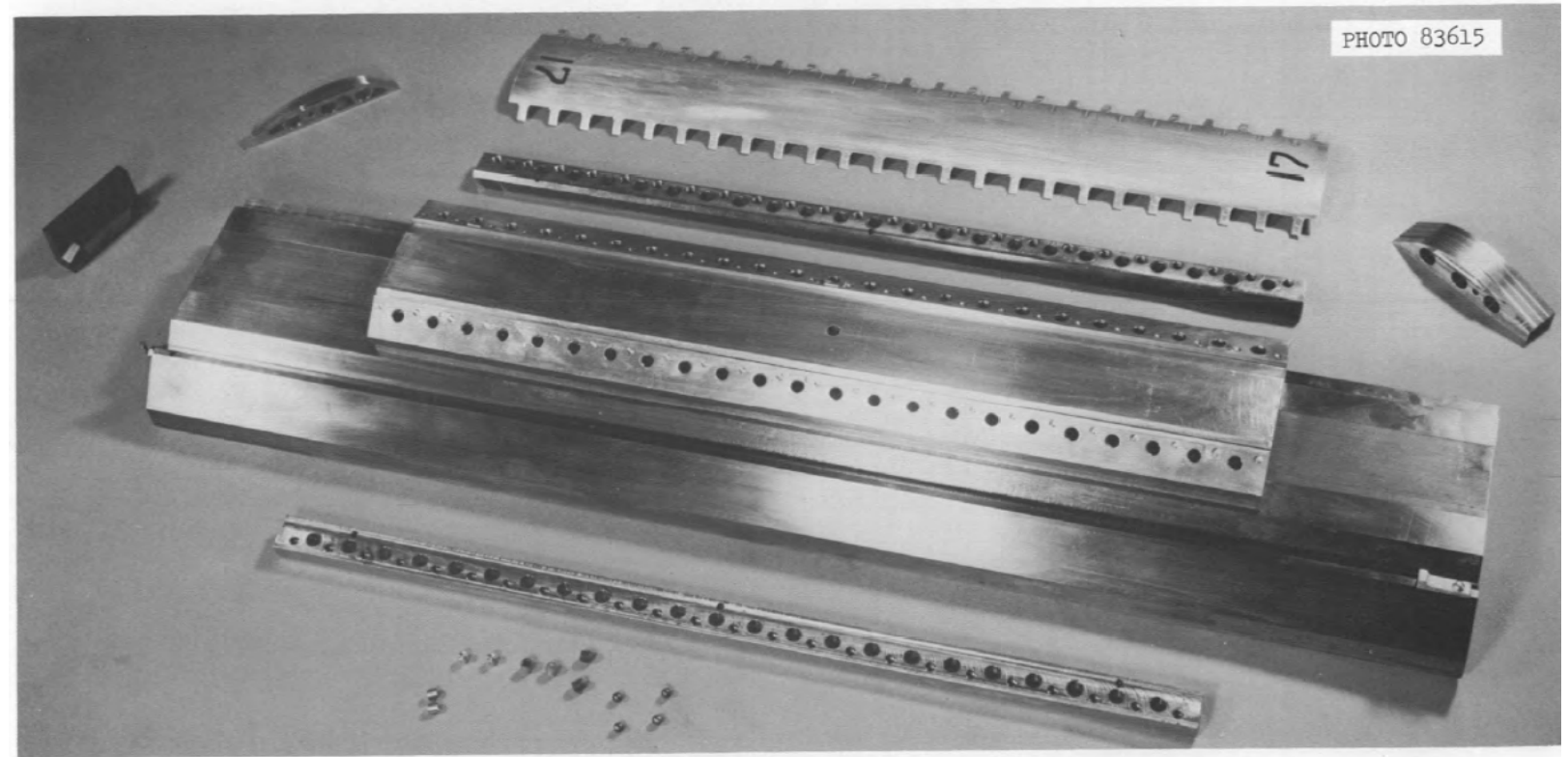

Figure 5.6. The components of the testing assembly. Source: [5]

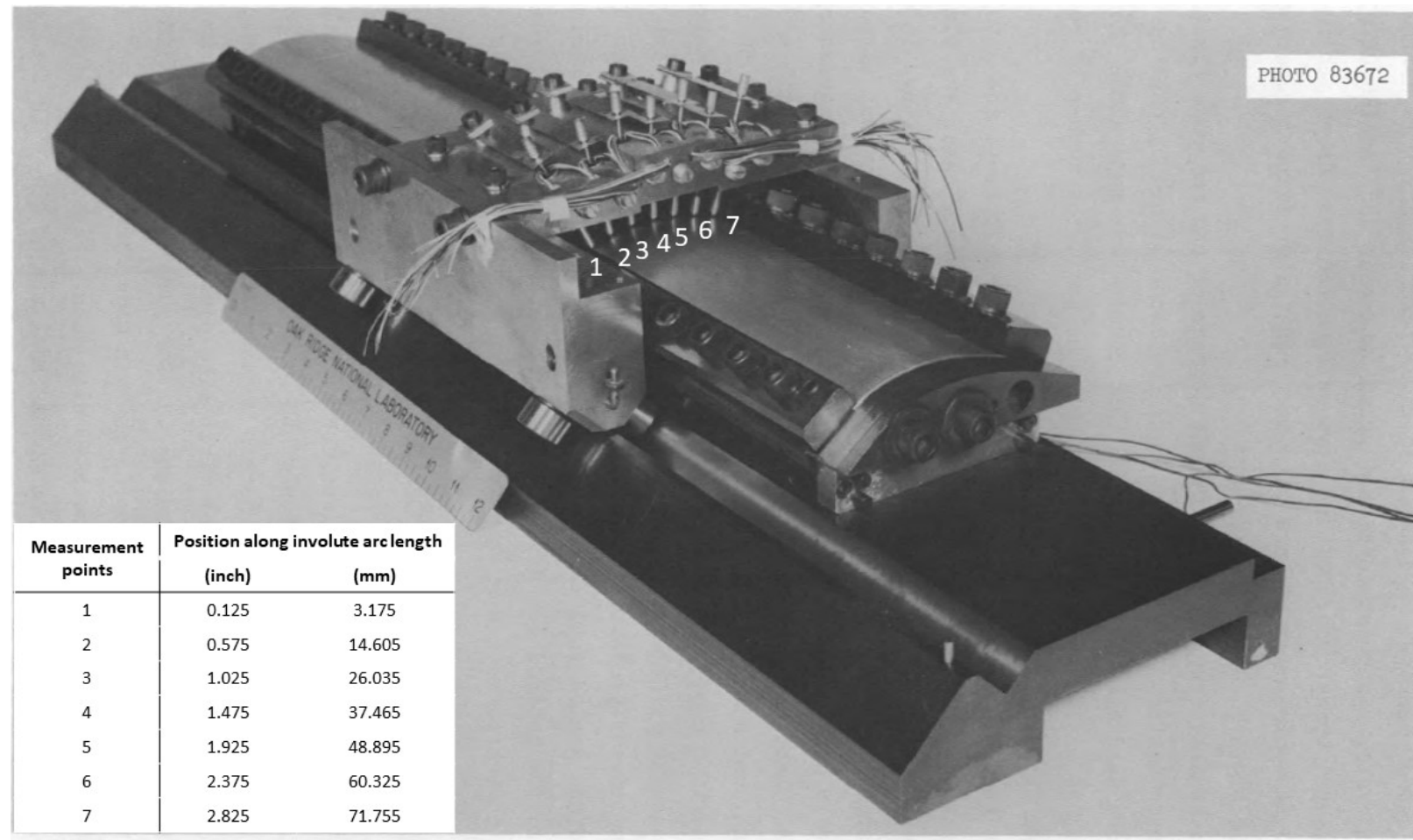

Figure 5.7. Test assembly with theoretical positions of the measurement points along the arc length. Source: [5] 


\subsection{Experimental Results}

The experiments analyzed the influence of several physical phenomena on the plate deflections separately, as well as the combined effects and the interactions between the phenomena. The experiment covered two types of plates: made of pure aluminum and aluminum with fuel, three types of base material: carbon steel, Monel and Invar, a range of pressure values on the concave surface of the involute plate and uniform thermal loads, as well as varying end and edge constraints. Cycle loads and creep tests were also covered. The reported parameter combinations used in the tests are presented in Figure 5.8 and Figure 5.9. As stated, not all these tests were discussed in detail in the report [5], because several of them were used to confirm the reproducibility of the experiment.

The experimental results were grouped in the report by parameters of interest. The discussion of results starts with the base case, which consists of an aluminum plate with $1 / 4$ inch $(6.35 \mathrm{~mm})$ tabs clamped in a carbon steel base subjected to $400{ }^{\circ} \mathrm{F}(477 \mathrm{~K})$ temperature load. The short edge constraint was taken as a variable. Figure 5.10 shows deflection curves for test case \#54, which belonged to the "base case" set of tests. The first deflection curve was created for a line along the plate where the deflection is the greatest. The other curves were created for planes crossing the plate along its length. It was indicated that the obtained deflection magnitudes are significant in the analysis of fluid flow and heat transfer. Readout for the plate midspan and ends from transformer \#4, positioned close to the center of the involute arc length, was selected for comparison between the cases with varying short edge restraint. It was stated that the deflection of the midspan of the plate increased with increasing end restraint, while the end deflection decreased as expected. It was mentioned that the actual degree of partial constraint was not known accurately, and it may have resulted in some data scatter. Small differences in measured deflections were attributed to the difference in the initial shape of the fuel plates and edge attachment. It was speculated that there may be a difference between the aluminum and fuel plates, but specific tests comparing the two type of plates showed that the difference is small.

Next, the "cold end" condition is covered, that exists in the reactor because of a few inches long nonfueled portion of the plate on both ends, which results in a steep gradient of temperature. This condition was modeled in the experiments by attaching a 2 inch-long $(50.8 \mathrm{~mm})$ piece of steel, which has a lower thermal expansion coefficient, to both ends of a 20 inch-long ( $508 \mathrm{~mm}$ ) aluminum plate. An increase of temperature up to $400^{\circ} \mathrm{F}$ results in significantly greater deflections of the midspan and slightly smaller deflections of the ends of the plate as compared to a pure aluminum plate. It was mentioned that because the modulus of elasticity of steel is greater than the modulus of aluminum, the end attachments create additional restraint and in an actual fuel plate the deflection would be smaller.

Different long edge restraints were tested thoroughly. Freedom of movement in the radial direction of an edge of the plate is a part of HFIR design, but the actual degree of edge restraint in the HFIR core was unknown. Therefore, a variety of edge restraints that could represent the actual conditions, was tested. Firstly, a plate was clamped in a Monel base, and the tab constraint was varied. Secondly, the possibility of radial movement was tested by means of a plate clamped in a split and a non-split base made of Invar. The split runs the length of the base and allows the plate to deflect radially outward. Two tests were performed at the temperature of $400^{\circ} \mathrm{F}(477 \mathrm{~K})$. The choice of the material for the base ensures a significant thermal differential between the base and the plate. With a very low thermal expansion coefficient, the expansion of the Invar base is negligible and therefore the relative displacement of the supports of the plate, due to the change in the base volume, can be ignored. Figure 5.11 shows a comparison of results for the two experimental tests with a solid (non-split) base and a

Involute Working Group - Development and Validation of the Finite Element Models of the Cheverton-Kelley Experiments 
split base. A significant difference in the plate deflection shape and magnitude was reported. The plate clamped in the split base deflected less than the plate clamped in the solid base in the midspan, and its ends deflected to the concave side (negative deflection) with similar absolute value, due to the freedom of movement of the base on the track. The plate with tabs clamped in the solid base experiences greater deflections, with almost twice as high maximum displacements, and the plate deflected mostly to the convex side along its span. The only deflection to the concave side can be noticed for the right corner of the plate at $X=0$, and both corners of the plate at $X=24$ inch $(609.6 \mathrm{~mm})$. Greater deflections are a result of the higher degree of edge movement constraint. As the plate did not have the possibility to expand, the bending deformations increased.

Next variable of interest was the temperature that would cause the plate to buckle. Most of the experiments were performed at $400^{\circ} \mathrm{F}(477 \mathrm{~K})$, because this was the operation limit of the differential transformers. In the last test the temperature was slowly increased to $600^{\circ} \mathrm{F}(589 \mathrm{~K})$ and the plate still did not buckle, instead, plastic flow occurred at the attachments and caused a relaxation of stresses in the plate.

To investigate the plate temperature as a variable, tests with two bases made of materials with different thermal expansion coefficient, carbon steel and Invar, were performed. Temperature was increased in increments and the deflections of the plate ends and the midspan were recorded as a function of differential strain between the plate and the base. It was concluded that over the range of considered temperatures, the effect of the plate temperature on deflections for a given differential strain, was insignificant.

Initial shape of the plate on thermal deflections was also considered. Imperfections of the initial shape of the plate were introduced by using alternate cup and ball force applicators to the tabs, which caused a sine wave type of deflection of the plate long edges. It was concluded that the plate heated up to temperature $400^{\circ} \mathrm{F}(477 \mathrm{~K})$ had essentially the same net deflection as a plate installed in the usual way and that the initial shape has little effect on the results.

Creep was tested on plates subjected to $400^{\circ} \mathrm{F}$ ( $477 \mathrm{~K}$ ) temperature for up to 15 days. No significant creep was recorded, and it was concluded that it was not an important factor in HFIR design. Thermal cycling was performed between room temperature $80^{\circ} \mathrm{F}(300 \mathrm{~K})$ and $400^{\circ} \mathrm{F}(477 \mathrm{~K})$. After four cycles no significant change in shape, compared to the initial shape, was noticed.

Deflections under pressure loads were investigated to determine what effect they had on thermal deflections and tendency to buckling. The load was applied to the plate with the use of vacuum on the convex side or pressurized air on the concave side. First tests showed that the deflections are very small and essentially the same for both methods of loading, and so the pressurized air method was used in the following tests. Due to the chosen method of applying the load, the test conditions were restricted to a plate installed in a non-split base with short edges attached to involute blocks. To keep the desired pressure level, the edges were sealed. The attachment on the long edge of the plate was varied to simulate the intermittent weld attachment. Most of the tests were done on plates with $1 / 4$ inch $(6.35 \mathrm{~mm})$ tabs, but $1 / 8$-inch $(3.18 \mathrm{~mm})$ tabs were used as well, which better represented the actual width of the welds. To investigate a missing weld or a potential failure of the welds on plate deflections, tests were performed with every other tab clamped in the base. Also, one test was performed with the tabs clamped and side bars tight against plate and cemented, to represent a case in which the plate has no possibility of movement within the side-plate grooves.

Figure 5.12 shows experimental deflection vs. load curves from a set of pressure tests. The reported measurements were taken on the midspan of the plate, $X=12$ in, by three sensors: \#2, \#3, \#5 located

Involute Working Group - Development and Validation of the Finite Element Models of the Cheverton-Kelley Experiments 
$0.575 \mathrm{in}(14.6 \mathrm{~mm}), 1.025 \mathrm{in}(26 \mathrm{~mm})$, and $1.925 \mathrm{in}(49 \mathrm{~mm})$ from the side-plate, measured along the arc length from the generating circle. The test conditions are as follows (numbering of the tests is original to the report [5]):

- plate \#60 - fuel plate, non-split Monel base, end attachment - involute blocks snug and cemented, edge attachment - every tab $\left(1 / 4^{\prime \prime}=6.35 \mathrm{~mm}\right)$, bars tights against plate and cemented, edges sealed with Scilastic, pressure on the concave side up to $60 \mathrm{psi}$,

- plate \#61 - fuel plate, non-split Monel base, end attachment - involute blocks snug and cemented, edge attachment - every tab $\left(1 / 8^{\prime \prime}=3.18 \mathrm{~mm}\right)$, edges sealed with Scilastic, pressure on the concave side,

- plate \#63 - fuel plate, non-split Monel base, end attachment - involute blocks snug and cemented, edge attachment - every tab $\left(1 / 4^{\prime \prime}=6.35 \mathrm{~mm}\right)$, edges sealed with Scilastic, pressure on the concave side,

- plate \#64 - fuel plate, non-split Monel base, end attachment - involute blocks snug and cemented, edge attachment - every other tab $\left(1 / 4^{\prime \prime}=6.35 \mathrm{~mm}\right)$, edges sealed with Scilastic, pressure on the concave side.

The fuel plates were pressurized from the concave side to $10 \mathrm{psi}(69 \mathrm{kPa}), 20 \mathrm{psi}(139 \mathrm{kPa})$, and 30 psi (207 kPa) at room temperature. Sensor \#2 recorded only negative deflections (to the convex side), sensor \#3 measured deflections close to or equal zero, and sensor \#5 showed positive deflections (towards the concave side), independently from the edge constraints. For pressures below 20 psi the pressure-deflection curves are linear, indicating no permanent deformation. It was reported that above this pressure "plastic flow definitely takes place" at least in the test cases where all 1/8" (3.18 $\mathrm{mm})$ tabs, and every other $1 / 4$ " (6.35 $\mathrm{mm})$ tabs, were constrained.

Figure 5.13 shows results for two test cases in which a plate was first subjected to $400^{\circ} \mathrm{F}$ temperature and then a pressure load was incrementally applied to the concave surface. Midspan deflections were recorded for (a) $400^{\circ} \mathrm{F}$ ( $477 \mathrm{~K}$ ), (b) $400^{\circ} \mathrm{F}$ and $15 \mathrm{psi}$ (477 $\mathrm{K}$ and $103 \mathrm{kPa}$ ), (c) $400^{\circ} \mathrm{F}$ and $30 \mathrm{psi}(477$ $\mathrm{K}$ and $207 \mathrm{kPa}$ ), loads. The difference between the cases was that plate \#32 did not have the edge bars cemented to the base and no sealant was used. The pressurized air was escaping the assembly and because of that, the deflections were slightly lower, than in the case of plate \#60 that was properly sealed.

In order to make the comparison between the experimental and computational results, the figures from the experimental report had to be converted into a digital form. The plots presented in this Section were digitized and combined in Appendix D.

Figure 5.14 shows end deflections and midspan average deflections measured by sensor \#4 for a set of tests, presented in the order of increasing end restraint. The values of deflections for each test are shown as double bars, to account for the different measurements of the two ends of the plate. The results presented in this figure were used to estimate the measurement uncertainty, which was not stated in the report. The measurement error was estimated from the base case tests which were performed on three fuel plates with the same conditions. These runs correspond to plates \#50, \#54, \#57. The digitized data varies on average $\pm 6 \%$ (with maximum absolute difference of $11 \%$ ) as compared to the mean. Based on engineering judgment, it was assumed that the uncertainty of measurement and digitization error along vertical axis will be accounted for in the digitized plots by adding vertical error bars that make up for $\pm 10 \%$ of the measured value.

As part of the IWG scope of work, numerical models that will be used to assess the mechanical behavior of the involute LEU reactor plates must be validated. Several experiments from the set 
described in this Section were selected as a reference for FEM modeling. Firstly, tests with only pressure load and varying edge restraint, were selected. In these tests, the thermal expansion of the plate and the base were neglected, as the tests were performed at room temperature. These tests were used to perform a mesh sensitivity study. Secondly, temperature load tests with a solid and split base were performed. In these tests, mechanical load was not accounted for. Lastly, tests with a combination of loads were modeled, in which application of both, pressure and temperature loads, resulted in plate deflections. By adopting this approach, separate and combined effects of the physical phenomena were evaluated. 


\begin{tabular}{|c|c|c|c|c|c|c|c|c|}
\hline $\begin{array}{l}\text { Test } \\
\text { Ho. }\end{array}$ & $\begin{array}{l}\text { Type } \\
\text { Puel } \\
\text { Plate }\end{array}$ & $\begin{array}{l}\text { Type } \\
\text { Base } \\
\text { Plate }\end{array}$ & $\begin{array}{l}\text { End } \\
\text { Attachment }\end{array}$ & $\begin{array}{l}\text { End } \\
\text { Attachment }\end{array}$ & Pressurized & $\begin{array}{c}\text { Thermal } \\
\text { Cycle }\end{array}$ & $\begin{array}{l}\text { Creep } \\
\text { Test }\end{array}$ & Date \\
\hline 10 & A & $\mathrm{E}$ & $\mathrm{L}$ & 0 & & & & $3 / 23 / 66$ \\
\hline 12 & A & $E$ & $\mathrm{~N}$ & 0 & & & 3 days & $3 / 25$ \\
\hline 13 & A & $E$ & $N$ & 0 & & & 15 days & $4 / 5$ \\
\hline 14 & C & $B$ & $N$ & 0 & & & 3 days & $4 / 21$ \\
\hline 15 & C & $\mathrm{F}$ & $\mathrm{N}$ & 0 & & & & $5 / 2$ \\
\hline 16 & $A$ & $F$ & $N^{a, b}$ & 0 & & & & $5 / 4$ \\
\hline 17 & A & $F$ & $J$ & $\mathrm{P}$ & & & & $5 / 5$ \\
\hline 18 & A & $\mathrm{F}$ & $\mathrm{JC}^{\mathrm{C}}$ & 0 & & & 3 days & $5 / 6$ \\
\hline 19 & A & $F$ & $N^{b}$ & 0 & & 3 cycles & 4 days & $5 / 12$ \\
\hline 20 & A & $\bar{F}$ & $2 \mathrm{~b}$ & 0 & & 2 cycles & 2 days & $5 / 18$ \\
\hline 21 & A & $F$ & $\mathrm{~J}$ & 0 & & & & $5 / 23$ \\
\hline 22 & A & $\mathrm{F}$ & $\mathrm{K}^{\mathrm{d}}$ & 0 & & & & $5 / 24$ \\
\hline 23 & A & $\mathrm{F}$ & $M$ & 0 & & & & $5 / 26$ \\
\hline 24 & A & $\mathrm{F}$ & $\mathrm{M}$ & $\mathrm{P}$ & & & & $5 / 27$ \\
\hline 25 & A & $F$ & M & $0^{e}$ & & & & $5 / 31$ \\
\hline 26 & A & $\mathrm{F}$ & K & 0 & & & & $6 / 6$ \\
\hline 27 & C & $F$ & $K$ & 0 & & & 3 days & $6 / 8$ \\
\hline 29 & $\mathrm{C}$ & $I$ & $M$ & $\mathrm{U}$ & Concave & & & $7 / 15$ \\
\hline 30 & C & $I$ & $M$ & $\mathrm{U}$ & Concave & & & $7 / 19$ \\
\hline 31 & C & $\mathrm{F}$ & $\mathrm{N}$ & $\mathrm{P}$ & & & & $7 / 21$ \\
\hline 32 & $\mathrm{C}$ & I & $M$ & $\mathrm{~T}$ & Concave & & & $7 / 22$ \\
\hline 33 & C & $I$ & M & $\mathrm{T}$ & Concave & & & $7 / 26$ \\
\hline 34 & $\mathrm{C}$ & I & M & $\mathrm{T}$ & Concave & & & $7 / 27$ \\
\hline 35 & C & $F$ & $N$ & $P$ & & & & $7 / 29$ \\
\hline 36 & C & G & $\mathrm{J}$ & 0 & & & & $8 / 18$ \\
\hline 37 & C & G & $\mathrm{J}$ & 0 & & & & $8 / 19$ \\
\hline 38 & $\mathrm{C}$ & $\mathrm{F}$ & $\mathbb{N}$ & $o^{e}$ & & & & $8 / 24$ \\
\hline 39 & C & $\mathrm{F}$ & $\mathbb{N}$ & $\mathrm{o}^{\mathrm{e}}$ & & 2 cycles & & $8 / 25$ \\
\hline 40 & B & $\mathrm{F}$ & $\mathrm{N}$ & 0 & & & & $9 / 1$ \\
\hline 41 & B & $\mathrm{F}$ & $\mathbb{N}$ & 0 & & & & $9 / 2$ \\
\hline 42 & C & $\mathrm{H}$ & $\mathbb{N}$ & 0 & & & & $9 / 7$ \\
\hline 43 & $\mathrm{C}$ & $\mathrm{H}$ & $M$ & 0 & & & & $9 / 9$ \\
\hline $4 \sqrt{4}$ & $B$ & $\mathrm{~F}$ & $\mathbb{N}^{b}\left(0.010^{11}\right)$ & 0 & & & & $9 / 16$ \\
\hline 45 & $\mathrm{~B}$ & B & $J$ & 0 & & & & $9 / 20$ \\
\hline 46 & B & $\mathrm{H}$ & J & 0 & & & & $9 / 21$ \\
\hline 47 & B & $\mathrm{H}$ & $J$ & 0 & & & & $9 / 26$ \\
\hline 48 & C & $\mathrm{H}$ & $J$ & 0 & & & & $9 / 28$ \\
\hline 49 & C & $\mathrm{H}$ & $J$ & 0 & & & & $10 / 5$ \\
\hline 50 & $\mathrm{C}$ & F & $J$ & 0 & & & & $10 / 7$ \\
\hline 51 & C & $F$ & M & 0 & & & & $10 / 10$ \\
\hline 52 & $\mathrm{C}$ & H & M & 0 & & & & $10 / 13$ \\
\hline 53 & $\mathrm{~B}$ & $\mathrm{H}$ & $\mathrm{N}\left(0.010^{11}\right)$ & o & & & & $10 / 17$ \\
\hline 54 & $\mathrm{C}$ & $\mathrm{F}$ & $J$ & 0 & & & & $10 / 24$ \\
\hline 55 & $\mathrm{C}$ & $\mathrm{H}$ & J & 0 & & & & $10 / 26$ \\
\hline 56 & C & $F$ & 3 & $P$ & & & & 10/31 \\
\hline 57 & $\mathrm{C}$ & $\mathrm{F}$ & $J$ & 0 & & & & $11 / 3$ \\
\hline 58 & $\mathrm{C}$ & F & $\mathrm{J}^{\mathrm{a}}$ & Q & & 4 cycles & 2 days & $11 / 7$ \\
\hline 59 & $\mathrm{C}$ & $\mathrm{F}$ & $J$ & $\mathrm{R}_{0}$ & & 4 cycles & & $11 / 16$ \\
\hline 60 & $\mathrm{C}$ & $I$ & M & $\mathrm{U}^{\mathfrak{f}}$ & $\begin{array}{l}\text { Concave } \\
60 \text { psi }\end{array}$ & & & $12 / 7$ \\
\hline 61 & $\mathrm{C}$ & I & M & $Q^{f}$ & Concave & & & $12 / 21$ \\
\hline 62 & C & $I$ & $M$ & $o^{f}$ & Concave & & & $1 / 6 / 67$ \\
\hline 63 & $\mathrm{c}$ & I & $\mathrm{M}$ & of & Concave & & & $1 / 11$ \\
\hline 64 & $\mathrm{C}$ & $I$ & $M$ & pf & Concave & & & $1 / 16$ \\
\hline 65 & $\mathrm{C}$ & I & $\mathrm{M}$ & $\mathrm{V}^{\mathrm{f}}$ & Concave & & & $1 / 18$ \\
\hline 66 & $\mathrm{C}$ & $\mathrm{H}$ & $\mathrm{J}$ & 0 & & & & $2 / 1$ \\
\hline
\end{tabular}

Figure 5.8. Experimental test case matrix that covers 55 tests with varying load and support conditions. See Figure 5.9 for the explanation on the experimental setup. Source: [5] 


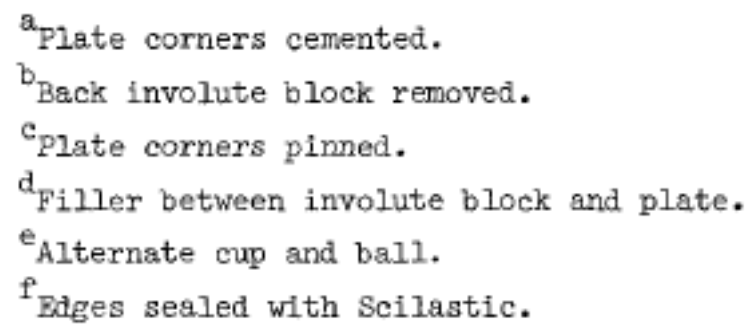

Mounting and Plate Conditions

Fuel Plate Types

A

B

C

Type Base Plate

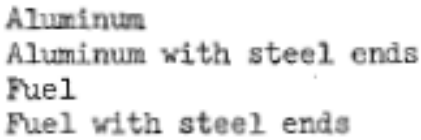

B
F
G
H
I

$$
\begin{aligned}
& \text { Steel, not split } \\
& \text { Steel, split } \\
& \text { Invar, not split } \\
& \text { Invar, split } \\
& \text { Monel, not split }
\end{aligned}
$$

End Attachment

$$
\begin{aligned}
& \text { J } \\
& \text { K } \\
& \text { L } \\
& \text { M } \\
& \text { N }
\end{aligned}
$$

Bdge Attachment
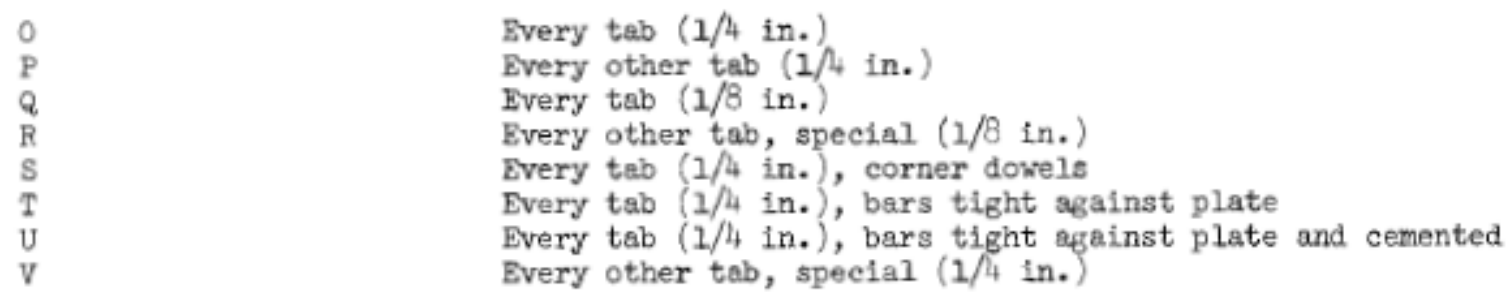

Figure 5.9. Experimental test case matrix, cont'd. Description of the conditions in experiments listed in Figure 5.8. Source: [5] 


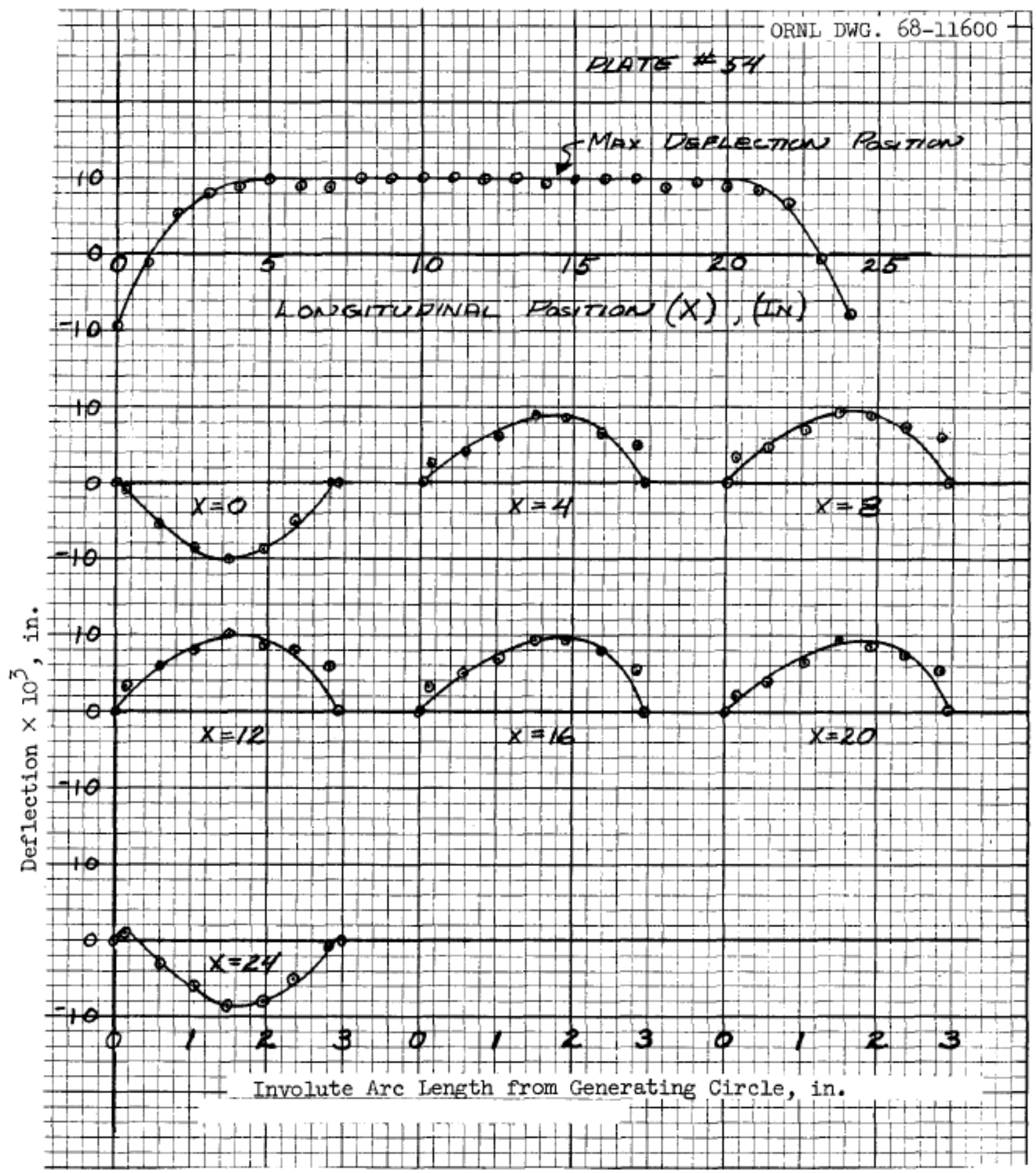

Figure 5.10. Experimental results: typical plate deflection curves for change in temperature from $80^{\circ} \mathrm{F}$ to $400^{\circ} \mathrm{F}$. Source: [5] 


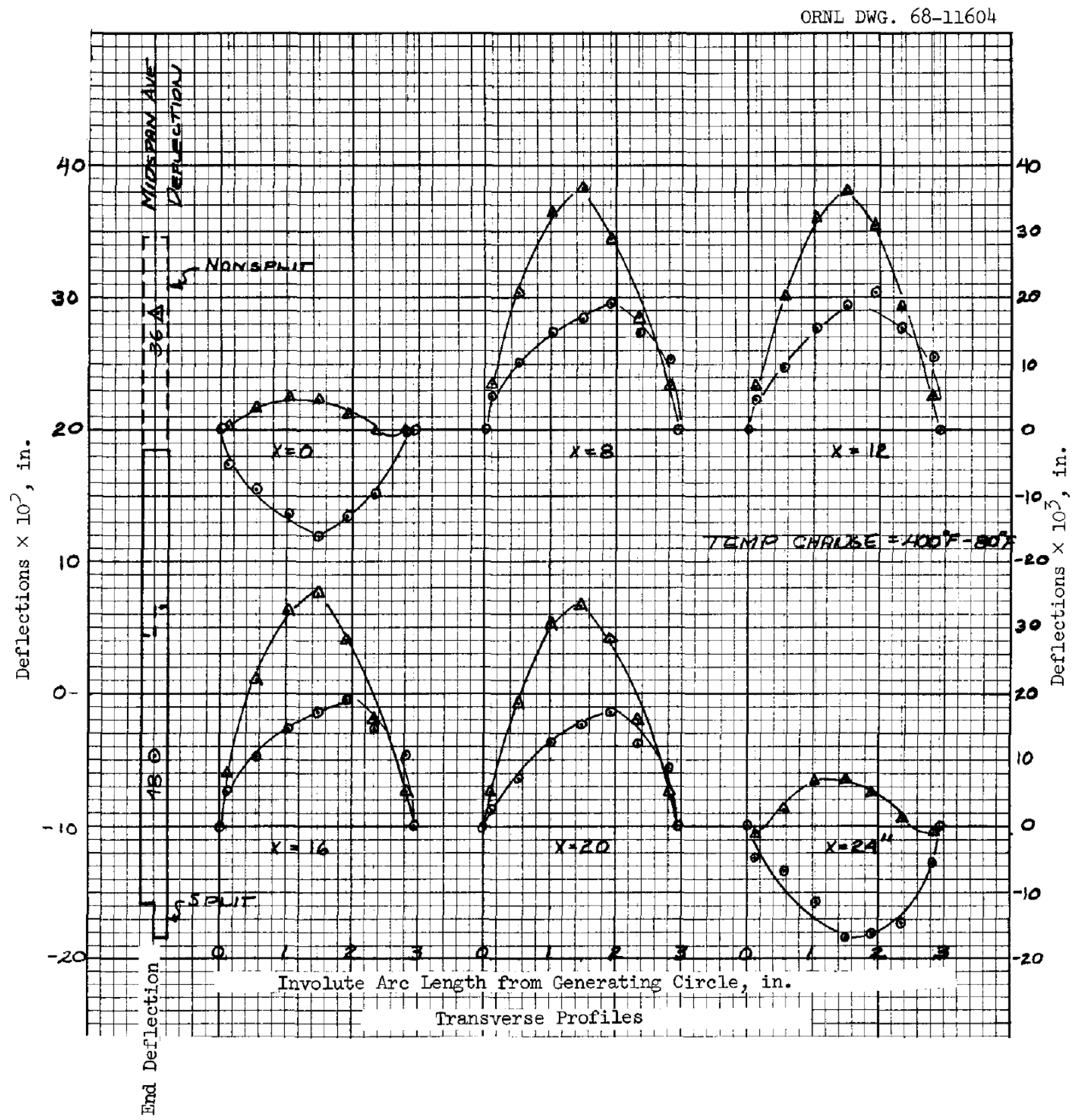

Figure 5.11. Experimental results: comparison of deflections with split and non-split Invar base. Source: [5] 


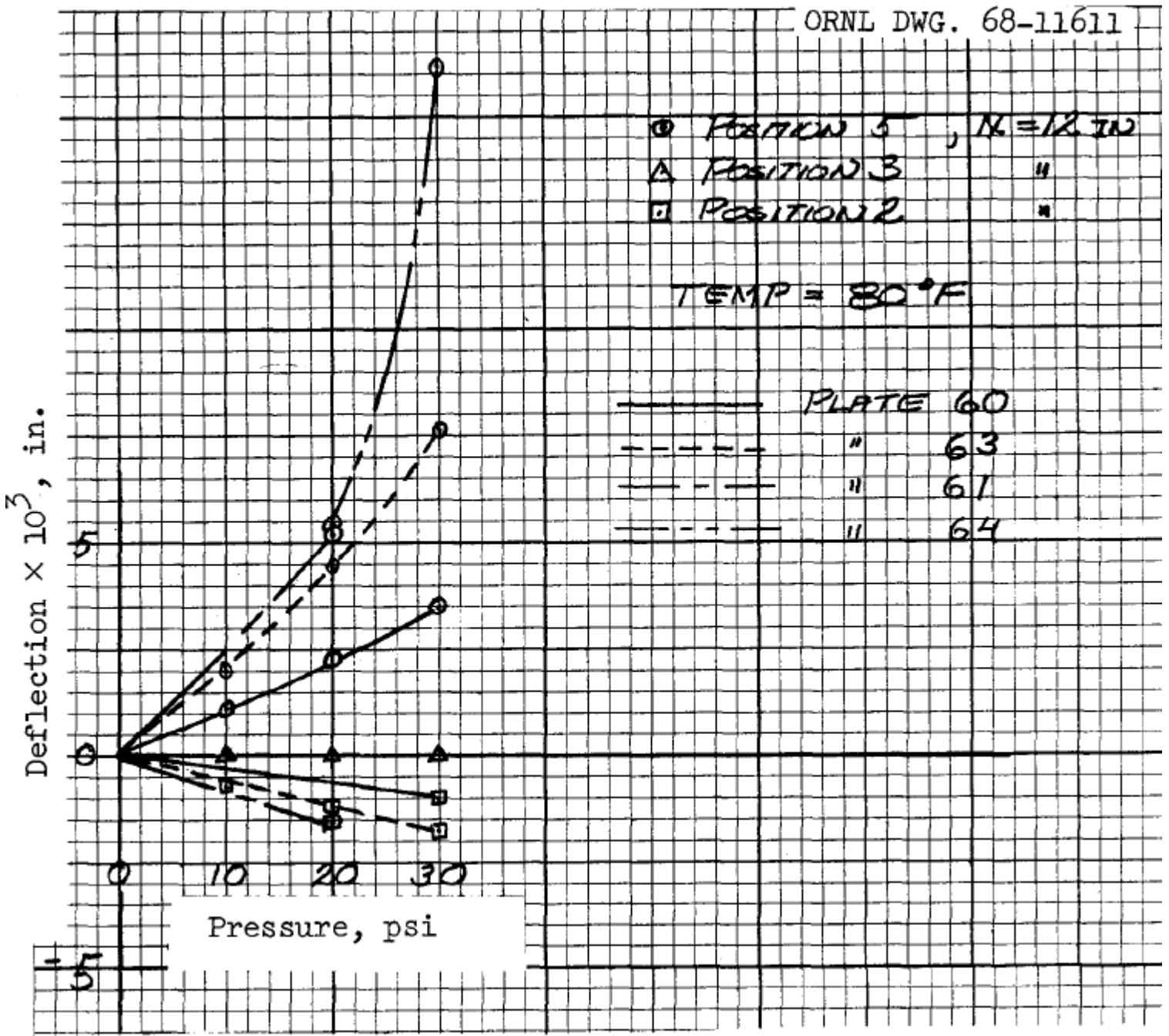

Figure 5.12. Experimental results: deflection for initial pressurization versus type edge attachment. Source: [5] 


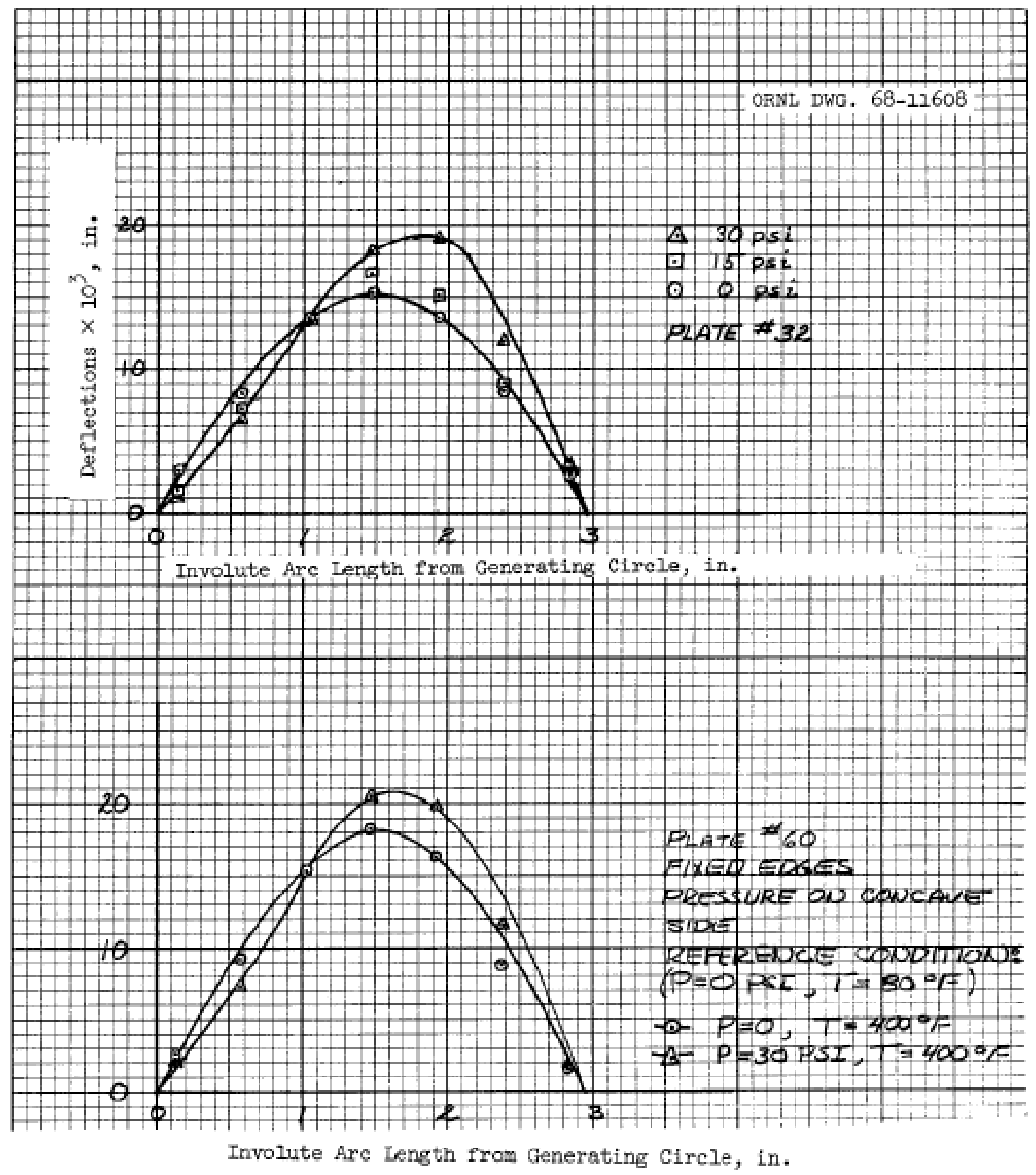

Figure 5.13. Experimental results: plate deflections caused by temperature $400^{\circ} \mathrm{F}$ and pressure up to 30 psi. Source: [5] 


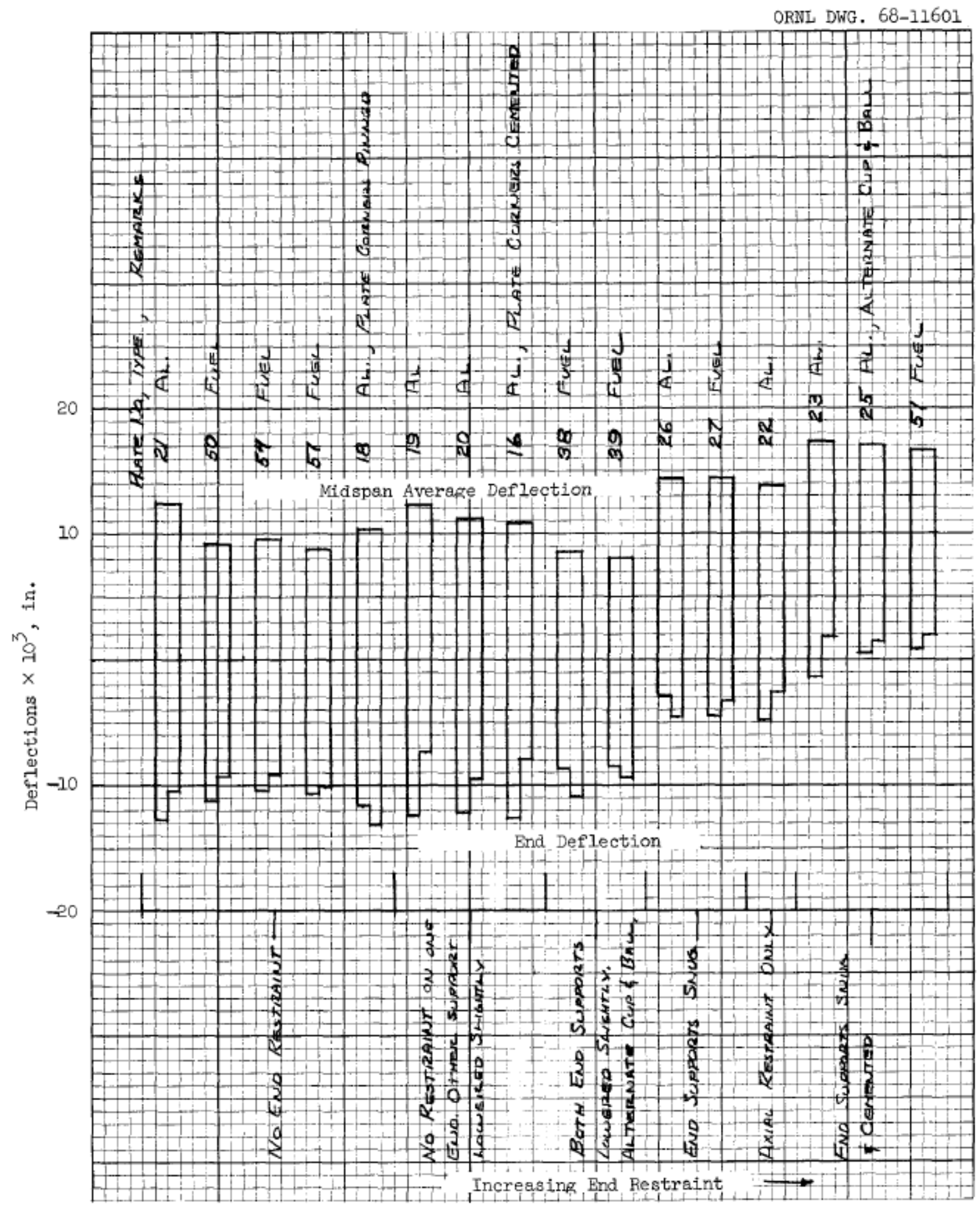

Figure 5.14. Experimental results: deflection vs. end restraint for all 1/4" tabs clamped in a split steel base. Source: [5] 


\section{Finite Element Modeling of the Cheverton and Kelley Experiment}

In this section, Finite Element Method modeling using the commercial code Simcenter STAR-CCM+ version 2020.2 [4], is discussed.

The main variable of interest in the study is the deflection of an involute plate, and specifically, its maximum magnitude and the direction. The physical phenomena that influence the variables of interest were discussed in Section 4. In this section, an analysis of the simulation input parameters that affect the modeling of those phenomena will be covered. The deflection magnitude and direction depend on a variety of factors, such as:

1. finite element type and mesh density,

2. choice of boundary conditions,

3. material models and property values,

4. load models.

The main computational models available in the software and used in the study are discussed in Section 6.1. The material models and properties used in modeling are presented in Section 6.2. Section 6.3 discusses the development of the geometry of the computational models. Section 6.4 covers the displacement boundary conditions, and Section 6.5 the load models used in the simulations. A finite element mesh sensitivity investigation is described in Section 6.6. The chapter ends with a discussion of the selected models, in Section 6.7.

\subsection{Physical Models}

Solid mechanics solver was added to the list of solvers available in STAR-CCM+ relatively recently, thus giving users new modeling capabilities. It uses the finite element method to discretize the continuum [18]. The available finite element shapes are tetrahedra, hexahedra, prisms, and pyramids. Polynomial shape functions used in the finite element formulation approximate the topology of the continuum as well as the displacement field. The software offers linear and quadratic shape functions. All volume and surface integrals are evaluated numerically using a full Gauss integration rule appropriate to the order and topology of the element. The steady solver can be used to solve a problem that is not time dependent, and the unsteady solver accounts for time dependency.

The relationship between stress and strain in the solid mechanics is defined by a material model. Linear elastic materials and elastoplastic materials with either isotropic, orthotropic, or anisotropic properties, and isotropic hyper elastic materials are available. User-defined elastoplastic material models can also be defined. In the case of relatively large displacements, the nonlinear geometry solver can be activated. Surface, line, or point mechanical loads and boundary conditions can be assigned to a body with the use of so-called segments.

Force, pressure, and traction type of loads are available. 'Force' is a point load, 'pressure', is equivalent to specify the normal component of a surface traction with tangential components equal to zero, and the 'traction' type of load allows for defining all three components of distributed load. The displacement constraints available are fixed, normal displacement, and displacement. 'Fixed' type of constraint sets all components of the displacement field to zero, 'normal displacement' prevents the

Involute Working Group - Development and Validation of the Finite Element Models of the Cheverton-Kelley Experiments 
part surfaces from moving in the normal direction, and the 'displacement' type requires to specify all three components of the displacement vector.

Temperature loads can be modeled in two ways. The Specified Temperature Load model accounts for the thermal strain that arises in a constrained body due to temperature loads. The Finite Element Solid Energy model allows to solve the energy transport equation for the solid temperature using the finite element approach. Boundary and volumetric inputs are available. More detailed information on the mechanical models used in the study is provided in Appendix A: Computational Tools .

\subsection{Material Properties}

Experiments by Cheverton and Kelley presented in Section 5 were performed on aluminum plates with a fuel core and pure aluminum plates. In a set of tests, they compared the experimental response of the two types of plates and concluded that the deflections were very similar. To simplify the modeling effort, it was assumed in the current study that the plates were modeled as if made of sheet aluminum 6061-T0. This approach was validated previously in a similar study [16]. The experiments were done with the involute plate clamped in a solid or a split base. The base material varied in the study: Monel, carbon steel, and Invar were chosen because of the difference in their thermal expansion coefficients. In the experiments modeled in the current study, only bases made of Monel and Invar were considered, because the carbon steel that was used in the experiments had a very similar thermal properties to Monel [5].

The material properties of the metals used in the experiments were not given explicitly in the report [5]. Therefore, the modeling of the material was based on data found in literature [17], [19], [20]. To account for the lack of experimental material property data, a sensitivity analysis was performed.

The researchers stated in the report, when describing the pressure tests, that: "For pressures below about 20 psi the pressure-deflections curves are essentially linear, indicating no plastic deformation. Above this pressure, plastic flow definitively takes places at least in the case of 1/8-inch and every other 1/4-inch in tabs" ([5], p.52). If the points follow the linear trend, irrespectively of the load, then the deformations are in the elastic range, but if the slope is not constant, then plastic flow occurs. Therefore, elastic, and elastoplastic material models were used in this study. The material model used was linear elastic with user defined plasticity.

Jain et al in their report [17] compared several material characteristics of the aforementioned metals at room temperature. The collected data is presented in Table 6.1.

Table 6.1. Material properties of the plate and base at room temperature. Source: [17]

\begin{tabular}{|c|c|c|c|c|c|c|}
\hline Material & $\begin{array}{c}\text { Density } \\
\text { (kg/m } \mathbf{3})\end{array}$ & $\begin{array}{c}\text { Modulus } \\
\text { of } \\
\text { elasticity } \\
\text { (GPa) }\end{array}$ & $\begin{array}{c}\text { Poisson's } \\
\text { ratio (-) }\end{array}$ & $\begin{array}{c}\text { Coefficient of } \\
\text { thermal } \\
\text { expansion } \\
\left(\mathbf{1 0}^{-\mathbf{6}} \mathbf{~ m / m - K )}\right.\end{array}$ & $\begin{array}{c}\text { Thermal } \\
\text { conductivity } \\
\text { (W/m-K) }\end{array}$ & $\begin{array}{c}\text { Specific heat } \\
\text { capacity } \\
\text { (J/kg-K) }\end{array}$ \\
\hline $\begin{array}{c}\text { Aluminum } \\
\text { 6061-T0 }\end{array}$ & 2700.0 & 69.0 & 0.33 & 23.6 & 167 & 896 \\
\hline Monel & 8800.0 & 169.0 & 0.295 & 13.9 & 21.8 & 427 \\
\hline Invar & 8050.0 & 141.0 & 0.30 & 1.30 & 10.15 & 515 \\
\hline
\end{tabular}


ASTM B209 Standard Specification for Aluminum and Aluminum-Alloy Sheet and Plate combines the mechanical property limits of aluminum at room temperature. According to the standard, sheet aluminum 6061-T0 with specified thickness 0.021-0.128 in (0.55-3.25 mm) has maximum tensile strength equal $22.0 \mathrm{ksi}(151.7 \mathrm{MPa})$, and maximum $0.2 \%$ offset yield strength equal $12.0 \mathrm{ksi}(82.7$ $\mathrm{MPa}$ ), see Table 3 in [19].

Martin and Weir report [20] covers testing results for several aluminum alloys and other metals in a wide range of temperatures. Aluminum properties, such as elastic modulus, yield strength, and ultimate tensile strength, in function of temperature can be found in the report and were presented in Appendix C - Material Properties. According to the digitized data presented in Figure C.5, the modulus of elasticity at room temperature is approximately $70.9 \mathrm{MPa}$ when established by sonic method, and the static modulus equals $69.5 \mathrm{GPa}$, which is close, but higher than the value reported by Jain et al. In the modeling, the lowest modulus of elasticity was accounted for. Figure C.6. shows that at room temperature the $0.1 \%$ offset yield strength is equal $57.8 \mathrm{MPa}$, which is higher than the actual yield point. Ultimate tensile stress was presented in Figure C.7. The report also provides stressstrain curves, which were plotted in Figure C.8. These data points were tabularized, and a userdefined elastoplastic material model was implemented in STAR-CCM+.

The material models used in the simulations of experiments performed at room temperature have properties based on Table 6.1. When thermal loads are involved in the modeling, the material properties of aluminum were based on the work by Martin and Weir, and the properties of other metals were based on work by Jain et al. because temperature dependent properties of Monel and Invar were not available to the authors of the present report at the time of writing.

The linear elasticity model assumes that stresses vary linearly with respect to displacements. The results of the set of simulations with changing modulus of elasticity show that the maximum midspan displacement indeed decreases linearly with increasing modulus, as shown in Table 6.2. The Poisson's ratio relates the strains in directions perpendicular to the direction of loading. The default value in STAR-CCM+ is 0.33 , which is also often found in literature [17]. The parameter value was varied from 0.3 to 0.36 and the obtained change in maximum displacements is again close to linear, with $\pm 9.1 \%$ change in the Poisson's ratio causing an average $\pm 2.3 \%$ variation in the deflections, as shown in Table 6.2 .

Table 6.2. Sensitivity study of the mechanical properties of aluminum on the plate deflections

\begin{tabular}{|c|c|c|}
\hline $\begin{array}{c}\text { Modulus of } \\
\text { elasticity } \\
\text { (GPa) }\end{array}$ & \multirow{2}{*}{$\begin{array}{c}\text { Poisson's } \\
\text { ratio (-) }\end{array}$} & $\begin{array}{c}\text { Max midspan } \\
\text { displacement } \\
\text { (mm) }\end{array}$ \\
\hline $6 n n$ & \multirow{2}{*}{0.33} & 0.0927 \\
\hline 69 & & 0.0914 \\
\hline 70 & 0.3 & 0.0901 \\
\hline \multirow{2}{*}{69} & 0.33 & 0.0934 \\
\cline { 3 - 3 } & 0.36 & 0.0914 \\
\cline { 3 - 3 } & & 0.0892 \\
\hline
\end{tabular}




\subsection{Geometry}

The experimental assembly was built of several components, as indicated in Figure 5.6. Representing all these components and the connections and interactions between them would result in a very complex model that would be computationally inefficient, would require significant computational resources and time to run simulations.

Instead, two computational models of the experimental setup were developed: a model of an involute plate only, with displacements constrained on the surfaces, and a plate constrained in a base. In this section, only the geometry of the models is discussed. The model of the involute plate with tabs is used to model validation cases that test the influence of the level of attachment of the long edge of the plate on the deflections. The model of the plate in a base is used to model the influence of thermal expansion of the base on the plate deflections.

The geometry of the involute plate with $1 / 4$-inch $(6.35 \mathrm{~mm})$ wide or $1 / 8$-inch $(3.18 \mathrm{~mm})$ wide tabs recreated from the reported data [5] is presented in Figure 6.1 and Figure 6.2. Figure 6.1 shows a view of the plate from the side. The main parts of the plate: the involute, the groove-wide strips on each side, as well as the tabs are marked in the figure. Also, the convex and concave surfaces were marked for reader's convenience. Figure 6.2(a) shows a top view of a plate with narrower tabs, and Figure 6.2(b) shows a top view of a plate with wider tabs.

A 3D rendering of a plate clamped in a base is shown in Figure 6.3. Figure 6.3 (a) shows a solid base, and Figure 6.3 (b), a base split along its length. Different colors of the plate and the base were chosen to distinguish these two parts of the model. It is worth mentioning, that the geometry of the base was not described thoroughly in [5] and that the geometry was recreated from one available standard drawing found in [17] and the photographs of the assembly. A scan of the drawing is presented in Figure 6.4.

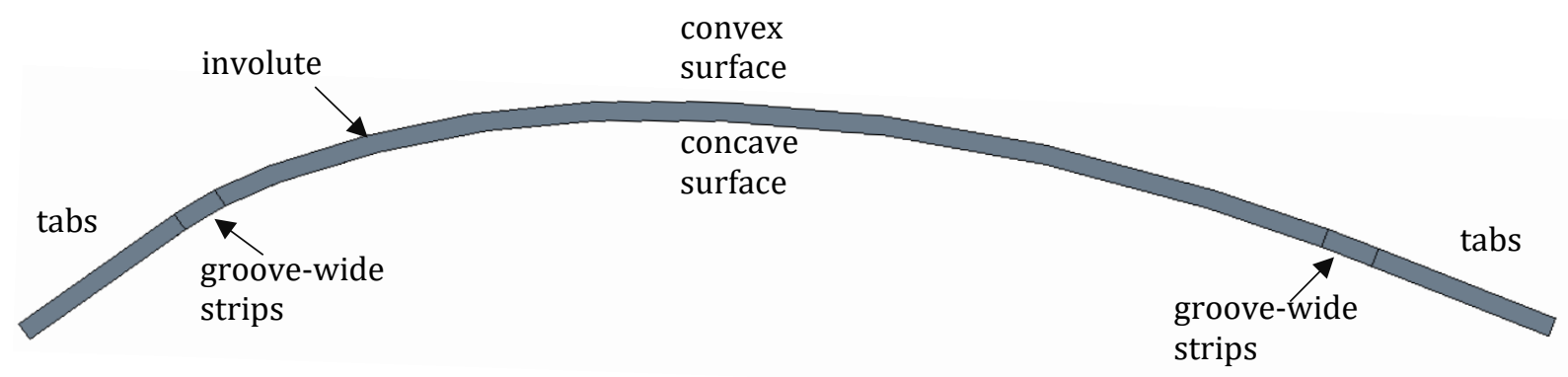

Figure 6.1. Front view of the geometry of the involute plate model 
(a)

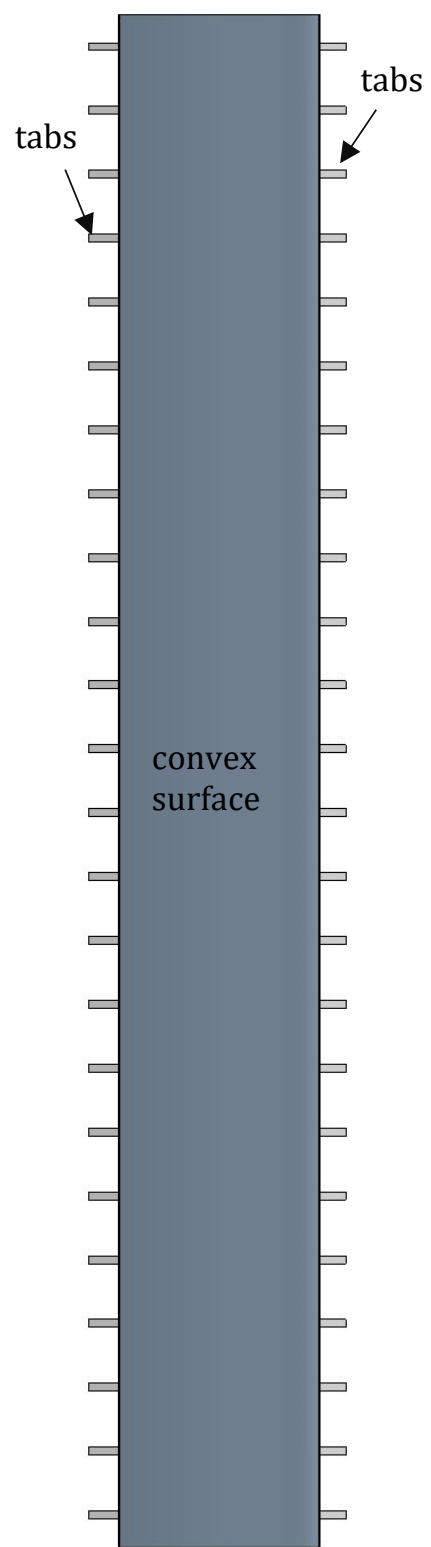

(b)

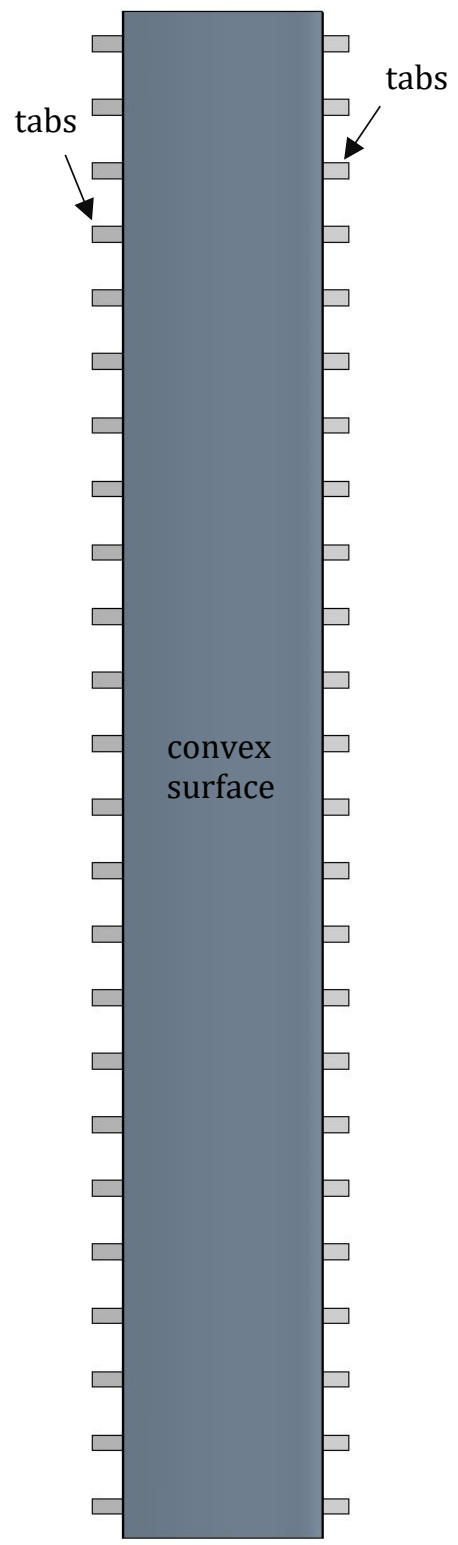

Figure 6.2. Top view of the geometry of the involute plate models, (a) model with $1 / 8$-inchwide tabs, (b) model with $1 / 4$-inch-wide tabs 
(a)

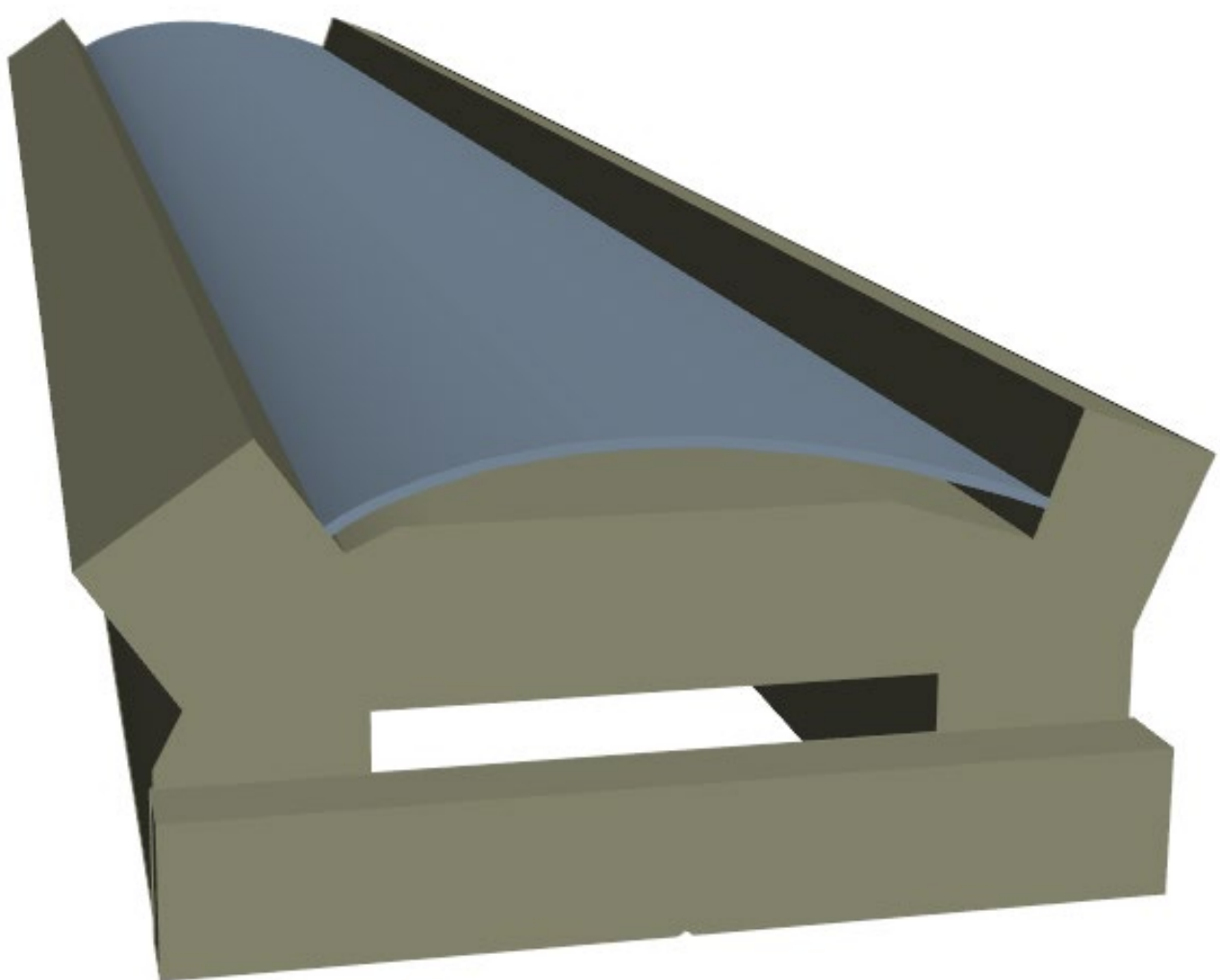

(b)

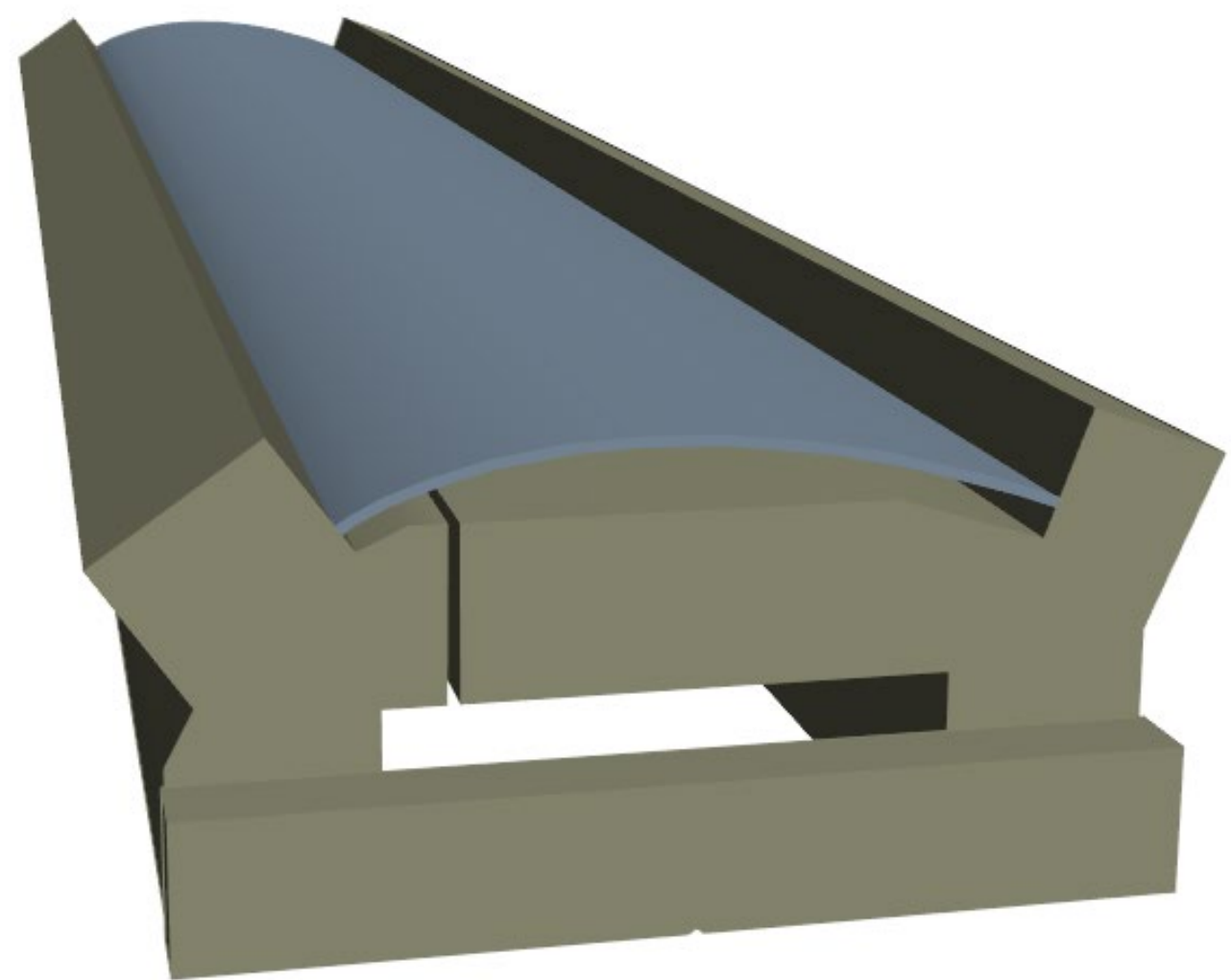

Figure 6.3. Perspective view of the involute plate (marked in steel grey) and the base (a) solid base, (b) split base (marked in warm grey)

Involute Working Group - Development and Validation of the Finite Element Models of the Cheverton-Kelley Experiments 


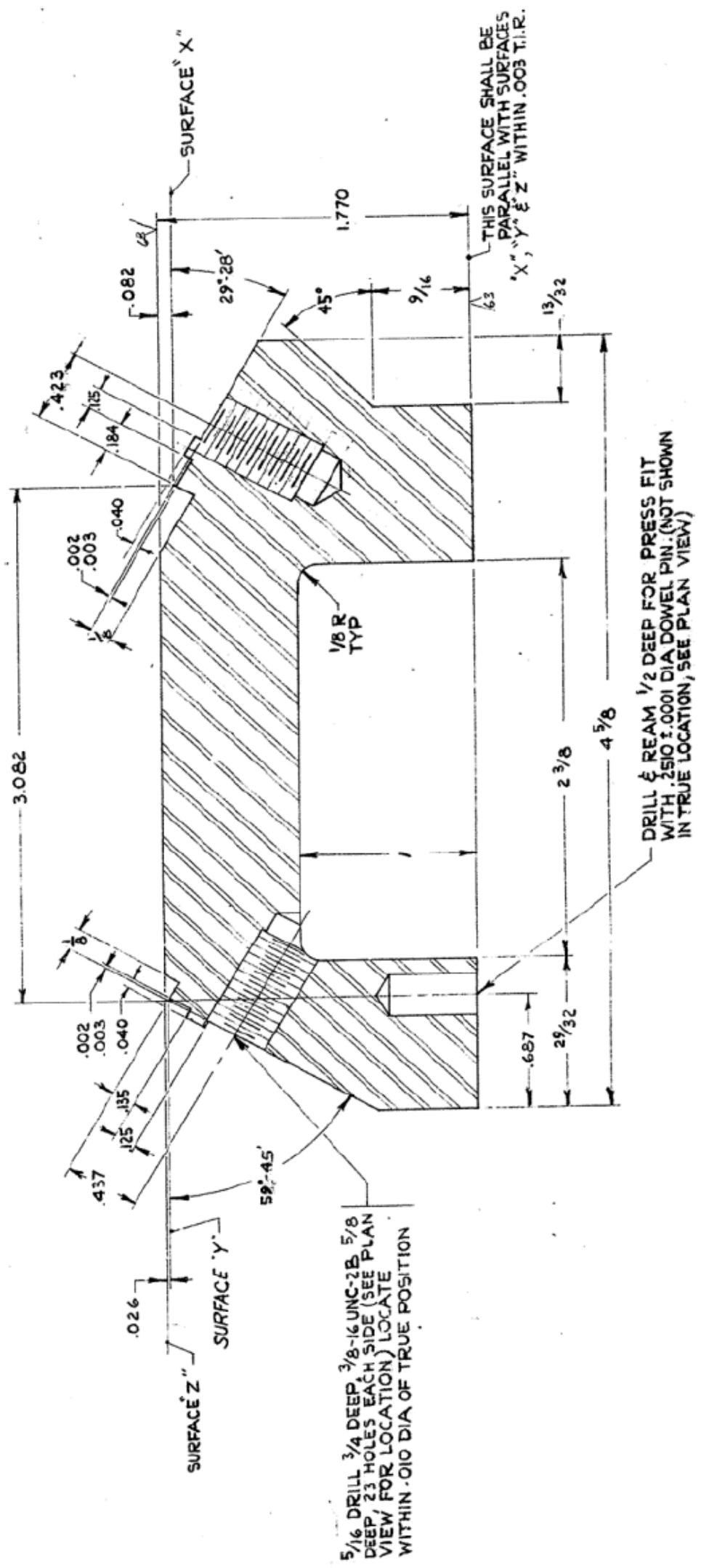

Figure 6.4. Drawing of the base geometry. Source: [17] 


\subsection{Displacement Boundary Conditions}

The displacement boundary conditions applied to the geometry of the two computational models: a model of an involute plate with tabs, with displacements constrained on the surfaces, and a plate constrained in a base, are presented in this section.

The model of a plate with tabs is computationally more efficient, as it does not include the meshedout geometry of the base. It makes it possible to vary the level of constraint, tested in the experiments, by changing the boundary conditions on the tab surfaces, as presented in Section 6.4.1.

The model of the plate constrained in a base is more complex and takes more computational time and resources to simulate. STAR-CCM+ software supports two types of mechanical interaction between bodies: a sliding frictionless and bonded contact. The model of a plate with a base is described in detail in Section 6.4.2

\subsubsection{Plate with Constrained Surfaces}

Computational models of the experiments performed on plates under pressure load at room temperature and attached to a solid base made of Monel with a varying level of attachment, described in Section 5.3, were developed. In this set of experiments the following options were tested (compare with Figure 5.8 and Figure 5.9):

1. every $1 / 4$-inch-wide $(6.35 \mathrm{~mm})$ tab was clamped, with clamp bars tight against the plate and cemented,

2. every $1 / 4$-inch-wide $(6.35 \mathrm{~mm})$ tab were clamped,

3. every other $1 / 4$-inch-wide $(6.35 \mathrm{~mm})$ tab was clamped,

4. every $1 / 8$-inch-wide $(3.18 \mathrm{~mm})$ tab was clamped.

Also, in all experiments, the edges were sealed to avoid leakage of the pressurized air, in such a way that the level of restraint was not changed. Also, the short edge of the plate was fixed.

The approach to model these experimental conditions is as follows. The constraint type (1), with the tabs clamped and clamp bars tight against the plate and cemented, was modeled with all displacements fixed on the tabs and on the thin strips along the long edges of the plate, where the bars would hold the plate. The surfaces with fixed displacements are highlighted in orange in Figure $6.5(\mathrm{a})$.

In the other variants of the constraints, (2)-(4), it is reported that only the tabs are clamped, but the level of constraint provided by the base is not described. Initial investigation showed that to obtain a good comparison with the experimental results, restraining the displacements only on the tabs is not sufficient and additional constraints should be considered. In the actual assembly, the involute plate was supported on the base, which provided a limitation on the downward movement of the plate sides, without constraining them completely.

To capture this kind of support, the following models were proposed:

1. All displacement components constrained on the tab surfaces. This model accounts for the restriction of the movement of the tabs, but not the involute plate. The plate can deform freely along its long edge. Figure 6.5 (b) shows the surface of the plate with the displacement boundary conditions highlighted in orange.

Involute Working Group - Development and Validation of the Finite Element Models of the Cheverton-Kelley Experiments 
2. All displacement components constrained on the tab surfaces, and zero normal displacements on the thin strips on concave side of the involute. This model adds a motion restriction of the long edge of the plate that is meant to model the support in the base. Figure 6.5 (c) present the surfaces were the boundary conditions are assigned (note this looks the same as Figure 6-9 (b) as only the type of boundary condition changes).

3. All displacement components constrained on the tab surfaces, and the groove-wide strips on the concave surface along the length of the plate are in contact with rigid planes which are tangent to the involute. These boundary conditions are highlighted in Figure 6.5 (d).

Figure 6.6 shows the two variants of the boundary conditions where (a) every tab is constrained, (b) every other tab is constrained (surfaces highlighted in orange are constrained). 
(a)

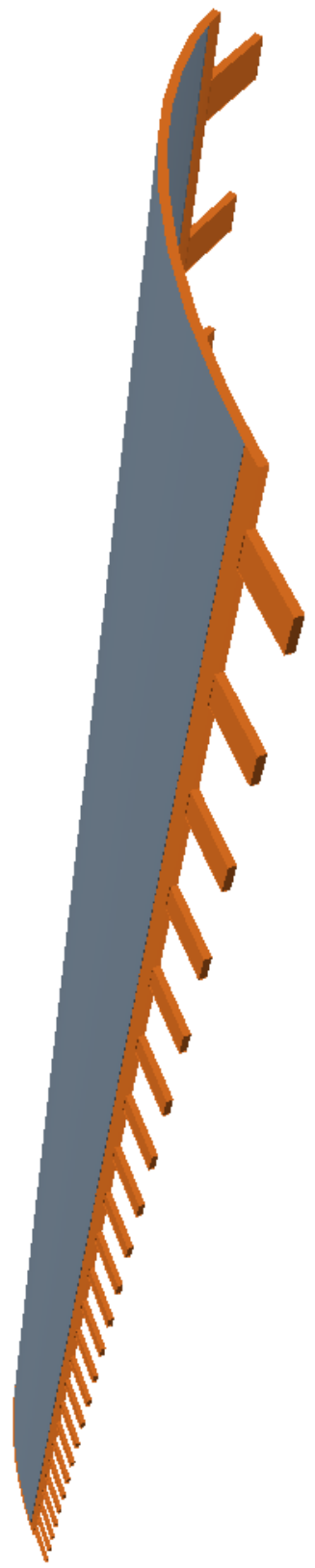

(b)

(c)

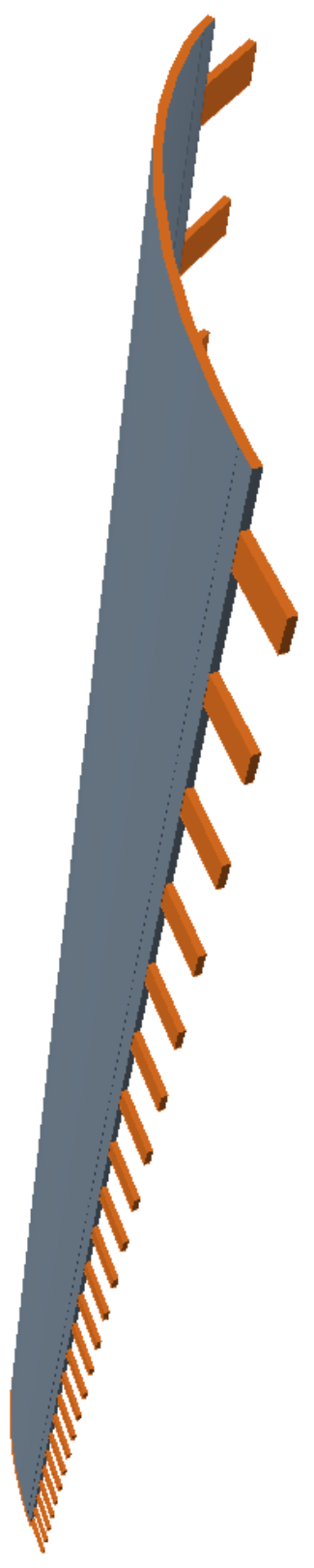

(d)

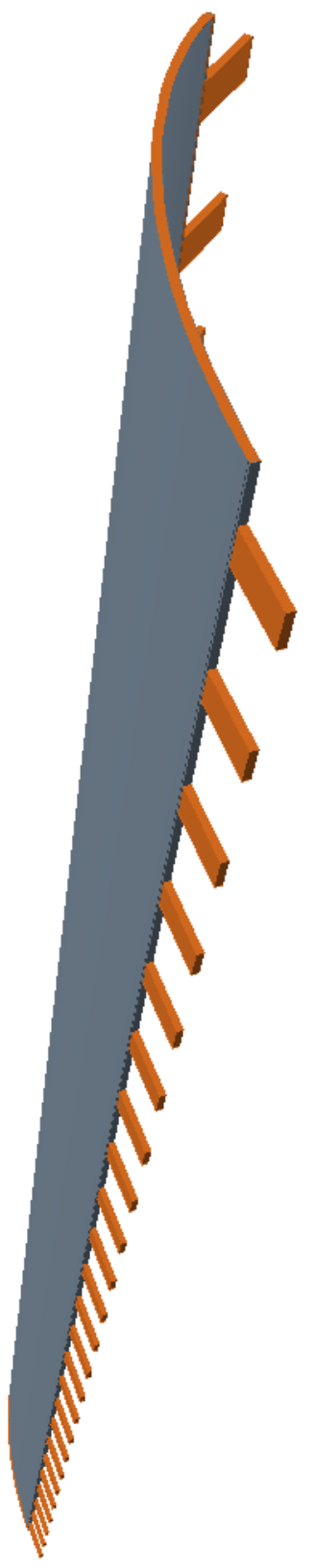

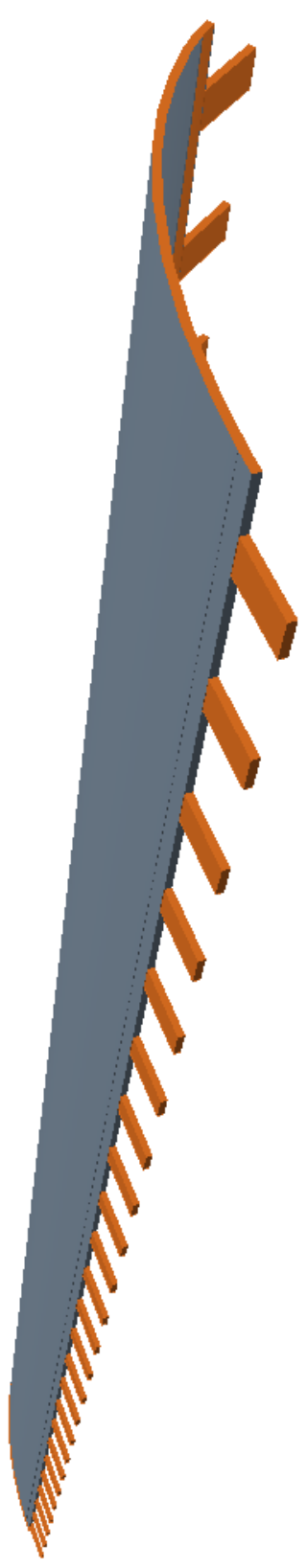

Figure 6.5. Boundary conditions of the plate sides used in the simulations. The highlighted surfaces have components of displacement vector constrained (a) fixed all components of displacement vector of the tabs and groove-wide strips on both sides, (b) fixed displacements of the tabs, (c) fixed all components of displacement vector of the tabs and zero displacement component normal to the surface of the thin strips on concave side, (d)

fixed all components of displacement vector of the tabs and groove-wide strips on the concave surface along the length of the plate in contact with rigid planes tangent to the involute. 
(a)

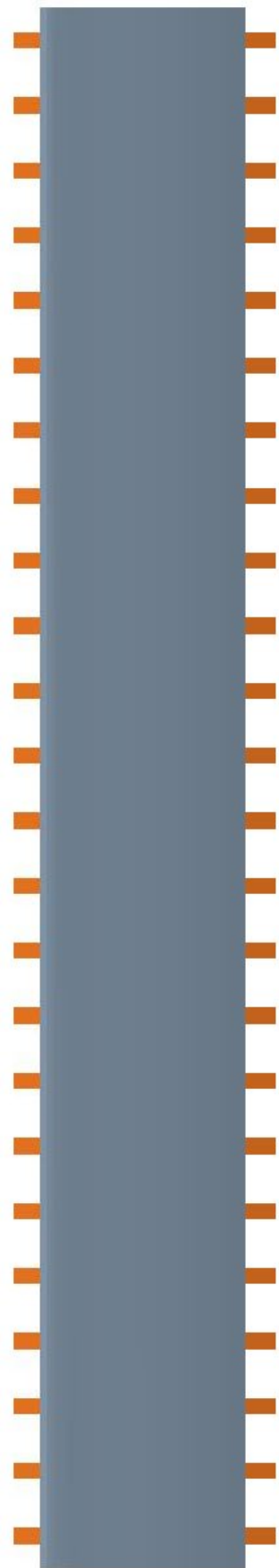

(b)

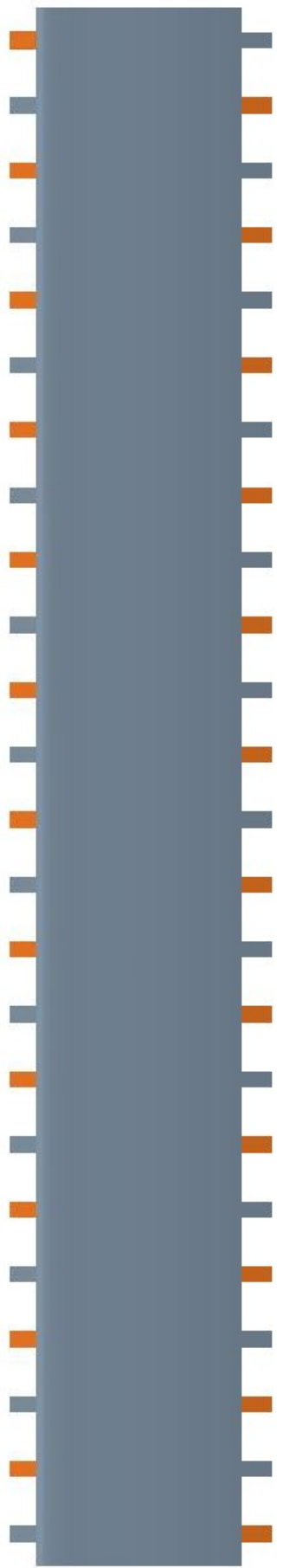

Figure 6.6. Two variants of the boundary conditions: (a) every tab is constrained, (b) every other tab is constrained (surfaces highlighted in orange are constrained) 


\subsubsection{Plate Constrained in a Base}

In the experimental setup, an involute plate was installed in a base aiming at limiting the displacements of the plate on the side and end edges. As presented in Section 5.2, the Cheverton and Kelley report contains a few photographs and sketches of the assembly but no details of the geometry of the base were provided there. Jain et al. [17] performed numerical simulations of this experiment using COMSOL Multiphysics software. Included in their publication is a figure showing a single standard drawing of a cross-section of the base, which gives insight into the dimensions and shape of this part of the assembly, as presented in Figure 6.4. Based on the limited data, a simplified geometry of the base was developed in the geometry module of STAR-CCM+, as presented in Figure 6.3.

In the experiments, the base was mounted on a track, used as a reference surface for the displacement measurements. The assembly was built in such a way that relative horizontal displacements between the base and the track were possible. The geometry of the track was not included in the model, instead the normal displacements on the bottom surfaces of the base were constrained, which makes it possible for the base to move freely in-plane, and not in the vertical direction. Finite element method formulation requires that a body is properly constrained, which means that the rigid body displacements: three translations, along $\mathrm{X}, \mathrm{Y}$, and $\mathrm{Z}$ axis, and three rotations, around $\mathrm{X}, \mathrm{Y}$, and $\mathrm{Z}$ axis, are eliminated from a model. Additional constraints (fixed displacements) were applied to small areas on the bottom surfaces of the end plates to constrain the body without introducing potentially significant deformations. Figure 6.7 shows a perspective view of the plate in a solid and split base with highlighted surfaces where displacement boundary conditions were applied. The displacement boundary conditions were the same in both models.

The finite element model presented in this section consists of three regions: the plate, the base, and the end plates. The interaction between the base and the end plates was modeled with a bonded mapped contact type of interface, which links faces of two boundaries using a proximity-based algorithm and assures a continuity of displacements between them. The interaction between the plate and the base was modeled twofold: (1) the plate without tabs was in bonded contact type with the base along its sides, and (2) the plate was modeled with the tabs and small sliding frictionless interaction was defined between the top and bottom bars and the plate, and the tabs were bonded with the base; also, a small space was added on the sides, so that the plate could expand tangentially. Figure 6.8 shows a perspective view of the model that includes the plate with tabs and the base. Figure 6.8(a) presents a view with opaque surfaces of the base, and in Figure 6.8(b) the opacity of the base surfaces was set to 0.5 , to show the otherwise invisible sections of the plate with tabs.

The end plates were used in two configurations: for tests with "free" ends of the plate, they were not in contact with the plate, and in the tests with "fixed" ends, they were bonded with the plate. 
(a)

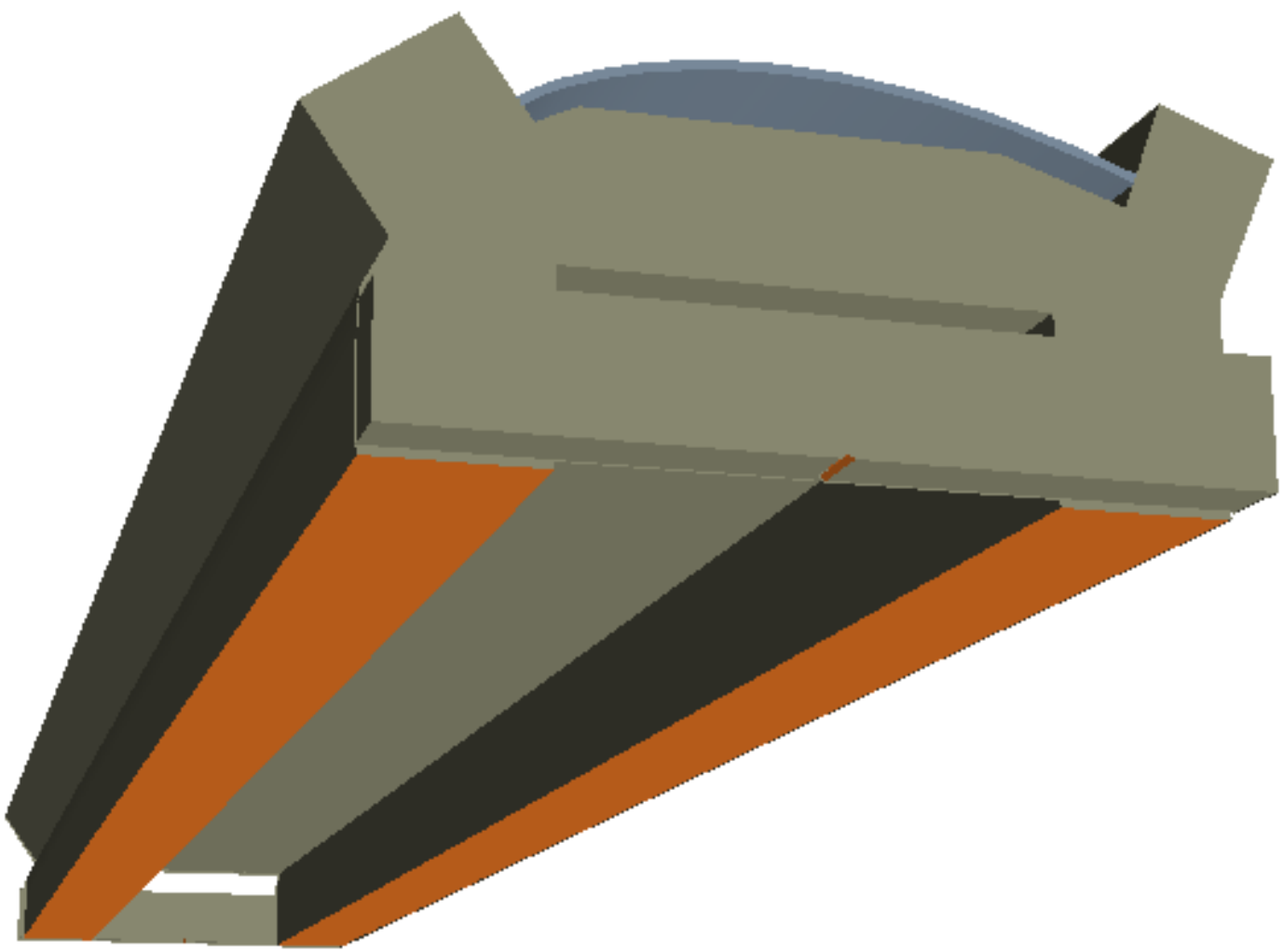

(b)

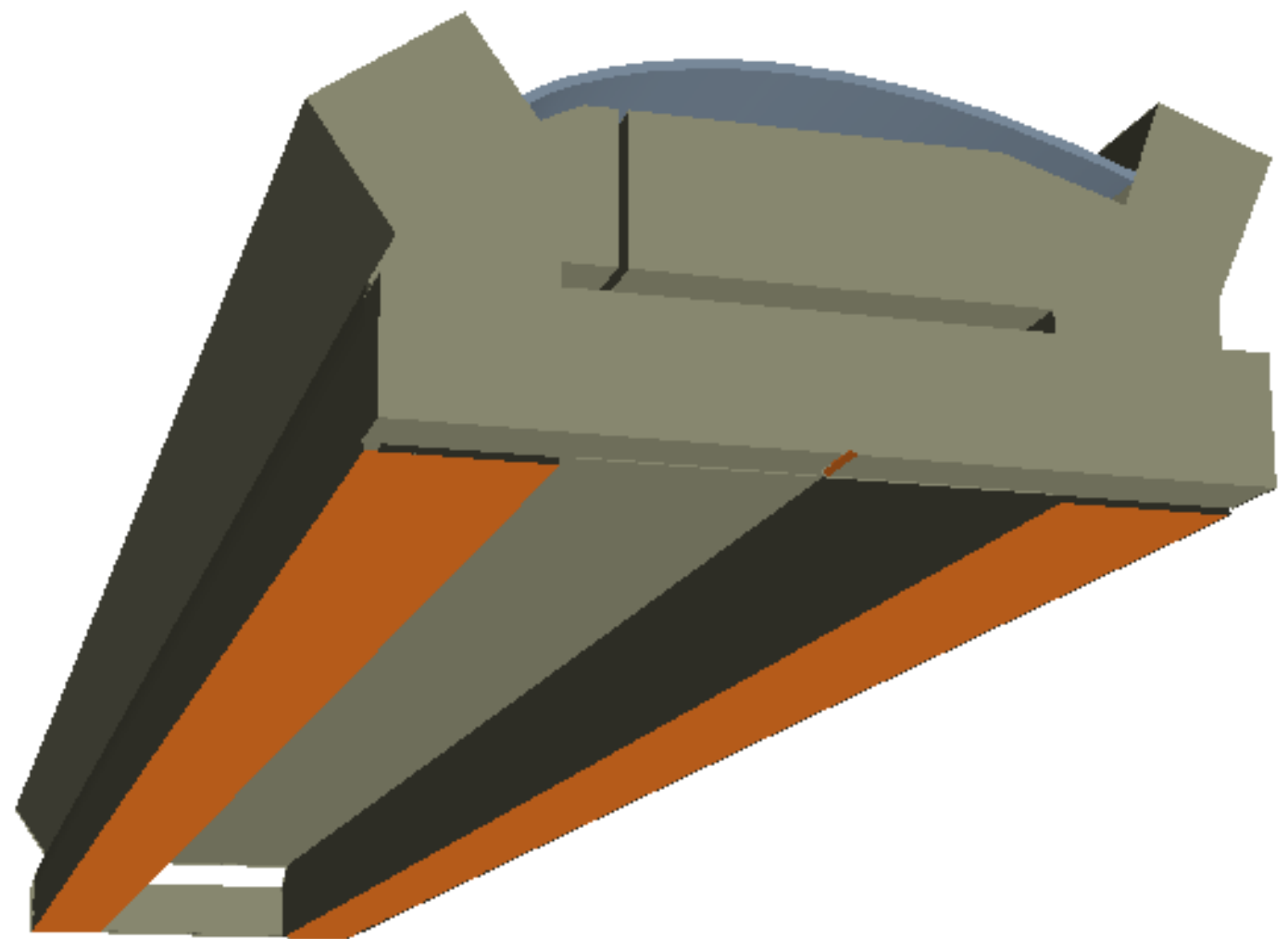

Figure 6.7. Perspective view of the involute plate and the (a) solid, (b) split base. Displacement boundary conditions are assigned to the surfaces highlighted in orange.

Involute Working Group - Development and Validation of the Finite Element Models of the Cheverton-Kelley Experiments 
(a)

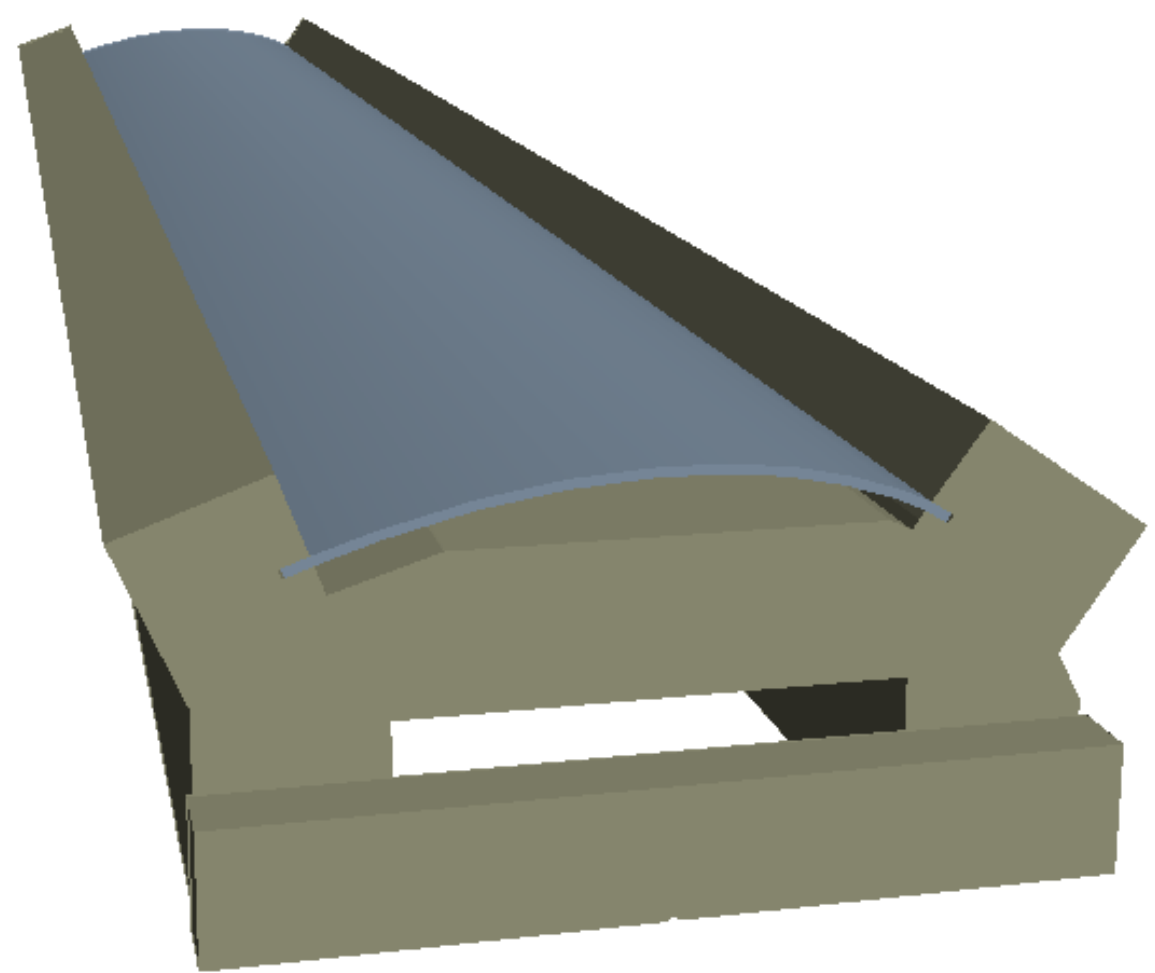

(b)

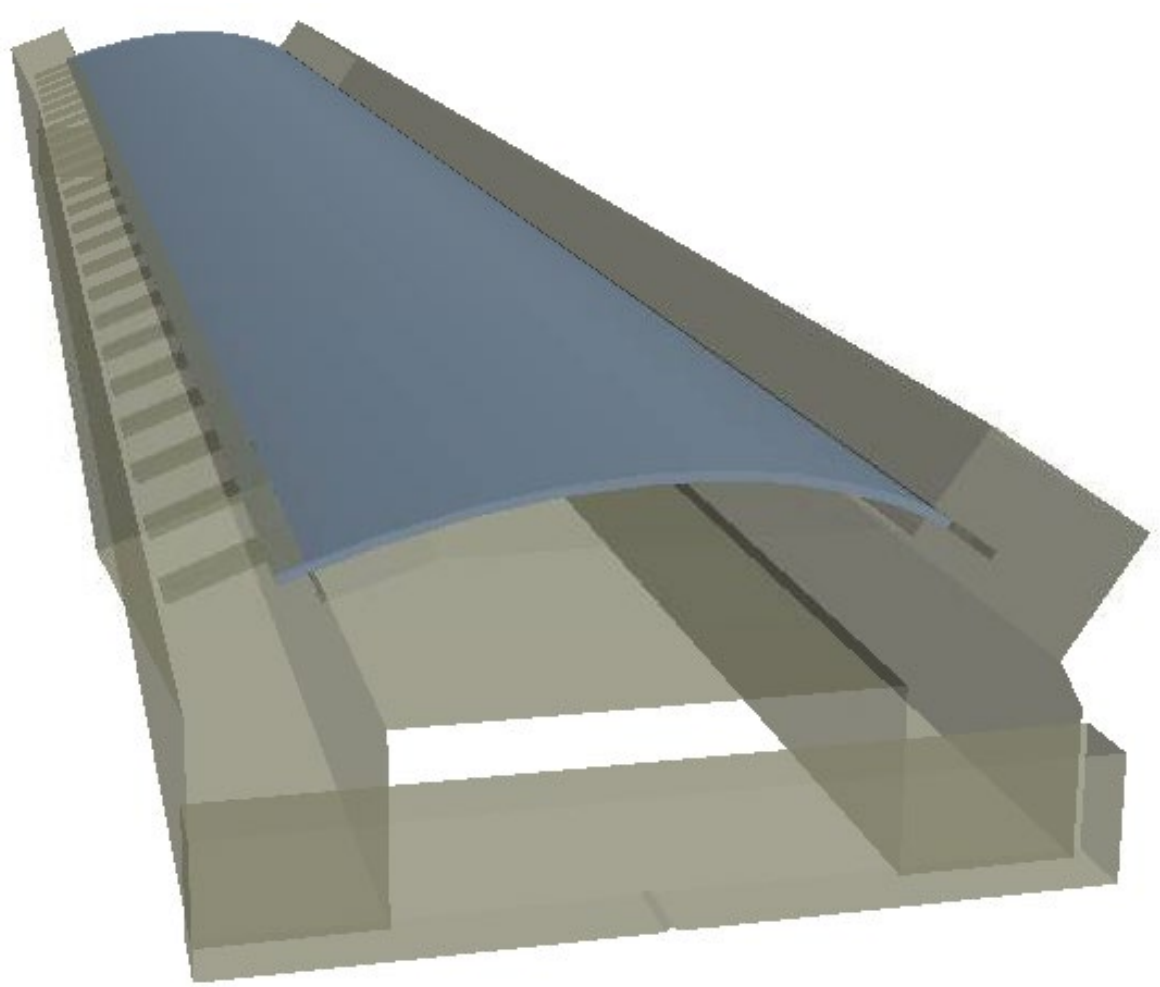

Figure 6.8. Perspective view of the involute plate and the solid base (a) non-transparent base surfaces, (b) opacity of the base surfaces is set to 0.5 to show the tabs. 


\subsection{Loads}

\subsubsection{Pressure Load}

Two types of mechanical loads were tested in the experiments by Cheverton and Kelley: pressure and temperature. In the computational setting, first separate effects of these load types were modeled, then a combination of pressure and thermal loads was considered.

The first set of computational simulations was developed for the experimental tests that were performed at room temperature. The experimental plates were incrementally pressurized on the concave side up to $30 \mathrm{psi}(207 \mathrm{kPa})$ in $10 \mathrm{psi}(69 \mathrm{kPa})$ increments. Also, in all cases, the edges were sealed to avoid leakage of the pressurized air, in such a way that the level of restraint was not changed.

The effect of the pressurized air acting on the concave surface of the involute plate was represented in the FEM model as a static uniformly distributed pressure load normal to the discretized surface. As in the experiment the loads were applied slowly, the dynamic effects can be ignored in the simulations. Pressure load type on a selected surface is defined by one parameter, its magnitude. A sketch of this type of load was presented in Figure 6.9.

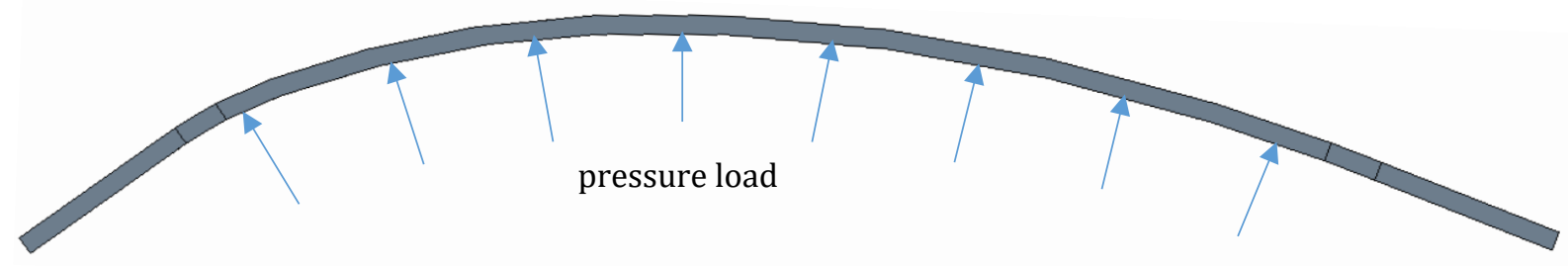

Figure 6.9. A sketch of the pressure load acting on the involute plate

\subsubsection{Temperature Load}

Temperature loads can be modeled in STAR-CCM+ 2020.2. using two methods, Specified Temperature Load solver, and Finite Element Solid Energy solver. Specified Temperature Load model requires the user to specify the continuum temperature and reference temperature, at which thermal strains are zero, as well as the thermal expansion coefficient of the material. The Finite Element Solid Energy solver calculates the temperature in a solid continuum in response to thermal boundary conditions or volumetric sources. Additional material characteristics, such as specific heat and thermal conductivity, need to be specified. In this case, all surfaces of the plate were assigned a convection boundary condition, with ambient temperature of $400^{\circ} \mathrm{F}(477 \mathrm{~K})$, and heat transfer coefficient 5 $\mathrm{W} / \mathrm{m}^{2} \mathrm{~K}$, similarly as in [17].

A test of the two temperature load options, using the steady solver, was performed on a model with unconstrained ends and constrained long edges of the involute plate. Both simulations converge to the same solution, with the maximum deflection of $1.045 \mathrm{~mm}$. Contour plot of normal displacements on the convex surface of the plate is presented in Figure 6.10.

The Specified Temperature Load solver requires less input data than the Finite Element Solid Energy solver and therefore is more convenient to use. Also, computations converged faster when using the first method. Because of this, it was selected to be used in the current study. 

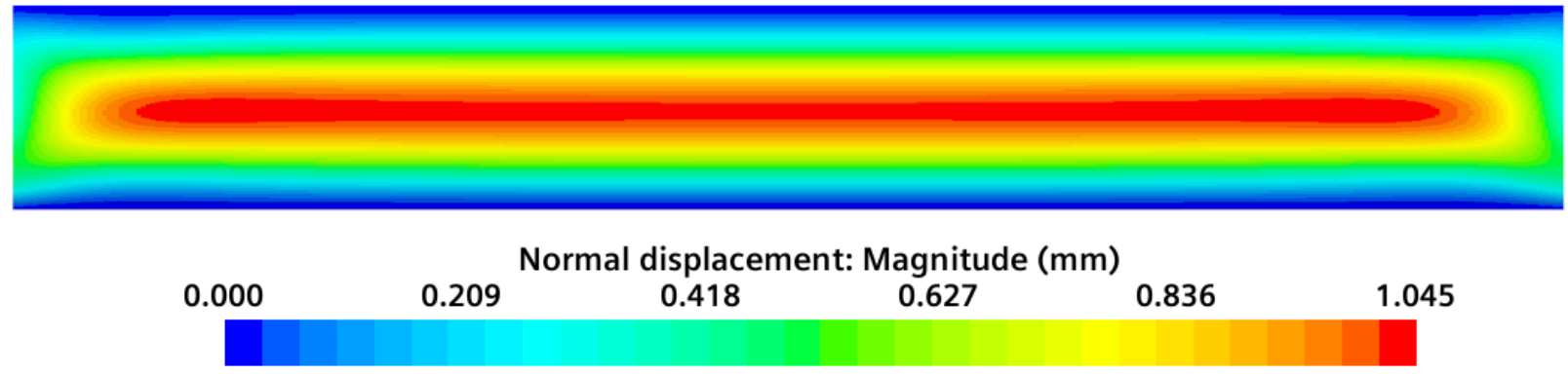

Figure 6.10. Contour plot of normal displacement magnitude on the convex surface of an involute plate under thermal loading obtained with the use of the Specified Temperature Load model

\subsection{Finite Element Mesh Sensitivity Study}

In finite element method modeling the continuum is discretized with the use of finite elements. Polynomial shape functions approximate the topology of the continuum as well as the displacement field. The available three-dimensional finite element shapes in STAR-CCM+ are tetrahedral Tet4 and Tet10, hexahedral Hex8 and Hex20, prismatic Wedge6 and Wedge15, and pyramids Pyramid5, Pyramid13, where the number in the name of the element refers to the number of nodes per element. By default, meshing in STAR-CCM+ creates finite elements with linear shape functions, such as Tet4, Hex8, Wedge6, and Pyramid5. If quadratic shape functions are preferred, the Mid-side Vertex Option should be selected for a specified Region to change the type of the finite element to one of the following: Tet10, Hex20, Wedge15, or Pyramid13. The mid-side nodes are added at the initialization of the computations.

According to the User's Manual [4], finite elements with quadratic shape functions are more accurate than linear as they approximate the topology and displacement field more accurately, but at the same time they have more degrees of freedom, and therefore, the computational cost of a simulation increases as well. Linear shape functions can give a reasonably accurate solution in structural analyses where stresses are not varying rapidly across the region, or if the mesh is fine enough in the regions of stress concentration. It is said that finite elements such as tetrahedral Tet4, wedge Wedge6, and pyramid Pyramid5 can cause locking, especially when used to represent thin structures under bending load. Locking characterizes with the computed displacements being of orders of magnitude smaller than expected and usually occurs when a finite element formulation cannot represent properly the displacement field due to the insufficient number of degrees of freedom or insufficient order of the shape function polynomial.

Hexahedral elements with linear shape functions, Hex8, are enriched with internal degrees of freedom, which overcome locking, and are more accurate than the other linear element types. This type of finite element is recommended by the Manual for problems of thin structures in bending. Hexahedral elements with mid-side nodes and quadratic shape functions, Hex20, tend to have better accuracy, according to the documentation, but at a cost of much more memory and operations. Wedge elements with mid-side nodes, Wedge15, are also suitable when the geometry is sufficiently regular, so that a triangular surface mesh can be extruded through the thickness of the part to create wedges. However, in transitions from thick to thin sections of the geometry, the mesher can create pyramid elements. Thin parts under bending should have at least two aligned elements through the thickness, 
when a linear stress-strain relationship is assumed. The number of elements through the thickness primarily affects the level of accuracy of the computed axial stress. For example, in beam theory, under the assumption of Hooke's law, the axial stress changes linearly through the beam thickness. When the material model is elastoplastic, the stresses change linearly in the elastic range, and are constant in the plastic range. Enough finite elements need to be chosen to represent this stress distribution.

Considering the above description of various finite element formulations available in the software, only hexahedral finite elements were tested to model the involute plate. The triangular finite elements were omitted, as they may cause locking, as well as because the user has less control over the meshing process, and pyramid elements may be created. The geometry of the plate is such that it can be represented well with hexahedrons with a few layers of finite elements across the thickness. The mesh was created with the use of Directed Mesher, which is the only approach available in STAR$\mathrm{CCM}+$ that gives full control over the number of elements, and therefore their size, along the model edges. Hexahedral Hex8 and Hex20 finite elements were tested.

A mesh sensitivity study was performed on a computational model of a test done on an involute plate with 30 psi (206.8 $\mathrm{kPa})$ pressure applied to the concave surface, every 1/4-inch-wide $(6.35 \mathrm{~mm})$ tab clamped, and clamp bars tight against the plate and cemented. The mechanical load was applied in form of a distributed load normal to the finite element surfaces, and the boundary condition was applied by constraining all three components of displacement on the tabs and thin strips along the length of the plate. The material model was linear elastic with Young's modulus of $69 \mathrm{GPa}$. This case was chosen because (1) the side and end constraints are relatively simple to model, and (2) the deflection of the plate observed in the experiment was relatively complex: the deflection was negative where the radius of involute curvature was relatively smaller, and positive otherwise (3) this experimental case did not show plastic deformation.

The maximum displacement of the plate midspan was chosen to be monitored in the process and compared between cases. Also, the deflection of the plate midspan was plotted for selected test cases. In each case the finite element mesh was created with a uniform distribution of finite elements. First, a coarse mesh made of Hex8 finite elements was built with 2 by 200 by 384 finite elements in the thickness, along the involute arch and plate length directions, respectively. Then the mesh density was iteratively increased in one direction at a time, across plate thickness, along the involute, and along the length of the plate. Next, the model was discretized with Hex20 finite elements, that have 20 nodes, instead of 8 . To keep the total number of nodes in the model the same as in the previous discretization, the initial number of finite elements was decreased to 1 by 100 by 192 . Then, the number of elements across the thickness was increased up to four. All models where Hex8 was used completed within a few minutes on a two-core desktop computer. The models discretized with Hex20 finite elements required more computational resources and when finer meshes were used, the time needed by the solver to find the solution increased significantly or, in some cases, issued an error, because it run out of memory. Moreover, the deflections obtained in simulations that finished successfully, were about 3\% lower than obtained with the Hex8 finite elements, which is a less conservative result.

Figure 6.11 shows a plot of the maximum midspan deflection vs. number of nodes in the model. The three curves represent the change in maximum deflection due to the increase in mesh density. They all show a good convergence of the deflection with the increase of the number of finite elements. Figure 6.12 presents the midspan deflection curves for the three discretizations in which the number of finite elements increased from 2 to 8 across the thickness of the plate.

Involute Working Group - Development and Validation of the Finite Element Models of the Cheverton-Kelley Experiments 
The mesh selected for further computations is presented in Figure 6.13. It consists of Hex8 finite elements, with 384 finite elements along the length of the involute, 200 finite elements across the plate and 4 finite elements in the thickness direction. Four finite elements were used along the width of the thin side strips, and eight by four elements were used to represent the geometry of the tabs.

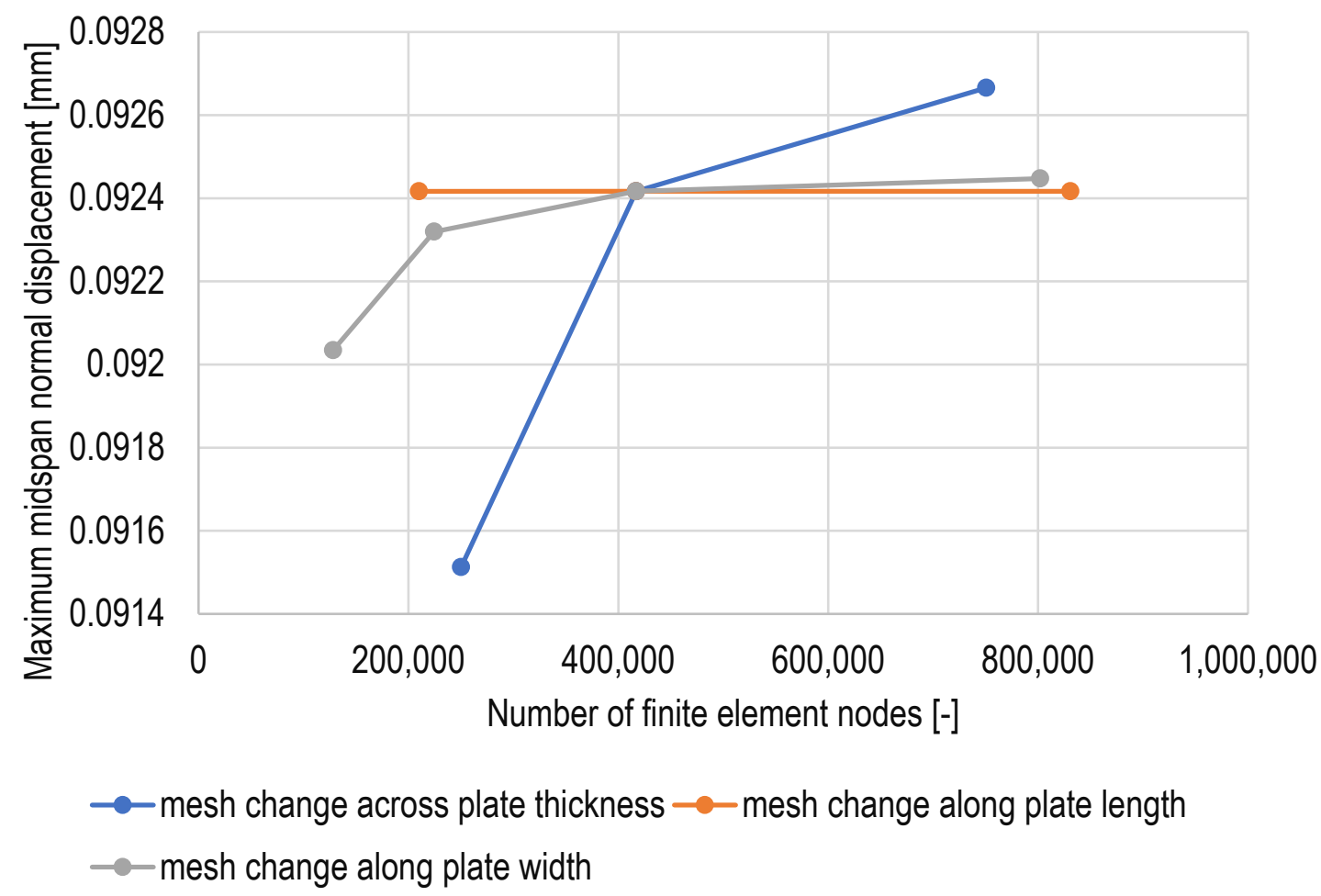

Figure 6.11. Maximum normal displacement on the midspan of the plate. Number of finite elements was increased across thickness, length, and width of the plate. 


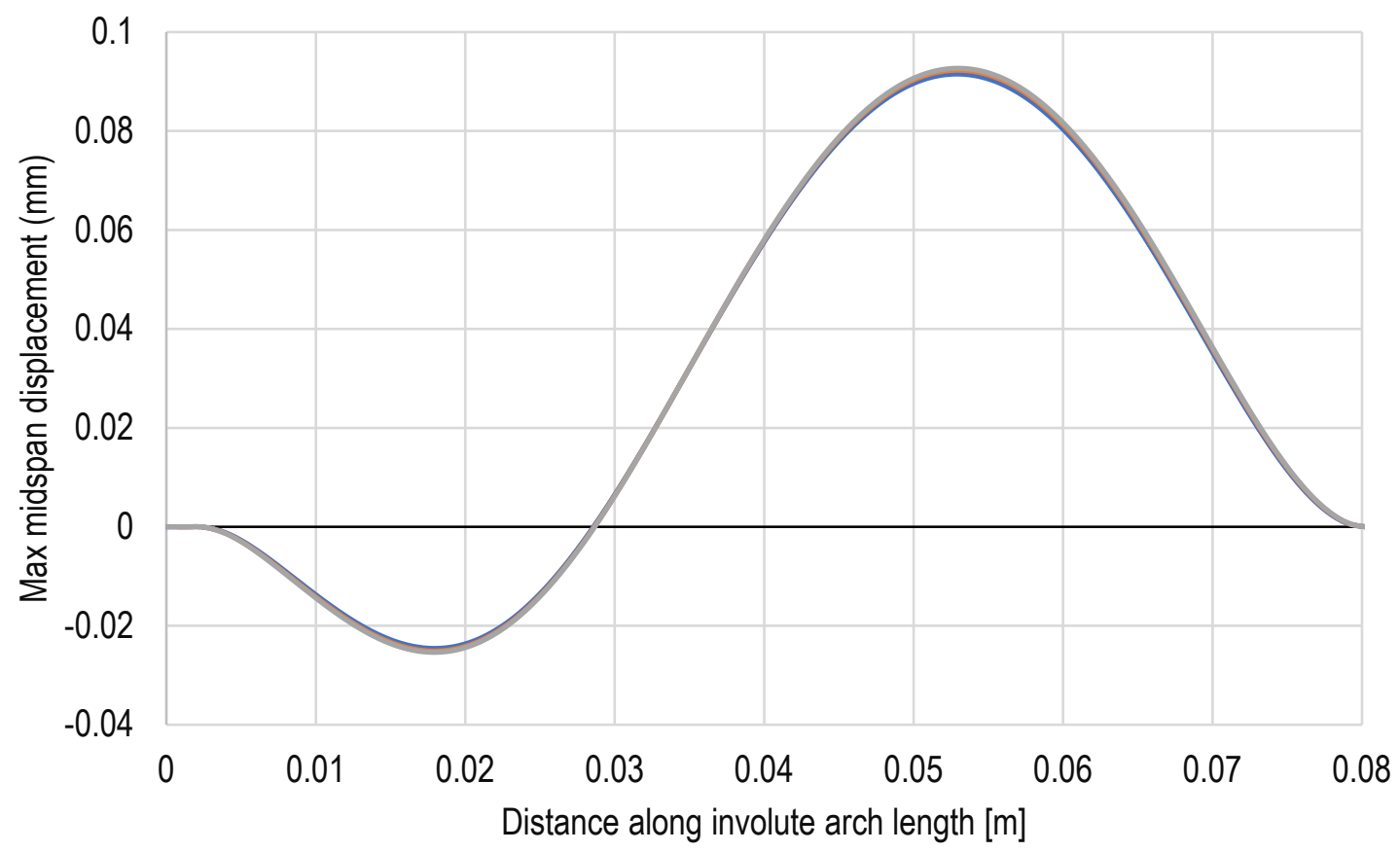

$-2 \mathrm{FE} \longrightarrow 4 \mathrm{FE} \longrightarrow 8 \mathrm{FE}$

Figure 6.12. Midspan normal displacements for varying mesh density across plate thickness: 2,4 , and 8 finite elements

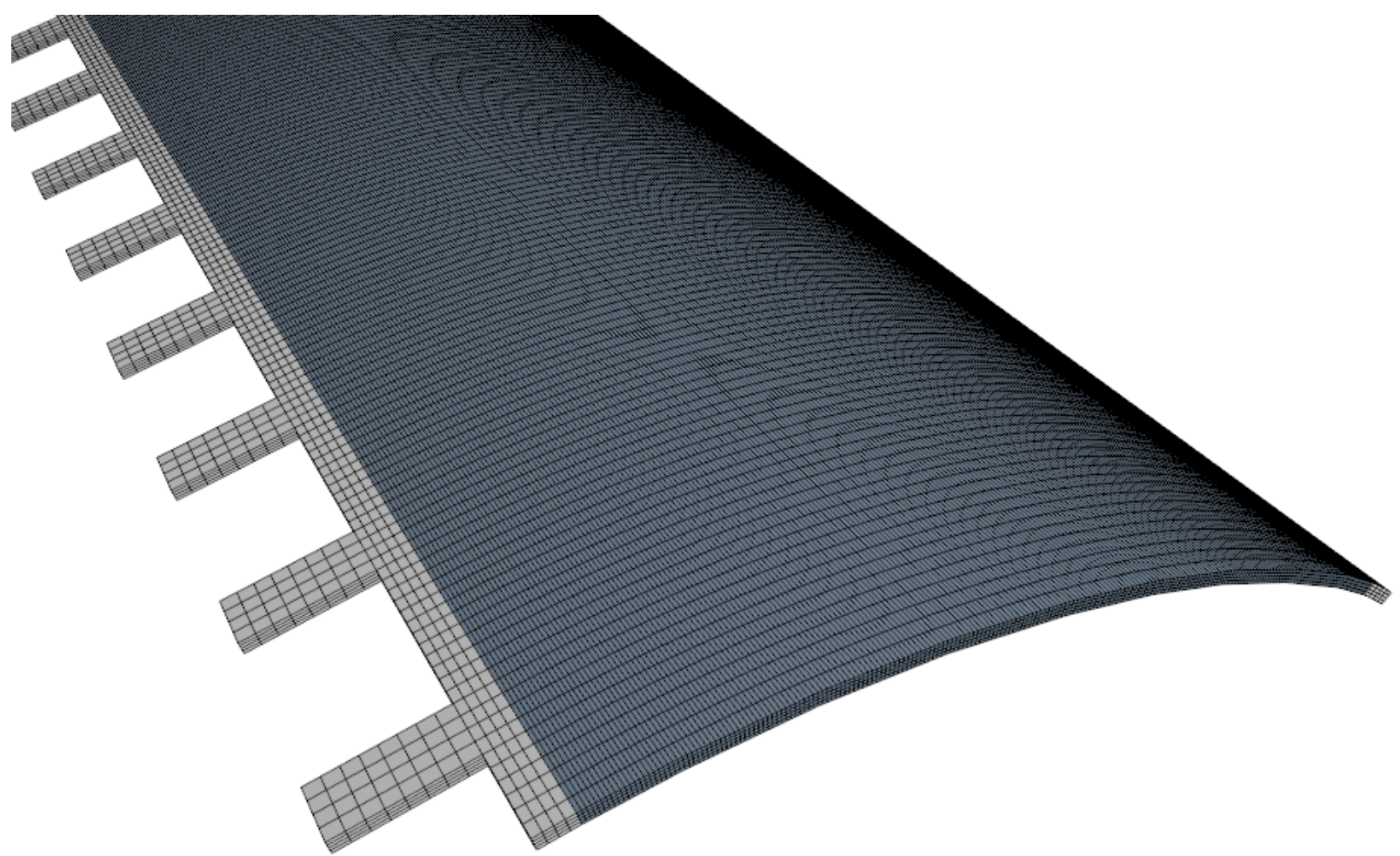

Figure 6.13. Close up of the FEM mesh used in the simulations 


\subsection{Discussion on the Selected Models}

As a part of the IWG research effort, CFD/FEM STARCCM+ software is evaluated to establish if it can be used as a computational tool for simulating deflections of fuel plates under normal operation conditions. Specifically, if the software provides solvers and models that make it possible to conduct an analysis of an aluminum plate under pressure differential and thermal loading. In this Section, the selected models are discussed.

The chosen material models for aluminum are isotropic linear elastic and elastoplastic with userdefined plasticity. The material properties used are based on data found in a literature review. The differences in elastic model parameter values were analyzed and a sensitivity study was performed, and it showed that the influence is not significant. The difference in structural response between the elastic and elastoplastic material models will be analyzed in the following Section.

The geometry of the assembly is based on the standard drawings provided by Cheverton and Kelley [5], and Jain et al [17]. Two models were developed to analyze various effects of the physical phenomena occurring in the validation experiments. Due to the simplifications made in the model geometry and uncertainty in the plate constraint conditions in the experiments, a set of displacement boundary conditions variants was proposed. A detailed description of the influence of the various constraints on the deflections and stresses in the involute plate will be presented in the following Section.

Based on the results from the tested cases, it is recommended that the load on the concave surface of the involute plate caused by pressurized air is modeled with the uniformly distributed Pressure type of load, and the load resulting from an increase in temperature is modeled with Specified Temperature Load model.

The hexahedral finite elements with linear shape functions, Hex8, are selected for further computations. The discretization developed with the Directed Mesher makes it possible to maintain full control over the mesh density. Based on the selected test case, a mesh density study was performed, and a discretization was recommended for use in further simulations. 


\section{Cheverton \& Kelley Experiment Finite Element Modeling Results}

Several tests performed as a part of the Oak Ridge experiments [5] were chosen for validation of the finite element model developed in the current study. They differ with the type of load: surface pressure, temperature, and combination of both. Models of a single plate with constrained edges, as well as a more complex models of a plate clamped in a base were developed and the simulation results were compared with the experimental measurements. The details of the experimental conditions used in each of the pressure tests can be found in Table 7.1, temperature tests in Table 7.2, and the experiments performed with the combination of loads in Table 7.3.

Table 7.1. Experimental conditions in pressure tests

\begin{tabular}{|c|c|c|c|}
\hline Edge attachment & $\begin{array}{c}\text { End } \\
\text { attachment }\end{array}$ & Base & Load \\
\hline $\begin{array}{l}\text { every } 1 / 8^{\prime \prime}(3.18 \mathrm{~mm}) \text { tab, } \\
\text { edges sealed with Scilastic }\end{array}$ & \multirow{3}{*}{ fixed } & \multirow{3}{*}{$\begin{array}{l}\text { Monel, } \\
\text { not split }\end{array}$} & \multirow{3}{*}{$\begin{array}{c}\text { room temperature } 80^{\circ} \mathrm{F}(300 \mathrm{~K}) \\
\text { pressure on the concave surface } \\
\text { up to } 30 \text { psi }(207 \mathrm{kPa})\end{array}$} \\
\hline $\begin{array}{l}\text { every } 1 / 4 "(6.35 \mathrm{~mm}) \text { tab, } \\
\text { edges sealed with Scilastic }\end{array}$ & & & \\
\hline $\begin{array}{l}\text { every other } 1 / 4 "(6.35 \mathrm{~mm}) \text { tab } \\
\text { edges sealed with Scilastic }\end{array}$ & & & \\
\hline
\end{tabular}

Table 7.2. Experimental conditions in temperature tests

\begin{tabular}{|c|c|c|c|}
\hline Edge attachment & $\begin{array}{c}\text { End } \\
\text { attachment }\end{array}$ & Base & Load \\
\hline & & Invar, split & \\
every $1 / 4^{\prime \prime}(6.35 \mathrm{~mm})$ tab & free & $\begin{array}{c}\text { temperature increase from } 80^{\circ} \mathrm{F} \\
(300 \mathrm{~K}) \text { to } 400^{\circ} \mathrm{F}(477 \mathrm{~K})\end{array}$ \\
& & Invar, not split & \\
\hline
\end{tabular}

Table 7.3. Experimental conditions in pressure and temperature tests

\begin{tabular}{|c|c|c|c|}
\hline Edge attachment & $\begin{array}{c}\text { End } \\
\text { attachment }\end{array}$ & Base & Load \\
\hline $\begin{array}{c}\text { every } 1 / 4 "(6.35 \mathrm{~mm}) \text { tab, bars } \\
\text { tight against plate }\end{array}$ & \multirow{2}{*}{ fixed } & \multirow{2}{*}{$\begin{array}{l}\text { Monel, } \\
\text { not split }\end{array}$} & $\begin{array}{l}\text { temperature increase from } 80^{\circ} \mathrm{F} \\
(300 \mathrm{~K}) \text { to } 400{ }^{\circ} \mathrm{F}(477 \mathrm{~K}) \text {; the } \\
\text { concave surface is pressurized in } \\
\text { increments to } 30 \text { psi }(206.8 \mathrm{kPa})\end{array}$ \\
\hline $\begin{array}{l}\text { every } 1 / 4 "(6.35 \mathrm{~mm}) \text { tab, bars } \\
\text { tight against plate and cemented, } \\
\text { edges sealed with Scilastic }\end{array}$ & & & $\begin{array}{l}\text { temperature increase from } 80^{\circ} \mathrm{F} \\
(300 \mathrm{~K}) \text { to } 400^{\circ} \mathrm{F}(477 \mathrm{~K}) \text {; the } \\
\text { concave surface is pressurized in } \\
\text { increments to } 30 \mathrm{psi}(207 \mathrm{kPa})\end{array}$ \\
\hline
\end{tabular}




\subsection{Pressure Tests. Model of a Plate with Varying Edge Constraints}

In this section, the computational results obtained for plates under pressure load with various types of constraints are discussed.

\subsubsection{Every 1/4-inch-wide Tab Clamped, with Clamp Bars Tight Against the Plate and Cemented}

The restraint used in the experiment and described as: "every 1/4-inch-wide tab is clamped, with clamp bars tight against the plate and cemented" was modeled by constraining the displacements of the tabs and groove-wide strips along the sides of the plate model. The short edges of the plate have fixed boundary displacements. The geometry and boundary conditions used in this test are presented in Figure 6.5(a).

Contour plots of the magnitude of displacement normal to the convex surface, obtained with the linear elastic material model, were combined for three values of pressure load in Figure 7.1. In the middle part of the plate, the deflection changes sign across the involute arch. It is negative in the part of the involute with the smallest radius of curvature and positive otherwise. The change in sign occurs in about one third of the arc length, measured from the generating circle. The deflection curves of the midspan are showed in Figure 7.2.

The maximum elastic displacement increases linearly due to the increase in the load and changes from $0.03 \mathrm{~mm}$ at $69 \mathrm{kPa}$, to $0.092 \mathrm{~mm}$ at $207 \mathrm{kPa}$. For the highest tested pressure differential, the deflection is $7.3 \%$ of the coolant channel thickness. Results obtained with the elastoplastic material model do not differ significantly: the maximum deflection at $207 \mathrm{kPa}$ is $0.095 \mathrm{~mm}$. A comparison with the experimental measurements for the location of sensors \#2 and \#5 (see Figure 5.12 for reference) was presented in Figure 7.3. The computationally obtained normal displacements of those locations compare very well with the experimental results. The trend of the experimental measurements vs. load is very close to linear, which may suggest that the deformations are elastic. The computations give the same trend. The biggest recorded difference between the computational and experimental results is $0.007 \mathrm{~mm}$.

The von Mises stress field was plotted in Figure 7.4. Maximum value changes from $37.1 \mathrm{MPa}$ for a 69 $\mathrm{kPa}$ load, $45.5 \mathrm{MPa}$ for a $138 \mathrm{kPa}$, to $65.8 \mathrm{MPa}$ for a $207 \mathrm{kPa}$ load. The highest value of the von Mises stress may be close to the yield strength for aluminum 6061-T0 used in the experiments. As it was mentioned before, the material properties of the specimens used in the experiments were not reported by Cheverton and Kelley in their report. An additional literature review allowed to estimate the values of the yield stress. According to [19] the $0.2 \%$ offset strength is equal max $82.7 \mathrm{MPa}$, and according to [20] $0.1 \%$ offset yield strength is equal $57.8 \mathrm{MPa}$. The elastoplastic material model used in the simulations is based on a strain-stress relationship, presented in Figure C.8, and gives the most detailed material behavior representation. More detailed information on material properties of aluminum was provided in Section 6.2 and Appendix C - Material Properties. 
(a)

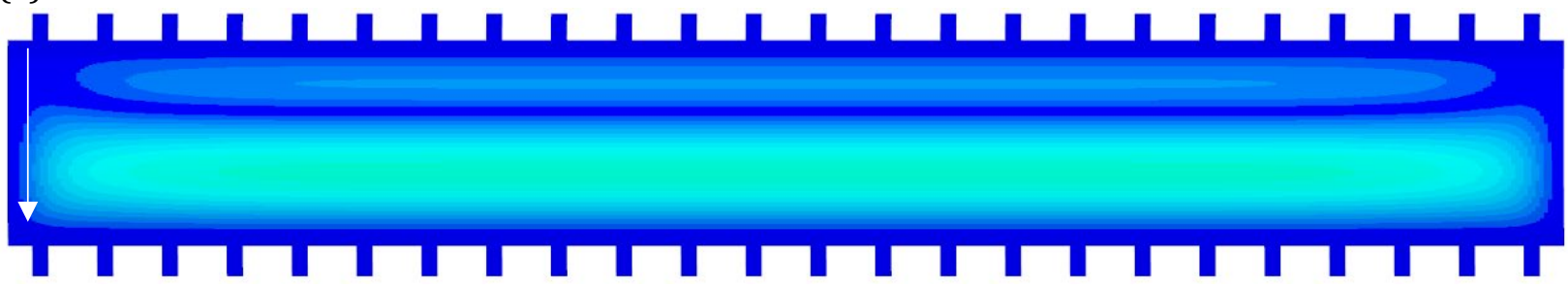

(b)

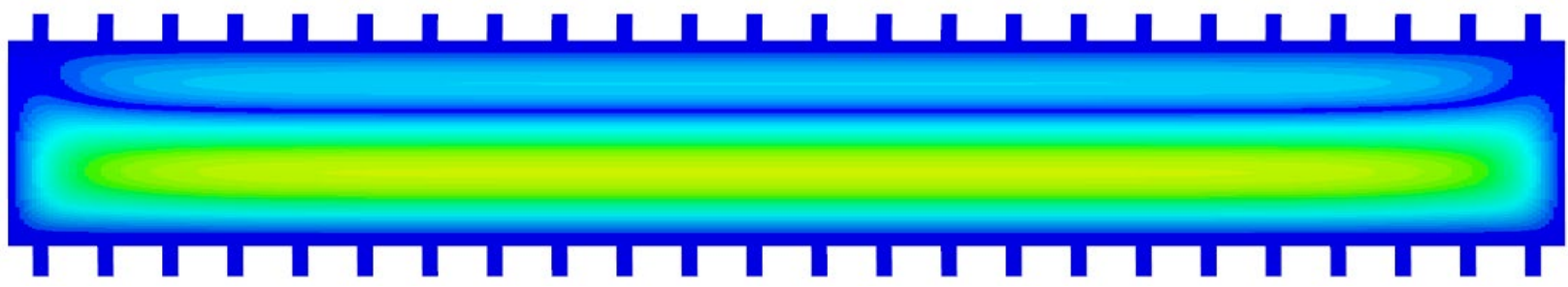

(c)

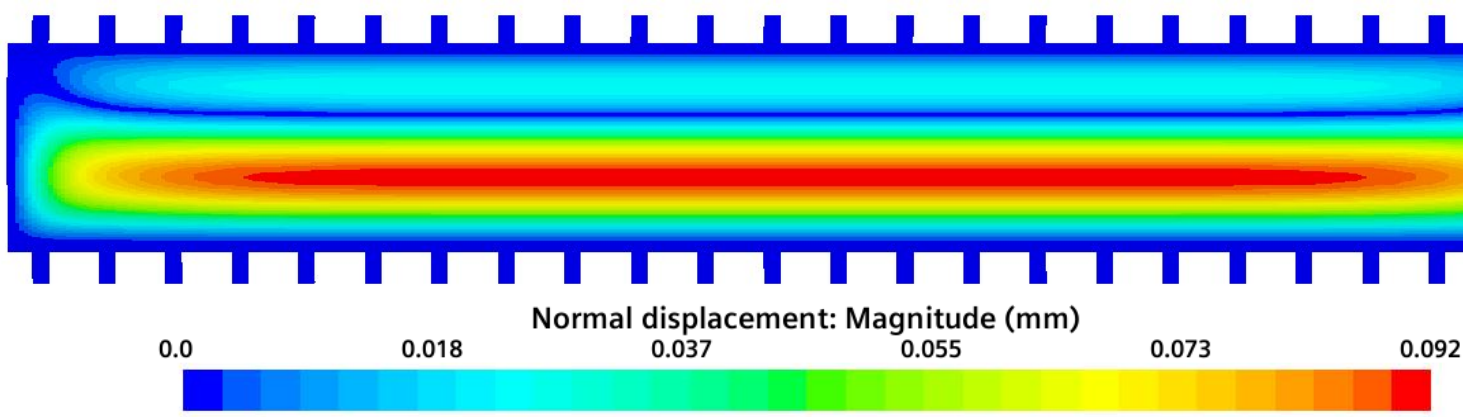

Figure 7.1. Displacement contour plots for a plate with every tab (1/4 in) clamped, clamp bars tightly against the plate, edges sealed, and pressure on the concave surface: (a) $69 \mathrm{kPa}$, (b) $138 \mathrm{kPa}$, (c) $207 \mathrm{kPa}$. The white arrow in figure (a) indicates the outward radial direction. 


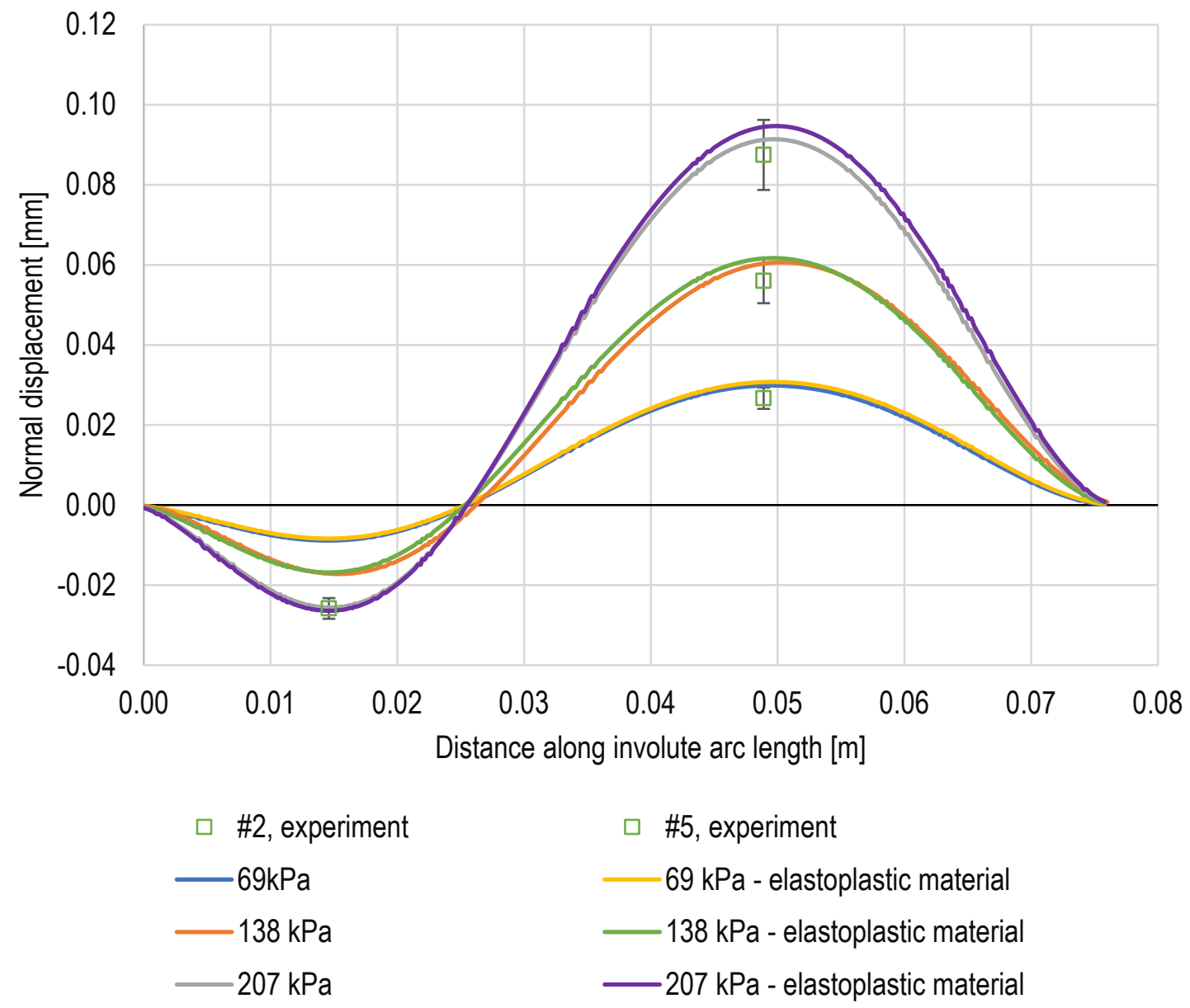

Figure 7.2. Midspan deflection of a plate with every $1 / 4$ " $(6.35 \mathrm{~mm})$ tab and bars clamped under various pressure loads applied to the concave surface of the involute. Error bars were estimated by the authors of this technical report. 


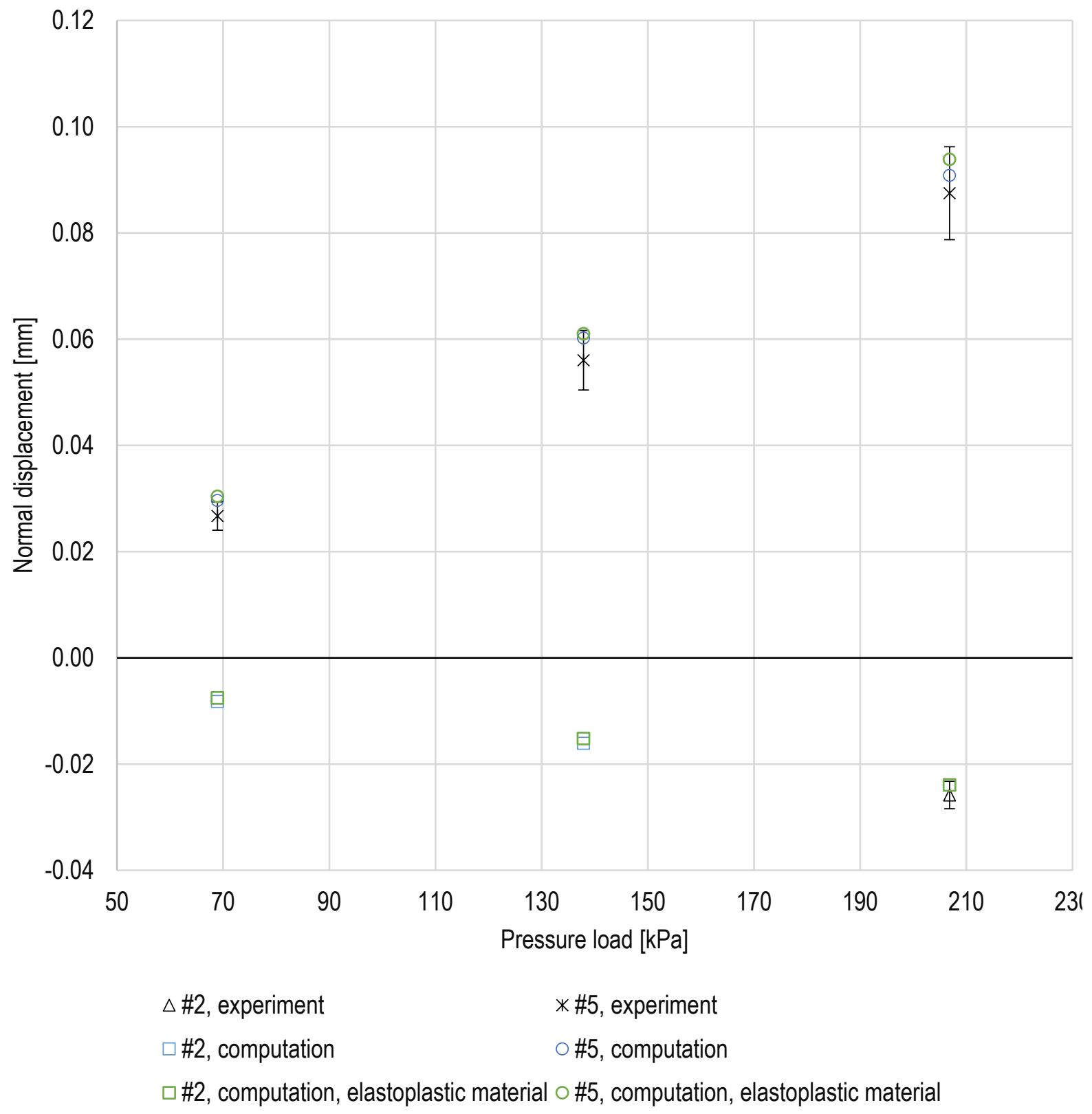

Figure 7.3. Experimental and computational normal displacements at sensor locations \#2 and \#5 for a plate with every 1/4-inch $(6.35 \mathrm{~mm})$ tab and bars clamped under various pressure loads. Error bars were estimated by the authors of this technical report. 
(a)

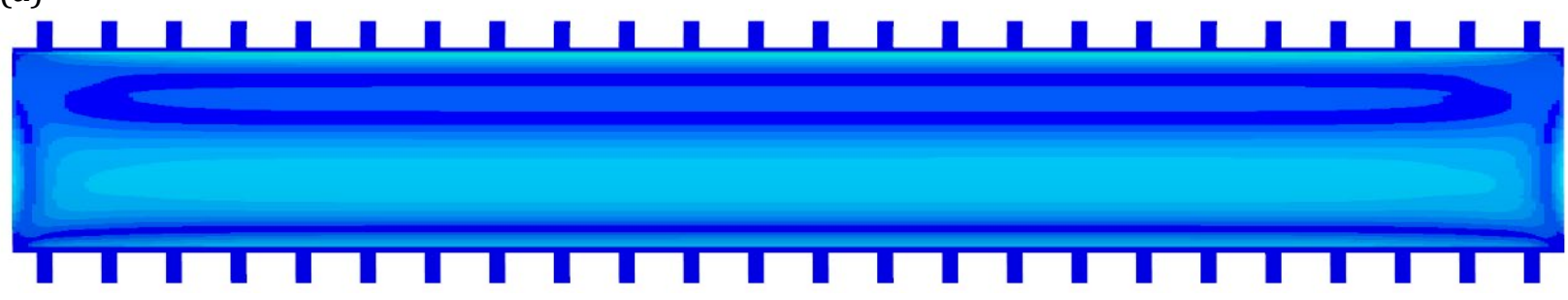

(b)

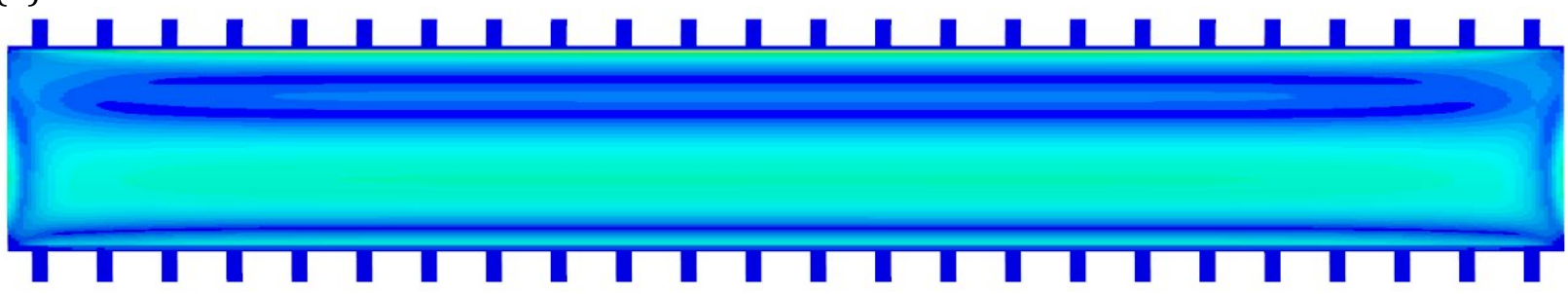

(c)

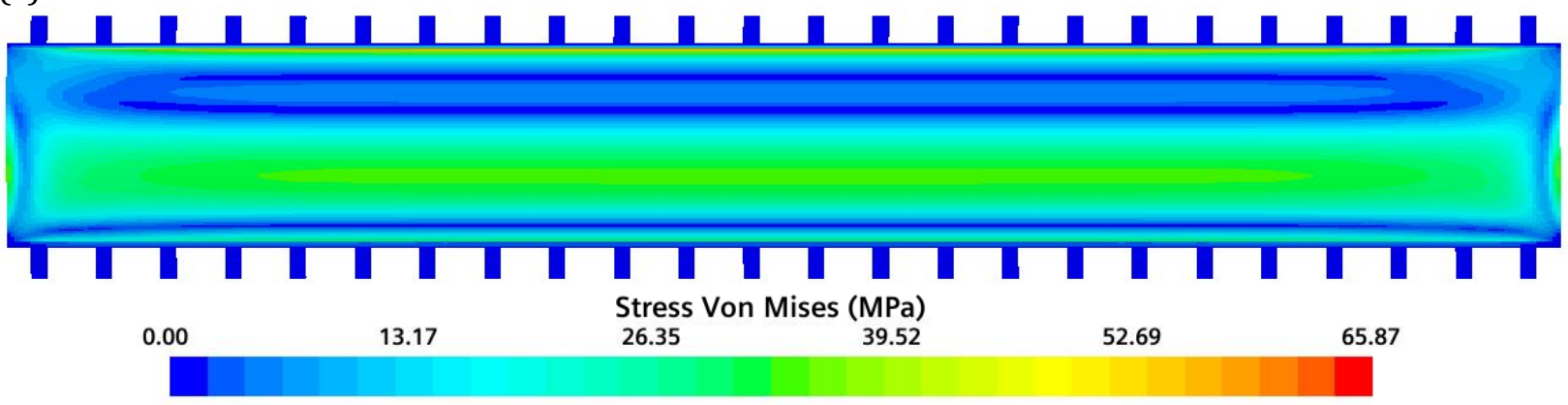

Figure 7.4. Von Mises stress contour plots for a plate with every $1 / 4$-inch $(6.35 \mathrm{~mm})$ tab clamped, clamp bars tightly against the plate, edges sealed, and pressure on the concave surface: (a) $69 \mathrm{kPa}$, (b) $138 \mathrm{kPa}$, (c) $207 \mathrm{kPa}$

\subsubsection{Every 1/4-inch-wide Tab Clamped}

In the experiment, every 1/4" (6.35 mm) tab was clamped, and the edges were sealed. Compared to the constraints described in Section 7.1.1, the level of restraint has decreased. The side bars do not hold tightly the long edges of the plate, only the tabs are clamped in the base. As mentioned in Section 6.4, models with varying boundary conditions were used to represent this level of constraint in the study. The geometry and boundary conditions used in this test are presented in Figure 6.5 (b), (c), and $(\mathrm{d})$.

Figure 7.5 to Figure 7.7 show a comparison of deflections normal to the convex surface of the plate on a cross-section going through the middle of the span for a plate with all 1/4-inch-wide tabs and edges clamped under different pressure load: $69 \mathrm{kPa}, 138 \mathrm{kPa}, 207 \mathrm{kPa}$, applied to the concave surface of the plate. Similarly to the case presented in Section 7.1.1, the deflection is negative in the part of the involute with the smallest radius of curvature, and positive otherwise. The change in sign occurs at about 0.37 arc length for the case in which only the tabs are constrained, and at about one third of the arc length for the cases with additional limit of edge displacements. Due to the decreased side constraints, the magnitude of deflections is greater than previously. 
Cheverton and Kelley [5] reported plate deflections for sensors \#2 and \#5, which results in two experimental data points for load $69 \mathrm{kPa}$ and $138 \mathrm{kPa}$, and only one data point for load $207 \mathrm{kPa}$. The computational deflection curves envelope the experimental results for all tested load values, as shown in figures from Figure 7.5 to Figure 7.7. For the tested load range, the model of a plate with fixed displacements of the tabs gives the greatest deflections, and the model of a plate with fixed displacements of the tabs and zero normal displacements on concave side of the thin strips gives the lowest magnitudes of deflections. The deflection curves obtained by these two models encompass the experimental measurements for the tested load values. The model of the plate in contact with a rigid plane on each side, gives deflection curves that fall in between the previously mentioned and compare very well with the experimental measurements. In this case, the difference between the elastic and elastoplastic material models is almost negligible for the lowest pressure load but becomes significant for the highest load value: at $207 \mathrm{kPa}$, the difference increases up to $25 \%$ in the maximum deflection, but the value does not exceed the result from the model with only tabs clamped.

According to the discussion in Section 6.4, the models presented in this part of the study are a simplification of the actual conditions that were present in the experiments. The tabs of the plate were tightly clamped, and the plate was supported along the long edges on the base. The two types of constraints in the model represent conditions that are underestimating and overestimating the level of constraint. The model with a plate in contact with a rigid base shows the best agreement with the measurements.

In the plots obtained with the model with only tabs constrained, the displacements normal to the convex surface are nonzero on the edges of the plate. This is a result of the lack of constraints on the edges of the plate. In the model with the long edges constrained, the displacements are zero.

The largest deflection of the plate is reported for $207 \mathrm{kPa}$. The maximum deflection predicted by the computational models varies from $0.15 \mathrm{~mm}$ to $0.205 \mathrm{~mm}$, depending on the long edge constraint. Assuming the most conservative prediction of the deflection into the coolant channel, equal 0.205 $\mathrm{mm}$, the value makes up for $16 \%$ of the gap between two neighboring fuel plates. Displacement contour plots obtained with model of a plate with fixed displacements of the tabs and zero normal displacements on concave side of the thin strips are presented in Figure 7.8.

The computational and experimental displacements at locations \#2 and \#5 were plotted against the pressure load in Figure 7.9. The dependency of the experimental deflections on the pressure load is not linear, which suggests that plastic deformations occurred in the experiments. The computational predictions of the von Mises stresses, presented in Figure 7.10, compared with the aluminum yield strength, confirm this observation. The stresses are close to, or exceed, the yield stress and stress concentrations are visible in the corners where tabs meet the plate. At pressure load $69 \mathrm{kPa}$, the maximum von Mises stress is equal $68.0 \mathrm{MPa}$, at the load of $138 \mathrm{kPa}$ it is equal $97.3 \mathrm{MPa}$, and at 207 $\mathrm{kPa}$ it is equal $142.6 \mathrm{MPa}$. 


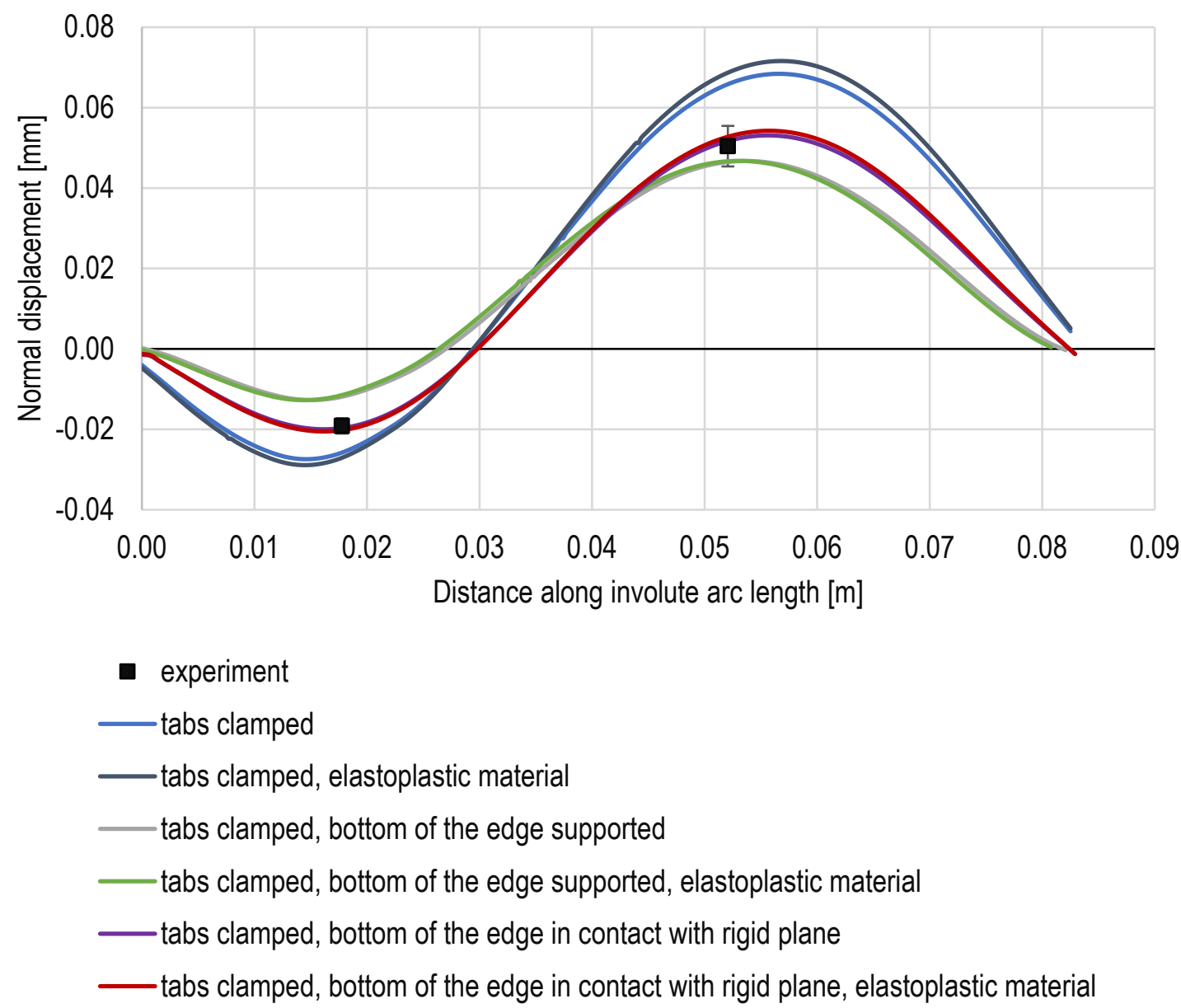

Figure 7.5. Midspan deflection of a plate with every $1 / 4$-inch $(6.35 \mathrm{~mm})$ tab clamped under pressure load $69 \mathrm{kPa}$. Error bars were estimated by the authors of this technical report. 


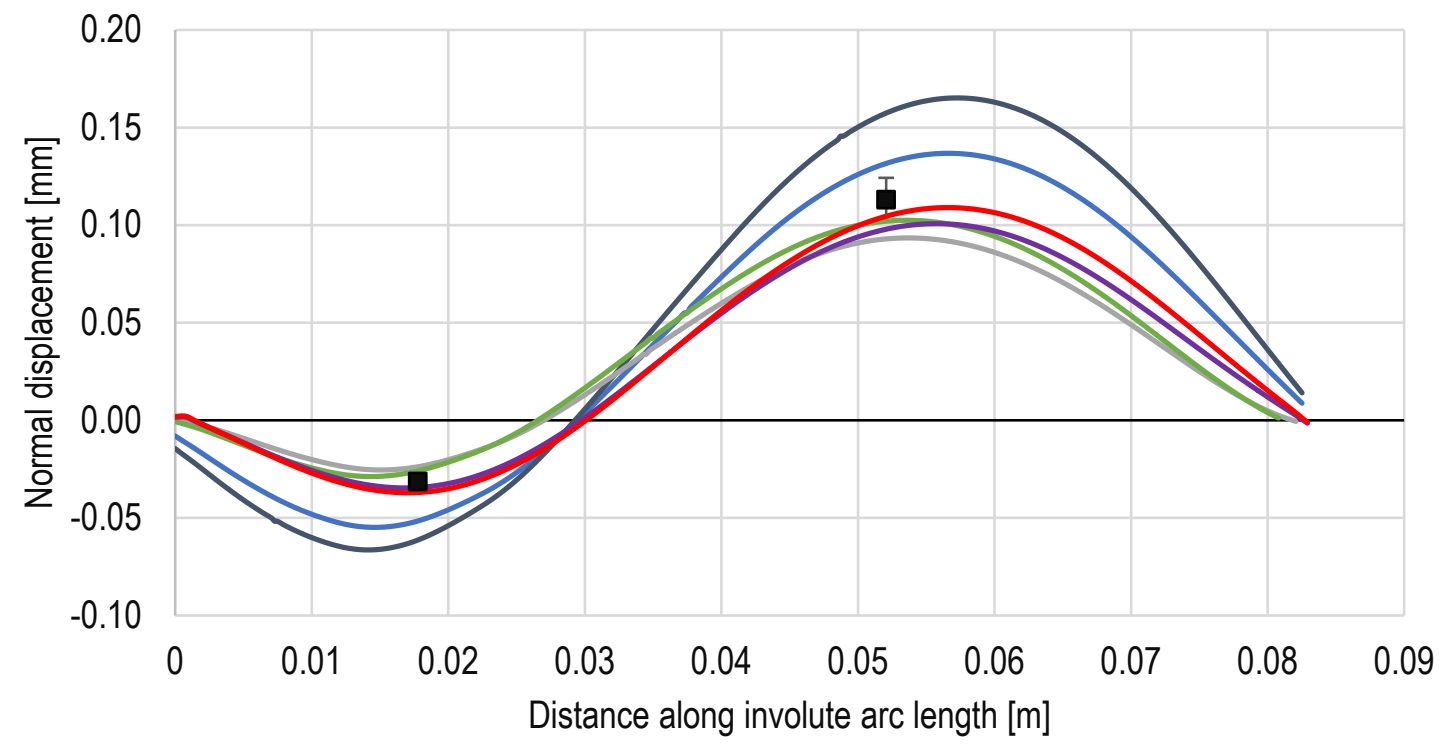

- experiment

- tabs clamped

— tabs clamped, elastoplastic material

_tabs clamped, bottom of the edge supported

_ tabs clamped, bottom of the edge supported, elastoplastic material

— tabs clamped, bottom of the edge in contact with rigid plane

— tabs clamped, bottom of the edge in contact with rigid plane, elastoplastic material

Figure 7.6. Midspan deflection of a plate with every 1/4-inch $(6.35 \mathrm{~mm})$ tab clamped under pressure load $138 \mathrm{kPa}$. Error bars were estimated by the authors of this technical report. 


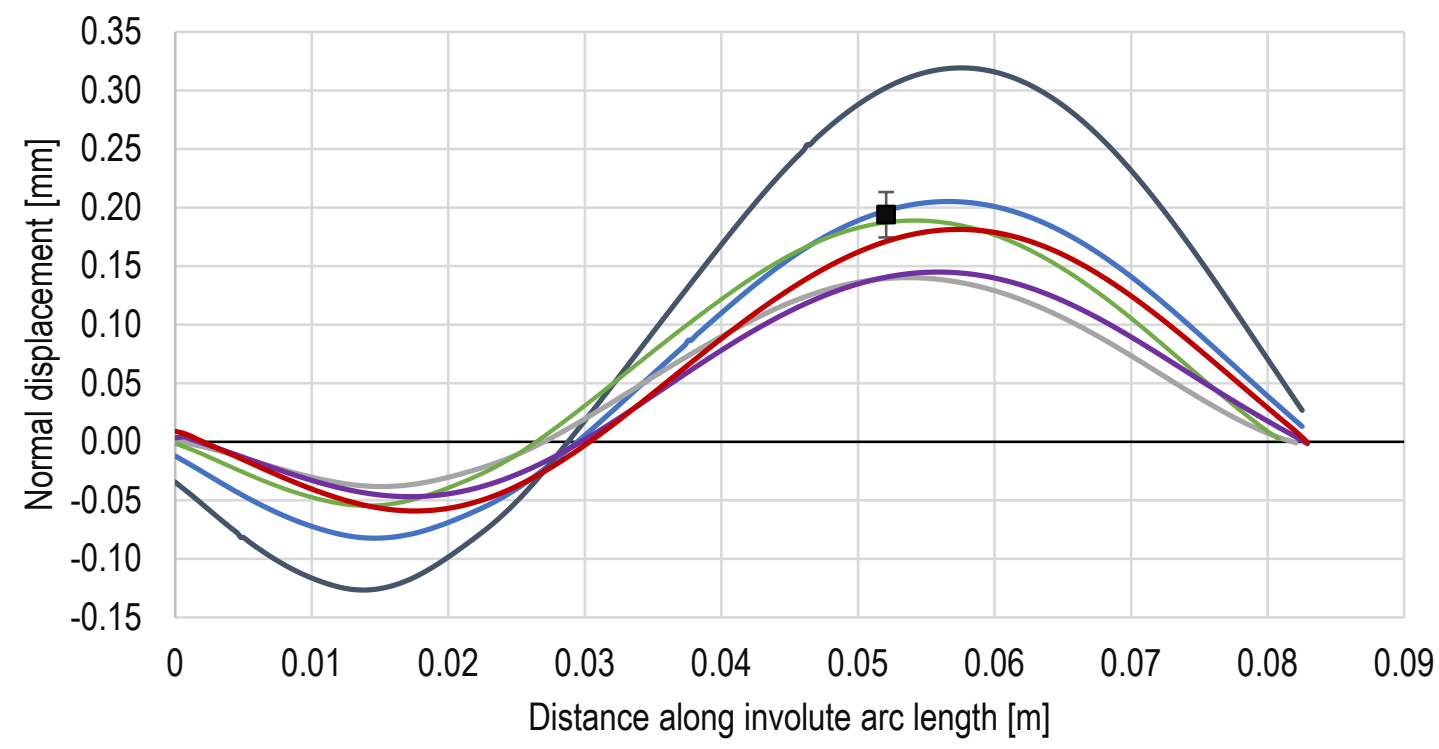

- experiment

- tabs clamped

_tabs clamped, elastoplastic material

_tabs clamped, bottom of the edge supported

_ tabs clamped, bottom of the edge supported, elastoplastic material

— tabs clamped, bottom of the edge in contact with rigid plane

— tabs clamped, bottom of the edge in contact with rigid plane, elastoplastic material

Figure 7.7. Midspan deflection of a plate with every 1/4-inch $(6.35 \mathrm{~mm})$ tab clamped under pressure load $207 \mathrm{kPa}$. Error bars were estimated by the authors of this technical report. 
(a)

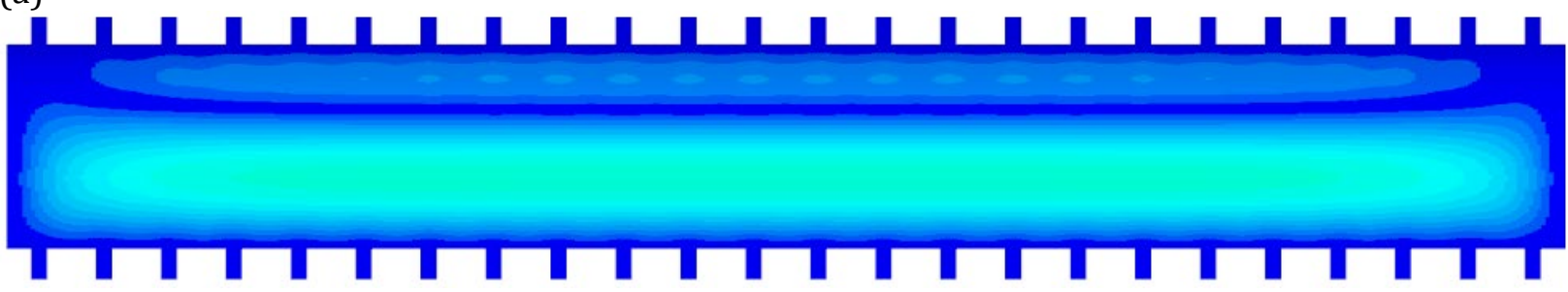

(b)

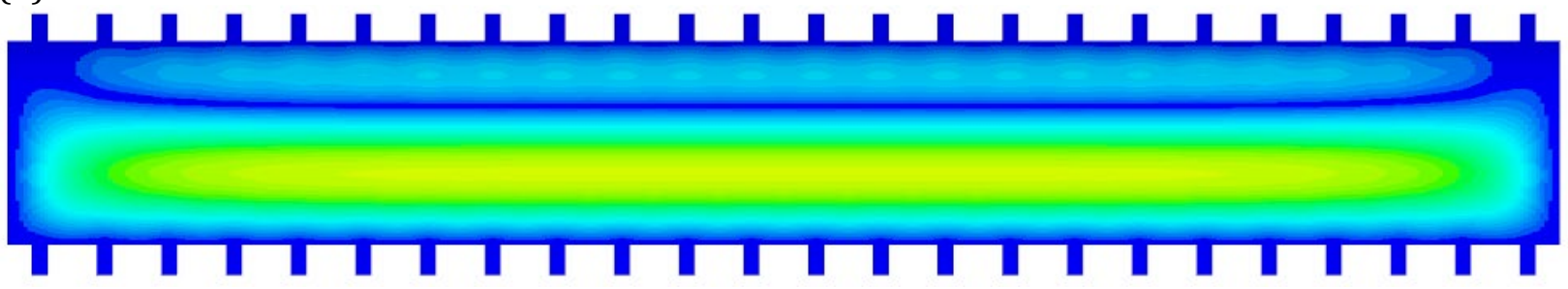

(c)

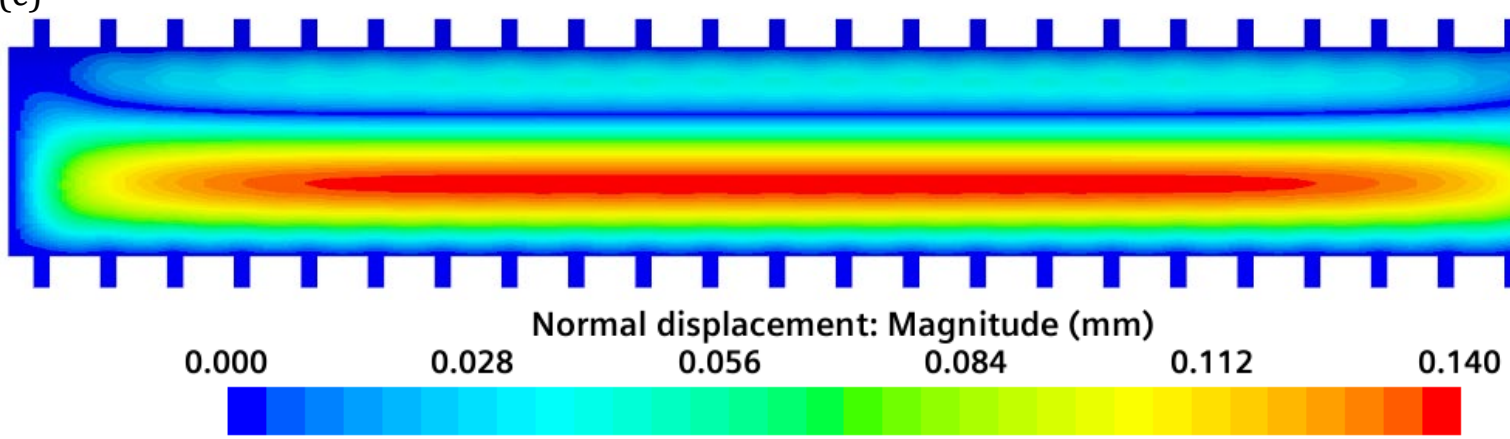

Figure 7.8. Displacement contour plots for a plate with every $1 / 4$-inch $(6.35 \mathrm{~mm})$ tab clamped, edges sealed, and pressure on the concave surface: (a) $69 \mathrm{kPa}$, (b) $138 \mathrm{kPa}$, (c) 207 $\mathrm{kPa}$. Model with zero displacements of the tabs and zero displacement component normal to the surface of the thin strips on concave side. 


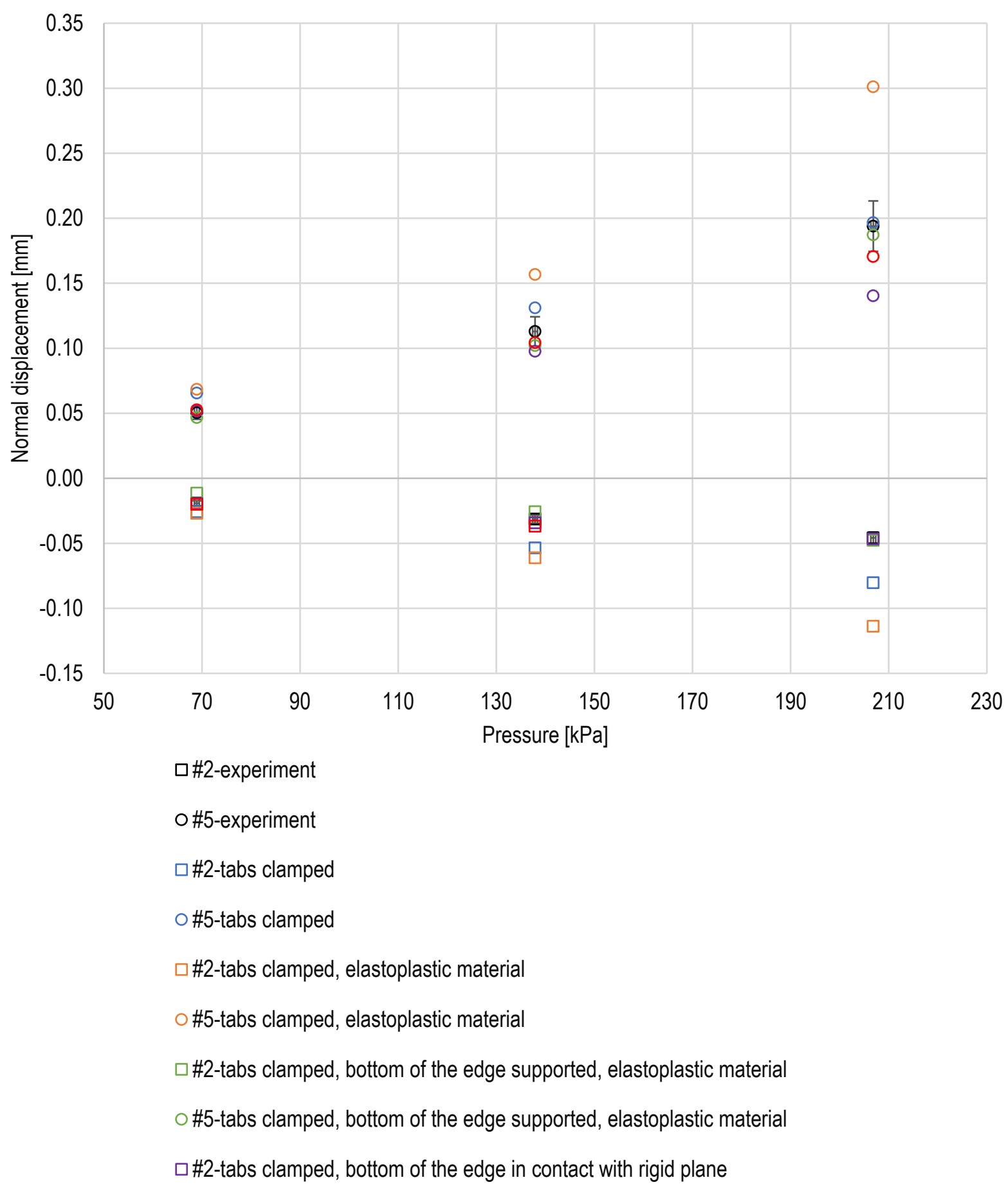

Figure 7.9. Experimental and computational normal displacements at sensor locations \#2 and \# 5 for a plate with every $1 / 4$-inch $(6.35 \mathrm{~mm})$ tab clamped. Error bars were estimated by the authors of this technical report. 
(a)

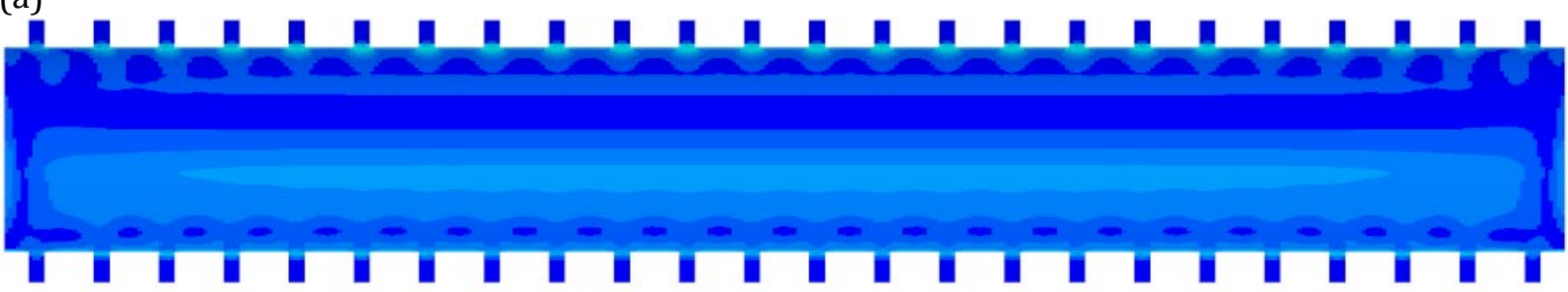

(b)

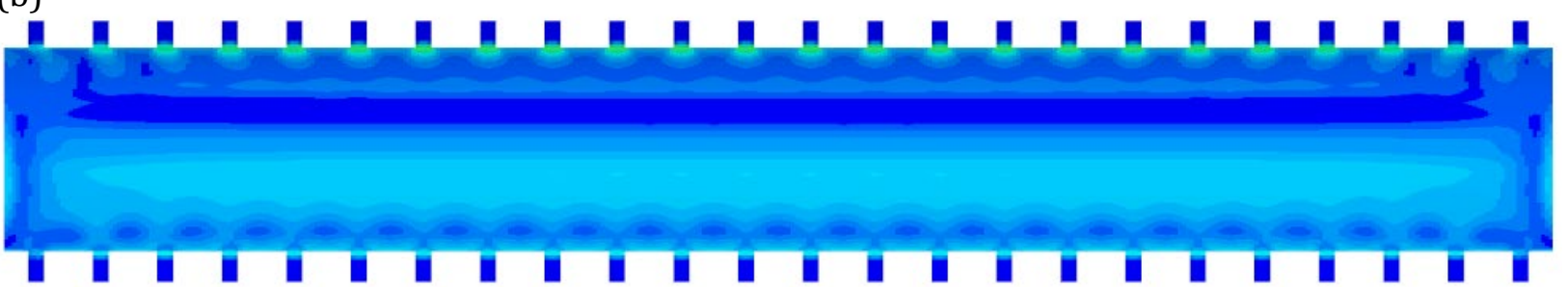

(c)

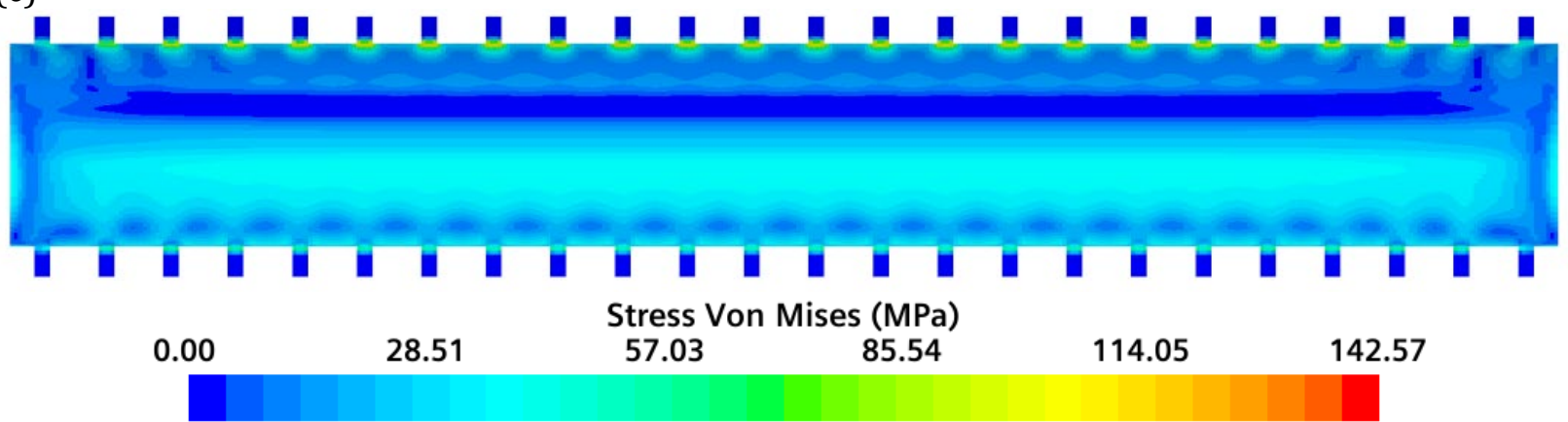

Figure 7.10. Von Mises stress contour plots for a plate with every $1 / 4$-inch $(6.35 \mathrm{~mm})$ tab clamped, edges sealed, and pressure on the concave surface: (a) $69 \mathrm{kPa}$, (b) $138 \mathrm{kPa}$, (c) 207 $\mathrm{kPa}$. Model with zero displacements of the tabs and zero displacement component normal to the surface of the thin strips on concave side.

\subsubsection{Every 1/8-inch-wide Tab Clamped}

One of the experiments was performed with narrower, 1/8" (3.18 $\mathrm{mm}$ ) wide tabs. The views of the geometry of the plate with $1 / 8$ " $(3.18 \mathrm{~mm})$ wide tabs used in this set of tests is presented in Figure 6.2. The type of the constraint along the long sides was the same as presented in Section 7.1.2 and therefore, the same types of computational models with varying displacement boundary conditions were developed. The short edge was fully constrained, as previously.

The boundary conditions were varied according to Figure 6.5 (b), (c), and (d), resulting in a different level of side constraint. Figure 7.11 to Figure 7.13 show the midspan normal displacements of the involute plate for pressure loads: $69 \mathrm{kPa}, 138 \mathrm{kPa}$, and $207 \mathrm{kPa}$, respectively. The experimental data was only available for a pressure load equal to $138 \mathrm{kPa}$. A comparison of experimental and computational results show that the two models: plate with fixed displacements of the tabs, and plate with fixed displacements of the tabs and zero normal displacements on the concave side of the thin strips, envelope the experimental data points from the top and bottom, respectively, and the model with contact with a rigid base falls in between. The same conclusion was derived in Section 7.1.2. Also, the same as in the previous section, it can be noticed that the edges in the model with only tabs 
clamped have non-zero normal displacement, and the model with contact, may have only positive edge displacements i.e. to the convex side of the plate.

As the attachment width is smaller than in the model presented in Section 7.1.2, it is expected the deflection to be larger. For the highest load, the maximum deflection predicted by the computational models increased to $0.365 \mathrm{~mm}$ when elastic material model was used, and up to $0.57 \mathrm{~mm}$ for elastoplastic model. The model that gave the best representation of the measurements is the model of a plate with clamped tabs and in contact with a rigid plane. The maximum deflection equals 0.16 $\mathrm{mm}$ for elastic material model, and $0.22 \mathrm{~mm}$ for elastoplastic material model, which is about $13 \%$ and $17 \%$ of the coolant channel thickness, respectively. The contour plots of displacement for different pressure loads can be seen in Figure 7.14.

Figure 7.15 presents the experimental and computational normal displacements at sensor locations \#2 and \#5. Only one experimental data point was provided for each location in the Cheverton and Kelley report, therefore it is not possible to conclude if plastic deformation occurred in the experiment. Nevertheless, the authors of the report [5] mentioned that such deformations took place. An analysis of the von Mises stress plots presented in Figure 7.16 shows, that they exceed the yield stress, and therefore permanent deformations are likely, especially at the tabs where stress concentrations occur. Stress concentrations can be seen at the feet of the tabs on the edge of the involute plate and that is where plastic flow most likely occurs. 


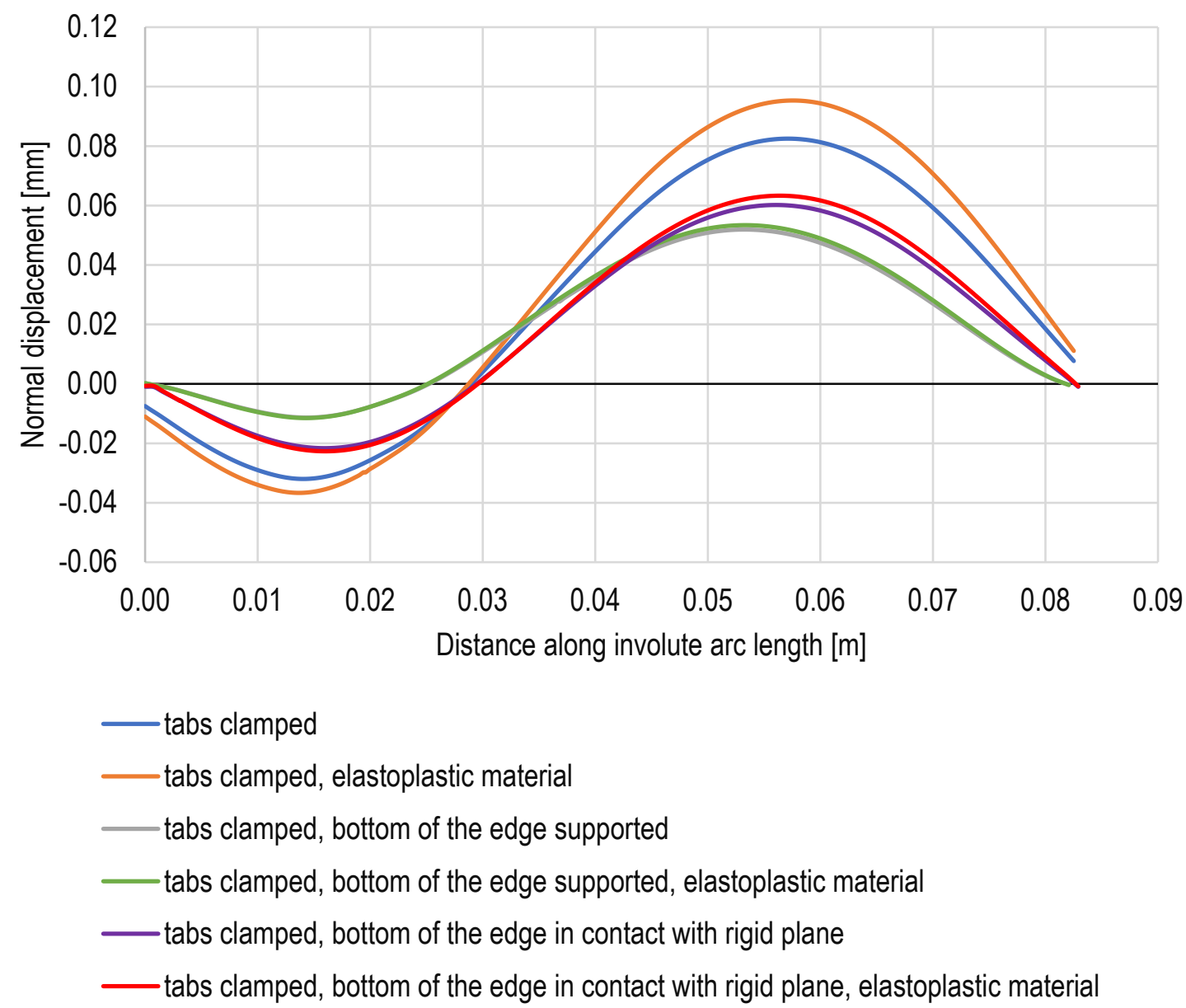

Figure 7.11. Midspan deflection of a plate with every $1 / 8$-inch $(3.18 \mathrm{~mm})$ tab clamped under pressure load $69 \mathrm{kPa}$ 


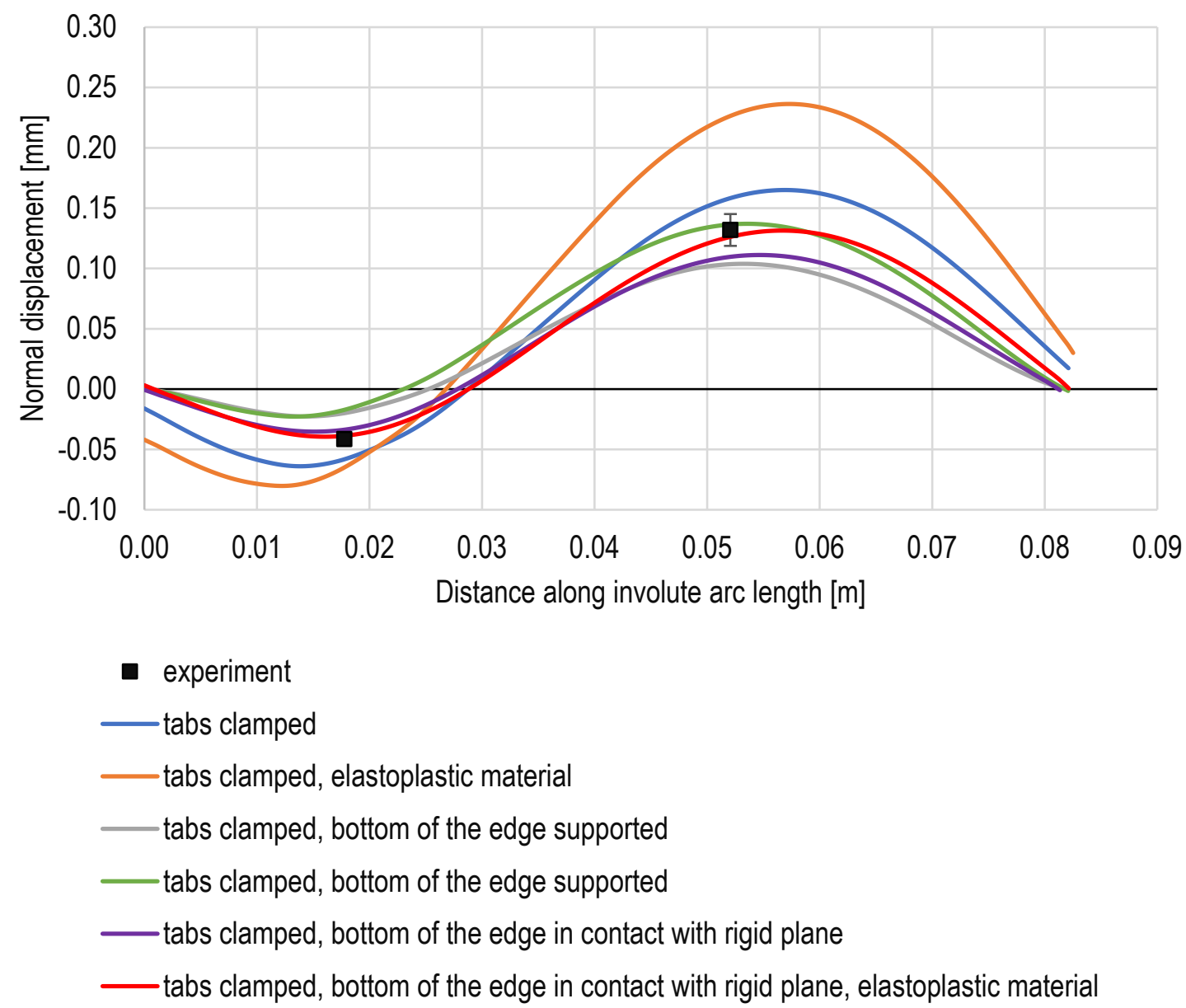

Figure 7.12. Midspan deflection of a plate with every $1 / 8$-inch $(3.18 \mathrm{~mm})$ tab clamped under pressure load $138 \mathrm{kPa}$. Error bars were estimated by the authors of this technical report. 


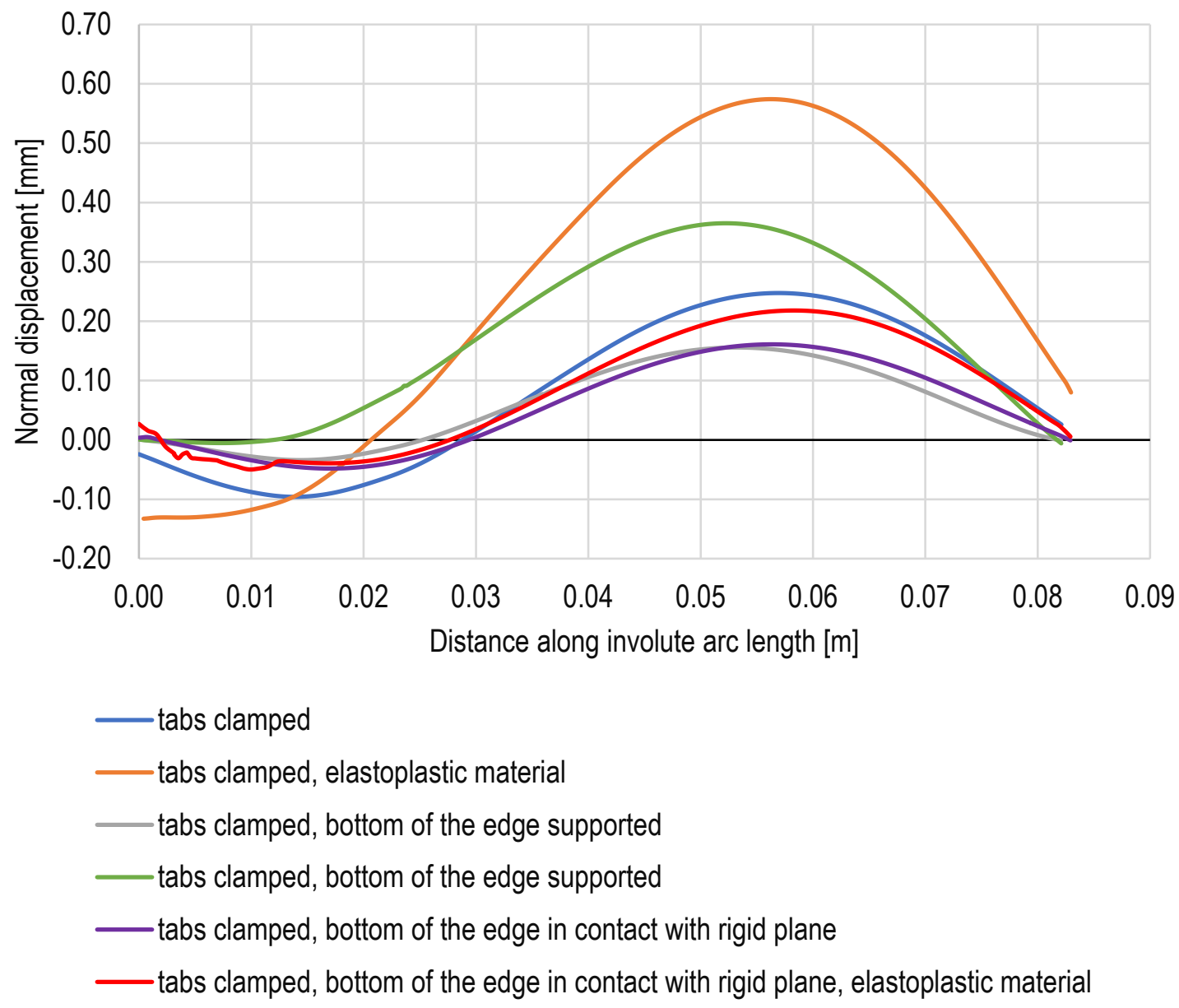

Figure 7.13. Midspan deflection of a plate with every $1 / 8$-inch $(3.18 \mathrm{~mm})$ tab clamped under pressure load $207 \mathrm{kPa}$ 
(a)

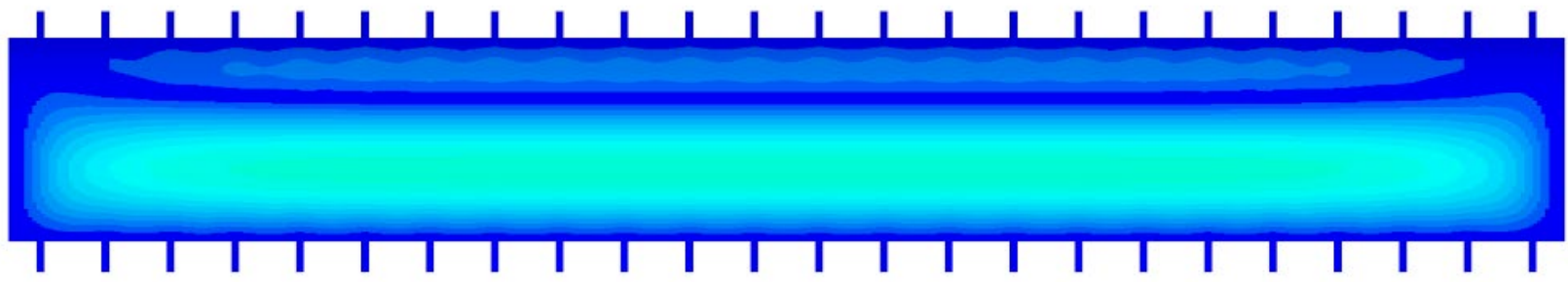

(b)

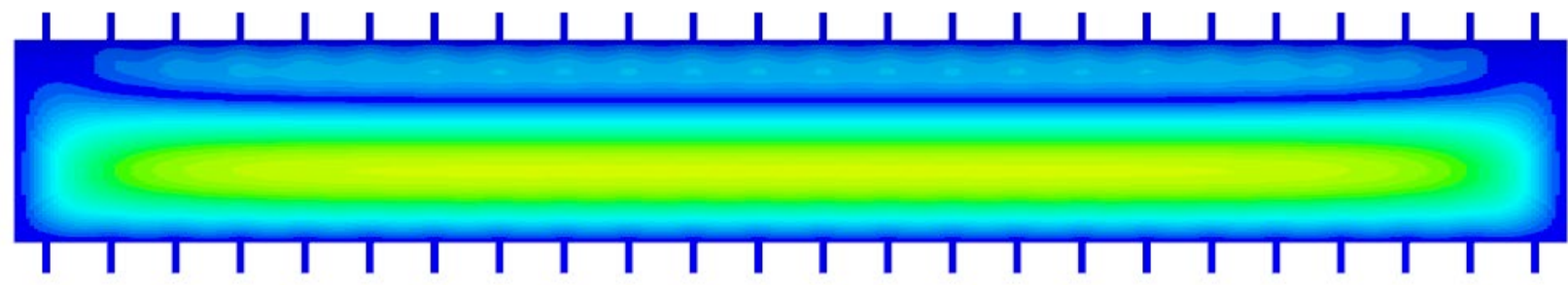

(c)

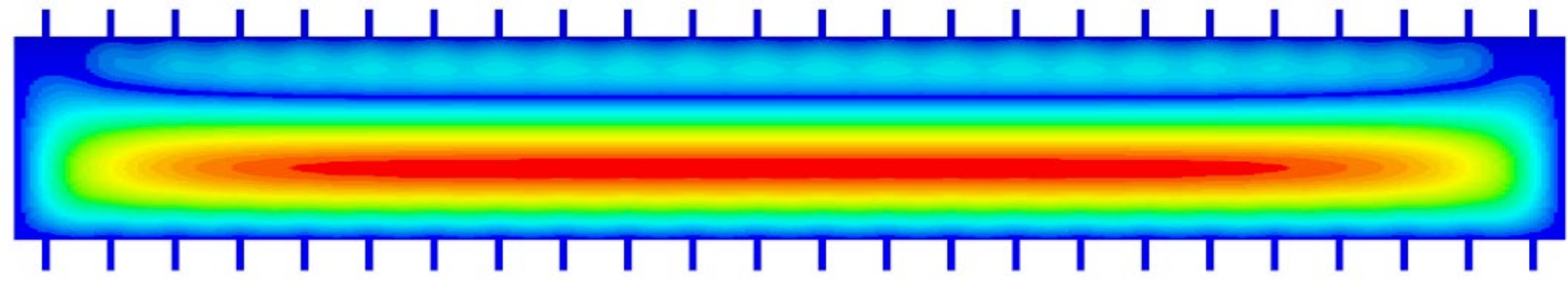

Normal displacement: Magnitude (mm)
0.000
0.031
0.062
0.094
0.125
0.156

Figure 7.14. Displacement contour plots for a plate with every 1/8-inch tab clamped, edges sealed, and pressure on the concave surface: (a) $69 \mathrm{kPa}$, (b) $138 \mathrm{kPa}$, (c) $207 \mathrm{kPa}$. Model with zero displacements of the tabs and zero displacement component normal to the surface of the thin strips on concave side. 


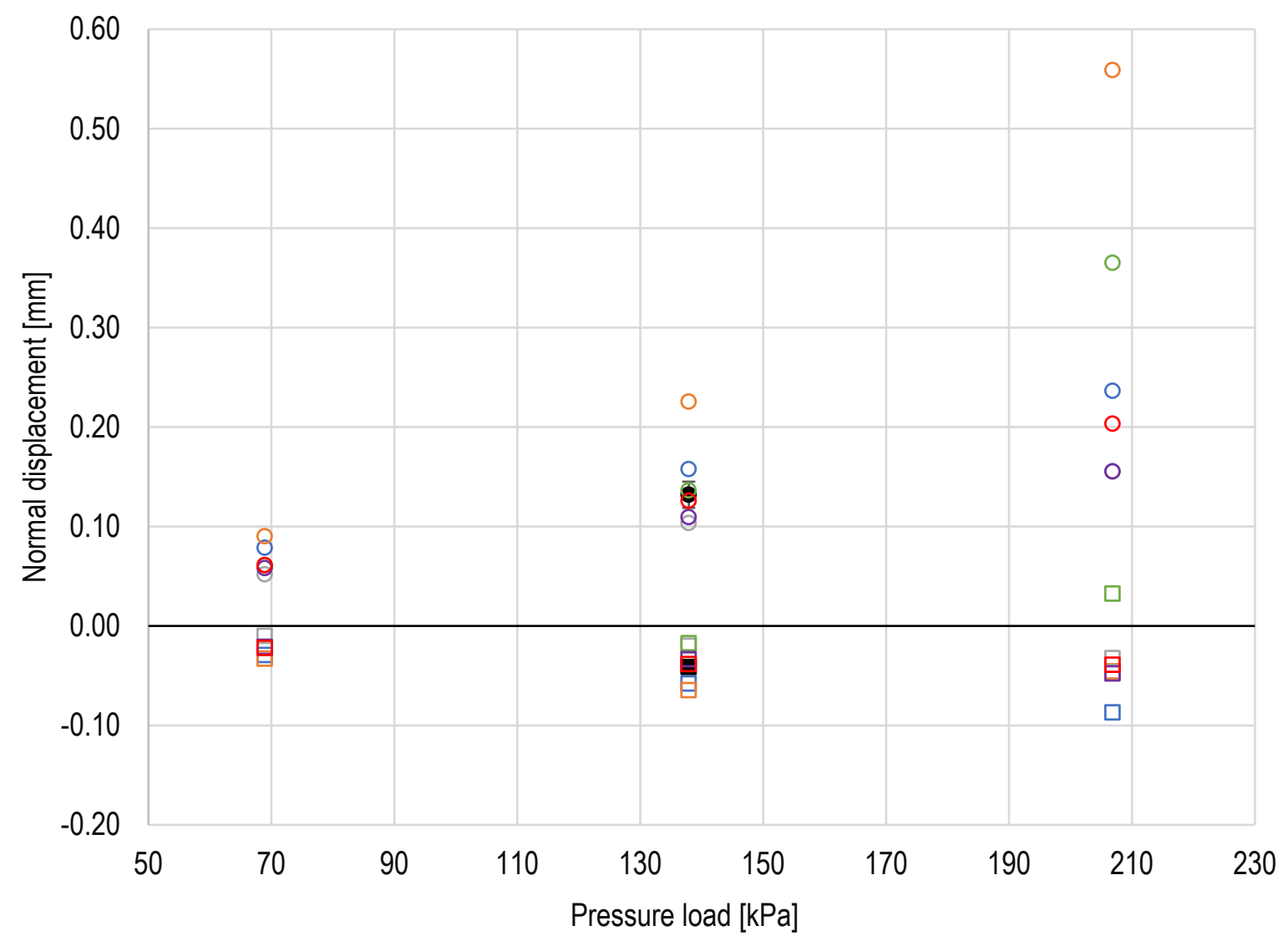

-\#2-experiment

-\#5-experiment

$\square$ \#2-tabs clamped

○\#5-tabs clamped

$\square$ \#2-tabs clamped, elastoplastic material

○ \#5-tabs clamped, elastoplastic material

$\square$ \#2-tabs clamped, bottom of the edge supported

$\circ$ \#5-tabs clamped, bottom of the edge supported

$\square$ \#2-tabs clamped, bottom of the edge supported, elastoplastic material

○ \#5-tabs clamped, bottom of the edge supported, elastoplastic material

$\square$ \#2-tabs clamped, bottom of the edge in contact with rigid plane

○ \#5-tabs clamped, bottom of the edge in contact with rigid plane

$\square \# 2$-tabs clamped, bottom of the edge in contact with rigid plane, elastoplastic material

○ \#5-tabs clamped, bottom of the edge in contact with rigid plane, elastoplastic material

Figure 7.15. Experimental and computational normal displacements at sensor locations \#2 and \#5 for a plate with every $1 / 8$-inch-tab clamped 
(a)

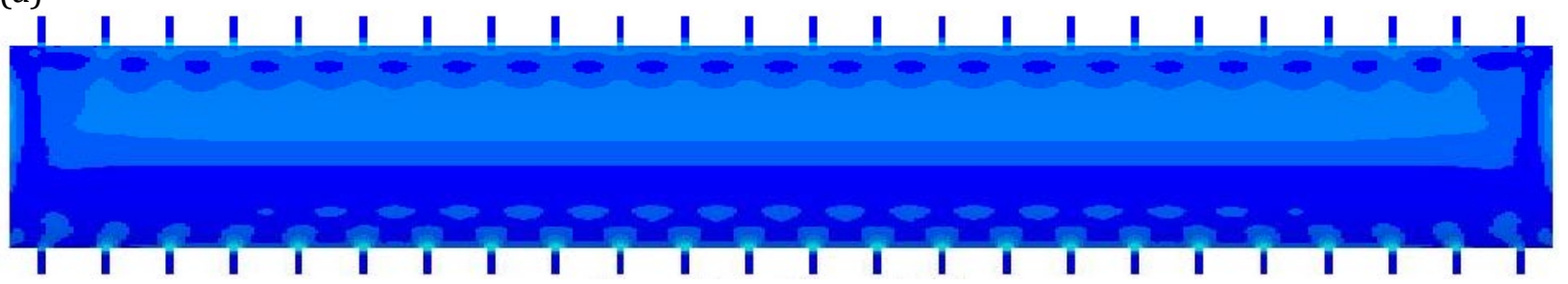

(b)

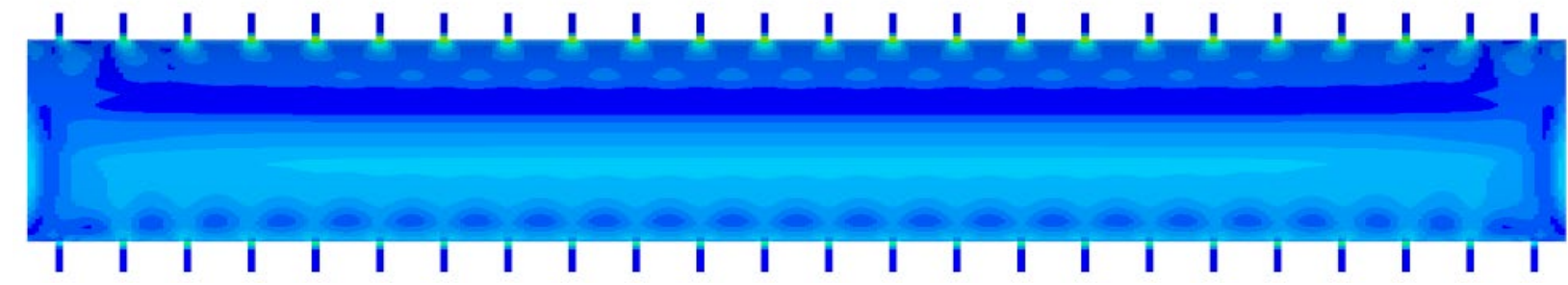

(c)

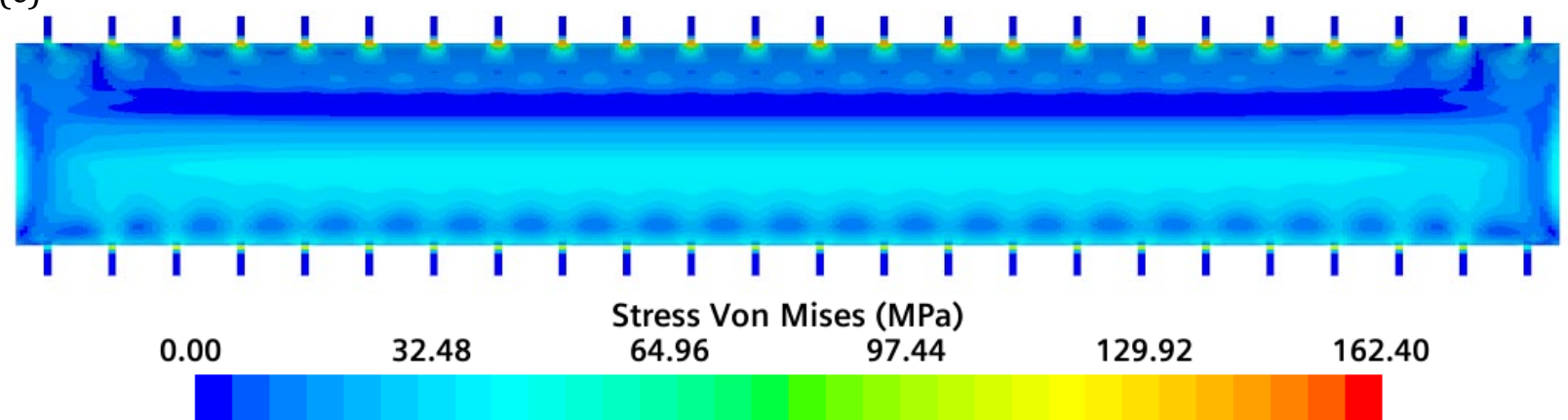

Figure 7.16. Von Mises stress contour plots for a plate with every $1 / 8$-inch tab clamped, edges sealed, and pressure on the concave surface: (a) $69 \mathrm{kPa}$, (b) $138 \mathrm{kPa}$, (c) $207 \mathrm{kPa}$. Model with zero displacements of the tabs and zero displacement component normal to the surface of the thin strips on concave side.

\subsubsection{Every Other 1/4-inch-wide Tab Clamped}

In the case in which a weld joining the involute plate to the side plates is missing or failed, the local constraint disappears, and the deflection of the plate will be larger under the same loads, which in turn may result in plate damage. In the experiment, every other tab was clamped, to simulate conditions in which every other weld is missing.

Figure 6.6 (b) highlights in orange the tabs with constrained displacements in the computational model. The remaining tabs are not constrained. Three models were compared: with only the tabs constrained, and with tabs and thin strips along the long edges of the plate are constrained, and the most complex model of a plate with every other tab fixed, the remaining tabs in contact with rigid planes on the convex and concave side and groove-wide strips on the concave side of the plate in contact with rigid planes tangent to the plate. The contact with a rigid plane is pressure based and frictionless.

The midspan deflections for varying pressure load are presented in Figure 7.17, Figure 7.18, and Figure 7.19. Two data points were obtained from the Cheverton and Kelley report: for $138 \mathrm{kPa}$ and $207 \mathrm{kPa}$ load at sensor location \#5. For the $138 \mathrm{kPa}$ load, the experimental data point falls in between 
the computational deflection curves and for the $207 \mathrm{kPa}$ load, the experimental measurement exceeds the computational predictions obtained with elastic model, but is lower than two results obtained with elastoplastic material model: every other tab is clamped and bottom of the plate long sides are supported, and the model with contact between the plate and rigid planes. This result indicates that plastic flow occurred in the experiment, which is in fact indicated by the nonlinearity of the experimental plot of load vs. deflection (see Figure 7.21). The computations confirm it: the contour plot of the von Mises stresses show that the yield strength for aluminum is exceeded for the tested range of loads (see Figure 7.22). Stress concentrations with the highest values are located at the feet of the tabs on the edge of the involute plate and the plastic flow will occur in those locations. These findings coincide with the experimental results reported by Cheverton and Kelley.

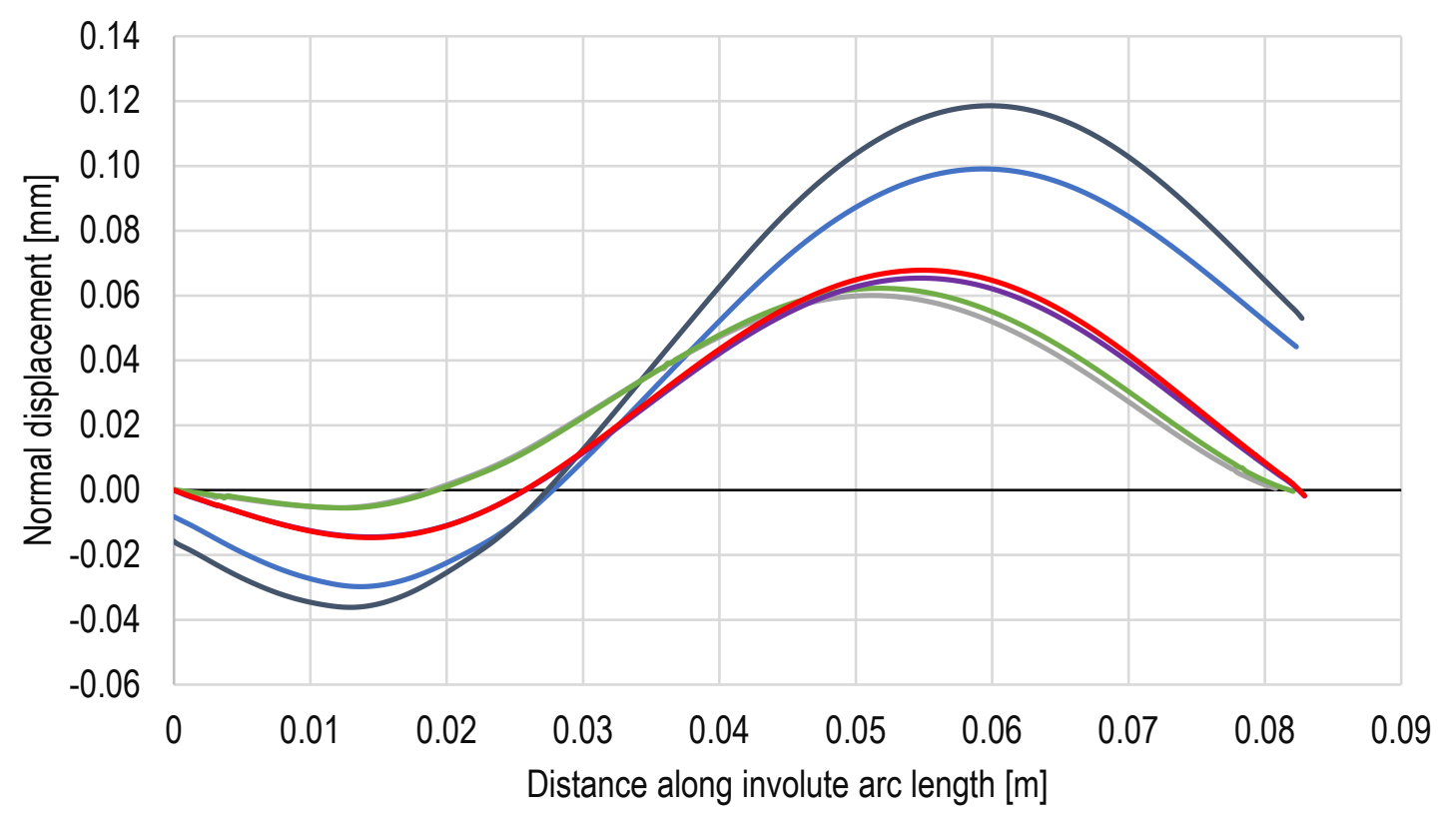

— tabs clamped

— tabs clamped, elastoplastic material

- tabs clamped, bottom of the edge supported

— tabs clamped, bottom of the edge supported, elastoplastic material

— tabs clamped, bottom of the edge in contact with rigid plane

— tabs clamped, bottom of the edge in contact with rigid plane, elastoplastic material

Figure 7.17. Midspan deflection of a plate with every other $1 / 4$-inch $(6.35 \mathrm{~mm})$ tab clamped under pressure load $69 \mathrm{kPa}$ 


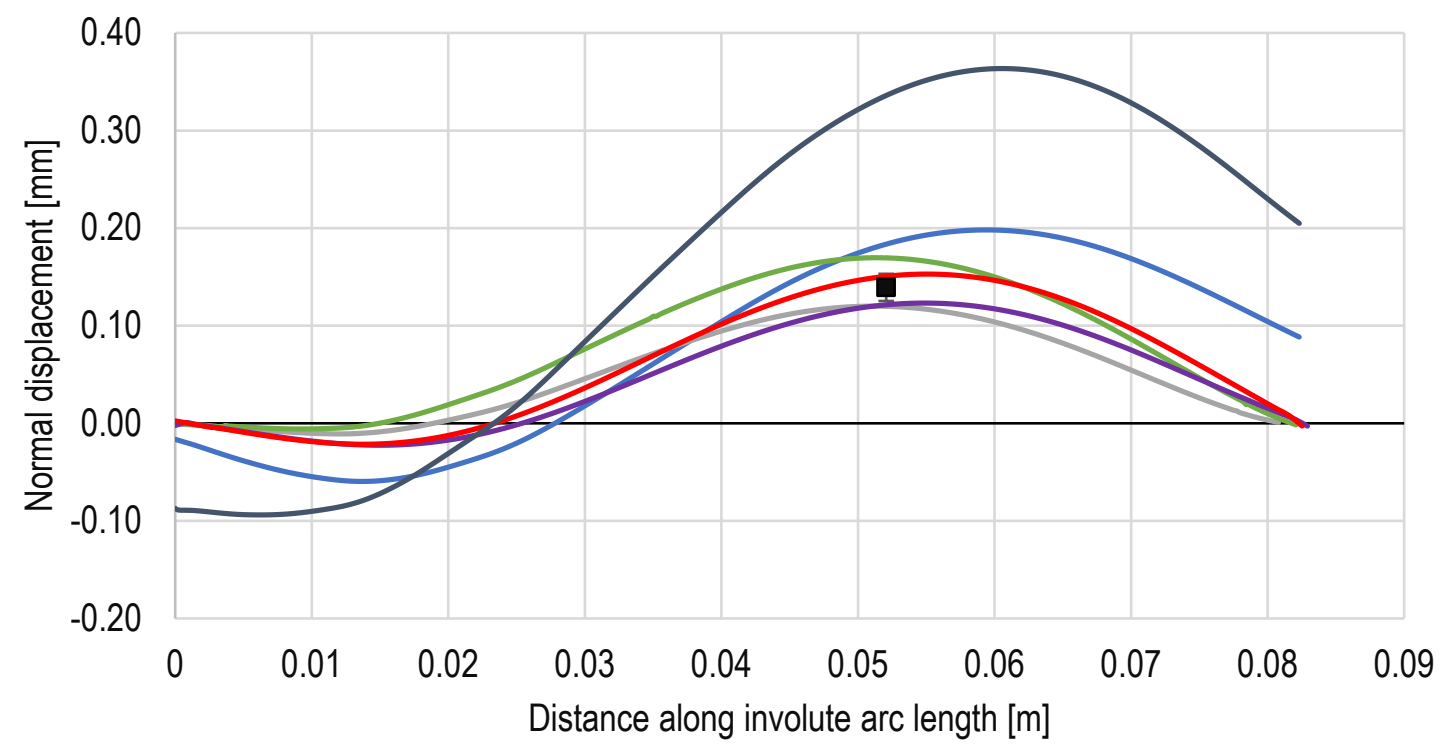

- experiment

- tabs clamped

- tabs clamped, bottom of the edge supported

_tabs clamped, bottom of the edge supported, elastoplastic material

— tabs clamped, bottom of the edge in contact with rigid plane

— tabs clamped, bottom of the edge in contact with rigid plane, elastoplastic material

— tabs clamped, elastoplastic material

Figure 7.18 Midspan deflection of a plate with every other 1/4-inch $(6.35 \mathrm{~mm})$ tab clamped under pressure load $138 \mathrm{kPa}$. Error bars were estimated by the authors of this technical report. 


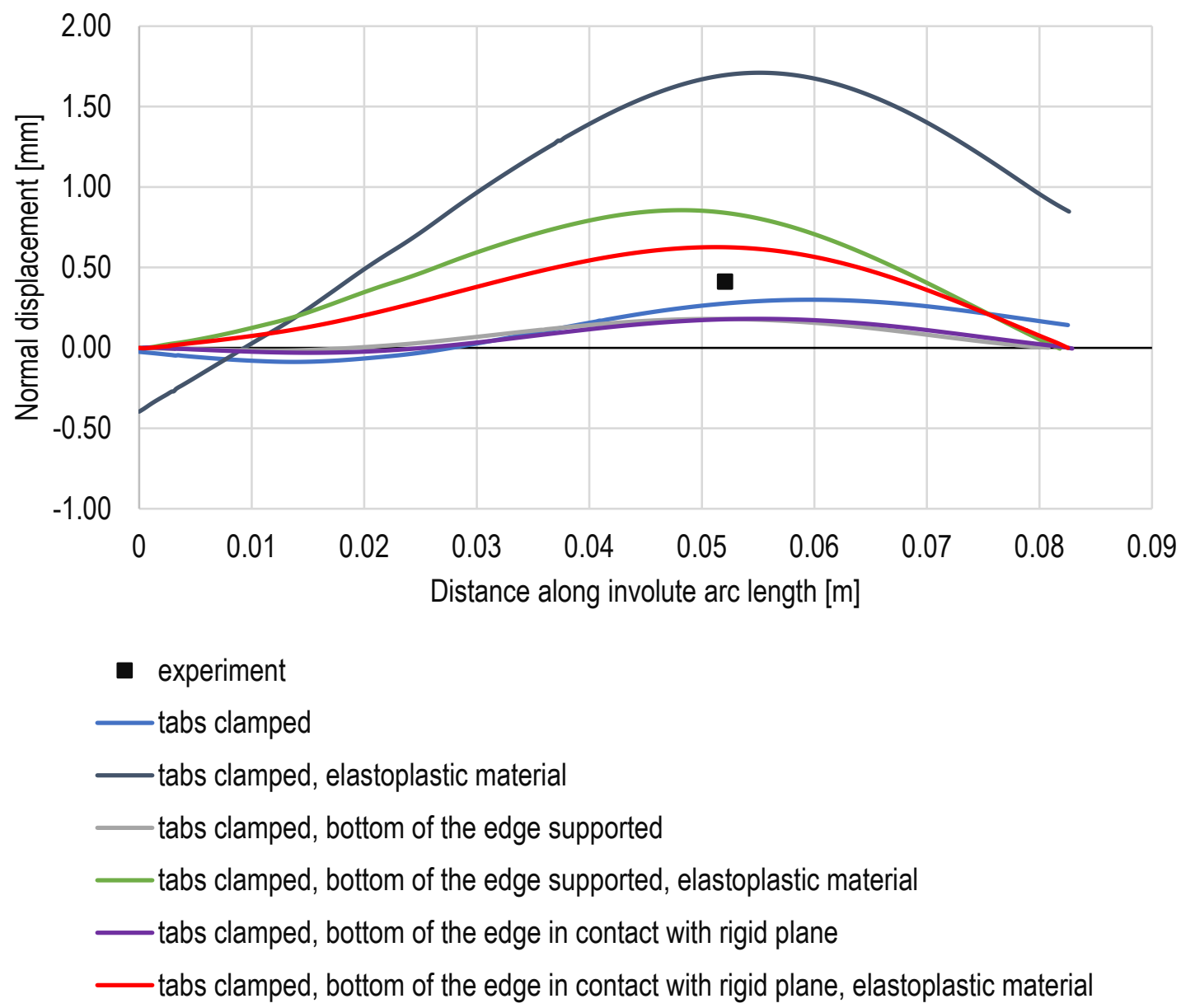

Figure 7.19 Midspan deflection of a plate with every other $1 / 4$-inch $(6.35 \mathrm{~mm})$ tab clamped under pressure load $207 \mathrm{kPa}$. Error bars were estimated by the authors of this technical report. 
(a)

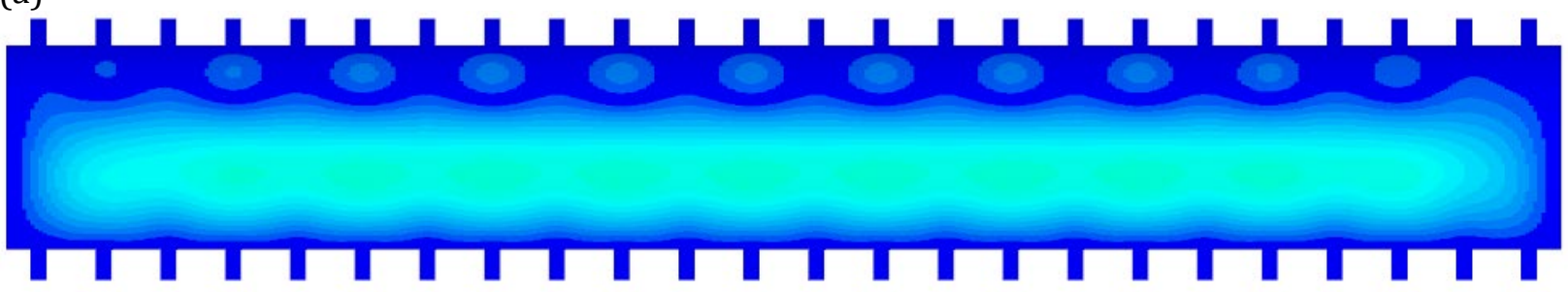

(b)

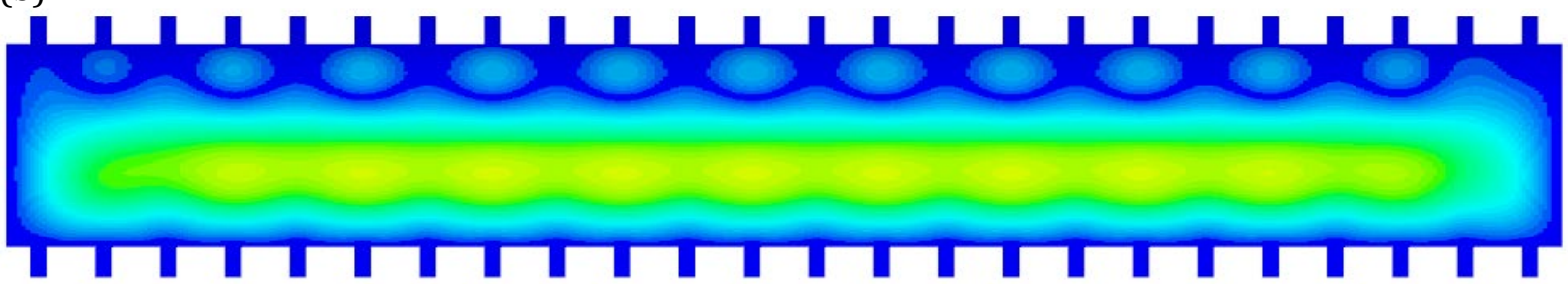

(c)

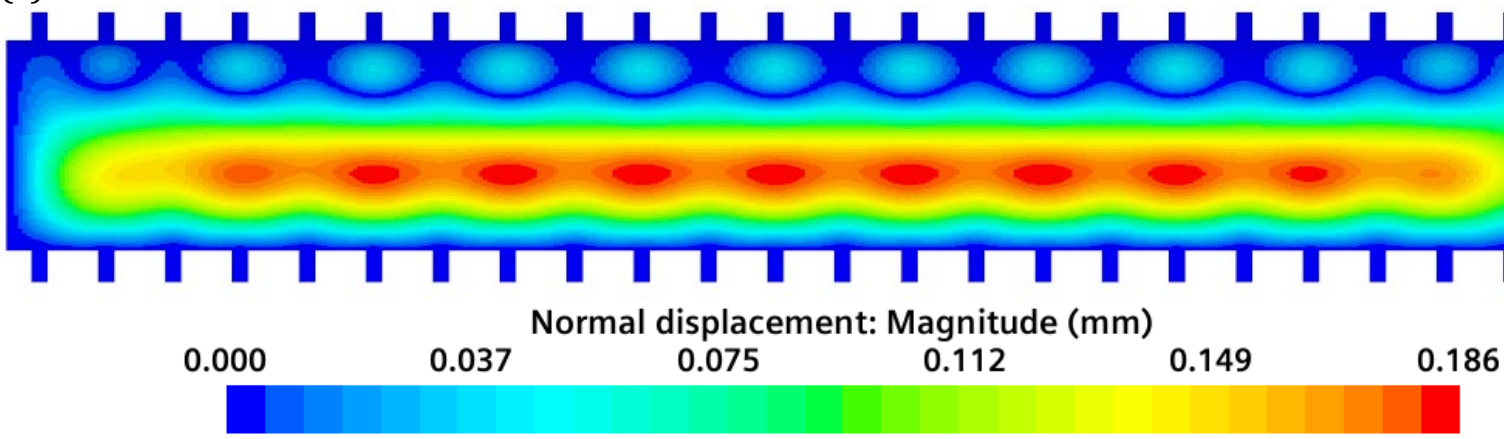

Figure 7.20. Displacement contour plots for a plate with every other $1 / 4$-inch tab clamped, edges sealed, and pressure on the concave surface: (a) $69 \mathrm{kPa}$, (b) $138 \mathrm{kPa}$, (c) $207 \mathrm{kPa}$. Model with zero displacements of the tabs and zero displacement component normal to the surface of the thin strips on concave side. 


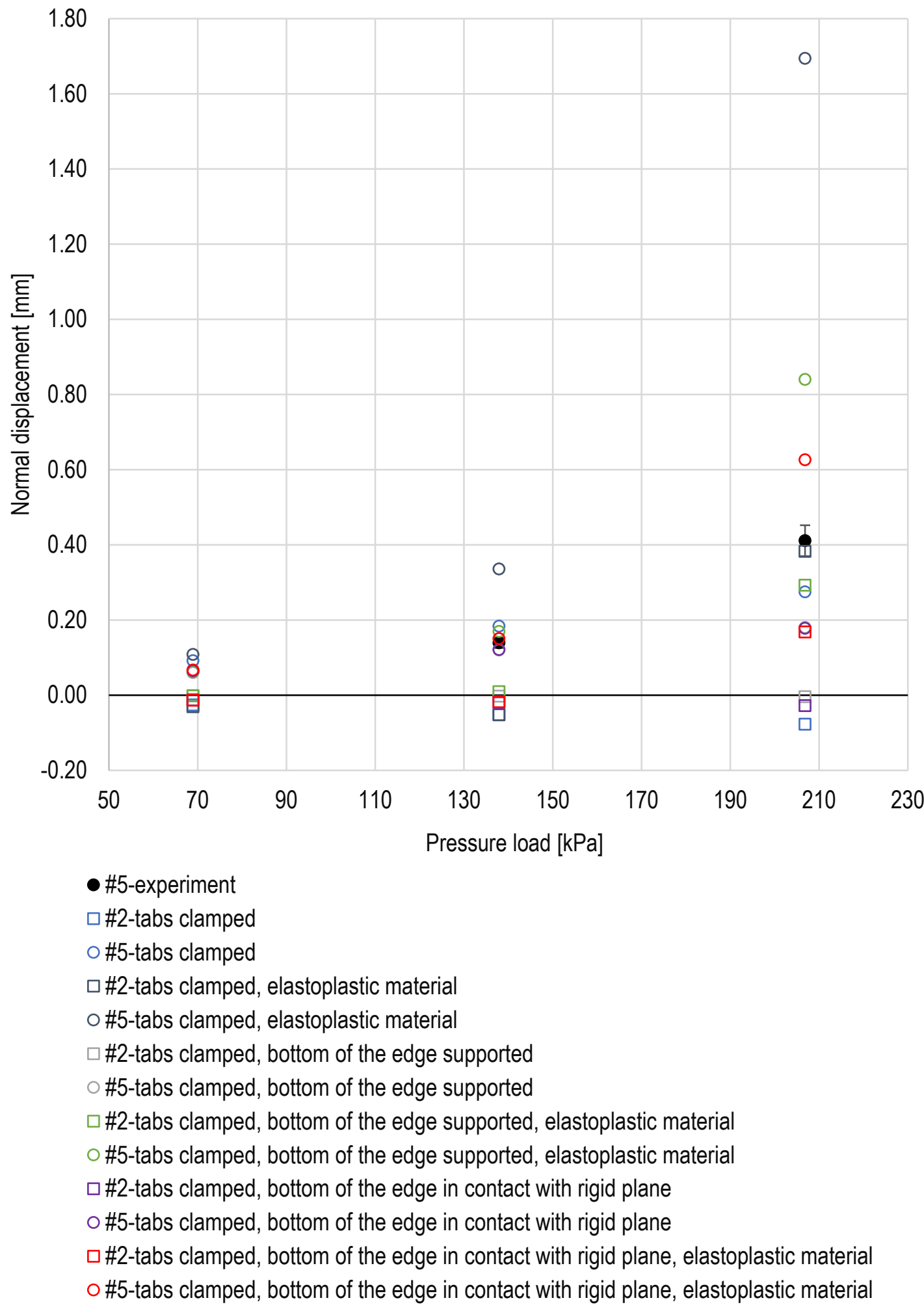

Figure 7.21 Experimental and computational normal displacements at sensor locations \#2 and \#5 for a plate with every other 1/4-inch tab clamped. Error bars were estimated by the authors of this technical report. 
(a)

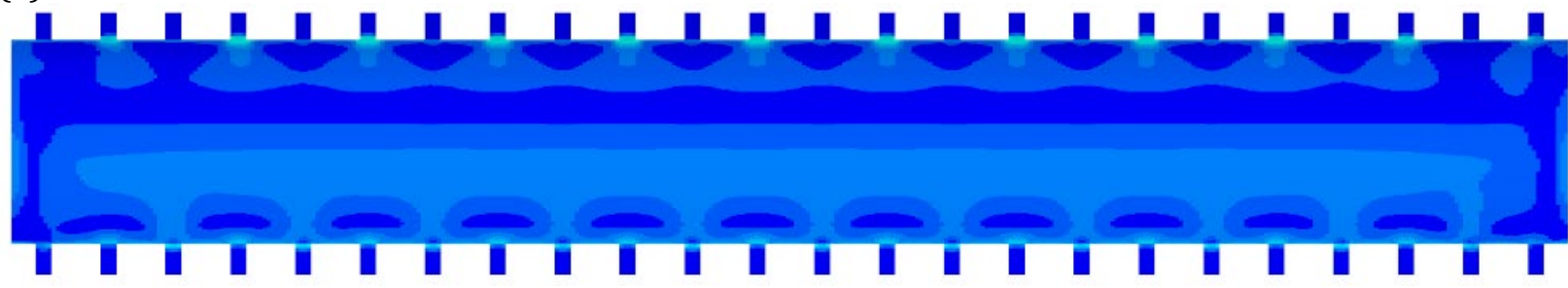

(b)

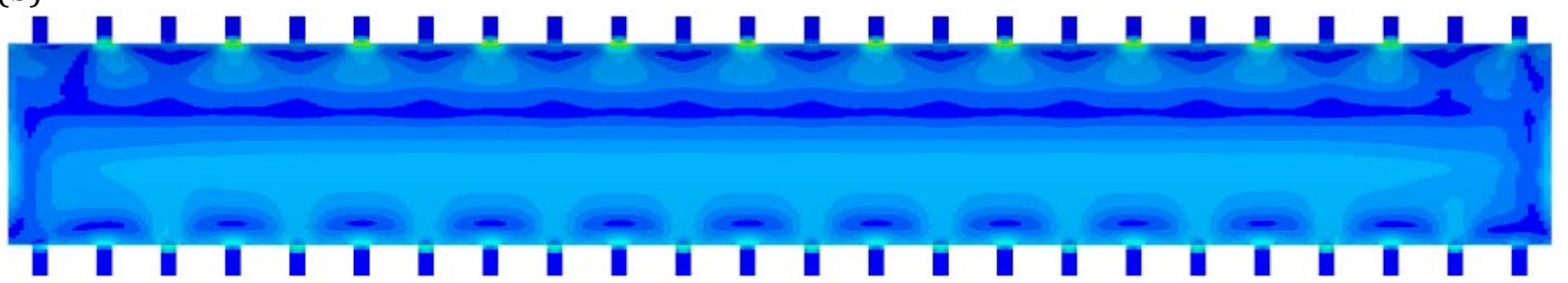

(c)

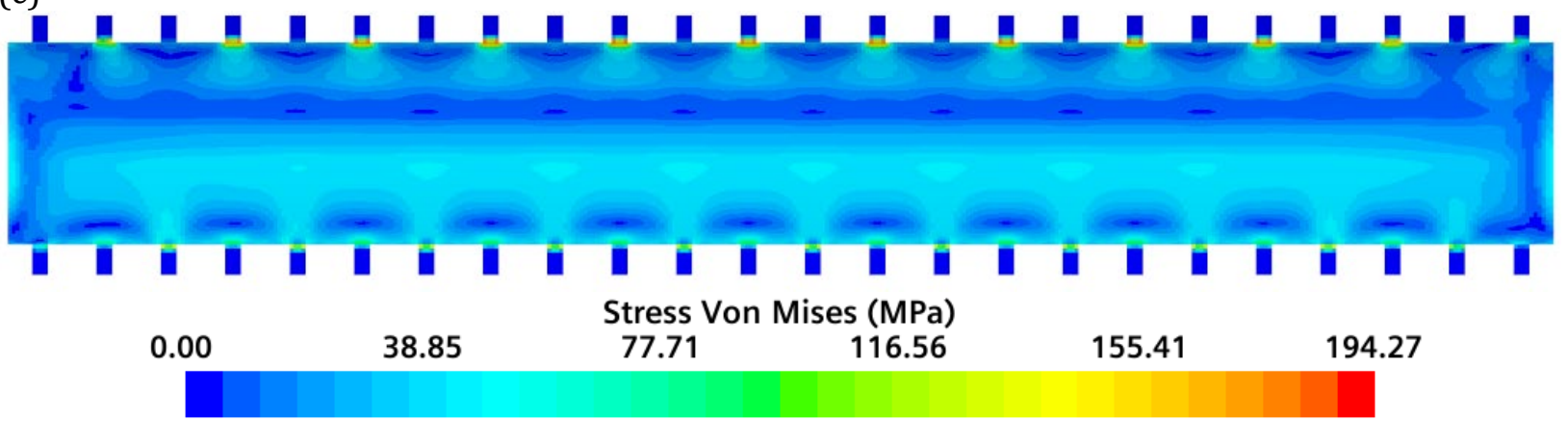

Figure 7.22. Von Mises stress contour plots for a plate with every other $1 / 4$-inch tab clamped, edges sealed, and pressure on the concave surface: (a) $69 \mathrm{kPa}$, (b) $138 \mathrm{kPa}$, (c) $207 \mathrm{kPa}$.

Model with zero displacements of the tabs and zero displacement component normal to the surface of the thin strips on concave side.

\subsection{Temperature Load Test. Model with a Solid Base}

\subsubsection{Model of a Plate with Constrained Edges}

One of the experiments consisted of heating up the entire test assembly from room temperature to $477 \mathrm{~K}$. In the computational model, a uniform thermal load was applied to an involute plate with the use of the Specified Temperature Load model. The initial condition for temperature was set to room temperature $(300 \mathrm{~K})$.

In the experiment, the $1 / 4 "$ " $6.35 \mathrm{~mm})$ tabs were clamped in a non-split base made of Invar. Invar is a metal which has a very low thermal expansion coefficient, as shown in Table 6.1, therefore its expansion is negligible in the range of temperatures considered in this study, and the relative displacement of the supports of the plate can be ignored in the computations. Also, the base was solid (not split into two pieces, a condition that will be considered in the following Sections), which limits the transverse relative displacement of the long edges of the plate. The ends of the plate are not constrained. The constraints of the long edges were represented in the computational model in several ways: (a) fixed displacements of the tabs, (b) fixed displacements of the tabs and zero normal displacements of the thin strips on bottom side of the plate, and (c) fixed displacements of the tabs 
and the long edges of the plate are in contact with a rigid base, as shown in Figure 6.5 (b), (c), (d), respectively.

Figure 7.23 shows a contour plot of the magnitude of the normal displacements on the convex surface obtained in the computations under thermal load for various boundary conditions. Small changes in the maximum displacement, and in the deflections of the ends of the plate are noticeable.

Figure 7.24 presents the contour plots of the von Mises stress field on the convex surface of the plate for varying boundary conditions on the sides of the involute plate. In each case the stresses exceed the yield strength of the aluminum, which suggests that plastic flow would occur in the tests.

(a)

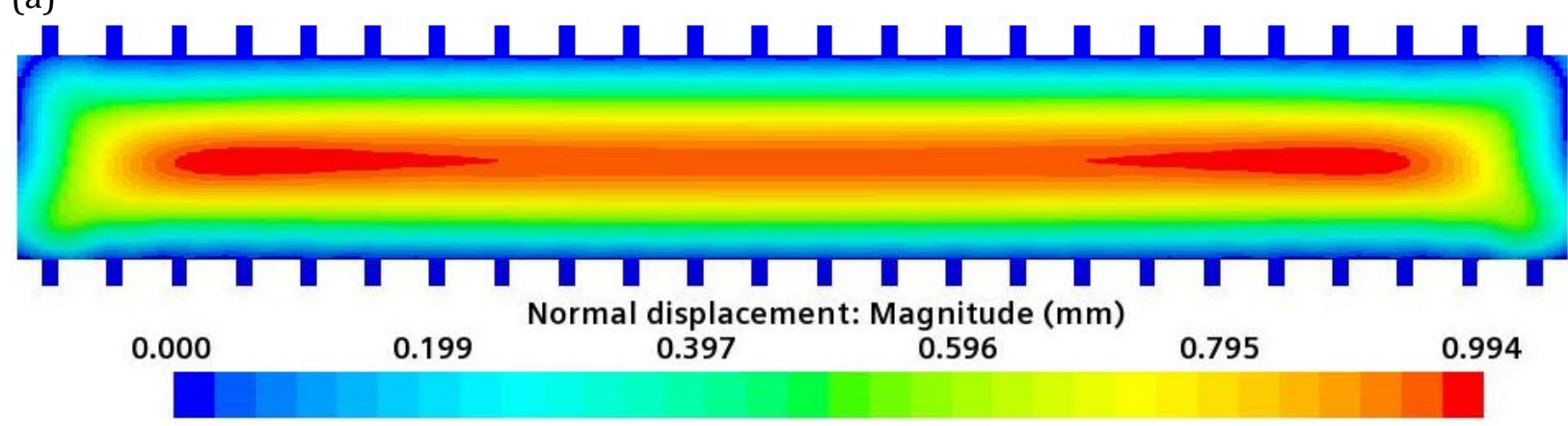

(b)

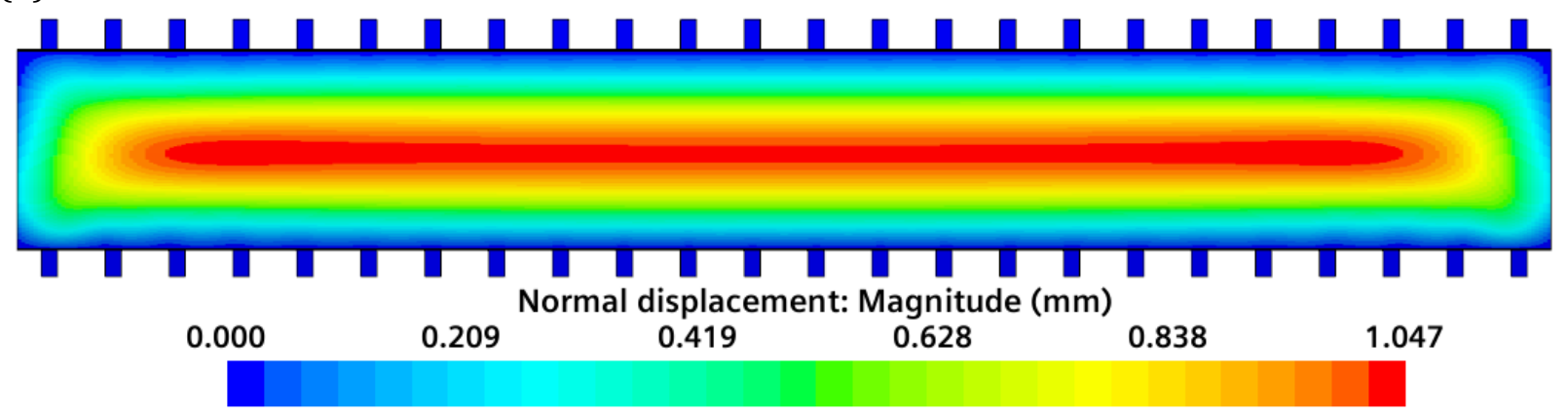

(c)

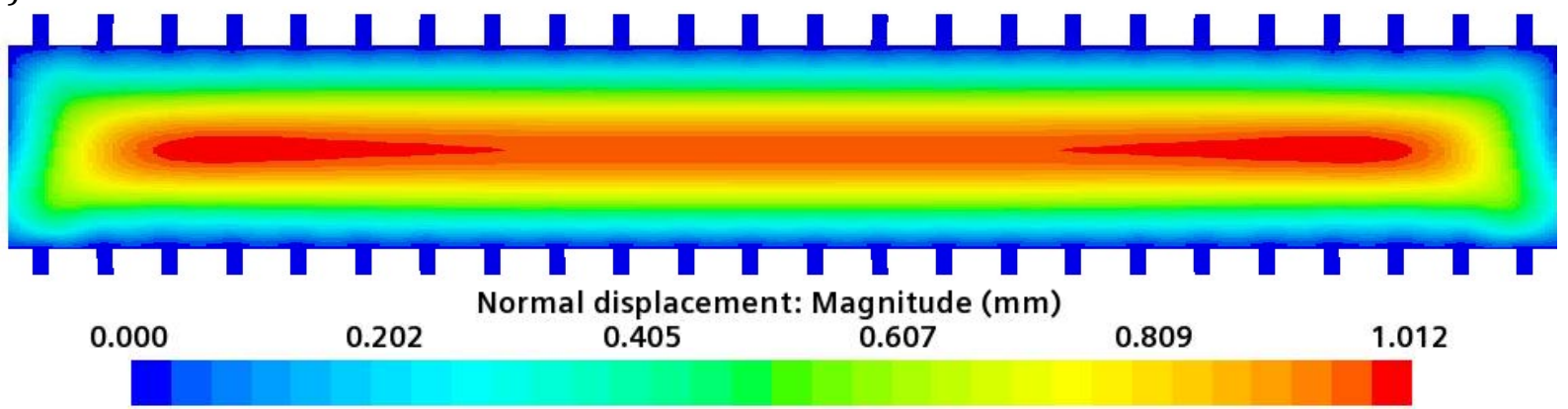

Figure 7.23. Displacement contour plot for a plate made of elastic material, under $477 \mathrm{~K}$ temperature load (reference temperature $300 \mathrm{~K}$ ), with free ends, and varying level of side constraint: (a) fixed displacements of the tabs, (b) fixed displacements of the tabs and zero normal displacements of the thin strips on bottom side of the plate, (c) fixed all components of displacement vector of the tabs and groove-wide strips on the concave surface along the length of the plate in contact with rigid planes tangent to the involute. 
(a)

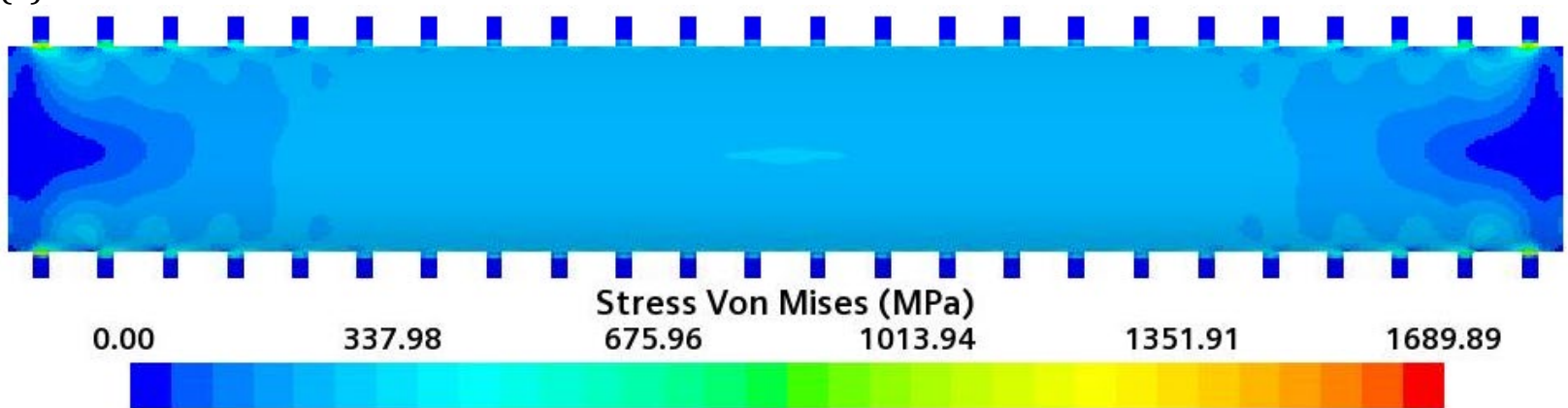

(b)

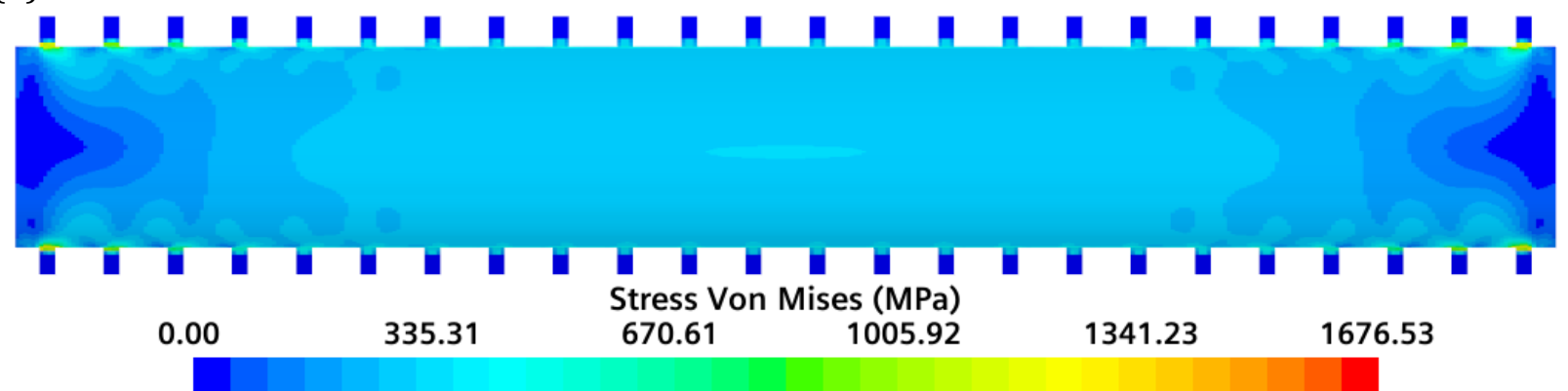

(c)

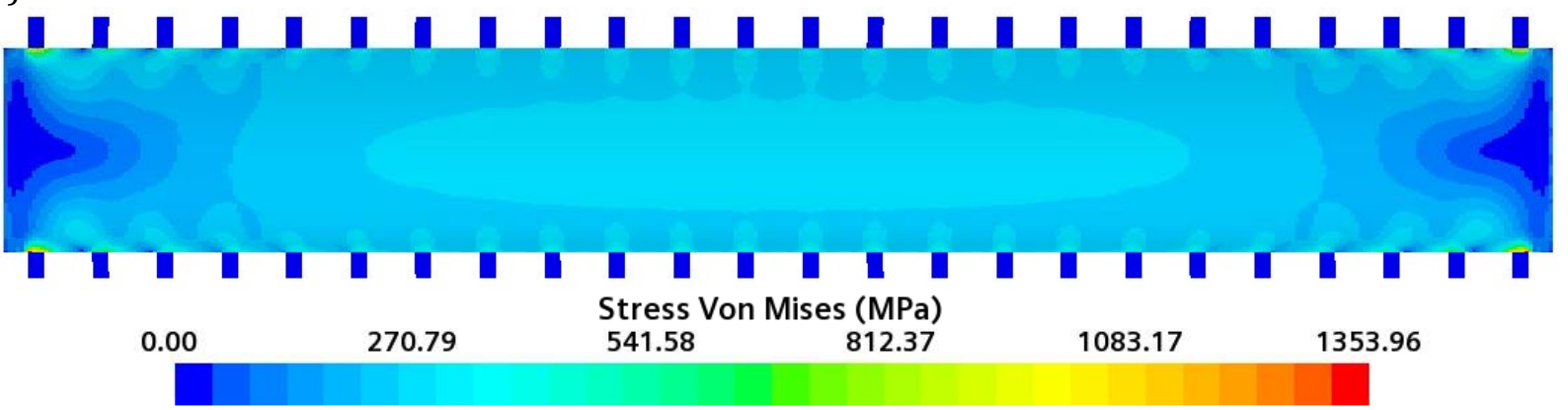

Figure 7.24. von Mises stress contour plot for a plate under $477 \mathrm{~K}$ temperature load, with free ends, and varying level of side constraint: (a) fixed displacements of the tabs, (b) fixed displacements of the tabs and zero normal displacements of the thin strips on bottom side of the plate, (c) fixed all components of displacement vector of the tabs and groove-wide strips on the concave surface along the length of the plate in contact with rigid planes tangent to the involute.

\subsubsection{Model of a Plate with a Base}

A more complex and computationally expensive model of a plate in a base was used. Thermal load was applied to the entire model with the use of the Specified Temperature Load model with the same setting as presented in Section 7.2.1. Two models were considered: the plate without tabs bonded with the base, and the plate with tabs in which the tabs are in a bonded contact with the base and the plate is in a sliding contact with the base, as described in Section 6.4.2. The base was assigned the mechanical properties of Invar given in Table 6.1. 
Displacements normal to the convex surface of the involute late are plotted in Figure 7.25. The distribution and magnitude are in good agreement with the results presented in Figure 7.23.

(a)

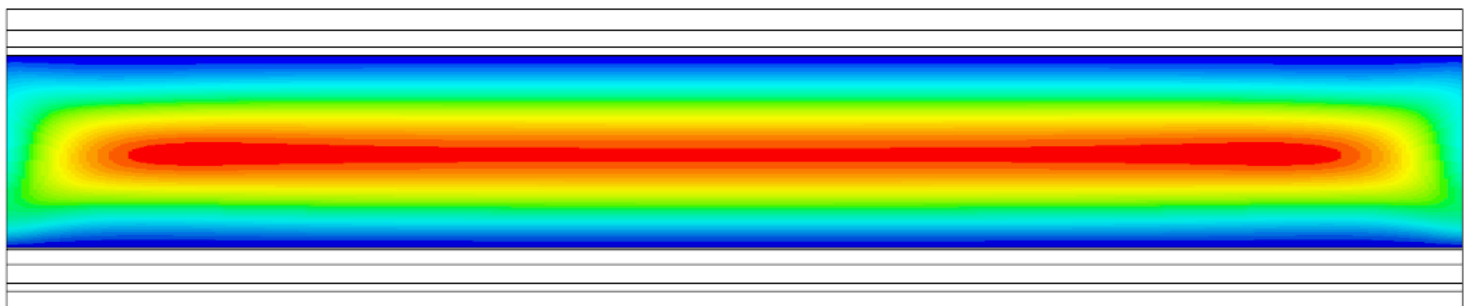
0.011
0.209
Normal displacement: Magnitude (mm)

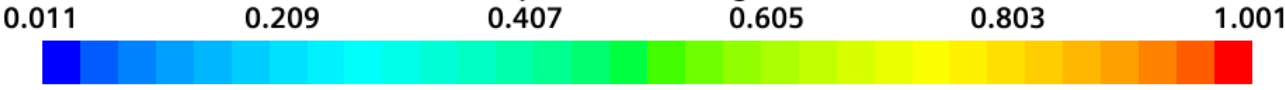

(b)

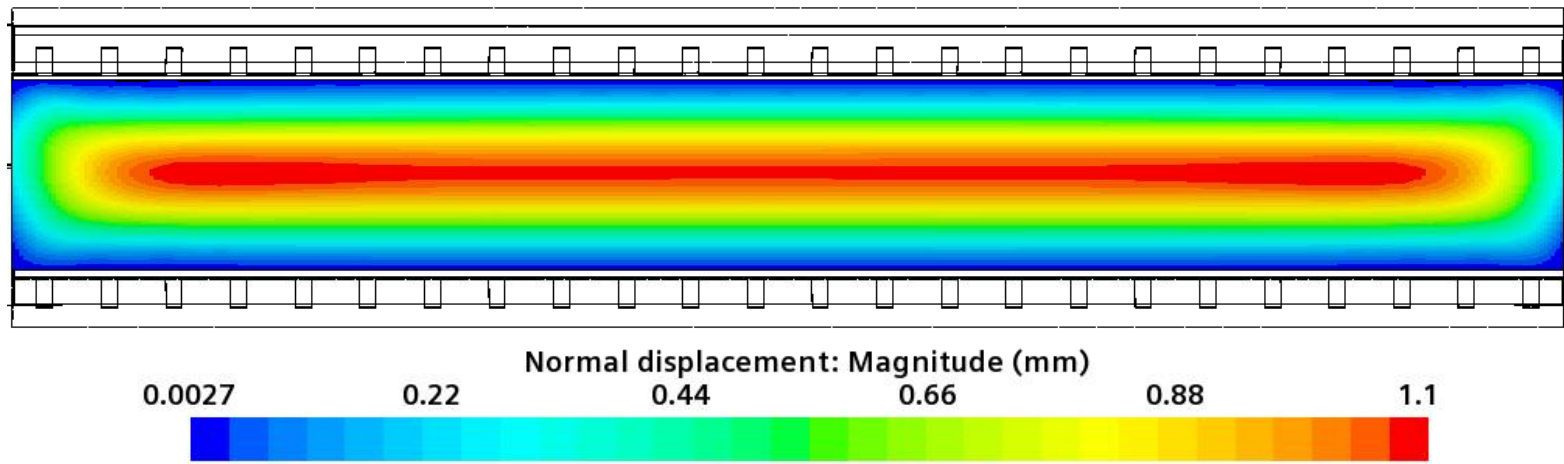

Figure 7.25. Displacement contour plot on the convex surface of an involute plate made of elastic material, under $477 \mathrm{~K}$ temperature load (reference temperature $300 \mathrm{~K}$ ) with free ends, (a) the plate is bonded with a solid base, (b) the plate is in sliding contact with the base, and the tabs are bonded with the base

\subsubsection{Comparison of Results of the Simulations with Temperature Load}

The results obtained from simulations with thermal load are compared with the experimental measurements as well as results presented by Jain et al. [17], where the authors used a model of an elastic involute plate with fixed displacements of the side surfaces. Figure 7.26 presents a comparison of the displacements of the ends of the plate, and Figure 7.27 presents a comparison of displacements of the midspan of the plate. The results from the experiment, as well as the current study are displacements normal to the convex side of the involute plate, and the results from Jain et al. are the vertical components of the resultant displacements.

The measurements of the deflections taken during the experiments on the two ends of the plate differ in shape and magnitude, as shown in Figure 7.26. The plate did not deform symmetrically during the experiment, which may suggest a lack of symmetry of the edge constraints. The maximum deflection at $\mathrm{X}=0$ is $0.12 \mathrm{~mm}$, and at $\mathrm{X}=0.6096 \mathrm{~m}$ is $0.2 \mathrm{~mm}$, which is a $67 \%$ increase.

The computational model is very close to symmetric, and therefore the end deflections are very similar. In the computational model, like in the experimental setup, the end deflections are strongly dependent on the edge constraints. The shape and the magnitude of the deflection curves change significantly due to the change in boundary conditions. 
The deflection of the ends of the plate was significantly overestimated by the model of a plate with fixed displacements of the side surfaces and the model of a plate bonded with a base, obtained in the current study as well as by Jain et al [17]. Both models give a conservative result, the measured maximum displacement was $0.2 \mathrm{~mm}$, and the computational result reached $0.5 \mathrm{~mm}$. The best representation of the shape of the deflected plate was achieved with the model of an elastic plate with fixed displacements of the tabs, and normal displacements fixed on the concave side of the thin strips along the sides of the plate, and the model of a plate in contact with a rigid base. The model of a plate with only the tabs constrained also gave a result close to the one measured in the experiment, but because the edges are not supported, it over-predicted the corner displacements. The model with the plate with tabs in contact with the base resulted in the most similar deformed shape to the experimental one, but estimated a larger deflection of $0.33 \mathrm{~mm}$. The simulations performed with the elastoplastic material model mostly overestimate the measurements, except for the model of a plate in contact with a rigid base.

The midspan deflections are greater than the end deflections and therefore are more relevant. The maximum measured deflection is $0.93 \mathrm{~mm}$, which represents $73 \%$ of the channel thickness. The computational deflections of the midspan are less affected by the choice of boundary conditions. All models give a very similar shape of the deflected plate, with zero, or close to zero, deflection on the edges, and maximum deflection in the center of the arc to the convex side. All models slightly overestimate the experimental results. The maximum elastic computational normal displacement of $1.07 \mathrm{~mm}$, and maximum elastoplastic normal displacement of $1.17 \mathrm{~mm}$ is the result of using the model of a plate bonded with the base, which overestimates the measured displacement by $15 \%$ and $26 \%$, respectively. 


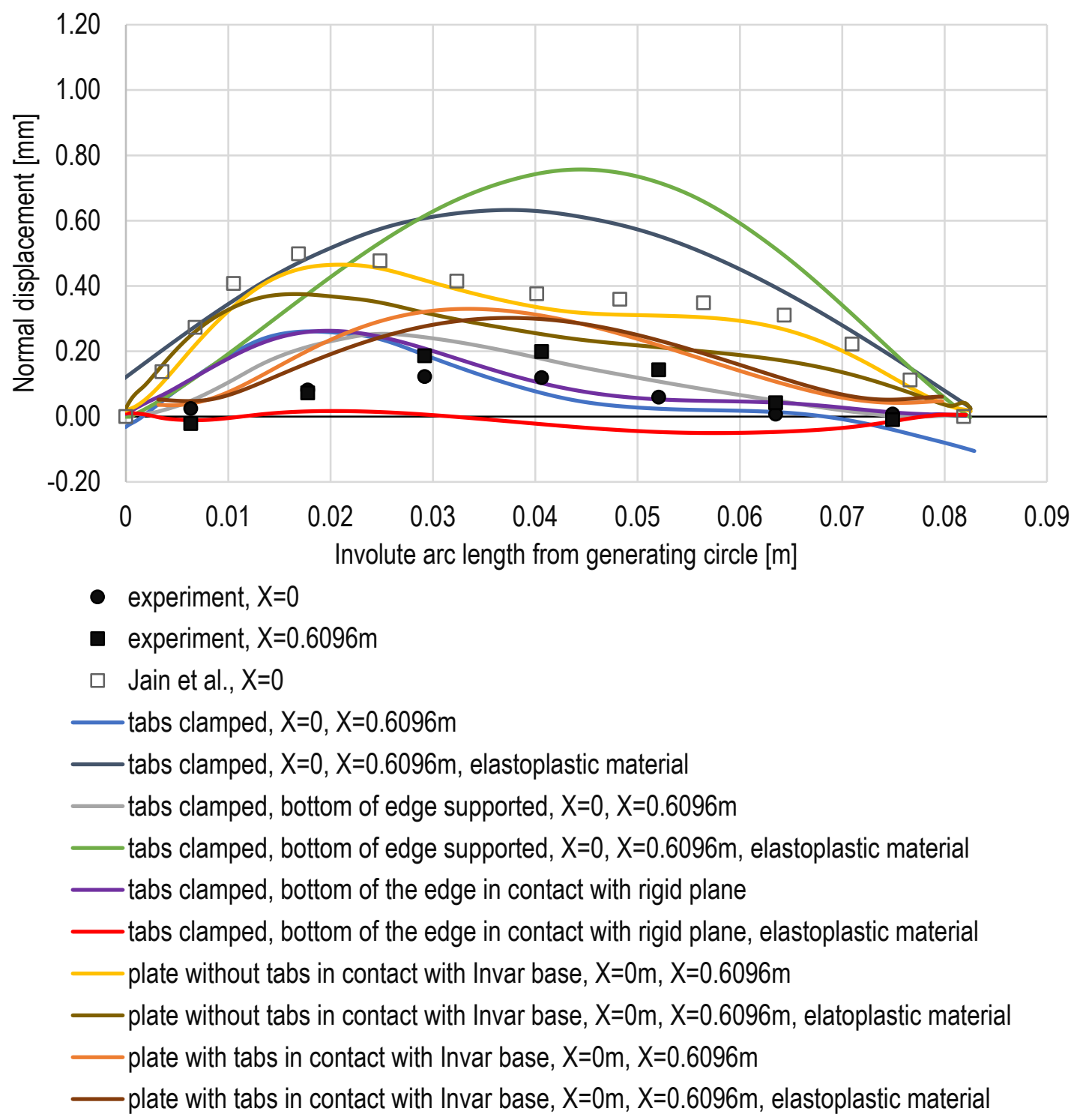

Figure 7.26. Comparison of computational and experimental normal displacements of the plate ends (short edges). Error bars were estimated by the authors of this technical report. 


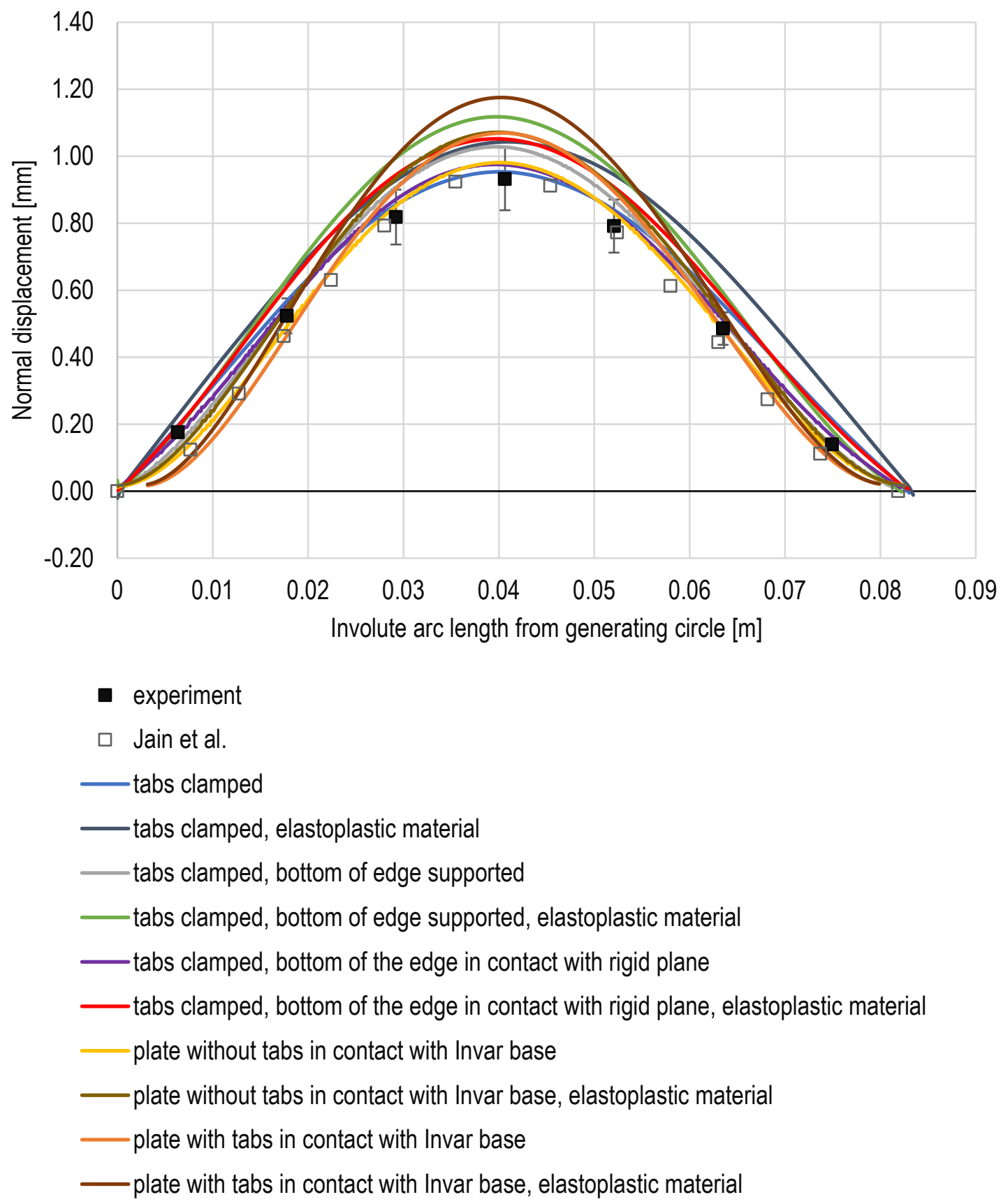

Figure 7.27. Comparison of computational and experimental normal displacements of the plate midspan. Error bars were estimated by the authors of this technical report. 


\subsection{Temperature Load Test. Model with a Split Base}

To model the edge constraint of the fuel plates in such a way that it considers the radial expansion of the fuel plates that is possible in HFIR, the bottom part of the base made of Monel was split into two pieces. The split makes it possible for the two parts of the base to move relative to each other under external loads.

The exact location and width of the gap was not reported [5]. The location and dimensions of the gap were assumed in the computational model, as presented in Figure 6.3. The same boundary conditions were applied to the bottom surfaces of the base and end plates, as in the model described in Section 7.2.2. The two bottom surfaces of the base have vertical displacement component constrained, and freedom of movement in-plane. No traction was assigned to these surfaces, because the friction coefficient between the base and the track was not reported by Cheverton et al. The difference is that the two parts of the base have freedom to move independently.

This test was not simulated with a model of a plate with tabs, because it is difficult to estimate a priori the relative displacement vector between the two parts of the base, which would need to be assigned as a boundary condition to the model.

The load applied to the model is a uniform temperature equal $477 \mathrm{~K}\left(400^{\circ} \mathrm{F}\right)$ to the entire assembly, with the reference temperature of $300 \mathrm{~K}$. It results in thermal expansion of the Monel base and expansion and bending of the aluminum involute plate. Figure 7.28 presents a contour plot of normal displacements on the convex surface of the involute plate, Figure 7.29 combined plots of normal displacements of the ends of the plate and Figure 7.30 shows normal displacements of the midspan, obtained in the computations and experiments.

The experimental measurements of the end deflections show a difference in the shape and magnitude. Similarly, to the test case with a solid base, the symmetry of the model with respect to the midspan was not retained. The biggest difference between deflections measured by the same sensor is at sensor \#6, where a deflection of $-0.25 \mathrm{~mm}$ was recorded at $X=0$, and $-0.37 \mathrm{~mm}$ at $X=0.6096 \mathrm{~m}$, where negative value means a deflection to the concave side of the plate. Moreover, there is an asymmetry of the plate deflection with respect to the centerline. The normal displacement of the ends and midspan is higher where the arc length ranges from $0.04 \mathrm{~m}$ to $0.08 \mathrm{~m}$ (right side of the plot), then in the range $0-0.04 \mathrm{~m}$ (left side of the plot). The maximum deflection in the midspan occurs at 0.052 $\mathrm{m}$ from the generating circle.

The computational deflection curves have a shape that is closer to symmetric. Even though the shape of the deflection curve differs from the experiment, the maximum deflection of the ends is predicted with a good accuracy. The deflection in the midspan is approximated well in the $0-0.04 \mathrm{~m}$ arc length range and is underpredicted in the $0.04 \mathrm{~m}-0.08 \mathrm{~m}$ range. These differences are attributed to several factors. In the model with the base, the boundary conditions are symmetric and there is no traction included. In the experiments the displacement of the base due to thermal expansion was probably not symmetric and some friction between the base and the track likely existed. The biggest experimental deflection was recorded in the midspan, and it was equal to $0.53 \mathrm{~mm}$, which represents $42 \%$ of the HFIR coolant channel thickness.

The deflection curves of the plate end and midspan obtained with STAR-CCM+ are comparable with those obtained with COMSOL software [17]. The end deflection predictions from this study is closer

Involute Working Group - Development and Validation of the Finite Element Models of the Cheverton-Kelley Experiments 
to the experimental results than the previous study, and COMSOL results show a better accuracy for the midspan deflection.

(a)

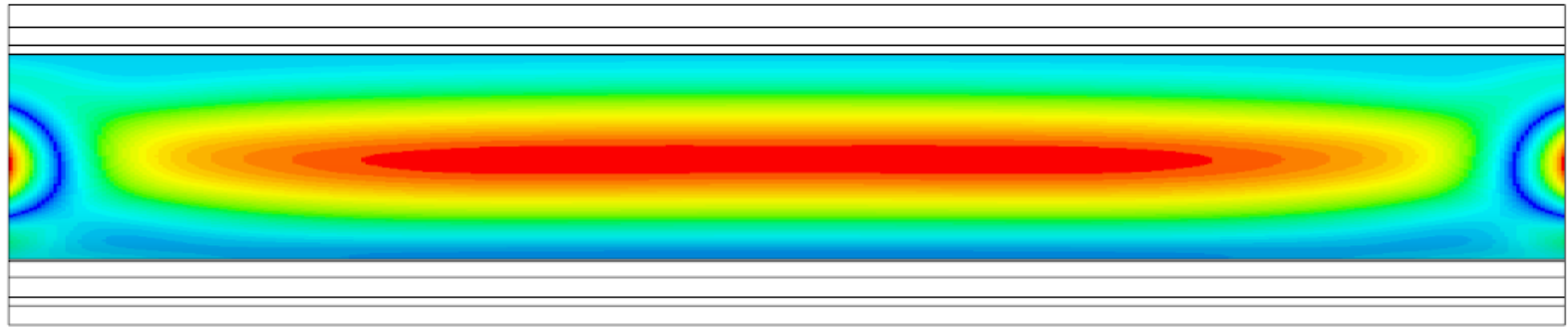

Normal displacement: Magnitude $(\mathrm{mm})$
0.000
0.084
0.169
0.253
0.337
0.421

(b)

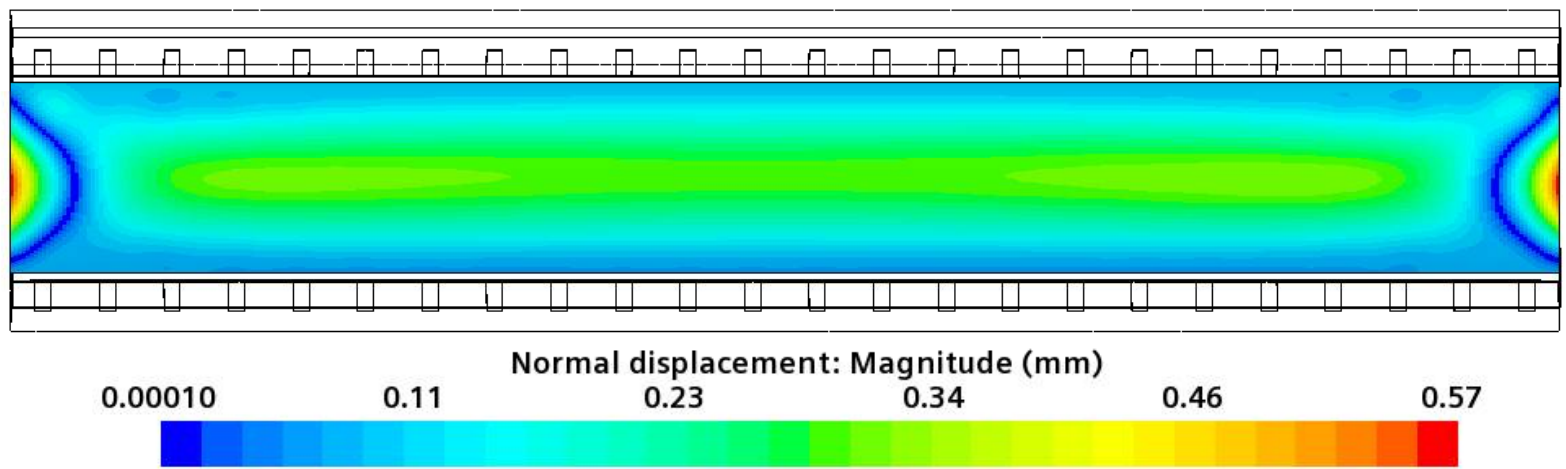

Figure 7.28 Displacement contour plot on the convex surface of an involute plate made of elastic material, under $477 \mathrm{~K}$ temperature load (reference temperature $300 \mathrm{~K}$ ) with free ends, (a) the plate is bonded with the split base, (b) the plate is in sliding contact with the base, and the tabs are bonded with the base 


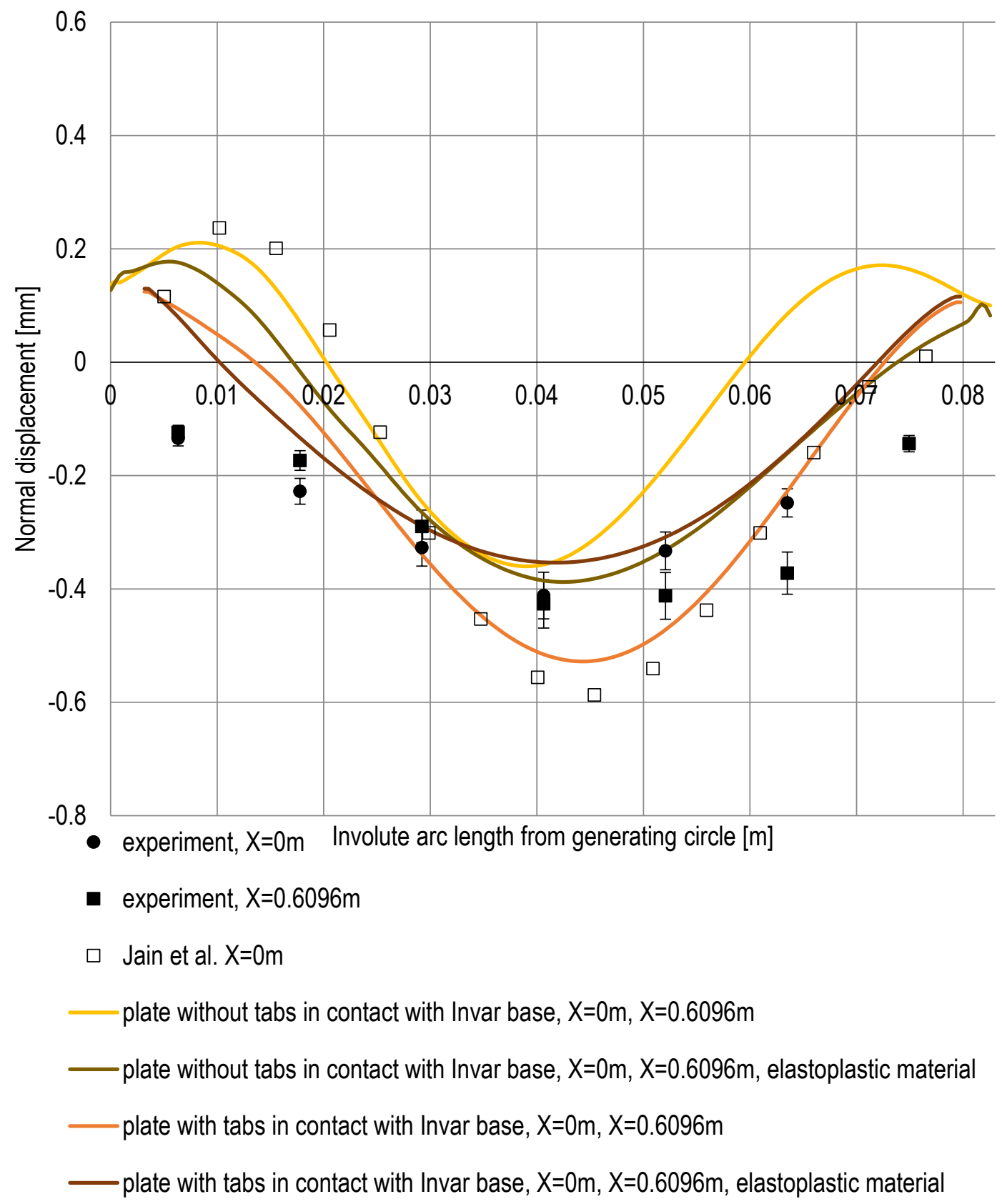

Figure 7.29 Normal displacements of the plate ends. Error bars were estimated by the authors of this technical report. 


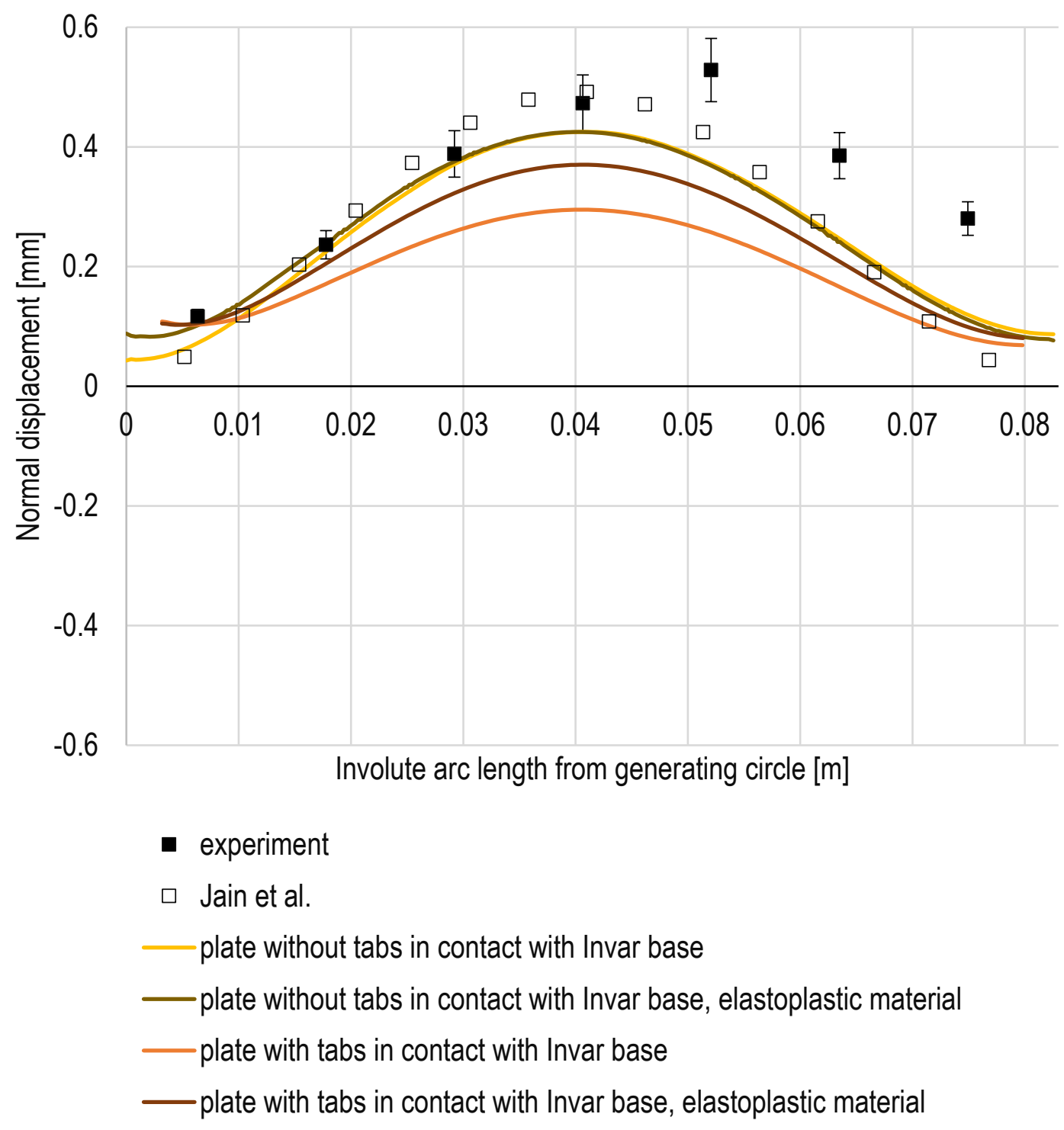

Figure 7.30 Normal displacements of the plate midspan. Error bars were estimated by the authors of this technical report. 


\subsection{Pressure and Temperature Loads}

In a set of experiments, a plate clamped in a Monel base was subjected to a combination of pressure and temperature loads. The material properties of Monel are described in Table 6.1. Two experiments were performed with the same setup, with the difference that one of them (\#32, see Figure 5.8) was performed without a sealant. It was reported that in this experiment, a leakage of the pressurized air occurred, which resulted in lower pressure values applied on the plate surface, and therefore lower deflections. Based on this statement, it is assumed that the results obtained in the test with a sealant (\#60, see Figure 5.8) are more reliable. The test consisted of two steps. First, the temperature was uniformly increased from $300 \mathrm{~K}$ to $477 \mathrm{~K}$, and then pressure was applied in increments up to $207 \mathrm{kPa}$ on the concave surface of the plate.

Figure 7.31 presents a set of contour plots of normal displacements of the plate under the temperature and pressure load (a) $0 \mathrm{kPa}$, (b) $103 \mathrm{kPa}$, and (c) $207 \mathrm{kPa}$. A comparison of results between these tests shows a small difference in deflections of the midspan cross-section depending on the pressure load value. At $477 \mathrm{~K}$, the temperature load has a much more significant influence on the deflections than the pressure load. Experiment \#60 gave the maximum deflection equal to 0.46 $\mathrm{mm}$ without pressure load, and $0.52 \mathrm{~mm}$ when $207 \mathrm{kPa}(30 \mathrm{psi}$ ) load was applied, which increased the deflection by $13 \%$. It is worth noting, that $0.52 \mathrm{~mm}$ deflection corresponds to $40 \%$ of the coolant channel thickness.

The maximum deflection is smaller than in the case of a solid Invar base, presented in Section 7.2.2. This is a consequence of the properties of the metals the bases were made of. Thermal coefficient of Monel is an order of magnitude higher than that of Invar, which means that the Monel base expands more under the temperature load and makes it possible for the aluminum plate to expand more freely. Because the plate is clamped in the base, the long edges translate and rotate with the base. As the edges of the plate have the freedom of relative movement, the magnitude of the normal displacements of the involute decreases. The horizontal displacement along the involute arch length at the midspan of the plate for the case with only temperature load, was plotted in Figure 7.32. The theoretical result was obtained from the linear relationship between thermal strain and displacement: $\Delta l=\alpha_{t} l \Delta T$, where $\alpha_{t}$ is thermal expansion coefficient, $l$ is the horizontal span of the involute equal $0.076 \mathrm{~m}, \Delta T$ is the temperature change. Then we get: $\Delta l=\left(14^{*} 10^{-6} 1 / \mathrm{K}\right) *(0.076 \mathrm{~m}) *(477 \mathrm{~K}-300 \mathrm{~K})=0.19 \mathrm{~mm}$. The computational result shows are in good agreement with the theoretical estimate. 
(a)

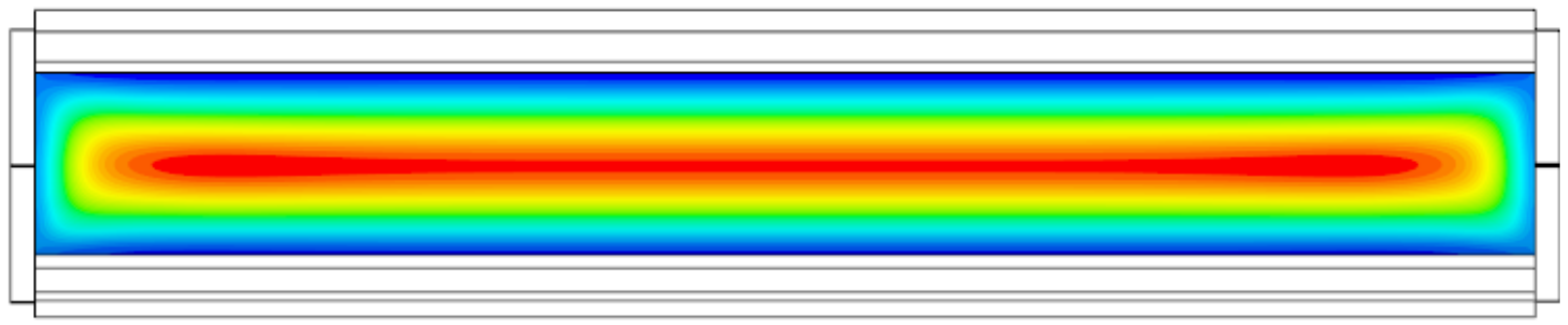

Normal displacement: Magnitude $(\mathrm{mm})$

\begin{tabular}{rrrrrrr} 
& $* .132$ & 0.218 & 0.304 & 0.390 & 0.476 & 0.562 \\
\hline & & & & & &
\end{tabular}

(b)

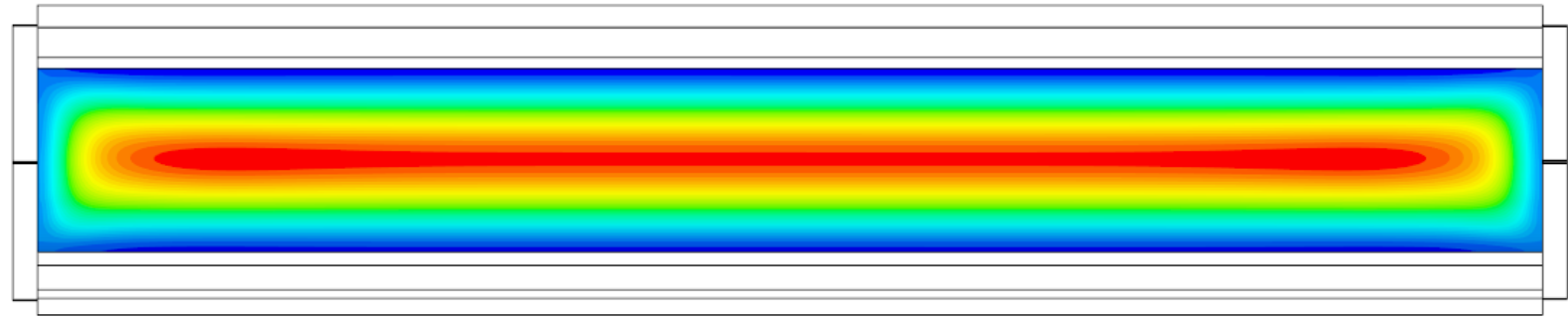

0.132

0.224

0.315

0.407

0.499

0.590

(c)

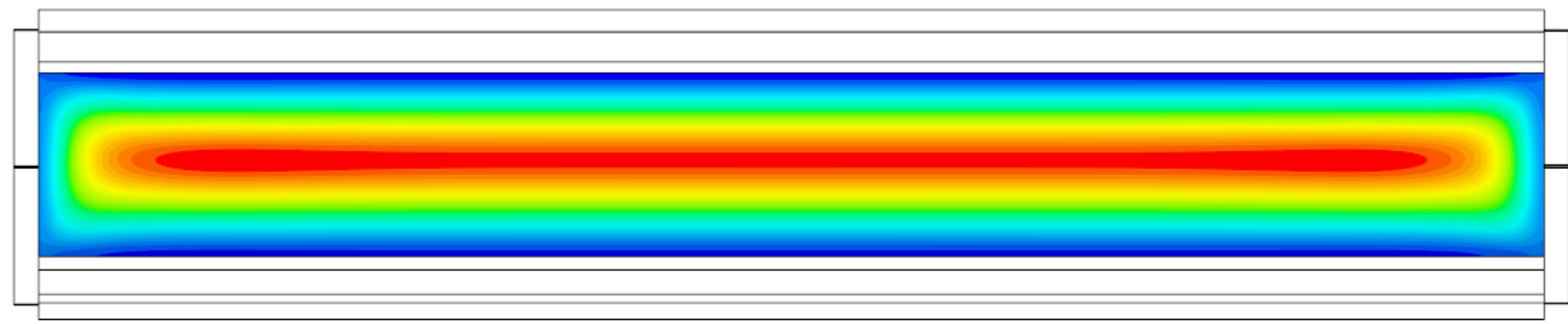

0.132

0.230

Normal displacement: Magnitude $(\mathrm{mm})$

0.328

0.426

0.523

0.621

Figure 7.31 Contour plots of normal displacement for a combination of temperature load and pressure load on the concave surface (a) $0 \mathrm{kPa}$, (b) $103 \mathrm{kPa}$, (c) $207 \mathrm{kPa}$ 


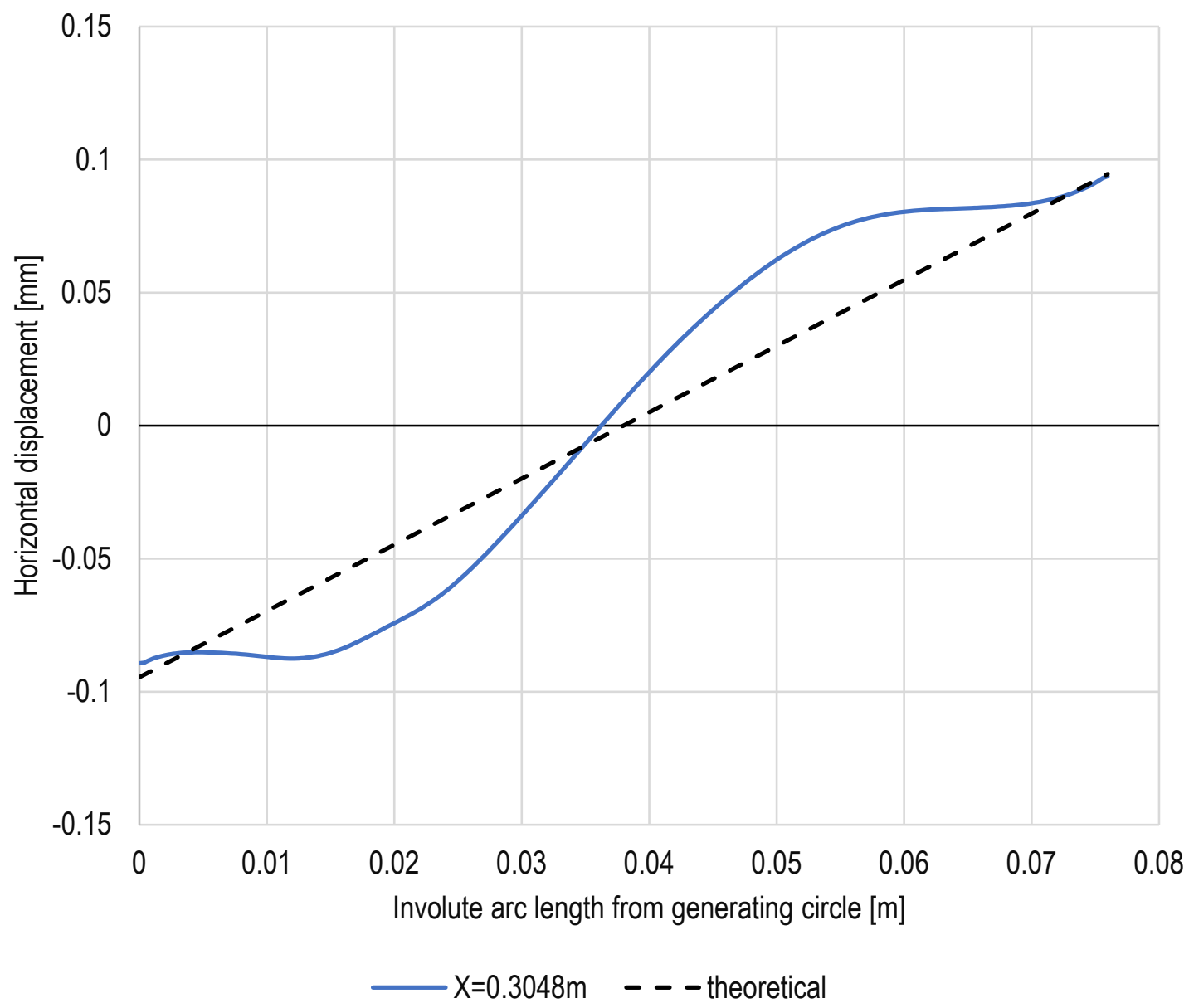

Figure 7.32 Horizontal displacement along the involute arch length at the midspan of the plate

A comparison of midspan deflection curves obtained in the computations with the experimental results is presented in Figure 7.33, Figure 7.34 and Figure 7.35 for varying pressure load. The simulations represent the shape of the deflected midspan of the plate with good accuracy but overpredict the magnitude of deflection. The computational deflection is uniformly higher across the plate than obtained in the experiment. In fact, the value of the difference corresponds to the expansion of the Monel base in the vertical direction. If we calculate the change in vertical dimension, we get: $\Delta l=$ $\left(14^{*} 10^{-6} 1 / \mathrm{K}\right) *(0.045 \mathrm{~m}) *(477 \mathrm{~K}-300 \mathrm{~K})=0.11 \mathrm{~mm}$. The curves obtained by shifting the computational displacements downward by $0.11 \mathrm{~mm}$ were plotted in Figure 7.36, Figure 7.37 and Figure 7.38. It can be noticed that the results for the simulations with elastic material model fall close to the experimental data points obtained in test \#60, which were assumed to be more reliable, regardless of the pressure load value. The elastoplastic material model overestimates the measurements for higher pressure loads. The authors of this report speculate that it is possible that: (i) in the experiment, the base was attached to the track in a way that prohibited its vertical expansion, or (ii) during the post-processing of the experimental results, the zero deflection point was shifted, by subtraction of the constant value of the base expansion to account only for the plate deformations. 


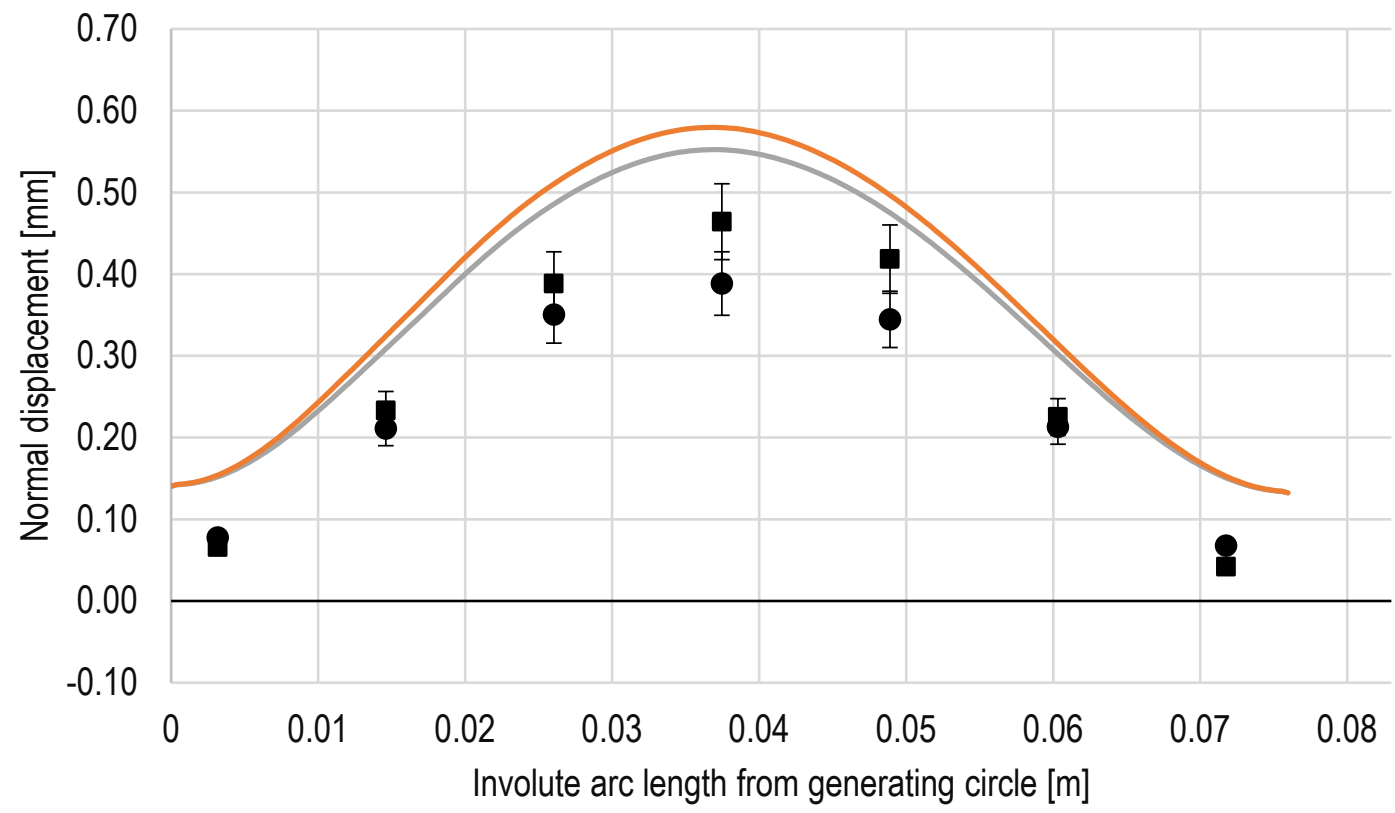

- experiment, case \#32

- experiment, case \#60

computations

- computations, elastoplastic material

Figure 7.33 Normal displacements of the plate midspan for a $400^{\circ} \mathrm{F}$ temperature load

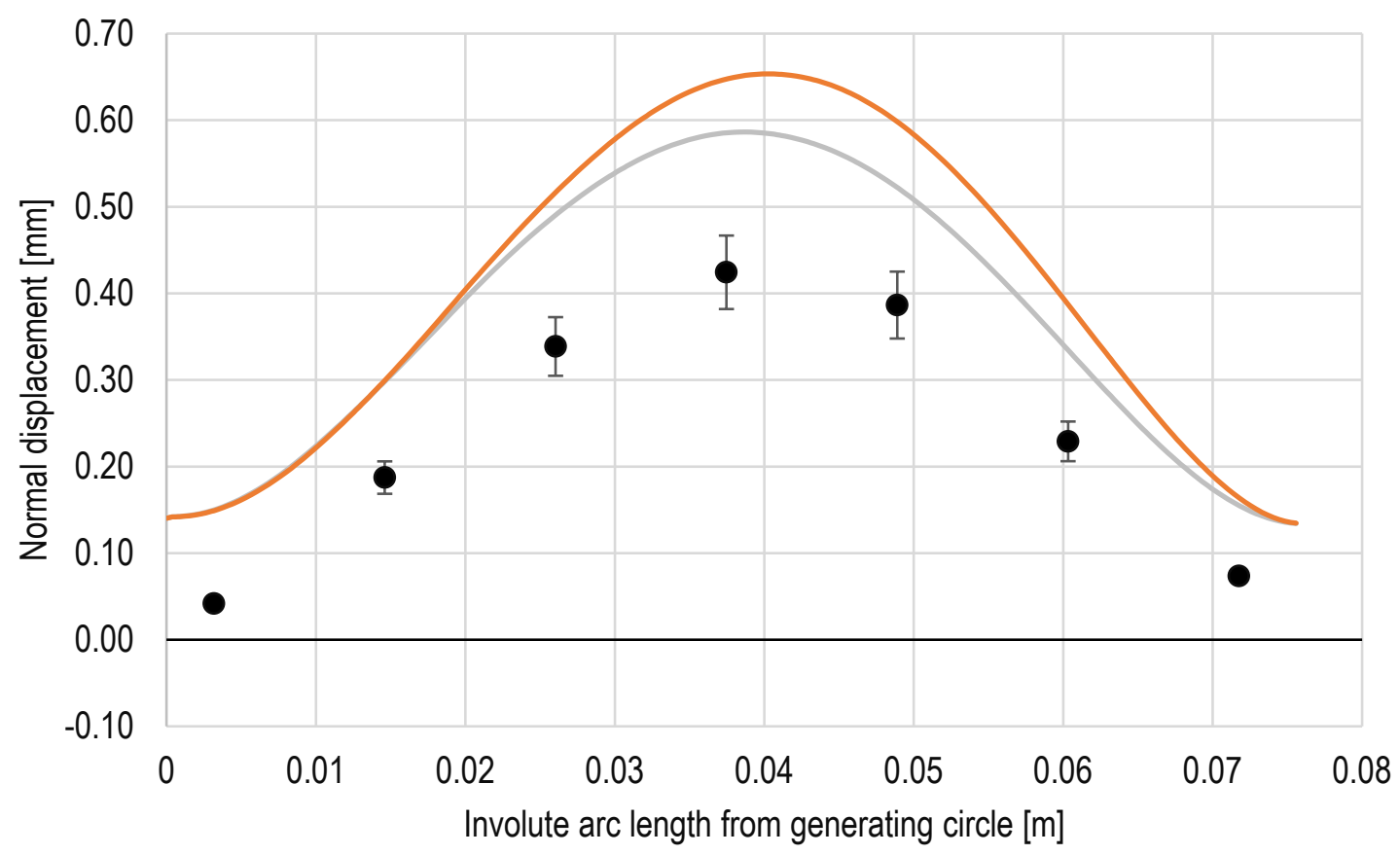

- experiment, case \#32 computations computations, elastoplastic material

Figure 7.34 Normal displacements of the plate midspan for a combination of $400^{\circ} \mathrm{F}$ temperature load and pressure load on the concave surface $103 \mathrm{kPa}$ 


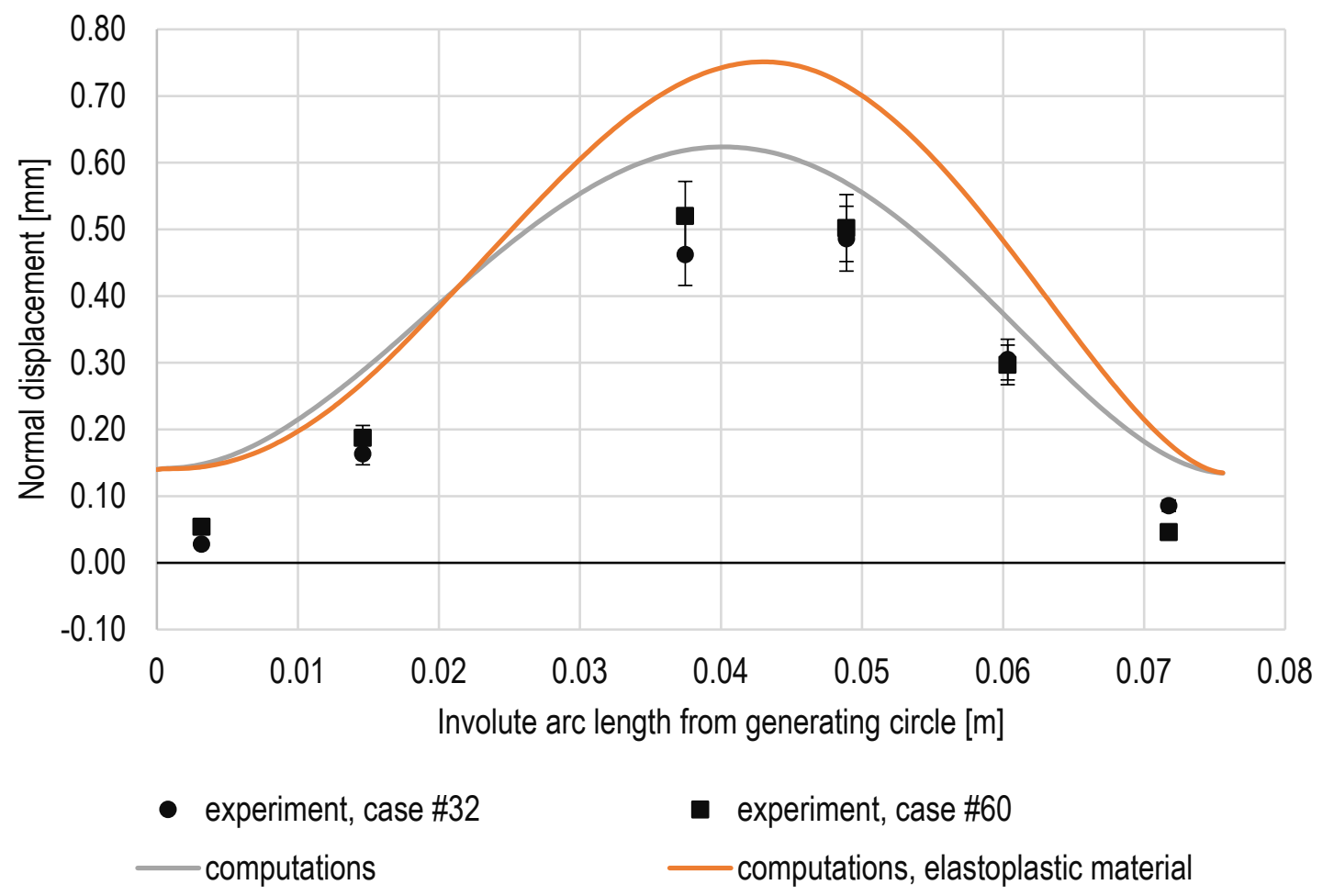

Figure 7.35 Normal displacements of the plate midspan for a combination of $400^{\circ} \mathrm{F}$ temperature load and pressure load on the concave surface $207 \mathrm{kPa}$

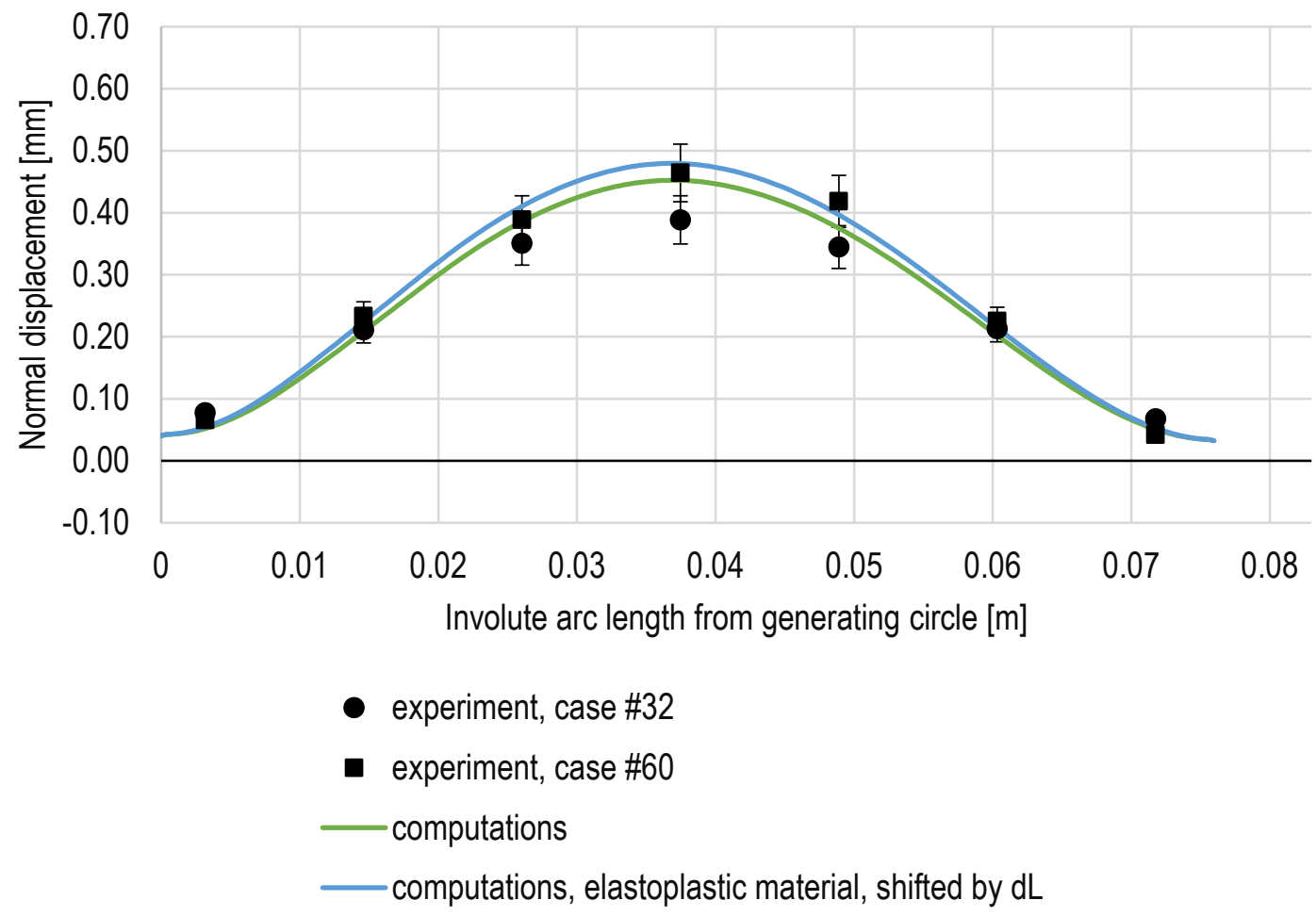

Figure 7.36 Normal displacements of the plate midspan for a $400^{\circ} \mathrm{F}$ temperature load normalized with the vertical expansion of the base

Involute Working Group - Development and Validation of the Finite Element Models of the Cheverton-Kelley Experiments 


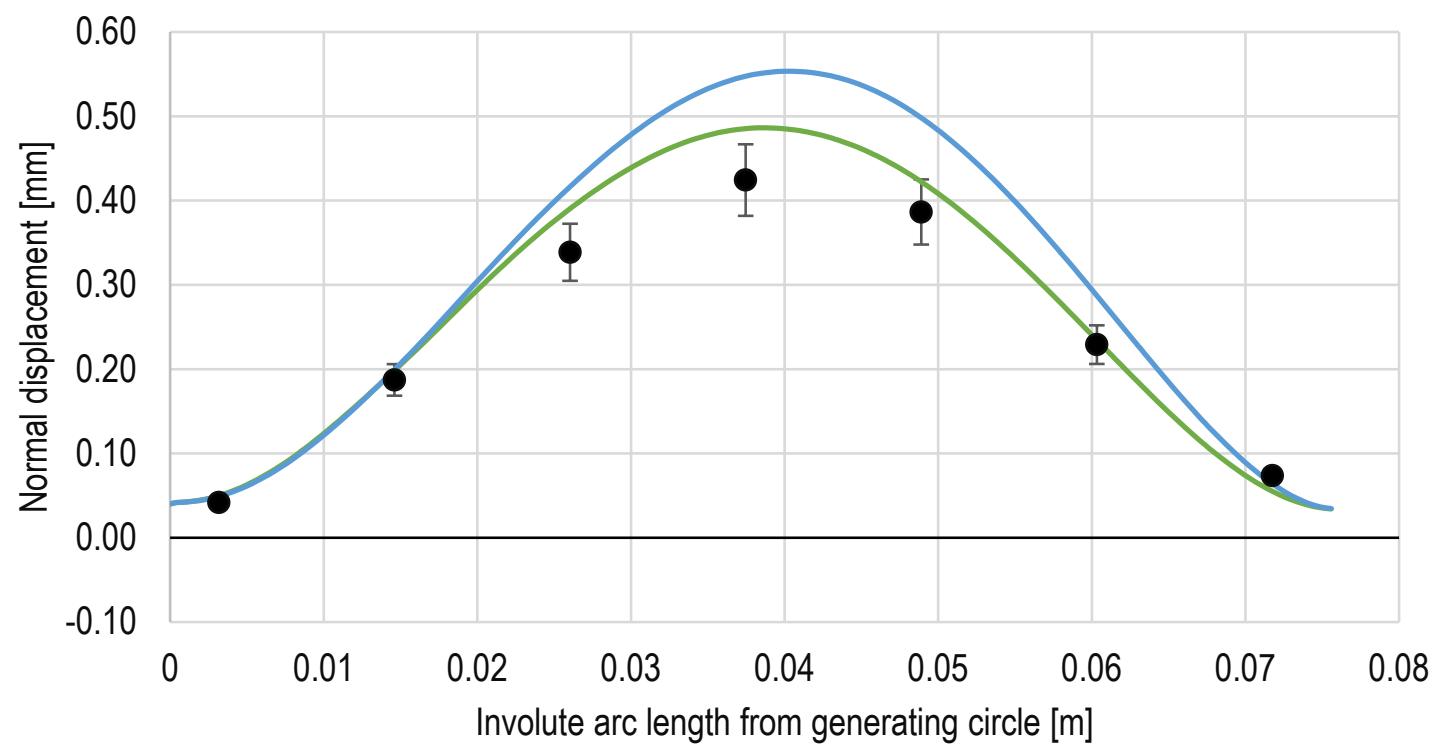

- experiment, case \#32

— computations, shifted by $\mathrm{dL}$

— computations, elastoplastic material, shifted by $\mathrm{dL}$

Figure 7.37 Normal displacements of the plate midspan for a combination of $400^{\circ} \mathrm{F}$ temperature load and pressure load on the concave surface $103 \mathrm{kPa}$, normalized with the vertical expansion of the base 


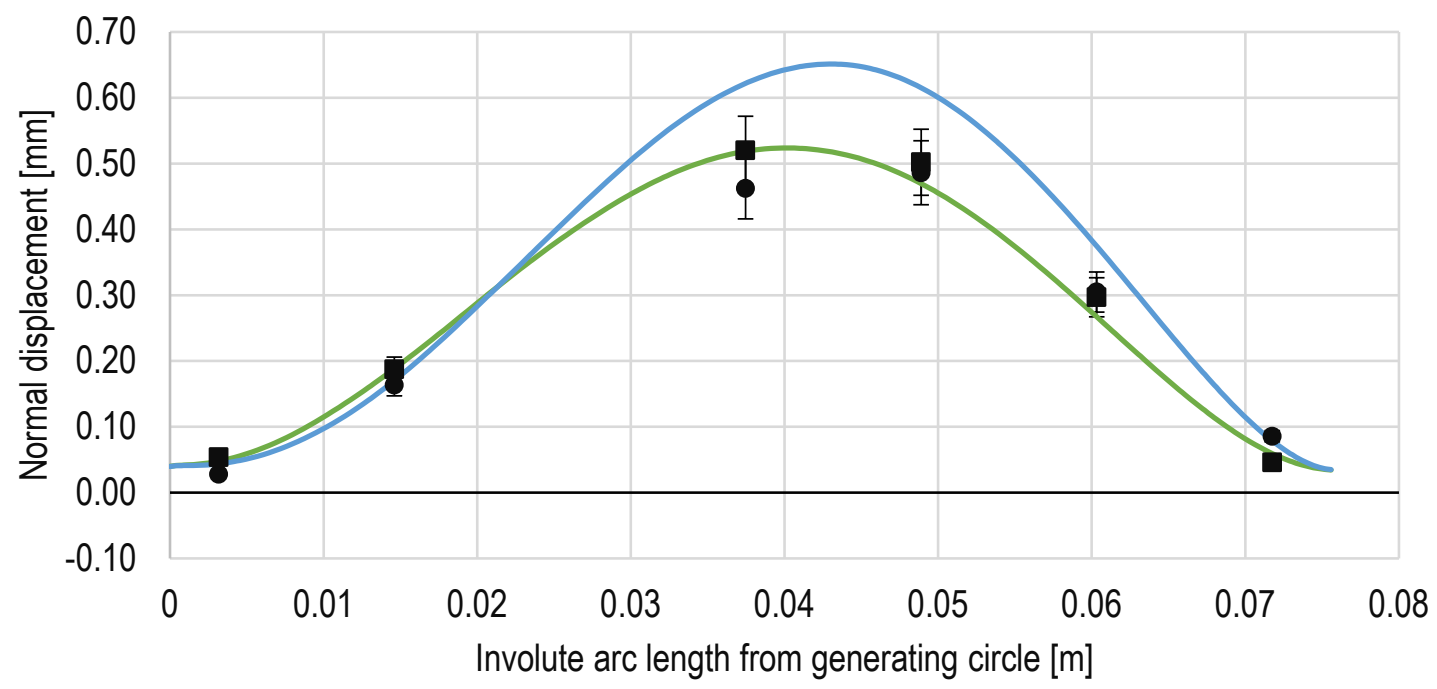

- experiment, case \#32

- experiment, case \#60

— computations, shifted by $\mathrm{dL}$

— computations, elastoplastic material, shifted by $\mathrm{dL}$

Figure 7.38 Normal displacements of the plate midspan for a combination of $400^{\circ} \mathrm{F}$ temperature load and pressure load on the concave surface $207 \mathrm{kPa}$, normalized with the vertical expansion of the base 


\subsection{Summary of Results}

In order to compare the computational results obtained from the various proposed models, the predicted displacements of sensor locations \#2 and \#5 were plotted against the experimental measurements in Figure 7.39. All models with varying displacement boundary conditions, loads, and material models presented in the previous sections are accounted for on the plot. The black dashed line represents points of equal computational and experimental values. The dotted black lines show $\mathrm{a} \pm 20 \%$ deviation from this line. The comparison shows that most of the models give results with deviation less than $\pm 20 \%$, irrespectively from the simulation input parameters.

There are three noticeable outliers. Firstly, the proposed computational models of a plate with every other tab clamped under a pressure load of $207 \mathrm{kPa}$ were not able to reproduce accurately the deflection of the plate. They either underestimate or overestimate the experimental measurement. It is worth noting, that the same model used for lower pressure values, gave a better accuracy of results. The reason for this deviation could be that the model cannot represent well the plastic deformations that occurred in the plate during the experiment. Cheverton and Kelley mentioned that such deformations occurred, i.e. plastic flow at the foot of the tabs. The elastoplastic material model used in this study is not complex enough to capture this behavior.

Secondly, it can be noticed that the various computational models proposed to represent the deflection of a plate constrained along the long edge in an Invar base and with free ends, subjected to $477 \mathrm{~K}$ temperature load, produce a wide range of deflection values for sensor \#4. Depending on the model, the magnitude varies from $0.1 \mathrm{~mm}$ to $0.35 \mathrm{~mm}$ for the elastic material model, and from -0.02 $\mathrm{mm}$ to $0.75 \mathrm{~mm}$ for the elastoplastic material model. This indicates that the deflection of the free end in this test case is very sensitive to the side boundary condition as well as the material properties. The experimental measurements confirm this finding. The deformation of the two ends of the plate was somewhat different, with the maximum deflection on one end of $0.119 \mathrm{~mm}$, and on the other end equal to $0.199 \mathrm{~mm}$, which may suggest that the constraints were not symmetric with respect to the midspan.

Two models that give the best accuracy of results were identified. For test cases in which the relative displacement of the plate side edges is negligible, i.e. in which the deformation of the base does not influence the deformation of the plate, the best results were obtained with the model in which contact was defined between the plate and a rigid base. It is computationally more efficient than the full model of a plate clamped in a base and makes it possible to model the variations of the tab constraints proposed by Cheverton and Kelley. Figure 7.40 shows the set of results obtained with elastic material model, and Figure 7.41 for elastoplastic material model.

For the test cases in which the deformation of the base had an impact on the deformation of the plate, such as the model of a split Invar base, or a solid Monel base under thermal loads, it is recommended to use a complex model of a plate in a base. Only this model can account for the interaction between the parts of the assembly. Figure 7.42 shows the set of results obtained with elastic material model, and Figure 7.43 for elastoplastic material model.

Most data points fall in between the $\pm 20 \%$ deviation lines. If the plate response is within, or close to, the elastic range, the computational results show a very good accuracy. Discrepancies occur when the loads are large enough to result in an elastoplastic response.

Involute Working Group - Development and Validation of the Finite Element Models of the Cheverton-Kelley Experiments 


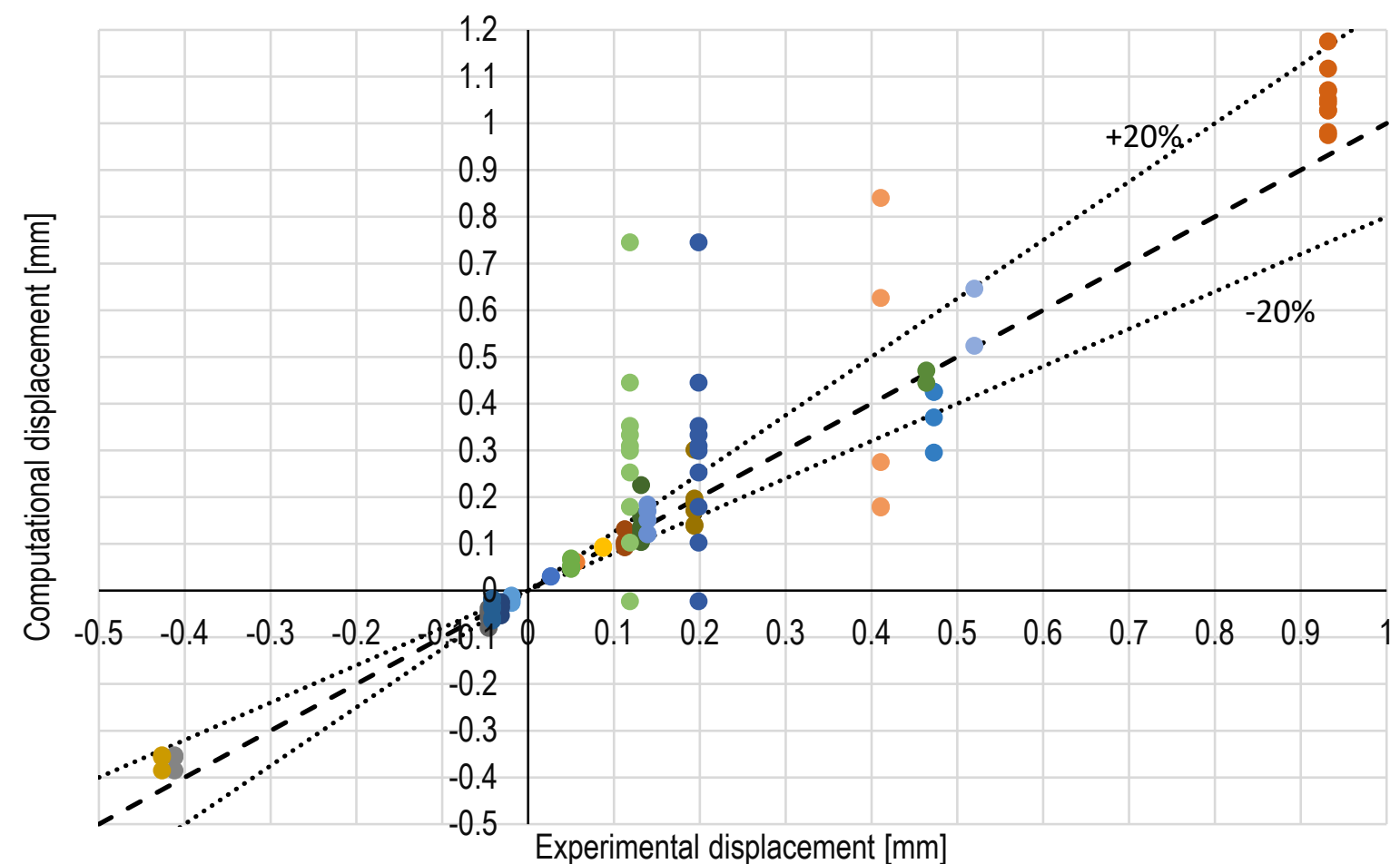

-\#5, plate midspan, bars and tabs clamped, load $69 \mathrm{kPa}$

- \#5, plate midspan, bars and tabs clamped, load $138 \mathrm{kPa}$

-\#2, plate midspan, bars and tabs clamped, load $207 \mathrm{kPa}$

- \#5, plate midspan, bars and tabs clamped, load 207kPa

-\#2, plate midspan, $1 / 4$ in tabs clamped, load $69 \mathrm{kPa}$

- \#5, plate midspan, 1/4in tabs clamped, load 69kPa

- \#2, plate midspan, $1 / 4 \mathrm{in}$ tabs clamped, load $138 \mathrm{kPa}$

-\#5, plate midspan, 1/4in tabs clamped, load $138 \mathrm{kPa}$

-\#2, plate midspan, 1/4in tabs clamped, load $207 \mathrm{kPa}$

-\#5, plate midspan, $1 / 4 \mathrm{in}$ tabs clamped, load $207 \mathrm{kPa}$

- \#2, plate midspan, $1 / 8$ in tabs clamped, load $138 \mathrm{kPa}$

-\#5, plate midspan, $1 / 8$ in tabs clamped, load $138 \mathrm{kPa}$

-\#5, plate midspan, every other $1 / 4$ in tab clamped, load $138 \mathrm{kPa}$

\#5, plate midspan, every other $1 / 4$ in tab clamped, load $207 \mathrm{kPa}$

\#4, plate end1, Invar base, load 477K

- \#4, plate end2, Invar base, load 477K

- \#4, plate midspan, Invar base, load 477K

-\#4, plate end1, split Invar base, load 477K

-\#4, plate end2, split Invar base, load 477K

- \#4, plate midspan, split Invar base, load 477K

-\#4, plate midspan, Monel base, load 477K

- \#4, plate midspan, Monel base, load 477K, 207kPa

Figure 7.39 Comparison of computational and experimental displacements under a range of pressure and temperature loads and with varying boundary conditions and material models 


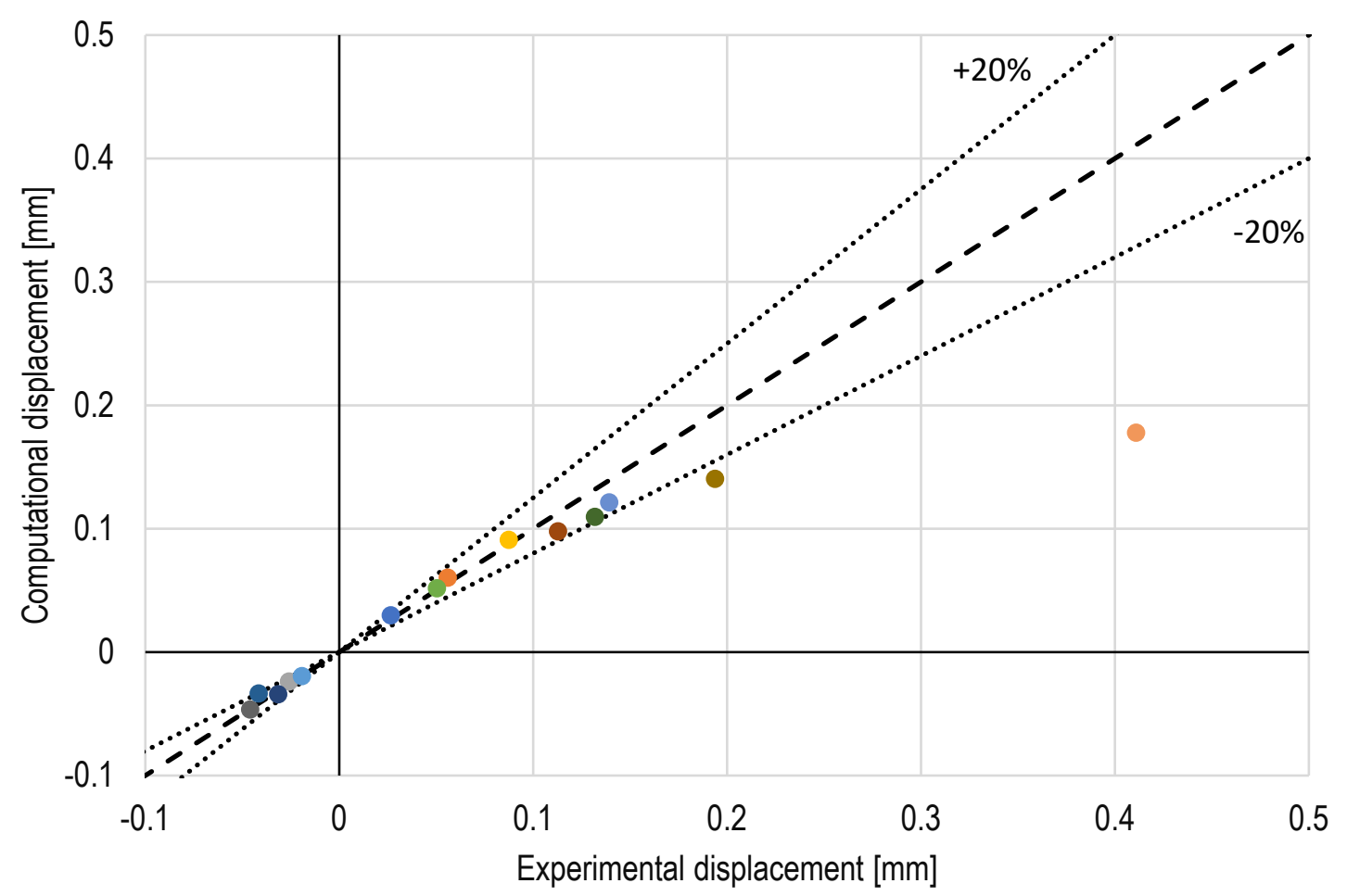

- \#5, plate midspan, bars and tabs clamped, load $69 \mathrm{kPa}$

-\#5, plate midspan, bars and tabs clamped, load $138 \mathrm{kPa}$

-\#2, plate midspan, bars and tabs clamped, load $207 \mathrm{kPa}$

-\#5, plate midspan, bars and tabs clamped, load $207 \mathrm{kPa}$

-\#2, plate midspan, 1/4in tabs clamped, load 69kPa

-\#5, plate midspan, 1/4in tabs clamped, load 69kPa

-\#2, plate midspan, 1/4in tabs clamped, load $138 \mathrm{kPa}$

-\#5, plate midspan, 1/4in tabs clamped, load $138 \mathrm{kPa}$

-\#2, plate midspan, 1/4in tabs clamped, load 207kPa

-\#5, plate midspan, 1/4in tabs clamped, load 207kPa

-\#2, plate midspan, $1 / 8$ in tabs clamped, load $138 \mathrm{kPa}$

-\#5, plate midspan, $1 / 8$ in tabs clamped, load $138 \mathrm{kPa}$

-\#5, plate midspan, every other $1 / 4$ in tab clamped, load $138 \mathrm{kPa}$

\#5, plate midspan, every other $1 / 4$ in tab clamped, load $207 \mathrm{kPa}$

Figure 7.40 The best fit of the computational results to the experimental data points obtained with the model of a plate in contact with rigid planes for test cases with pressure load and elastic material model. 


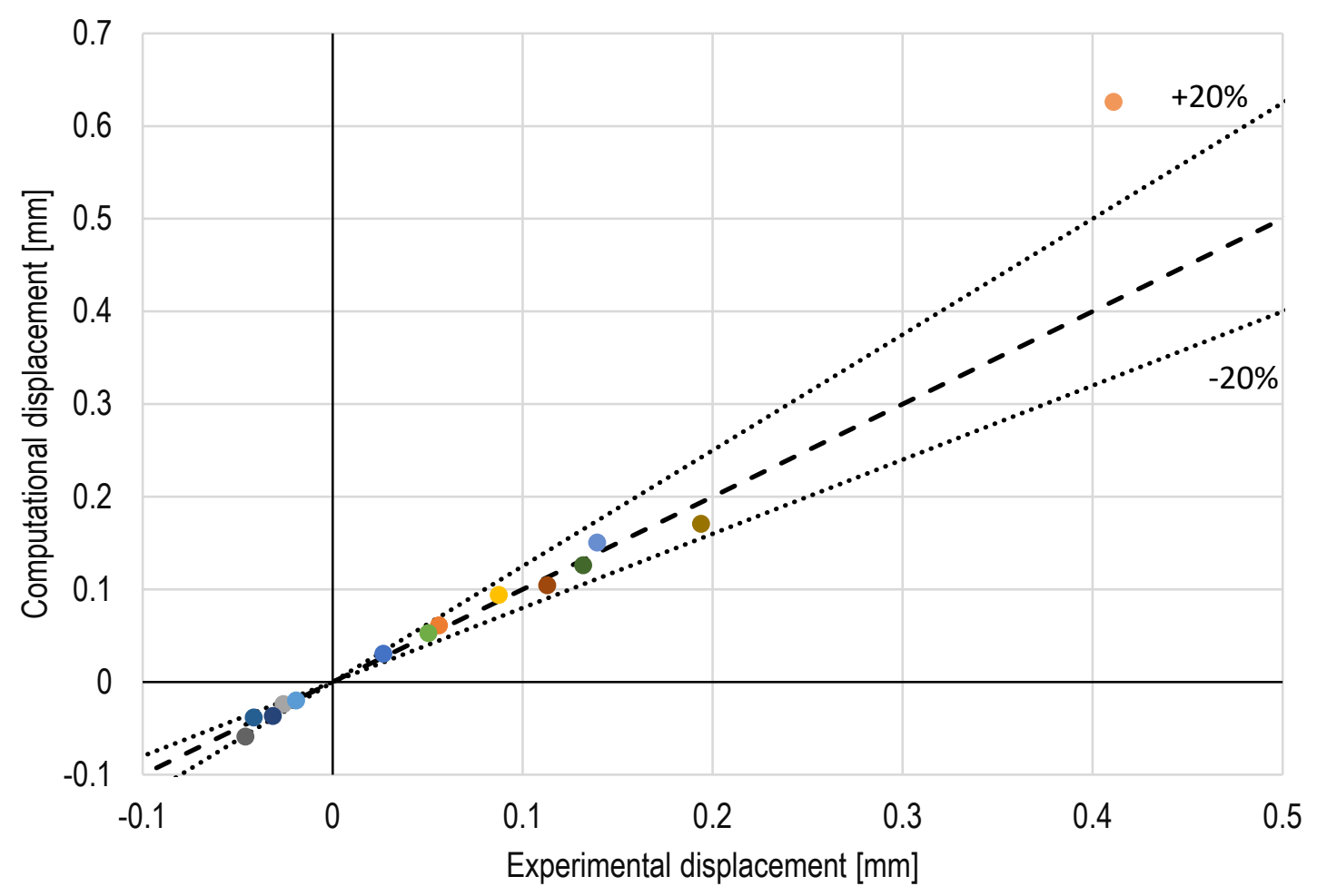

- \#5, plate midspan, bars and tabs clamped, load $69 \mathrm{kPa}$

- \#5, plate midspan, bars and tabs clamped, load $138 \mathrm{kPa}$

- \#2, plate midspan, bars and tabs clamped, load 207kPa

- \#5, plate midspan, bars and tabs clamped, load 207kPa

-\#2, plate midspan, 1/4in tabs clamped, load $69 \mathrm{kPa}$

- \#5, plate midspan, 1/4in tabs clamped, load $69 \mathrm{kPa}$

-\#2, plate midspan, 1/4in tabs clamped, load $138 \mathrm{kPa}$

-\#5, plate midspan, $1 / 4$ in tabs clamped, load $138 \mathrm{kPa}$

-\#2, plate midspan, 1/4in tabs clamped, load 207kPa

-\#5, plate midspan, 1/4in tabs clamped, load $207 \mathrm{kPa}$

-\#2, plate midspan, 1/8in tabs clamped, load $138 \mathrm{kPa}$

-\#5, plate midspan, 1/8in tabs clamped, load 138kPa

- \#5, plate midspan, every other $1 / 4$ in tab clamped, load $138 \mathrm{kPa}$

- \#5, plate midspan, every other $1 / 4$ in tab clamped, load $207 \mathrm{kPa}$

Figure 7.41 The best fit of the computational results to the experimental data points obtained with the model of a plate in contact with rigid planes for test cases with pressure load and elastoplastic material model. 


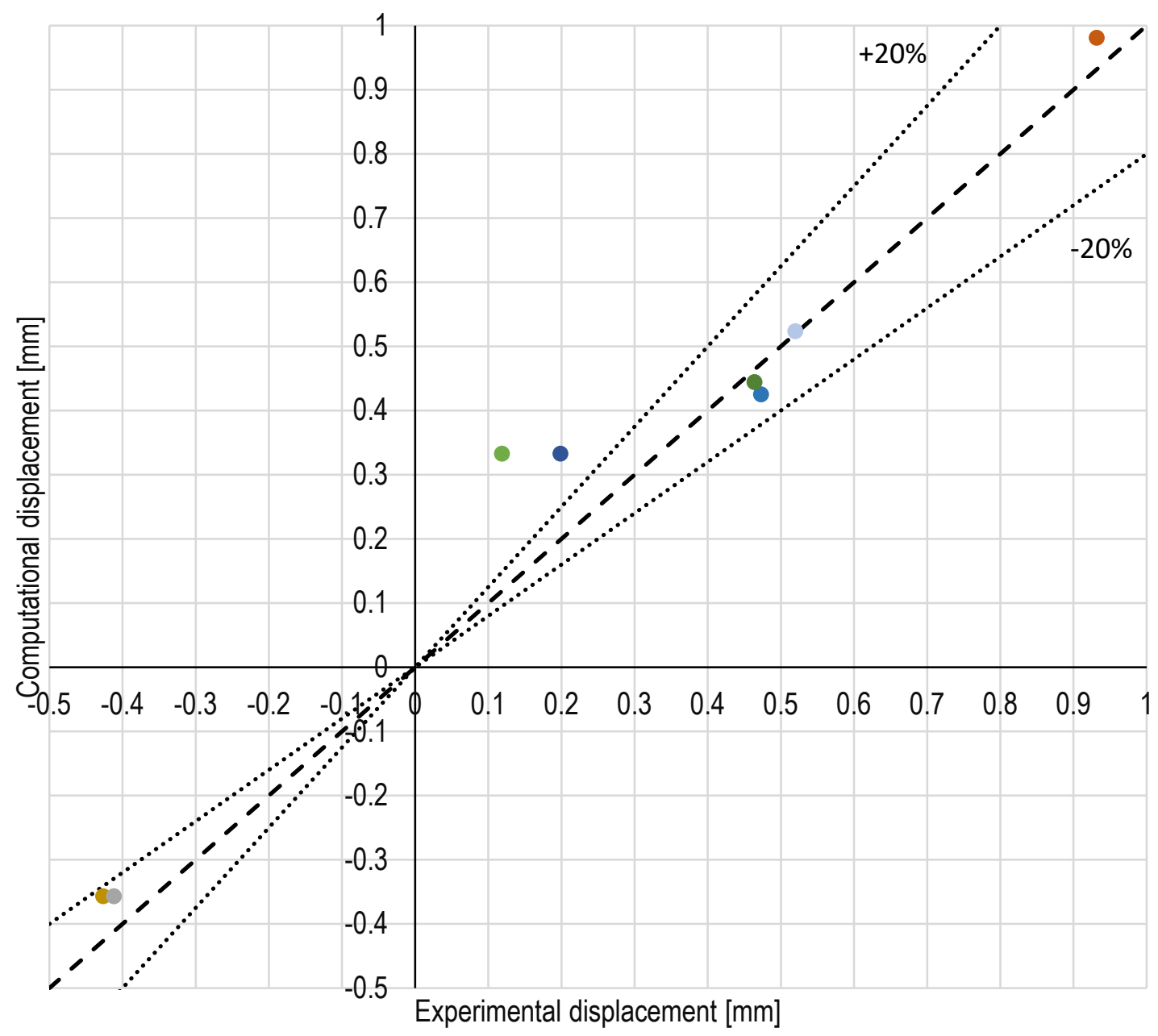

-\#4, plate end1, Invar base, load 477K

-\#4, plate end2, Invar base, load 477K

-\#4, plate midspan, Invar base, load 477K

-\#4, plate end1, split Invar base, load 477K

-\#4, plate end2, split Invar base, load 477K

-\#4, plate midspan, split Invar base, load 477K

-\#4, plate midspan, Monel base, load 477K

\#4, plate midspan, Monel base, load 477K, 207kPa

Figure 7.42 The best fit of the computational results to the experimental data points obtained with the model of a plate clamped in a base for test cases with temperature load and a combination of pressure and temperature load, and elastic material model. 


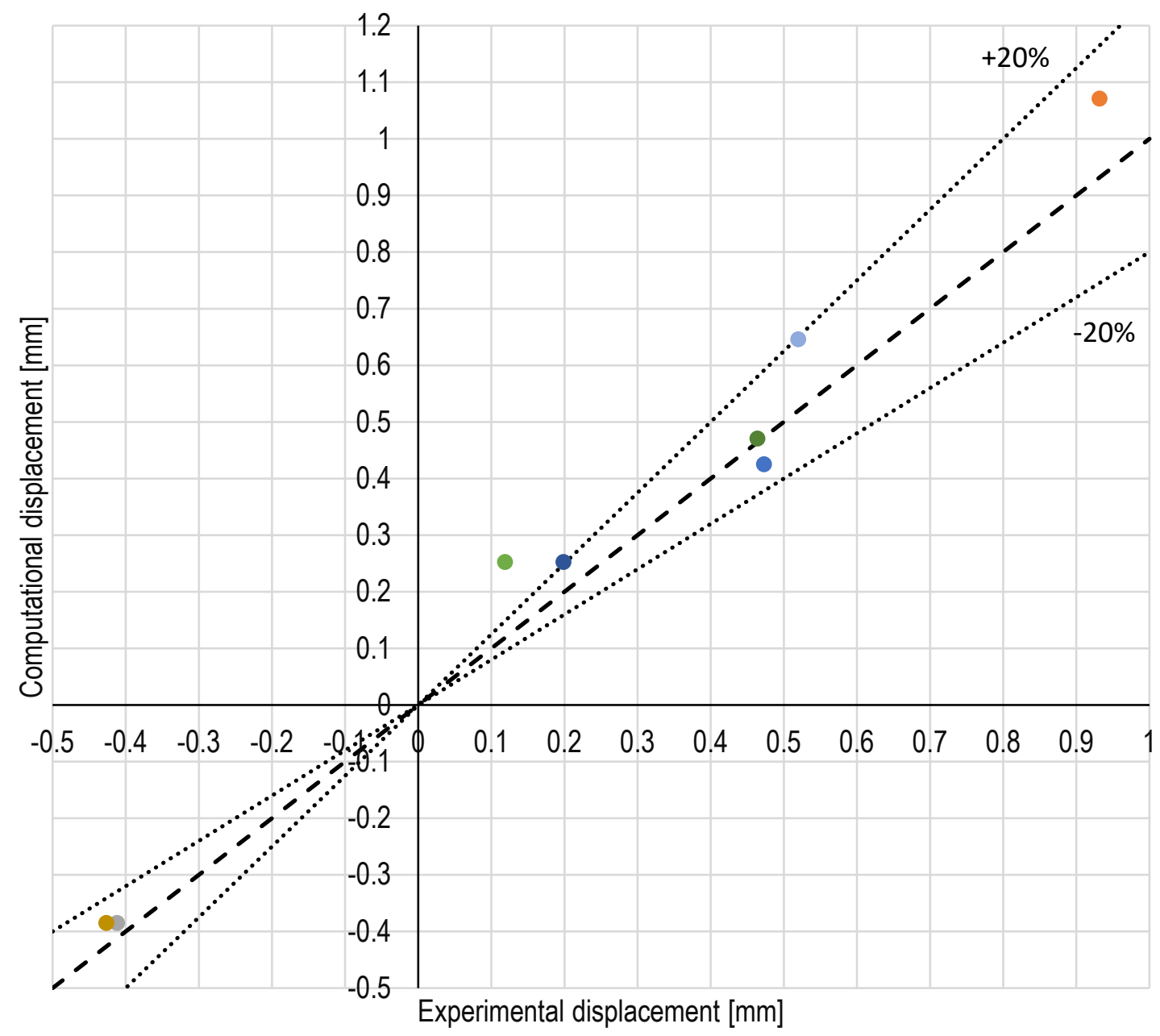

-\#4, plate end1, Invar base, load 477K

-\#4, plate end2, Invar base, load 477K

-\#4, plate midspan, Invar base, load 477K

-\#4, plate end1, split Invar base, load 477K

-\#4, plate end2, split Invar base, load 477K

-\#4, plate midspan, split Invar base, load 477K

-\#4, plate midspan, Monel base, load 477K

\#4, plate midspan, Monel base, load 477K, 207kPa

Figure 7.43 The best fit of the computational results to the experimental data points obtained with the model of a plate clamped in a base for test cases with temperature load and a combination of pressure and temperature load, and elastoplastic material model. 


\section{Conclusions}

Conversion of research reactors from Highly Enriched Uranium to high density, Low Enriched Uranium fuel is an ongoing effort for the operators of the three involute research reactors HFIR (USA), RHF (France), and FRM II (Germany). The researchers from these institutions as well as Argonne National Laboratory formed the Involute Working Group (IWG) that focuses on the conversion analysis. Group's activities include benchmarking, code verification and validation based on comparisons with experiments as well as with equivalent computational tools.

These reactors characterize with fuel elements that have an annular shape, and fuel plates, curved as a circle involute (a spiral generated around a circle) are attached to two concentric side-plates. The plates are installed in vertical grooves machined in the side-plates and are welded at multiple points along the axis. The space between two neighboring fuel plates is filled with coolant that flows at high speeds to evacuate the heat generated by nuclear reactions.

Assessing the mechanical integrity of the LEU fuel plates is part of the conversion analysis scope. The initial analysis is based on computational simulations with the use of available software. One of the IWG tasks is to evaluate the suitability of the commercial CFD/FEM code STAR-CCM+ as a scientific computational tool to simulate the deflections of LEU fuel plates under representative operational loads. To perform such analysis, the computational models offered by the code need to be verified and validated.

Simcenter STAR-CCM+ is a multiphysics commercial Computer Aided Engineering (CAE) software developed for solving multidisciplinary and multiphysics problems in both fluid and solid continuum mechanics with a single integrated user interface. STAR-CCM+ is compliant with the ASME Nuclear Quality Assurance-1 (NQA-1).

STAR-CCM+ Verification Suite is a compilation of test cases which allow for an assessment of the computational solution correctness based on a comparison with analytical solutions. Two cases offered in the Suite that test the solid stress solver were simulated with the use of STAR-CCM+2020.2 version, and both provide satisfactory results.

The experiment selected for validation was performed by R. D. Cheverton and W. H. Kelley on models of the HFIR reactor plates. It is particularly well suited for the involute reactors as it was designed to study the deflections of the HFIR plates under pressure and thermal loads that cover the range of nominal conditions of operation of the involute reactors. The experiments were conducted in such a way, as to analyze the separate effects of multiple physical phenomena, as well as of their combinations. They performed a series of tests with simplified, uniformly distributed pressure differential loads up to $207 \mathrm{kPa}$ (30 psi), thermal loads up to $600^{\circ} \mathrm{F}(589 \mathrm{~K})$, and their combinations. The researchers stated in their report that the plate was subjected to pressures three times greater, and temperature $200^{\circ} \mathrm{F}$ higher $(111 \mathrm{~K})$, than the ones occurring in HFIR operating conditions. Freedom of movement in the radial direction of the edges of the plate is a part of HFIR design. Because the actual degree of edge restraint in the HFIR core was unknown, various models of the edge restraints, that could represent the actual conditions, were proposed, and tested. They include installing the plate in a solid and split base made of materials with different thermal coefficients, which allows for a varying degree of deformation along the involute arch length. The spot weld attachment on the long edge of the plate was modeled by an addition of 24 tabs on each side that were constrained in the base. This setup made it possible to assess the effect of missing welds or failed welds.

Involute Working Group - Development and Validation of the Finite Element Models of the Cheverton-Kelley Experiments 
The analysis of the experimental measurements of the maximum deflections under the tested range of pressure and temperature loads shows that for the majority of cases they range from $0.2 \mathrm{~mm}$ to 0.5 $\mathrm{mm}$, but they may reach up to $0.94 \mathrm{~mm}$, depending on the side edge constraints, with smaller deflections obtained for plates with less side constraint, and greater deflections for plates fixed on the sides.

A sensitivity study was performed for a set of simulation input parameters, such as: finite element formulation, mesh density, material model, thermal load model, and boundary conditions. Hexahedral Hex8 and Hex20 finite element formulations were considered in the mesh sensitivity study. Hexahedral elements with linear shape functions, Hex8, are enriched with internal degrees of freedom, which overcome locking, and are more accurate than the other linear element types. This type of finite element is recommended by the Manual for problems of thin structures in bending. Hexahedral elements with mid-side nodes and quadratic shape functions, Hex20, tend to have better accuracy but at a cost of more memory and operations. The triangular finite elements were omitted, as according to the documentation they may cause locking, as well as because the user has less control over the meshing process, which may lead to a prohibitively large number of cells or the mesher can create pyramid elements that can cause locking. The geometry of the plate is such that it can be represented well with hexahedrons with a few layers of finite elements across the thickness. The mesh was created with the use of Directed Mesher, which is the only approach available in STAR$\mathrm{CCM}+$ that gives full control over the number of elements, and therefore their size, along the model edges. The discretization selected in the process for the involute consists of Hex8 finite elements, with 384 finite elements along the length of the involute, 200 finite elements across the plate and four finite elements in the thickness direction. Four finite elements were used along the width of the groove-wide side strips, and eight by four elements were used to represent the geometry of the tabs.

Two types of static mechanical loads were tested in the experiments by Cheverton and Kelley: pressure and temperature. The pressure load was modeled as a distributed load applied to the surfaces of the finite elements. The thermal load was modeled using the Specified Temperature Load solver.

Two geometries of the experimental assembly were developed, a model of an involute plate only, with displacements constrained on the surfaces, and a plate with a base. The model of the single plate was proposed as a simplification of the real conditions to save on computational time and resources when running the case matrix. The geometry of the base was not included in the model and the constraints applied to the involute plate were represented with displacement boundary conditions: fixed, normal displacements equal zero, or frictionless contact with a rigid plane. A series of simulations was performed for varying loads: pressure, or temperature, using the models with different boundary conditions. The analysis of results showed that the model with a rigid base gives the best results in the test cases where the deformation of the base is negligible.

In the cases with thermal loads where the thermal expansion of the base is significant and it affects the deflections of the plate, the full model of a plate in a base is recommended. This model consists of several parts: the involute plate, the base and end plates. Two types of contact models were tested, bonded and small sliding frictionless. The model is more complex, and the discretization consists of many more finite elements. The details of the geometry of the base were not known to the authors, it was recreated from the photographs and one standard drawing. Nevertheless, the results are in reasonable agreement with the experiments.

Involute Working Group - Development and Validation of the Finite Element Models of the Cheverton-Kelley Experiments 
The analysis of results with various side boundary conditions also showed that the deflection of the plate ends is very sensitive to the type of boundary conditions. On the other hand, the midspan deflections, which are greater than the end deflections, do not show this kind of behavior.

The tests were performed on pure aluminum plates, with elastic and elastoplastic material properties. The material characteristics were not reported by Cheverton and Kelley, so the modeling of the material was based on data found in literature. This uncertainty of input was accounted for in the study by performing a set of computations with varying elastic modulus and Poisson's ratio. The variation in the resulting plate deflections was deemed insignificant in the range of interest. The experimentalists reported that in some tests, plastic flow occurred. For this reason, the computational simulations were performed not only using a linear elastic material model, but also an elastoplastic model with the stress-strain relationship derived experimentally [20], which was tabularized and implemented to the software as a user-defined plasticity. The post-processing showed that for relatively small plastic deformations, this approach resulted in a good accuracy of results. When the deformations were greater, the computational model overestimated the experimental results.

Computational simulations of varying level of complexity were developed, that can represent the experimental conditions. The numerical results are in good agreement, both qualitatively and quantitatively, with the experimental measurements by Cheverton and Kelley, and with the computational results obtained with an equivalent software, COMSOL. 


\section{References}

1. Oak Ridge National Laboratory, "High Flux Isotope Reactor", https://neutrons.ornl.gov/hfir last accessed July 23, 2018.

2. Institut Laue-Langevin, "The ILL High-Flux reactor", https://www.ill.eu/reactor-andsafety/high-flux-reactor/, last accessed July 23, 2018.

3. Technical University of Munich, "Research Neutron Source Heinz Maier-Leibnitz (FRM II)", https://www.frm2.tum.de/en/home/, last accessed July 23, 2018.

4. Simcenter STAR-CCM+ Documentation, https://documentation.thesteveportal.plm.automation.siemens.com/starccmplus latest en /index.html?param=JzdGX\&authLoc=https://thesteveportal.plm.automation.siemens.com/ AuthoriseRedirect, last accessed September 2020.

5. R. D. Cheverton, W. H. Kelley, "Experimental Investigation of HFIR Fuel Plate Deflections Induced by Temperature and Pressure Differentials", ORNL-TM-2325, 1968.

6. C. Bojanowski, A. Bergeron, J. Licht, "Involute Working Group - Validation of CFD Turbulence Models for Steady-State Safety Analysis", ANL/RTR/TM-19/5, 2020.

7. A. Bergeron, "Review of the Oak Ridge National Laboratory (ORNL) Neutronic Calculations Regarding the Conversion of the High Flux Isotope Reactor (HFIR) to the Use of Low Enriched Uranium (LEU) Fuel", ANL/RERTR/TM-12/49, Argonne National Laboratory, 2012.

8. A. Bergeron, "Neutronic Conversion Analyses of the Laue-Langevin Institute (ILL) High Flux Reactor (RHF)", ANL/GTRI/TM-14/15, Argonne National Laboratory, 2014.

9. A. Rohrmoser, "Core Model of New german Neutron Source FRM II", Nuclear Engineering and design 240 pp. 1417-1432, 2010.

10. Reduced Enrichment for Research and Test Reactor, "International Meeting on Reduced Enrichment for Research and Test Reactors", last accessed October 29, 2019.

11. C. Bojanowski et al., "Experimental Validation of CFD Turbulent Models Relevant for InvolutePlate Reactors", RERTR 2018, 39th International Meeting on Reduced Enrichment for Research and Test Reactors. Edinburgh, Scotland, Nov. 4-7, 2018.

12. A. Bergeron et al., "Involute Working Group - Progress towards Validation of CFD for InvolutePlate Reactors Safety Analysis", RERTR 2019, 40"th International Meeting on Reduced Enrichment for Research and Test Reactors. Zagreb, Croatia, Oct. 6-10, 2019.

13. Nuclear Quality Assurance (NQA-1) Certification, https://www.asme.org/certificationaccreditation/nuclear-quality-assurance-nqa1-certification, last accessed August 2020.

14. US Nuclear Regulatory Commission, 10CFR21 https://www.nrc.gov/reading-rm/doccollections/cfr/part021/, last accessed August 2020.

15. US Nuclear Regulatory Commission, https://www.nrc.gov/reactors/newreactors/oversight/quality-assurance/vendor-insp/comm-grade-dedication.html, last accessed September 2020

16. A. Tentner, et al. "Evaluation of Thin Plate Hydrodynamic Stability through a Combined Numerical Modeling and Experimental Effort", ANL/RTR/TM-16/9, 2017.

17. P. K. Jain, J. D. Freels, D. H. Cook, "3D COMSOL Simulations for Thermal Deflection of HFIR Fuel Plate in the "Cheverton-Kelley" Experiments", ORNL/TM-2012/138, 2012.

18. O.C. Zienkiewicz, R.I. Taylor, J.Z. Zhu., "The Finite Element Method: Its Basis and Fundamentals, 7th Edition", Hardcover ISBN: 9781856176330, eBook ISBN: 9780080951355, ButterworthHeinemann, 2013.

19. "Standard Specification for Aluminum and Aluminum-Alloy Sheet and Plate, ASTM B209-14", https://www.astm.org/Standards/B209.htm, last accessed July 2020.

20. W. R. Martin, J. R. Weir, "Mechanical Properties of X8CO1 and 6061 Aluminum Alloys and Aluminum-Base Fuel Dispersion at Elevated Temperatures”, ORNL-3557, 1964.

Involute Working Group - Development and Validation of the Finite Element Models of the Cheverton-Kelley Experiments 
21. "Qualification of scientific computing tools used in the nuclear safety case - $1^{\text {st }}$ barrier", ASN Guide 28, Authorite de Surete Nucleaire, 2017.

22. S. P. Timoshenko, J. N. Goodier, "Theory of Elasticity, 3rd Ed.”, McGraw-Hill, 1982.

23. R.H. MacNeal., "Finite elements: their design and performance”, ISBN 0-8247-9162-2, Marcel Dekker, Inc., 1994.

24. "MatWeb - Material Property Data".

http://asm.matweb.com/search/SpecificMaterial.asp?bassnum=MA60610, last accessed July 2020. 


\section{Acknowledgements}

This work was sponsored by the U.S. Department of Energy, Office of Material Management and Minimization in the U.S. National Nuclear Security Administration Office of Defense Nuclear Nonproliferation under Contract DE-AC02-06CH11357.

The authors would like to thank the ORNL staff involved in the Cheverton \& Kelley experiment COMSOL modeling as their foundational work helped guide the analysis discussed herein. 


\section{Appendix A: Computational Tools}

\section{A.1 Computational Software Evaluation}

The study presented in this technical report aims to tackle the problem of verification and validation of the selected models available in the commercial software Simcenter STAR-CCM+ v.2020.2. Although not exhaustive, the analysis follows the recommendations provided by the guide prepared by the French Safety Authority (ASN), regulator of the RHF reactor, which describes guidelines of the steps that should be followed before a scientific computational tool can be declared as qualified [21]. The qualification of the software implies that it can provide results that are usable for a nuclear safety case, based on the data produced by verification, validation, quantification of uncertainties and transposition operations. These steps are as follows:

1. Define the intended scope of utilization.

2. Perform verification and validation.

3. Perform transposition of the validation cases to the intended scope of utilization.

The intended scope of utilization is defined as all scenarios that the software will be used for. Firstly, this step involves defining the variables of interest. Secondly, the physical phenomena which influence these variables of interest are identified, and ranked in order of importance, starting with the most important and ending with the least important. Next, the simulation input parameters which influence the physical phenomena are identified and ranked in order of importance, starting with the most important and ending with the least important. Finally, the variation range of the most influential variables of interest is determined, which enables to specify the utilization range.

The verification and validation procedures are performed with the goal to assess if the software is capable to correctly represent the physical phenomena that it intends to model.

Verification is a formal process to determine whether the equations are solved correctly. It covers the numerical methods and algorithms, as well as their implementation. In the case of coupled software, the link between them is also covered. If the software is used on a different IT platform than that used for verification, the influence of this change on the verification should be assessed.

Validation consists of ensuring that the computational tool can represent the physical phenomena in a way that fulfills the expectations within the validation range, i.e. within the variation range for the characteristic geometrical or physical variables for which the results are considered acceptable. Preferably, the validation follows a two-step process to minimize the error compensation, which starts with an analysis of the separate effects of the modeled physical phenomena and is followed by an integral validation that enables the analysis of all physical phenomena and their interactions. The validation is based on comparing the computational results with experimental measurements, results from reference computing tools or analytical solutions. If this process cannot be followed, it is recommended to choose the following approach instead: identify the models concerned, establish the sensitivity of the computational result to these models, and reassess the uncertainties taking into account the gaps in the validation or evaluate a penalty to be applied in the methods to cover these gaps.

The justification of the applicability of the validation cases should be provided. It consists of a description of the studied physical phenomena and measured variables, together with their variation

Involute Working Group - Development and Validation of the Finite Element Models of the Cheverton-Kelley Experiments 
range, instrumentation used and the uncertainty of the measurements; a description of the cases with separate effects and integral, their goals, the analysis and interpretation of the results; assessment of the variation range of the influential parameters.

In the case of a lack of experimental data, alternative approaches may be taken. The validation can be carried out based on comparisons with computational results obtained with a reference scientific computational tool, or cross-evaluation with other equivalent software.

It is recommended that the choices of the physical models, mesh, temporal discretization, numerical schemes, convergence criteria etc. are consistent between the simulations. Adjustments of modeling parameters to minimize the difference between the computed and reference values is acceptable if they are explained and justified.

The various uncertainties resulting from the validation of separate effects and integral should be evaluated. An uncertainty is defined as a range of variation in the result of a measurement or calculation which characterizes the possible values and probably contains the real value of the response. The adopted quantification methods should be described and justified. If it is difficult to determine the uncertainties, the method of adopting the conservative approach can be used, in which the applied conservative hypothesis results in conservative values of the variables of interest.

Transposition of the validation cases to the intended scope of utilization is a means to assess how the conclusions of the validation analysis apply to the intended scope of utilization. Firstly, the geometrical, e.g. scale effect, and physical differences between the validation cases and the scope of utilization are identified. The influence of the differences on the solution is evaluated within the validation range. Next, if there is a significant difference in the validation range and the utilization range, the predictive ability of the models must be evaluated.

The qualification of the scientific computational tool is declared when it can calculate the variables of interest for the intended scope of utilization with uncertainty values adapted to the specific needs and the utilization range is within the validity range.

\section{A.2 STAR-CCM+ History and Pedigree}

STAR-CCM+ has been developed from early 2000's by CD-Adapco, a US based company that was in 2016 purchased by the company Siemens. STAR-CCM+ was completely rewritten based on its predecessor STAR-CD to modernize the user interface and simplify the interaction of the user with the solver. After the purchase of CD-Adapco by Siemens in 2016, STAR-CCM+ has been integrated with the Siemens family of CAE products including NX, the CAD software Solid Edge, the optimization tool HEEDS and others. STAR-CAD tools allow for performing CFD analysis from other commercial CAD environment like Catia, PTC Creo, SolidWorks or NX.

\section{A.3 NQA-1 Certification}

STAR-CCM+ has been present in the nuclear engineering field with US National Laboratories and many commercial vendors employing it for fuel assembly analysis. STAR-CCM+ has been developed under ASME Nuclear Quality Assurance-1 (NQA-1) compliance since July 2017 [4]. The NQA-1 is a certification of the quality assurance program for organizations that supply items or services that provide a safety function for nuclear facilities in conformance with the requirements of the ASME NQA-1 standard [13]. It can be leveraged to support safety related calculations under the U.S. Nuclear Regulatory Commission Regulations Title 10, part 21-Reporting of Defects and Noncompliance

Involute Working Group - Development and Validation of the Finite Element Models of the Cheverton-Kelley Experiments 
(10CFR21) requirements [14] through NQA-1 error reporting on the support portal. With each code release SIEMENS releases a verification routine that includes test cases that can be used for installation verification. In particular, a number of the test cases are marked as "CGD" as they were part of the commercial grade dedication process of older STAR-CCM+ versions. Commercial-grade dedication is "a process by which a commercial-grade item (CGI) is designated for use as a basic component. This acceptance process is undertaken to provide reasonable assurance that a CGI to be used as a basic component will perform its intended safety function and, in this respect, is deemed equivalent to an item designed and manufactured under a 10 CFR Part 50, Appendix B, quality assurance program." [15].

\section{A.4 Theoretical Basis}

STAR-CCM+ models a range of physics phenomena including fluid mechanics, solid mechanics, heat transfer, electromagnetism, and chemical reactions. The description of the laws of physics for these space-dependent and time-dependent problems are usually expressed in terms of partial differential equations (PDEs). For example, conservation laws such as the law of conservation of energy, conservation of mass, and conservation of momentum can all be expressed as PDEs. Constitutive relations may also be used to express these laws in terms of variables like temperature, density, velocity, electric potential, and other dependent variables.

The conservation laws for a continuum can be expressed using a Eulerian approach or a Lagrangian approach. In the Eulerian approach, a given volume represents a portion of space where material can flow through. In the Lagrangian approach, a given volume represents a portion of material in the body, so that an observer follows the material as it moves through space. For most problems, PDEs cannot be solved with analytical methods. Instead, an approximation of the equations can be constructed, typically based upon different types of discretization. Discretization methods, such as the finite volume (FV), finite element (FE), and finite difference (FD) methods, approximate the PDEs with numerical model equations, which can be solved using numerical methods. The finite volume method, which is based on the Eulerian approach of continuum description, is used to solve these approximations in STAR-CCM+ for mass and heat transfer. Finite element method, which is based on the Lagrangian approach, is used to solve for structural response of deforming solids. For details of implementation of these methods in STAR-CCM+ refer to the User's Manual [4].

\section{A.5 Capabilities and Limitations}

A short description of the capabilities and limitations of STAR-CCM+ 2020.2 is as follows:

\section{Capabilities}

STAR-CCM+ is a CFD-focused multiphysics code, used by many industries. Structural analysis makes use of a relatively small fraction of the overall modeling capabilities available inside the code, including:

1. Solid stress solver to analyze the response of deformable bodies under external loads of various types with the use of the finite element method.

2. Heat transfer in solids.

3. User-defined relationships for temperature-dependence of thermo-physical properties, including density, thermal conductivity, viscosity, and specific heat.

4. User-defined relationships for temperature-dependence of mechanical properties, such as modulus of elasticity. 
5. User-defined relationships for elastoplastic material behavior.

6. Mesh topologies including mixture of polyhedral, hexahedral, prisms and pyramids.

7. Availability of standard displacement and load boundary conditions.

8. User coding functionality for specification of detailed boundary conditions, initial conditions, source terms, and advanced pre- and post-processing.

There are multiple other modeling capabilities in STAR-CCM+ that are not used in structural analysis problems. A complete list of capabilities is available in the software documentation [4].

\section{Limitations}

The finite element solver has been introduced relatively recently and is currently being developed and improved. The displacement and load boundary conditions are applied to the geometry of the model with the use of region-based line or surface segments. This approach makes it difficult in some cases to model the desired constraints. A penalty-based contact of a deformable body with a rigid plane is available. The model is pressure based and it does not include traction, i.e. it is frictionless. The software supports only two types of contact between deformable bodies: bonded and small sliding frictionless which is insufficient in many structural mechanics applications. The small sliding frictionless option is intended only for flat interfaces and when the relative displacement is smaller than the mesh element length. Using the feature with curved surfaces or sliding that exceeds the finite element size is believed to lead to inaccurate results [4].

\section{A.6 Verification of the Code}

The verification approach proposed by the developers of STAR-CCM+ is to run a set of test cases from the Verification Suite [4]. The Verification Suite provides cases that come from the Siemens Digital Industries Software quality-assurance process. This process includes an internal test system that is known as STAR-Test, which is used continuously for the development and release builds of the software. The Verification Suite covers a wide variety of test cases, such as: aeroacoustics, flow and energy, time, radiation, combustion, Lagrangian multiphase, multiphase, multiphase VOF, solid stress, finite element solid stress, electromagnetism, compressible flow, turbulence. In this technical report, only those pertinent to the Finite Element Solid Stress Solver are presented in Table A.1.

The Simcenter STAR-CCM+ Verification Suite is in the process of an upgrade to include the NQA-1 Commercial Grade Dedication (CGD). This upgrade involves reviewing, and modifying as needed, automated tests from their existing academic orientation to more exacting safety standards for potential energy applications. The cases that have been upgraded have a "(CGD)" at the end of their documentation titles.

Table A.1 List of STAR-CCM+ software capabilities and relevant verification approach

\begin{tabular}{|l|l|l|l|}
\hline $\begin{array}{l}\text { SM-1 } \\
\text { (CGD) }\end{array}$ & $\begin{array}{l}\text { Bending of a Cantilever Beam } \\
\text { This is a basic structural capability } \\
\text { used to predict deformations of } \\
\text { solids due to external load }\end{array}$ & $\begin{array}{l}\text { The results of the simulation are } \\
\text { compared with analytical solution } \\
\text { presented in reference [9]. }\end{array}$ & $\begin{array}{l}\text { SM- } \\
\text { 1_Bending_Of_Cantilever_B } \\
\text { eam.sim }\end{array}$ \\
\hline SD-2 & $\begin{array}{l}\text { 3Dis capability is used to predict } \\
\text { Teformations of thin 3D structures } \\
\text { (like fuel plates) due to external } \\
\text { loads }\end{array}$ & $\begin{array}{l}\text { Verification test problems are } \\
\text { compared with NAFEMS benchmark } \\
\text { collections [10]. }\end{array}$ & $\begin{array}{l}\text { SM- } \\
\text { 2_Shell_Deformation.sim }\end{array}$ \\
\hline
\end{tabular}

Involute Working Group - Development and Validation of the Finite Element Models of the Cheverton-Kelley Experiments 


\section{SM-1 Finite Element Bending of a Cantilever Beam}

Problem description: This case is a validation of the exact Timoshenko solution of bending of a cantilever under plane strain conditions [22]. This simulation calculates displacements and stresses in a cantilevered rectangular beam that is subjected to pressure loads. The beam is loaded with a parabolic shear stress using the continuous option for the traction load on the right end face. The constraints on the left end of the beam are based on the exact solution, which allows for some rotation of the beam. The edges of the beam cross-section are not aligned with the laboratory coordinate system but are at $45^{\circ}$ angle as shown in the following diagram. In this coordinate system, the loaded end is at $\mathrm{x}=0 \mathrm{~m}$ and the free end is at $\mathrm{x}=30 \mathrm{~m}$. The beam thickness is $1.0 \mathrm{~m}$.
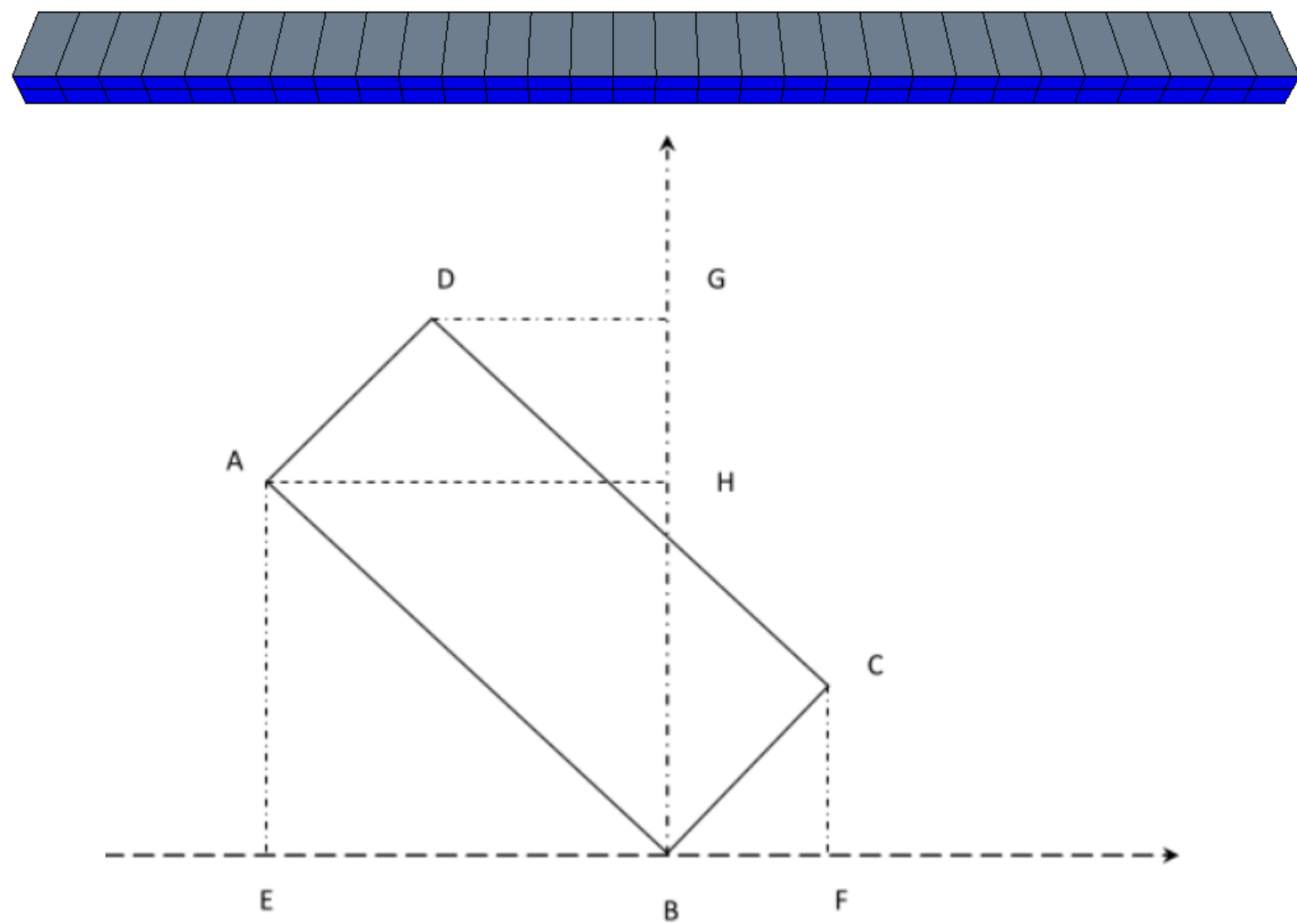

Figure. Geometry description for case SM-1

\section{Geometry:}

The cross section is defined as follows:

- $\mathrm{AB}=2.0, \mathrm{BC}=1.0$

- $\quad \mathrm{BE}=\mathrm{AB} \cos (45 \mathrm{deg})=1.414213$

- $\mathrm{BF}=\mathrm{BC} \cos (45 \mathrm{deg})=0.707107$

- $\mathrm{BH}=\mathrm{AB} \cos (45 \mathrm{deg})=1.414213$

- $\mathrm{GH}=\mathrm{AD} \cos (45 \mathrm{deg})=0.707107$

Physics Models:

*Linear Isotropic Elastic

*Solid

*Solid Stress

\section{Material properties:}

Linear elastic isotropic material model with

- Young's modulus $=9 \times 10^{5} \mathrm{MPa}$

- Poisson's ratio $=0.3$

- $\quad$ Density $=2702 \mathrm{~kg} / \mathrm{m}^{3}$

\section{Boundary Conditions:}

- $x=30 \mathrm{~m}$ displacement defined by following components: 
*Steady

*Three Dimensional

Finite Element Formulation: Hexahedral Hex20

$$
\begin{gathered}
U_{x}=\frac{2 P\left(1-v^{2}\right)}{E}\left(y\left(3 x^{2}-\left(\frac{2-v}{1-v}\right) y^{2}-3\left(l^{2}-\frac{1}{2(1-v)}\right)\right)\right) \\
U_{y}=\frac{2 P\left(1-v^{2}\right)}{E}\left(-\frac{3 v}{1-v} x y^{2}-x^{3}+3 x l^{2}-2 l^{3}\right) \\
U_{z}=0
\end{gathered}
$$

- $\quad \mathrm{x}=0 \mathrm{~m}$ traction is defined as:

$$
\tau_{\mathrm{xy}}=1.5 P\left(1-\left(\frac{y}{h / 2}\right)^{2}\right) \quad P=\int_{-\frac{h}{2}}^{\frac{h}{2}} \quad \tau_{\mathrm{xy}} d y=1.0 \times 10^{6}
$$

Expected Results (Passing Criteria): The acceptance criteria for the comparison are the unsigned relative differences in maximum displacement in Y-direction and maximum bending stress, between the prediction of the simulation and the analytical calculation. The difference in maximum displacement should not be more than $0.1 \%$ and the difference in maximum bending stress should not be greater than 1\%. The maximum predicted displacement is $109.1984 \mathrm{~mm}$, which is exactly as the theoretical value obtained by Timoshenko [22]. The maximum stress at the fixed boundary is predicted at $179.80 \mathrm{MPa}$, which is exactly as the value obtained by Timoshenko and presented in the STAR-CCM+ Verification manual.
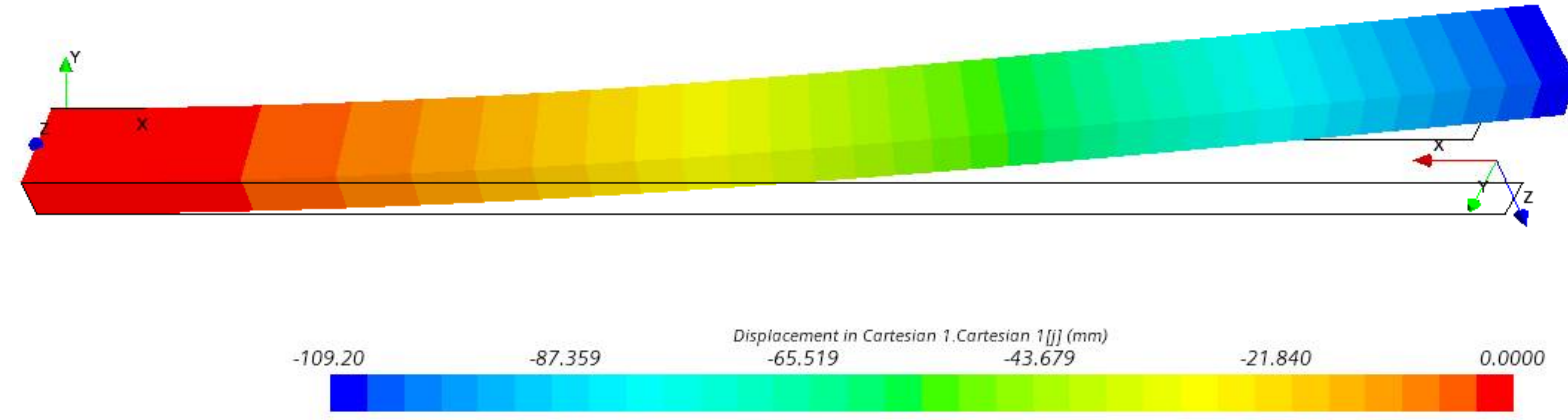

Figure. Displacement field in elastic beam in structural mechanics case SM-1

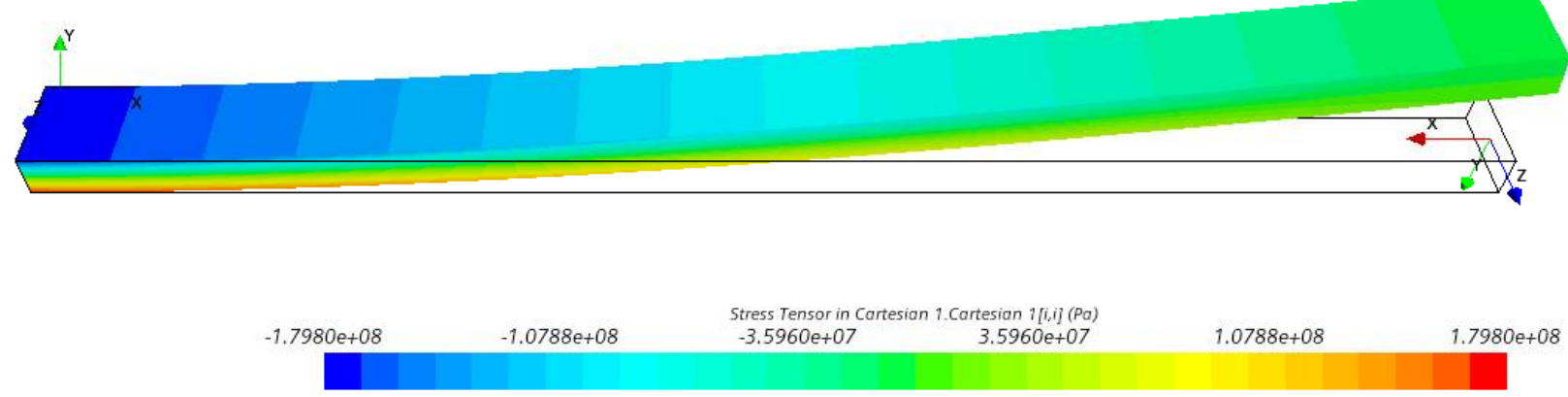

Figure. Stress distribution in elastic beam in structural mechanics case SM-1

\section{SM-2 Scordelis-Lo Roof}

Problem description: The Scordelis-Lo Roof case is a widely used benchmark test to check the accuracy of finite element types for curved shell problems. This case comprises a moderately thin shell that is subject to gravity loading. It has inextensional bending modes which are a very important feature of this problem. A quarter of a cylindrical roof is modeled with solid elements with appropriate boundary conditions and subjected to gravity load. The variable of interest is the vertical 
displacement of the point in the middle of the free edge, as presented in the figure. The example is based on reference [23].

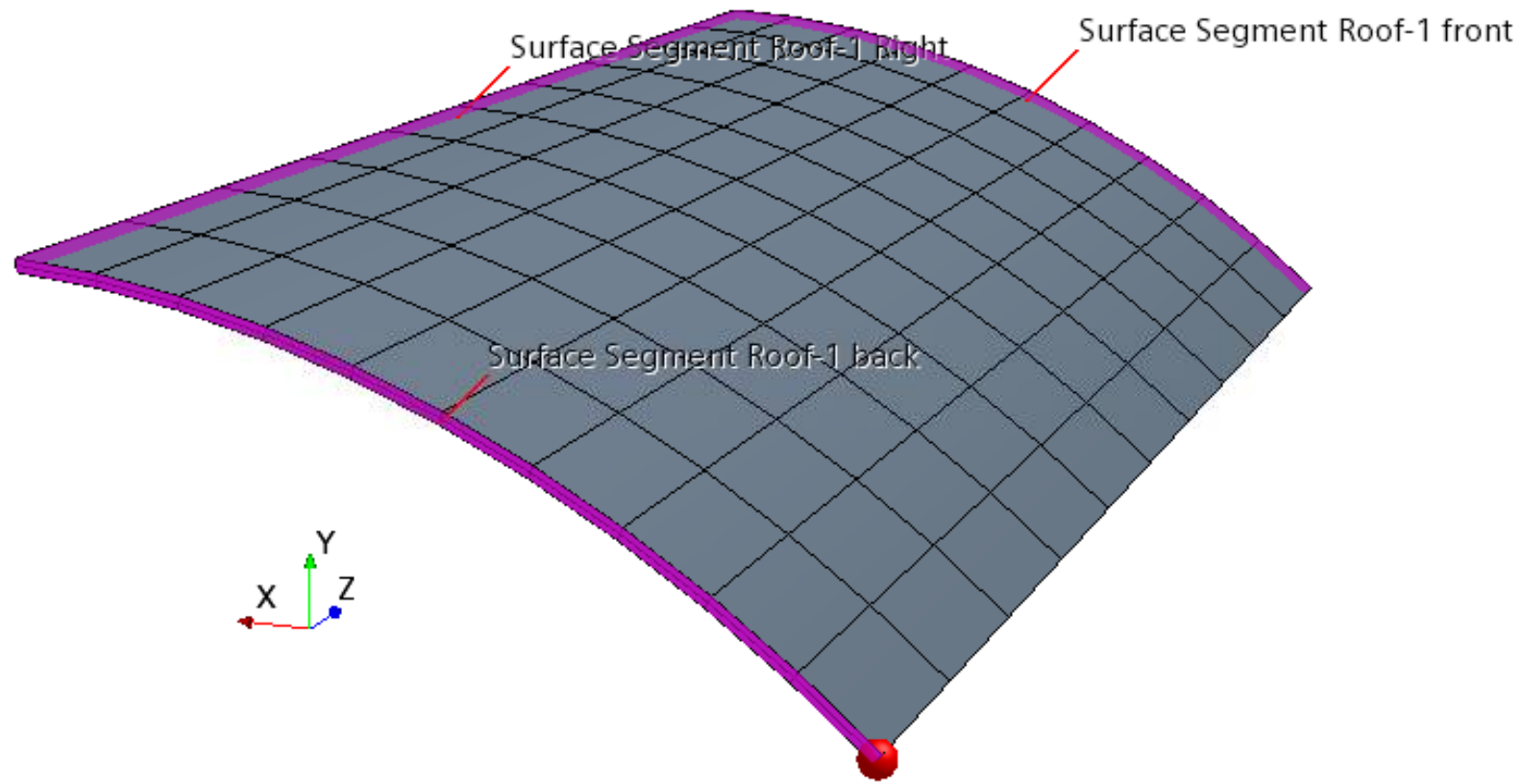

Figure. Geometry description for case SM-2

Geometry:

- Roof length $2 \mathrm{~L}=50 \mathrm{~m}$

- Roof radius $\mathrm{R}=25 \mathrm{~m}$

- Thickness $\mathrm{t}=0.25 \mathrm{~m}$

Domain extents (m):

$\mathrm{X}=16.23, \mathrm{Y}=44.4, \mathrm{Z}=25.0$

Physics Models:

*Gravity

*Linear Isotropic Elastic

*Solid

*Solid Stress

*Steady

*Three Dimensional

Finite Element Formulation:

Hexahedral Hex8
Material Model:

Linear elastic isotropic material model with

- Young's modulus E = 432.0 MPa,

- Poisson's ratio $=0.0$,

- Density $=1.0 \mathrm{~kg} / \mathrm{m}^{3}$.

\section{Boundary Conditions:}

- Surface Segment Roof-1 back - component of displacement in z-direction $(\mathrm{m})=0.0$,

- Surface Segment Roof-1 front - component of displacement in $\mathrm{x}$-direction $(\mathrm{m})=0.0$ and in $\mathrm{y}$ direction $(\mathrm{m})=0.0$,

- Surface Segment Roof-1 Right - component of

Load: displacement in $\mathrm{x}$-direction $(\mathrm{m})=0.0$

- Gravitational acceleration

$$
=[0.0,-360.0,0.0] \mathrm{m} / \mathrm{s}^{2}
$$

Expected Results (Passing Criteria): The theoretically obtained deflection of a point on the roof in the negative Y direction is $0.3024 \mathrm{~m}$ [23]. The computational solution obtained with STAR-CCM+ v.15.04 on the model developed by Siemens converged to $0.297768 \mathrm{~m}$, which gives an error of $1.532 \%$ as compared to the analytical result. 


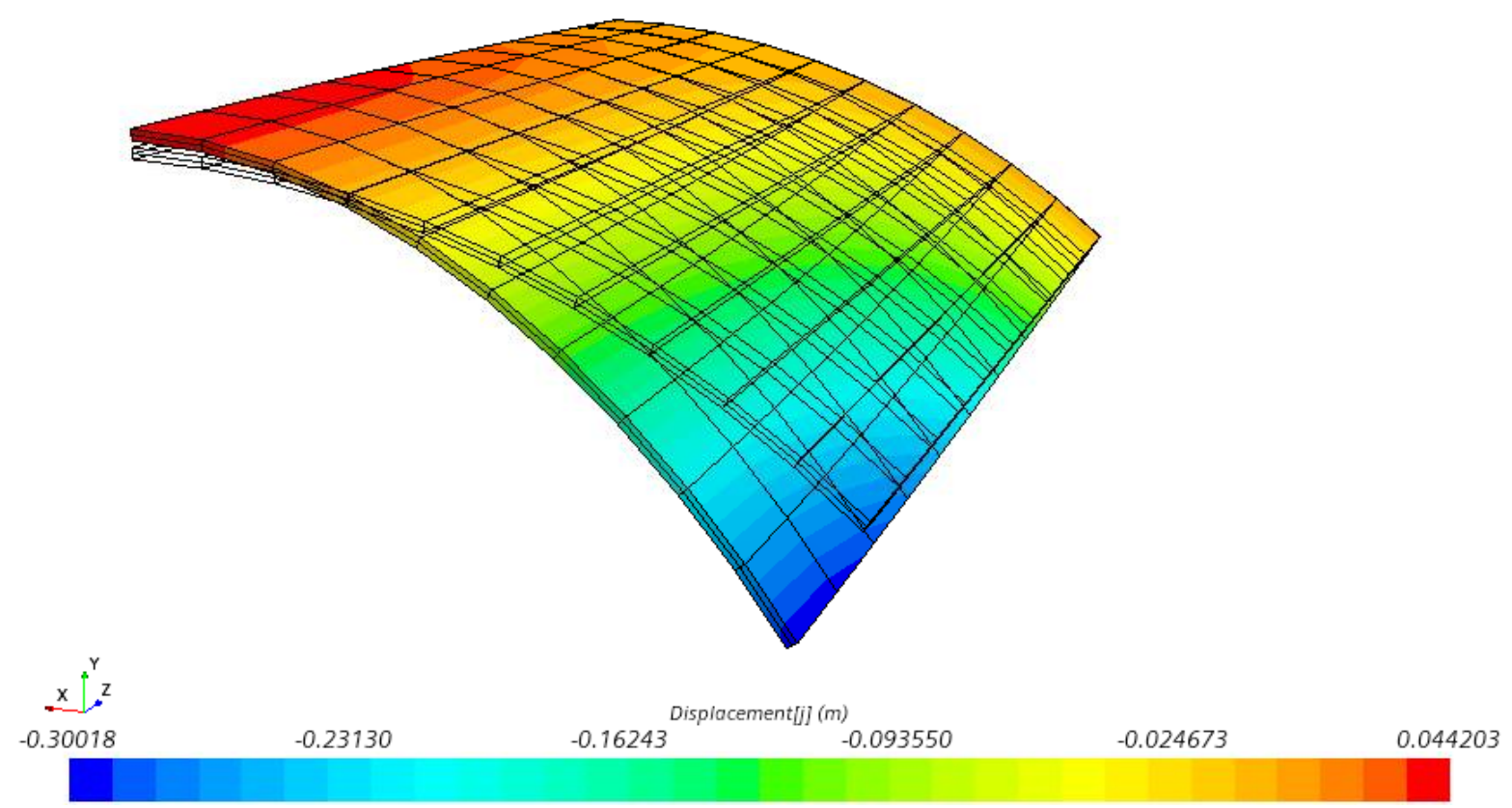

Figure. Displacement field in the shell for case SM-2 (the deformation was scaled up to better visualize the solution)

\section{A.7 Mechanical Models Available for the Stress Analysis}

Solid Stress model makes it possible to represent the response of a solid continuum to applied loads. It uses the finite element methodology to compute displacements at the finite element nodes, and then strains and stresses in the finite elements.

When a model is built of more than one solid parts, interfaces need to be created on the common surfaces. The mapped contact interfaces between solid parts model two types of mechanical interaction: Bonded, with the displacements and strains being continuous across the interface for interfaces between bodies made of the same material, or with the displacements being continuous and strains discontinuous for interfaces between different materials; and Small Sliding Frictionless where the surfaces at the two sides of the interface can slide over each other in the interface plane and the movement in the normal direction is constrained. This option is suitable for interfaces between flat surfaces, with the assumption of small sliding.

The relationship between stress and strain in a solid is defined by a material model. Linear elastic materials and elastoplastic materials with isotropic, orthotropic, or anisotropic properties, and isotropic hyperelastic materials are available in the software. User defined elastoplastic material models can also be defined. Linear elastic materials deform elastically under loading, returning to their original shape when the load is removed. The relationship between stress and strain is linear, according to Hooke's law. When defining a linear elastic material, the Young's modulus and Poisson's ratio needs to be specified. By default, STAR-CCM+ treats solid materials as compressible. When Poisson's ratio is close, or exceeds, 0.45 , then material is considered incompressible and Nearly Incompressible Material model should be used.

In general, linear elastic material model can be used for modeling most metals, including aluminum, provided that the stress is below the yield stress. To model plastic behavior of materials, which results in irreversible deformations, the Plasticity model should be activated along with the Linear Elasticity 
model. Perfect plasticity or plasticity with hardening can be modeled. There are three types of hardening models available: Linear Isotropic Hardening in which the yield stress is a linear function of the plastic strain, Saturation Hardening in which the yield stress is a nonlinear function of the plastic strain, and User-defined, in which the stress-strain curve is defined directly by specifying the yield stress and its derivative with respect to the equivalent plastic strain.

Thermal properties of materials can be modeled with the use of one of the existing material law models: Isotropic, Orthotropic, or Anisotropic Thermal Expansion. The material properties that a user needs to specify are thermal expansion coefficient and the reference temperature at which the thermal strain is assumed to be zero.

By default, the Solid Stress model accounts for small deformations in the continuum, which means that the relationship between displacement and strain is linear. If large displacements or rotations, or hyperelastic material properties need to be modeled, the Nonlinear Geometry model should be activated.

To account for gravity, the Gravity model should be activated.

Surface, line, or point mechanical loads can be assigned to a body with the use of so-called segments, which are parts-based points, curves, or surfaces. The software provides force, pressure, and traction loads. Body loads such as body mass, are applied to a region. The type of load used in the current study is 'pressure', which is equivalent to specifying the normal component of a surface traction with tangential components equal to zero.

Thermal loads can be modeled in two ways. The Specified Temperature Load solver allows for applying temperature load distributions to regions using a constant value, field function, or a table of values. This approach is also suitable for temperature loads that were computed on a different mesh representation and are mapped to a newly created geometry. The Finite Element Solid Energy solver calculates the temperature in a solid in response to thermal setting at boundaries. This model also accounts for the conjugate heat transfer between a fluid and a solid.

The displacement constraints are applied to part-based segments. Prescribed displacement can be defined on points, curves, and surfaces. The available types of constraints are fixed, normal displacement, and displacement. 'Fixed' type of constraint sets all components of the displacement field to zero, 'normal displacement' prevents the part surfaces from moving in the normal direction with tangential displacements allowed, and the 'displacement' type specifies which components of displacement vector are constrained.

Mechanical interaction between two deformable bodies can be modeled as Small Sliding Frictionless or bonded. The Small Sliding Frictionless model allows the contacting surfaces to slide over each other in the direction tangential to the interface, whereas movement in the normal direction is prohibited. The shear stress at the interface is equal to zero, and the normal forces are equal and opposite. This option is intended for small sliding at flat interfaces. Sliding of vertices at curved interfaces or sliding of vertices that exceed the mesh element length, leads to inaccurate results. This option targets applications where unrealistic stress concentrations would otherwise occur, for example, thermal-stress analysis involving interfaces between materials with different thermal expansion coefficients. When Bonded option is used, the contacting surfaces undergo continuous displacements. If the solid regions are different materials, discontinuities in the strain are preserved across the material interface.

Involute Working Group - Development and Validation of the Finite Element Models of the Cheverton-Kelley Experiments 
Modeling large displacements and rotations, for which strain-displacement relationship is nonlinear, is possible if Nonlinear Geometry model is activated. In the STAR-CCM+ manual it is assumed that nonlinear analysis is required when the displacement magnitudes exceed the model dimensions by $10 \%$ or rotations are greater than 4 degrees, or a slender structure is under compression or tension. When performing a static analysis with small nonlinearities, it is recommended to use either Steady model or Implicit Unsteady model in Static Analysis mode. The second method allows to run a static analysis while ramping the applied loads using time-dependent functions. In the case of large nonlinearities, the Steady model is recommended with loads gradually applied to the structure, which can be achieved with Solid Stress Load Step solver. 


\section{Appendix B - Conversion of Units}

Basic unit conversion from English unit system to the metric unit system was provided for the reader's convenience in Table B.1

Table B.1 Conversion of units used in the report. English unit system to metric unit system

\begin{tabular}{|c|c|c|}
\hline Quantity & $\begin{array}{c}\text { English unit } \\
\text { system }\end{array}$ & Metric unit system \\
\hline Length & $1 \mathrm{in}$ & $=0.0254 \mathrm{~m}=25.4 \mathrm{~mm}$ \\
\hline Mass & $1 \mathrm{lb}$ & $=0.45 \mathrm{~kg}$ \\
\hline Pressure & $1 \mathrm{psi}$ & $=6895 \mathrm{~Pa}=6.895 \mathrm{kPa}$ \\
\hline Temperature & $1^{\circ} \mathrm{F}$ & $=\left(1^{\circ} \mathrm{F}-32\right) \times 5 / 9+273.15=256 \mathrm{~K}$ \\
\hline
\end{tabular}




\section{Appendix C - Material Properties}

Stress-strain curves from a uniaxial tension test performed at various temperatures on aluminum specimens were made available by Martin and Weir [20]. Figure C.1 to Figure C.4 show screenshots of the original plots from the report. Figure C.1 presents the temperature effect on the modulus of elasticity, Figure C.2 shows yield strength of several alloys, 6061-T0 included, as a function of temperature, Figure C.3 shows the ultimate tensile strength of alloys as a function of temperature, and Figure C. 4 shows the stress-strain curves for aluminum 6061-0 at various temperatures.

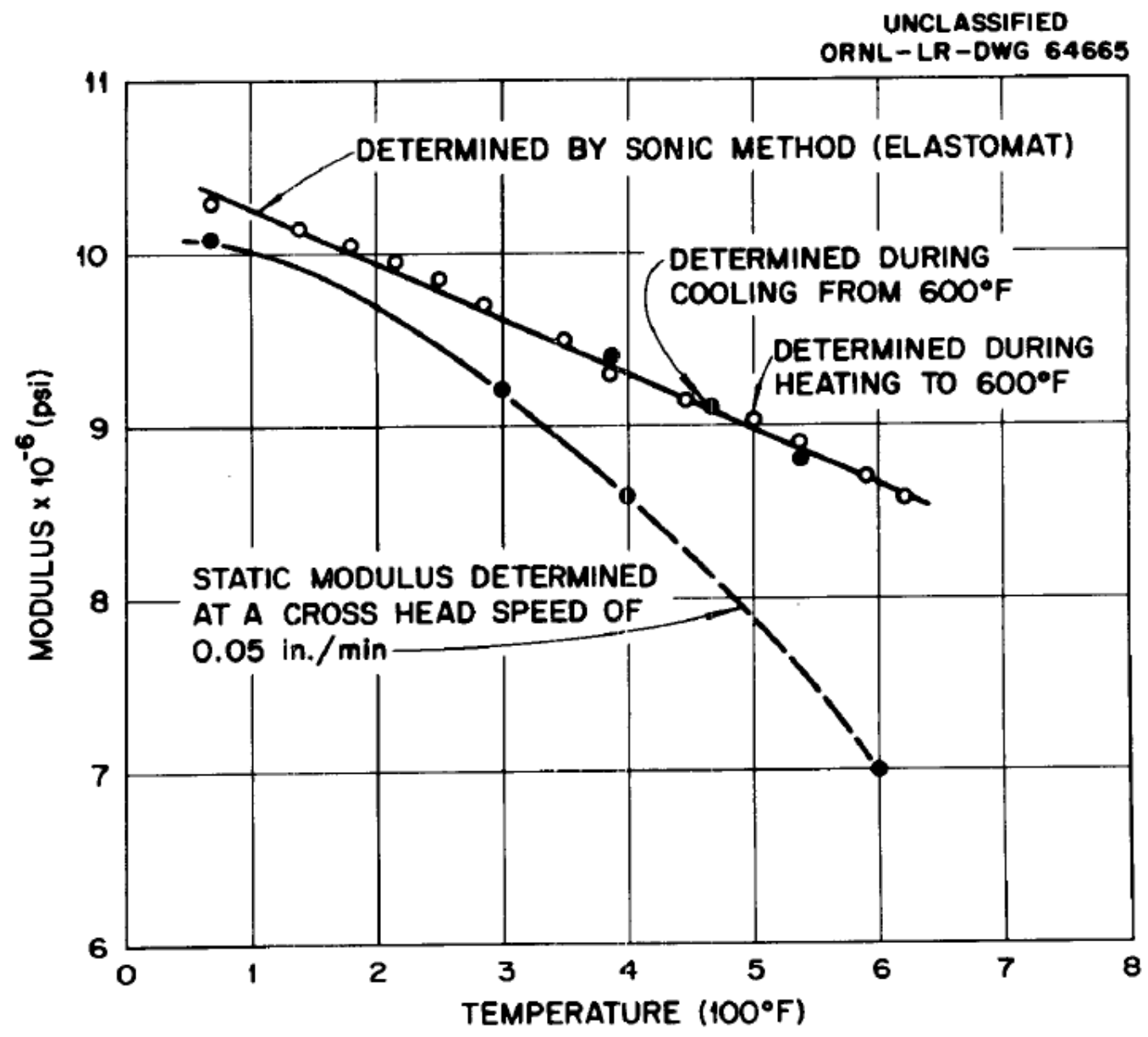

Fig. 2. Effect of Temperature on Modulus of Elasticity of 6061 Aluminum.

Figure C.1. Effect of temperature on the modulus of elasticity of 6061-T0 aluminum.

Source: [20] 
UNCLASSIFIED

ORNL-LR-DWG 62422

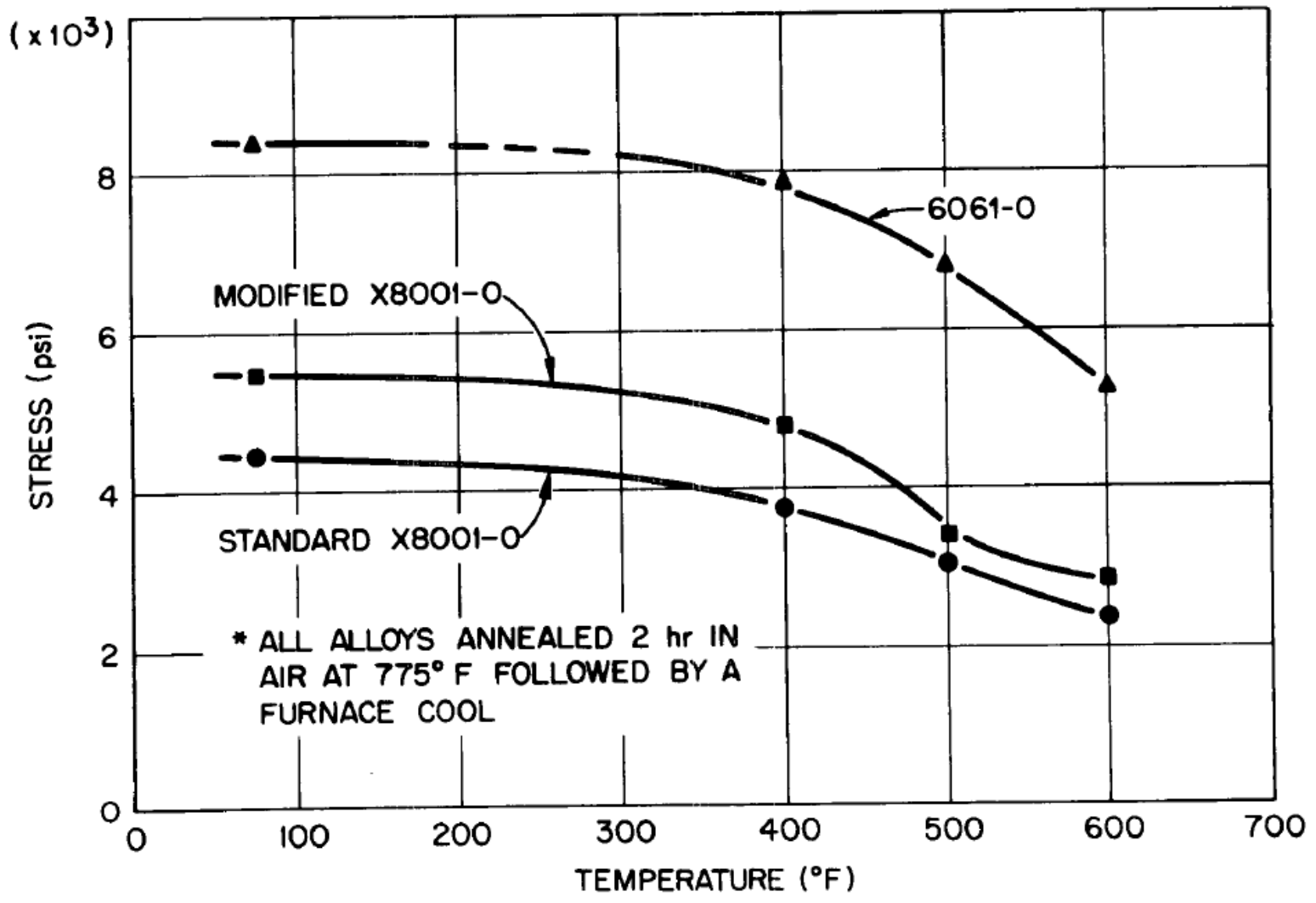

Fig. 3. Yield Strength of Alloys as a Function of Test Temperature.

Figure C.2. Yield strength of alloys as a function of temperature. Source: [20] 


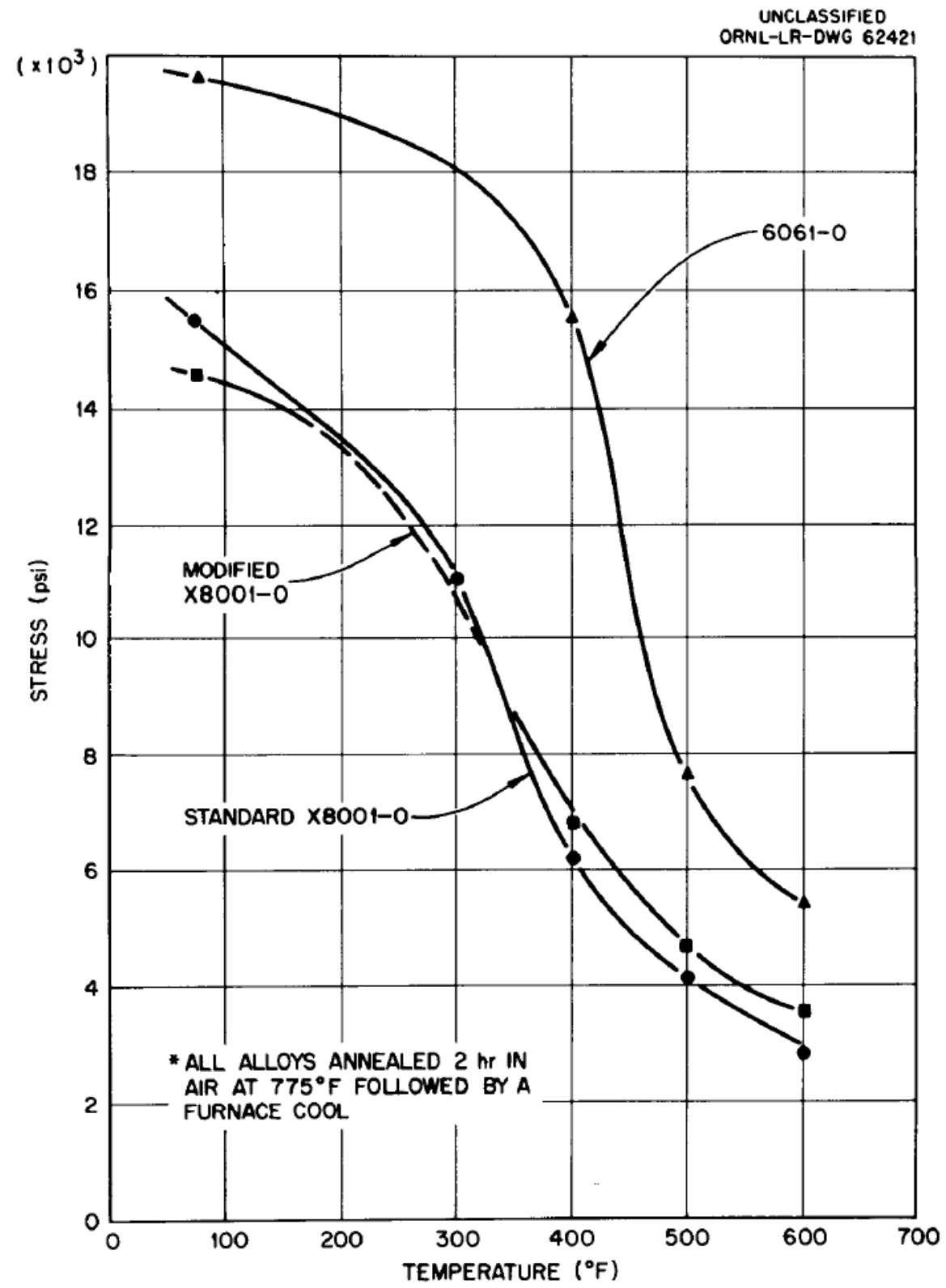

Fig. 4. Ultimate Tensile Strength as a Function of Temperature for Several Aluminum Alloys.

Figure C.3. Ultimate tensile strength of alloys as a function of temperature. Source: [20] 


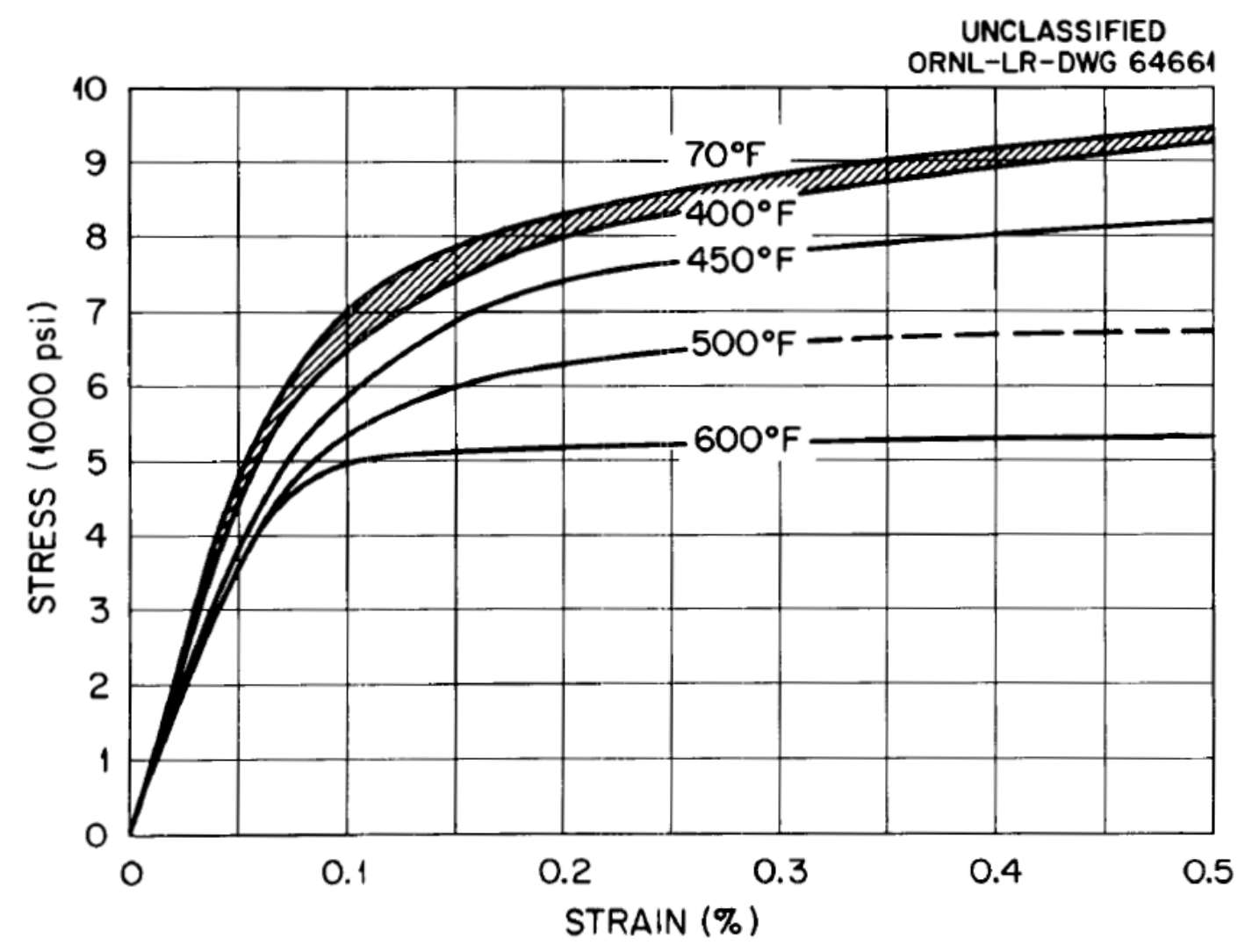

Fig. 5. Stress-Strain Tensile Curve for Aluminum Alloy 6061-0.

Figure C.4. Stress-strain curves for aluminum 6061-0 at various temperatures. Source: [20] 
The data points representing dependence of material properties of aluminum on temperature were digitized and the values were combined in Tables C.1 to C.4 in English and metric unit systems. The digitized plots are presented in figures from Figure C.5 to Figure C.8.

Table C. 1. Digitized elastic modulus determined by sonic method

\begin{tabular}{|c|c|c|c|}
\hline $\begin{array}{c}\text { temp } \\
{\left[{ }^{\circ} \mathbf{F}\right]}\end{array}$ & $\begin{array}{c}\text { temp } \\
{[\mathbf{K}]}\end{array}$ & $\begin{array}{c}\text { modulus } \\
{[\mathbf{p s i}]}\end{array}$ & $\begin{array}{c}\text { modulus } \\
{[\mathbf{G P a}]}\end{array}$ \\
\hline 70 & 294 & $1.03 \mathrm{E}+07$ & 70.9 \\
\hline 139 & 333 & $1.01 \mathrm{E}+07$ & 69.9 \\
\hline 182 & 357 & $1.01 \mathrm{E}+07$ & 69.3 \\
\hline 217 & 376 & $9.94 \mathrm{E}+06$ & 68.5 \\
\hline 252 & 396 & $9.86 \mathrm{E}+06$ & 68.0 \\
\hline 285 & 414 & $9.71 \mathrm{E}+06$ & 66.9 \\
\hline 350 & 450 & $9.50 \mathrm{E}+06$ & 65.5 \\
\hline 385 & 469 & $9.30 \mathrm{E}+06$ & 64.1 \\
\hline 445 & 503 & $9.14 \mathrm{E}+06$ & 63.0 \\
\hline 504 & 535 & $9.04 \mathrm{E}+06$ & 62.3 \\
\hline 537 & 554 & $8.91 \mathrm{E}+06$ & 61.4 \\
\hline 621 & 600 & $8.58 \mathrm{E}+06$ & 59.2 \\
\hline
\end{tabular}

Table C. 2. Digitized static elastic modulus

\begin{tabular}{|c|c|c|c|}
\hline $\begin{array}{c}\text { temp } \\
{\left[{ }^{\circ} \mathbf{F}\right]}\end{array}$ & $\begin{array}{c}\text { temp } \\
{[\mathbf{K}]}\end{array}$ & $\begin{array}{c}\text { modulus } \\
{[\mathbf{p s i}]}\end{array}$ & $\begin{array}{c}\text { modulus } \\
{[\mathbf{G P a}]}\end{array}$ \\
\hline 70 & 294 & $1.01 \mathrm{E}+07$ & 69.5 \\
\hline 301 & 422 & $9.22 \mathrm{E}+06$ & 63.6 \\
\hline 400 & 477 & $8.59 \mathrm{E}+06$ & 59.2 \\
\hline 600 & 588 & $7.02 \mathrm{E}+06$ & 48.4 \\
\hline
\end{tabular}

Table C. 3. Digitized yield strength of 6061-T0 aluminum

\begin{tabular}{|c|c|c|c|}
\hline $\begin{array}{c}\text { temp } \\
{\left[{ }^{\circ} \mathbf{F}\right]}\end{array}$ & $\begin{array}{c}\text { temp } \\
{[\mathbf{K}]}\end{array}$ & $\begin{array}{c}\text { yield } \\
\text { strength } \\
{[\mathbf{p s i}]}\end{array}$ & $\begin{array}{c}\text { yield } \\
\text { strength } \\
{[\mathbf{M P a}]}\end{array}$ \\
\hline 76 & 298 & $8.39 \mathrm{E}+03$ & 57.8 \\
\hline 400 & 478 & $7.87 \mathrm{E}+03$ & 54.2 \\
\hline 500 & 533 & $6.79 \mathrm{E}+03$ & 46.8 \\
\hline 600 & 589 & $5.24 \mathrm{E}+03$ & 36.1 \\
\hline
\end{tabular}


Table C. 4. Digitized tensile strength of 6061-T0 aluminum

\begin{tabular}{|c|c|c|c|}
\hline $\begin{array}{c}\text { temp } \\
{\left[{ }^{\circ} \mathbf{F}\right]}\end{array}$ & temp $[\mathrm{K}]$ & $\begin{array}{c}\text { tensile } \\
\text { strength } \\
{[\mathbf{p s i}]}\end{array}$ & $\begin{array}{c}\text { tensile } \\
\text { strength } \\
{[\mathbf{M P a}]}\end{array}$ \\
\hline 80 & 300 & $1.96 \mathrm{E}+04$ & 135.2 \\
\hline 400 & 478 & $1.54 \mathrm{E}+04$ & 106.5 \\
\hline 500 & 533 & $7.65 \mathrm{E}+03$ & 52.7 \\
\hline 600 & 589 & $5.38 \mathrm{E}+03$ & 37.1 \\
\hline
\end{tabular}

Table C. 5. Digitized stress-strain curves for aluminum $6061-0$ at $70{ }^{\circ} \mathrm{F}$ and $400{ }^{\circ} \mathrm{F}$

\begin{tabular}{|c|c|c|c|}
\hline \multicolumn{2}{|c|}{$7{ }^{\circ} \mathrm{F}$} & \multicolumn{2}{|c|}{$\mathbf{4 0 0}{ }^{\circ} \mathrm{F}$} \\
\hline strain [-] & $\begin{array}{c}\text { stress } \\
{[\text { MPa] }}\end{array}$ & strain [-] & $\begin{array}{c}\text { stress } \\
{[\text { MPa] }}\end{array}$ \\
\hline 0.00000 & 0.0 & 0.00000 & 0.0 \\
\hline 0.00009 & 6.9 & 0.00022 & 13.8 \\
\hline 0.00019 & 13.9 & 0.00032 & 20.9 \\
\hline 0.00029 & 20.8 & 0.00039 & 24.8 \\
\hline 0.00039 & 27.7 & 0.00044 & 27.7 \\
\hline 0.00050 & 33.3 & 0.00050 & 30.4 \\
\hline 0.00053 & 35.2 & 0.00057 & 33.0 \\
\hline 0.00062 & 38.1 & 0.00063 & 35.8 \\
\hline 0.00072 & 41.5 & 0.00069 & 38.0 \\
\hline 0.00078 & 43.2 & 0.00076 & 39.8 \\
\hline 0.00085 & 45.2 & 0.00083 & 41.5 \\
\hline 0.00093 & 46.8 & 0.00092 & 43.1 \\
\hline 0.00100 & 48.3 & 0.00101 & 44.8 \\
\hline 0.00107 & 49.7 & 0.00112 & 46.4 \\
\hline 0.00117 & 51.0 & 0.00123 & 47.9 \\
\hline 0.00132 & 52.8 & 0.00133 & 49.5 \\
\hline 0.00144 & 53.8 & 0.00146 & 50.7 \\
\hline 0.00158 & 55.0 & 0.00159 & 52.0 \\
\hline 0.00174 & 56.1 & 0.00174 & 53.3 \\
\hline 0.00192 & 57.0 & 0.00188 & 54.3 \\
\hline 0.00209 & 57.6 & 0.00202 & 55.2 \\
\hline 0.00228 & 58.6 & 0.00215 & 55.9 \\
\hline 0.00249 & 59.4 & 0.00229 & 56.6 \\
\hline 0.00280 & 60.4 & 0.00253 & 57.3 \\
\hline 0.00318 & 61.4 & 0.00310 & 59.1 \\
\hline 0.00349 & 62.3 & 0.00349 & 60.2 \\
\hline 0.00400 & 63.5 & 0.00400 & 61.5 \\
\hline 0.00450 & 64.4 & 0.00450 & 62.7 \\
\hline 0.00500 & 65.2 & 0.00500 & 63.7 \\
\hline & & & \\
\hline
\end{tabular}




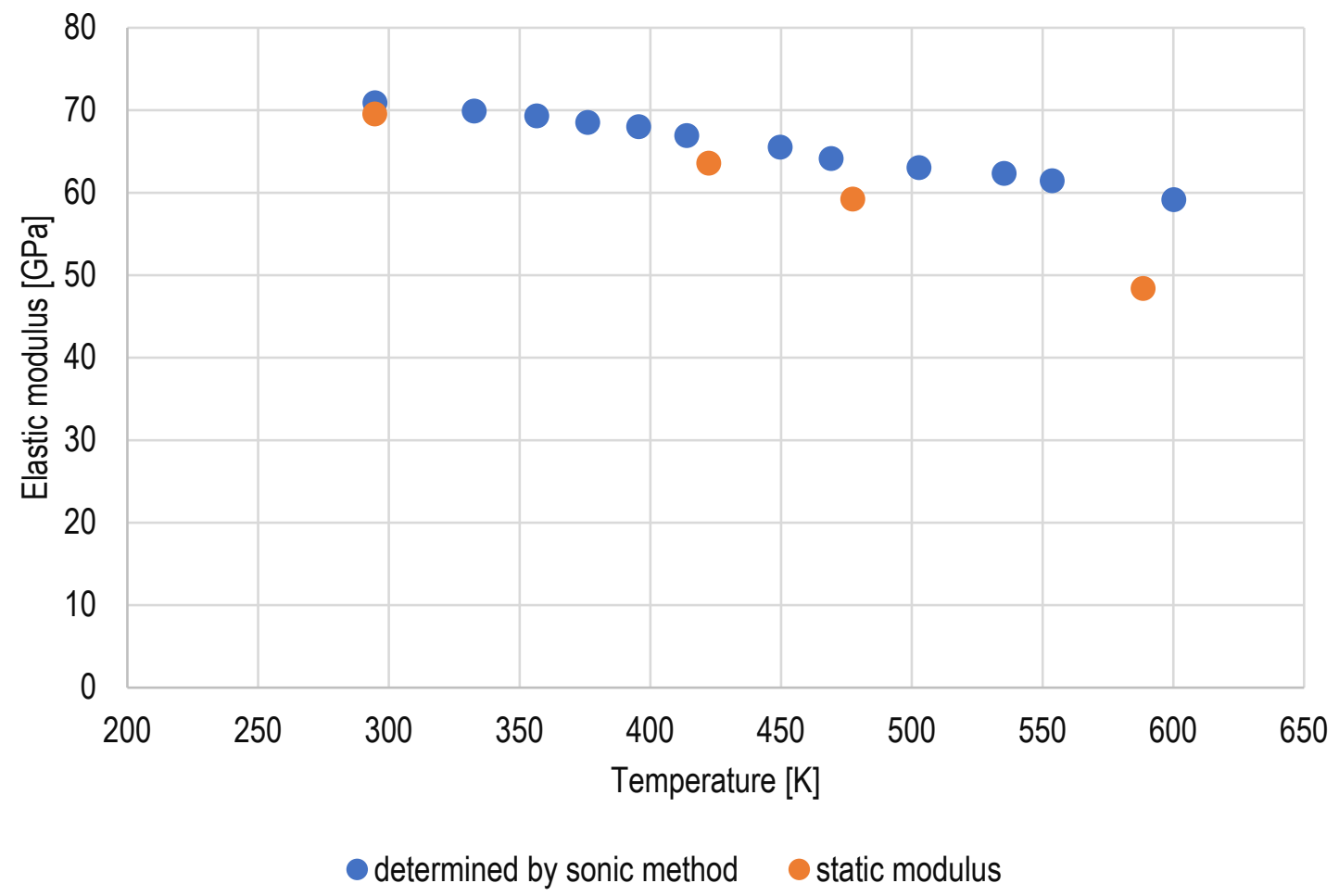

Figure C.5. Digitized plot: effect of temperature on the modulus of elasticity of 6061-T0 aluminum

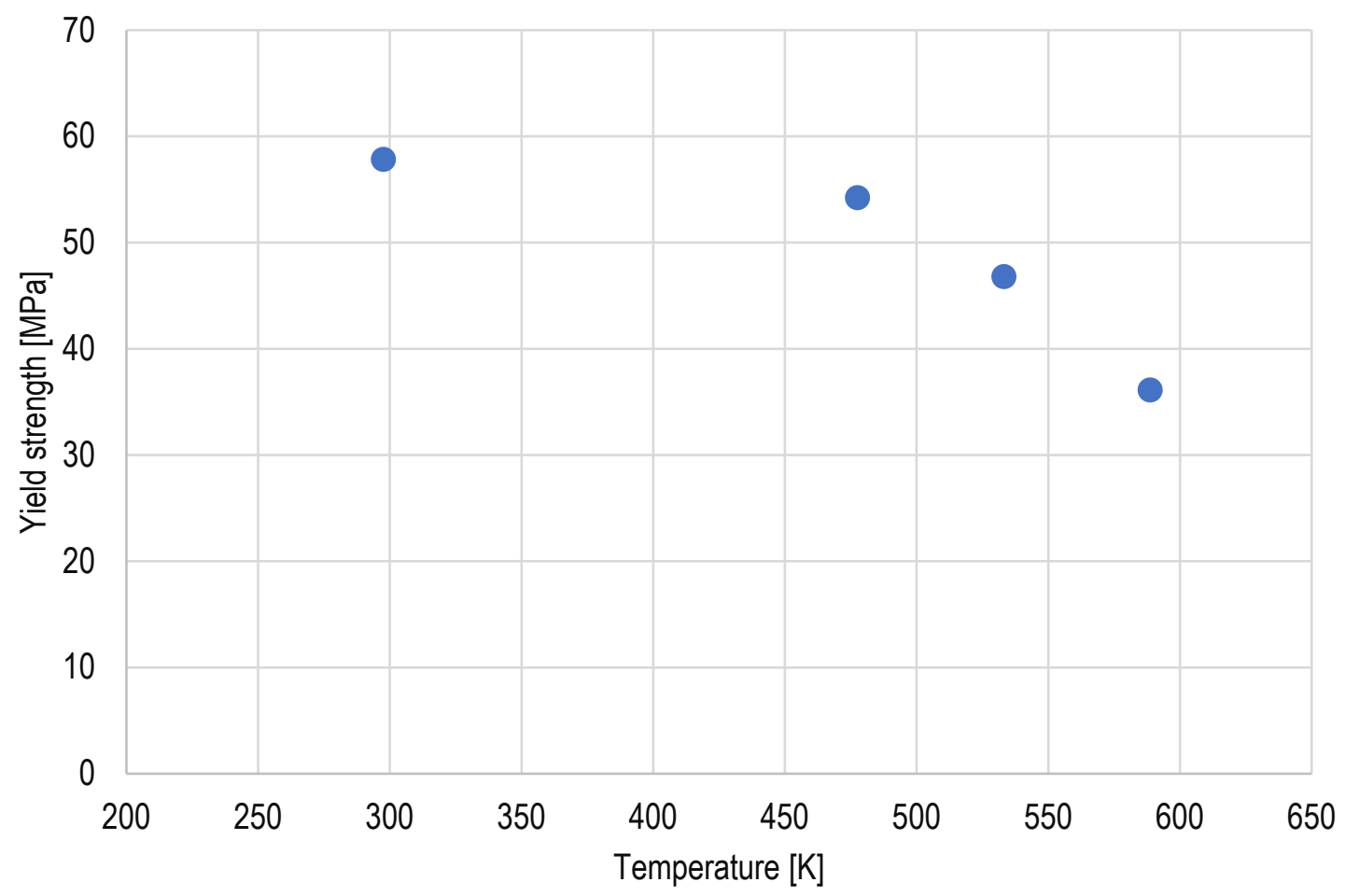

Figure C.6. Digitized plot: yield strength of 6061-T0 aluminum as a function of temperature

Involute Working Group - Development and Validation of the Finite Element Models of the Cheverton-Kelley Experiments 


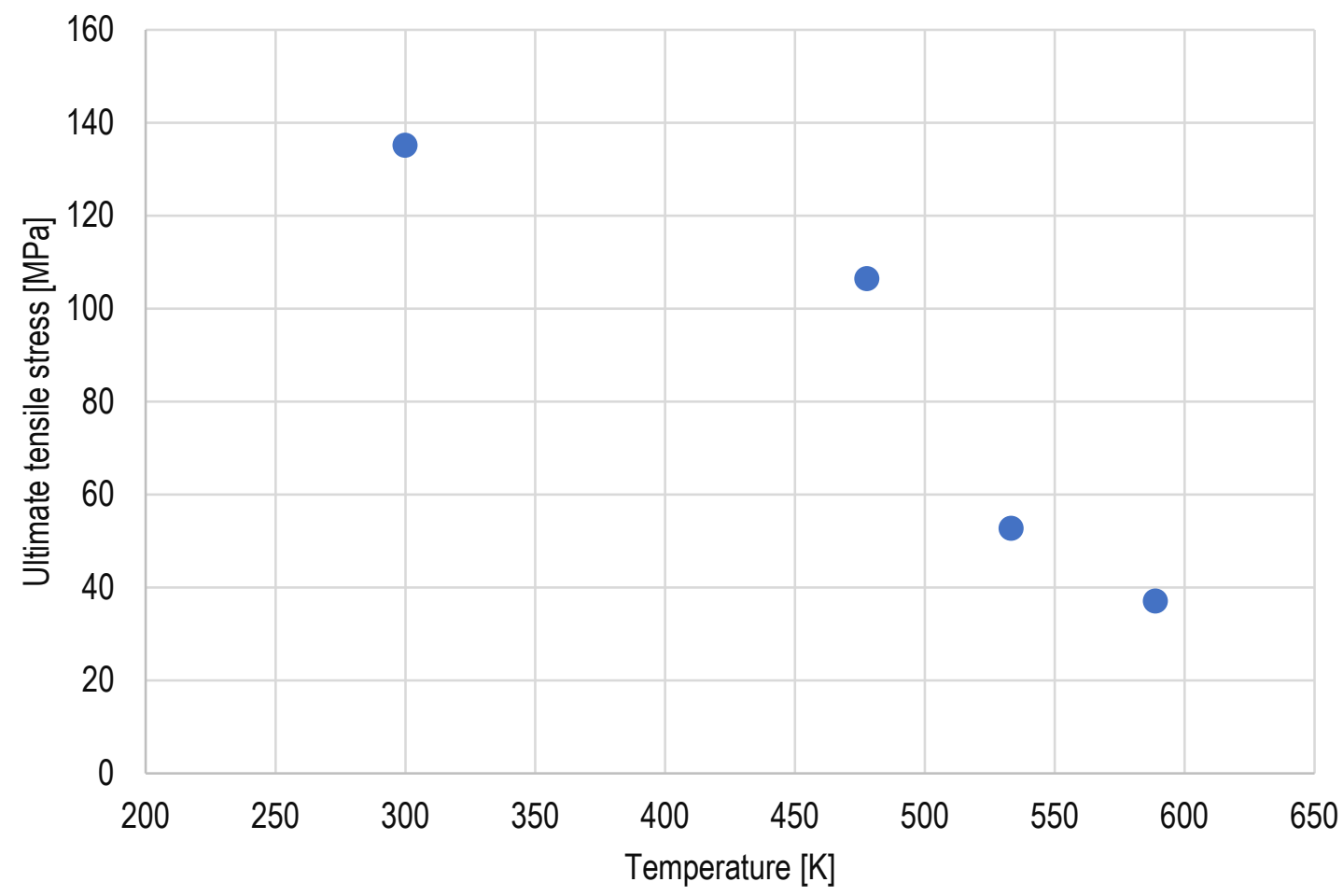

Figure C.7. Digitized plot of the ultimate tensile strength of 6061-T0 aluminum as a function of temperature

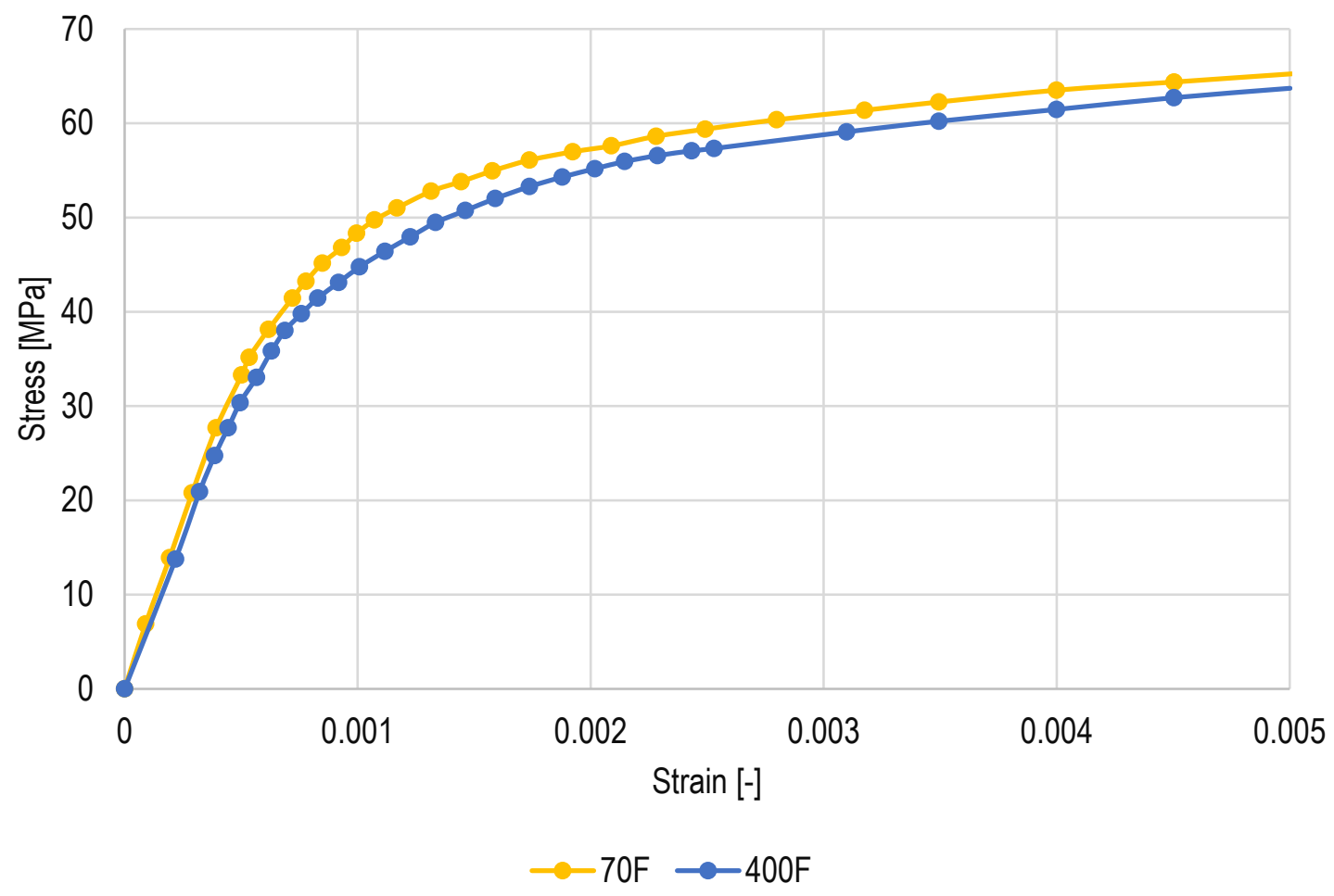

Figure C.8. Digitized plot of the stress-strain curves for aluminum $6061-0$ at $70{ }^{\circ} \mathrm{F}$ and $400^{\circ} \mathrm{F}$

Involute Working Group - Development and Validation of the Finite Element Models of the Cheverton-Kelley Experiments 
According to the digitized data presented in Figure C.5 the modulus of elasticity at $294 \mathrm{~K}$ equals approximately $70.9 \mathrm{MPa}$ when established by sonic method, and the static modulus equals $69.5 \mathrm{GPa}$. At $477 \mathrm{~K}$ those moduli are approximately $63.7 \mathrm{GPa}$ and $59.2 \mathrm{GPa}$, respectively.

Figure C.6 shows that at temperature $294 \mathrm{~K}$ the yield stress is equal $57.8 \mathrm{MPa}$. This yield stress is a so called $0.1 \%$ offset yield strength that was chosen to approximate the elastic limit. The offset yield point approximates the material's elastic limit, and it is often reported for materials for which the real onset of plastic range is not easy to find from the stress-strain curve. It is established through intersecting the stress-strain curve with a line parallel to the elastic range line, translated by the offset strain. The offset yield strength is always higher than the real yield point, as shown in Figure C.9. For this reason, this parameter was not used in the modeling, instead, the stress-strain curves plotted in Figure C. 8 were tabularized, and a user-defined material model was implemented in STAR-CCM+. The user-defined elastoplastic model is defined by specifying the yield stress and its derivative, the tangent modulus, with respect to equivalent plastic strain. The equivalent, or accumulated, plastic strain is a quantity that represents the incremental plastic strain that is accumulated as the plastic damage increases [4].

The stress-strain curves were provided only for strains up to 0.5\%, as shown in Figure C.4 and Figure C.8. It is a very limited range, considering that the elongation of an aluminum specimen at failure in a tensile test can reach 25\% [19]. Due to the lack of other data, it was assumed in the computations that beyond this range, the yield strength and tangent modulus are constant and equal to the values corresponding to $0.5 \%$ strain.

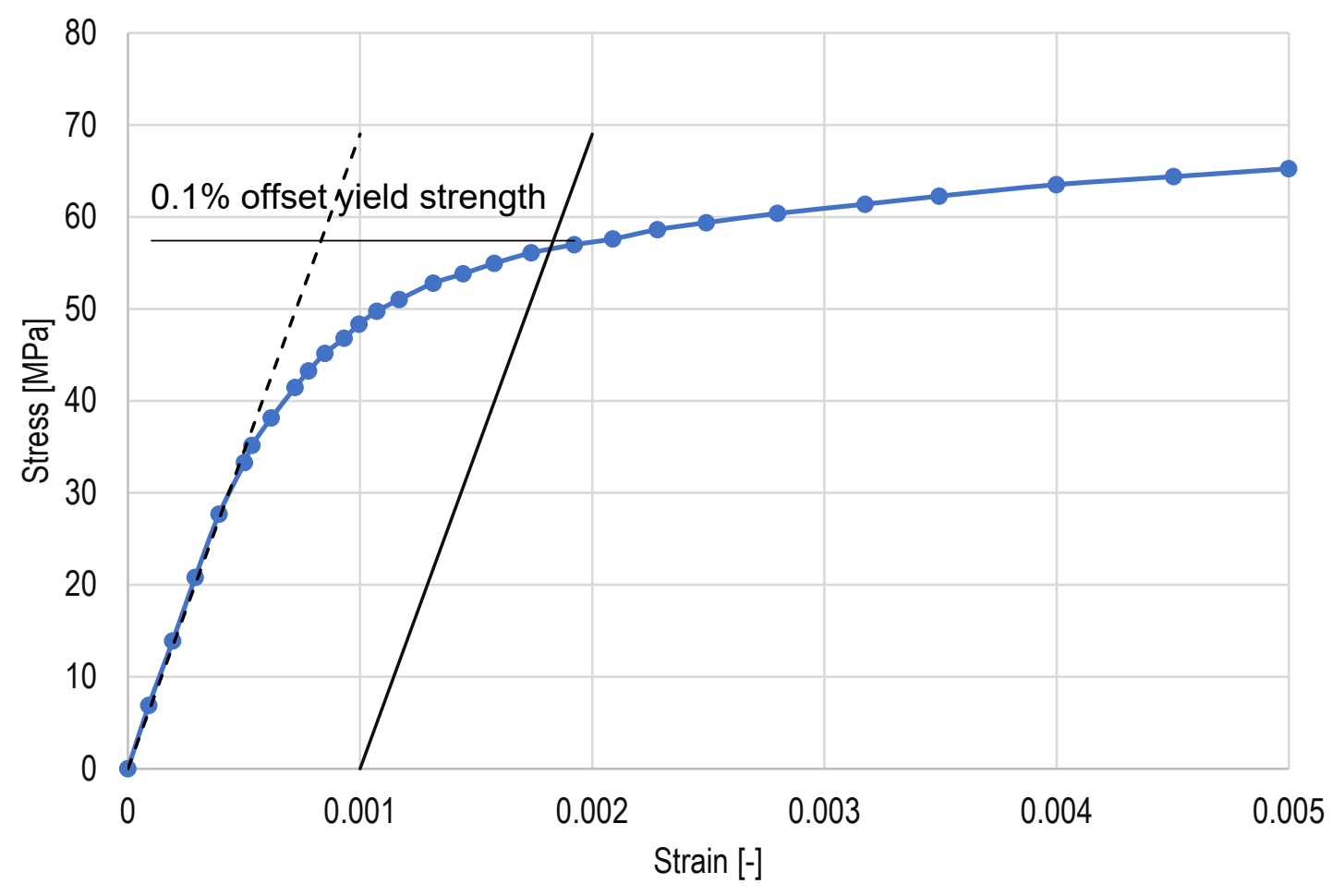

Figure C.9. Calculation of the $0.1 \%$ offset yield strength 


\section{Appendix D - Digitized Experimental Data}

Experimental measurements from Cheverton and Kelley report [5], presented in Section 5.3 were digitized and the units were converted from the English unit system to the metric system, with the goal of using them as a reference in the process of code validation. Table D. 1 to Table D. 3 present the digitized deflections measured by sensors and Figure D. 1 to Figure D. 4 show the digitized plots. Error bars in the plots were added by the authors of the present study to account for a potential $\pm 10 \%$ measurement error.

Table D. 1. Experimental deflections [mm] normal to the plate convex surface under pressure loads at room temperature

\begin{tabular}{|c|c|c|c|c|}
\hline \multirow{2}{*}{ Pressure load } & Sensor & $69 \mathrm{kPa}$ & $138 \mathrm{kPa}$ & $207 \mathrm{kPa}$ \\
\hline $\begin{array}{c}\text { Side constraint } \\
\text { every 1/4" tab and } \\
\text { bar clamped }\end{array}$ & $\# 2$ & n.a. & n.a. & -0.026 \\
\cline { 2 - 5 } $\begin{array}{c}\text { every 1/4" tab } \\
\text { clamped }\end{array}$ & $\# 5$ & 0.027 & 0.056 & 0.087 \\
\hline & $\# 2$ & -0.019 & -0.031 & -0.046 \\
\hline $\begin{array}{c}\text { every 1/8" tab } \\
\text { clamped }\end{array}$ & $\# 5$ & 0.050 & 0.113 & 0.194 \\
\hline $\begin{array}{c}\text { every other 1/4" } \\
\text { tab clamped }\end{array}$ & $\# 2$ & n.a. & -0.041 & n.a. \\
\cline { 2 - 5 } & $\# 2$ & n.a. & 0.132 & n.a. \\
\hline
\end{tabular}

Table D. 2. Experimental deflections [mm] normal to the plate convex surface of the midspan of a plate under thermal and mechanical loads (a) without sealant, (b) with sealant

\begin{tabular}{|c|c|c|c|c|c|}
\hline & \multicolumn{3}{|c|}{$(\mathrm{a})$} & \multicolumn{2}{c|}{ (b) } \\
\hline $\begin{array}{l}\text { Sensor Load } \\
\text { location [m] }\end{array}$ & $\begin{array}{c}400 \mathrm{~F}, \\
0 \mathrm{kPa}\end{array}$ & $\begin{array}{c}400 \mathrm{~F}, \\
103 \mathrm{kPa}\end{array}$ & $\begin{array}{c}400 \mathrm{~F}, \\
207 \mathrm{kPa}\end{array}$ & $\begin{array}{c}400 \mathrm{~F}, \\
0 \mathrm{kPa}\end{array}$ & $\begin{array}{c}400 \mathrm{~F}, \\
207 \mathrm{kPa}\end{array}$ \\
\hline 0.003 & 0.08 & 0.04 & 0.03 & 0.07 & 0.05 \\
\hline 0.015 & 0.21 & 0.19 & 0.16 & 0.23 & 0.19 \\
\hline 0.026 & 0.35 & 0.34 & n.a. & 0.39 & n.a. \\
\hline 0.038 & 0.39 & 0.42 & 0.46 & 0.46 & 0.52 \\
\hline 0.049 & 0.34 & 0.39 & 0.49 & 0.42 & 0.50 \\
\hline 0.060 & 0.21 & 0.23 & 0.30 & 0.23 & 0.30 \\
\hline 0.072 & 0.07 & 0.07 & 0.09 & 0.04 & 0.05 \\
\hline
\end{tabular}


Table D. 3. Experimental deflections [mm] normal to the plate convex surface of the midspan of a plate under thermal load in a (a) solid, (b) split base

\begin{tabular}{|c|c|c|c|c|c|c|}
\hline & \multicolumn{3}{|c|}{ (a) } & \multicolumn{2}{c|}{ (b) } & \\
\hline $\begin{array}{r}\text { Sensor } \\
\text { location [m] }\end{array}$ & end 1 & midspan & end 2 & end 1 & midspan & end 2 \\
\hline 0.003 & 0.02 & 0.18 & -0.02 & -0.13 & 0.12 & -0.12 \\
\hline 0.015 & 0.08 & 0.52 & 0.07 & -0.23 & 0.24 & -0.17 \\
\hline 0.026 & 0.12 & 0.82 & 0.19 & -0.33 & 0.39 & -0.29 \\
\hline 0.038 & 0.12 & 0.93 & 0.20 & -0.41 & 0.47 & -0.43 \\
\hline 0.049 & 0.06 & 0.79 & 0.14 & n.a. & 0.53 & -0.41 \\
\hline 0.060 & 0.01 & 0.49 & 0.04 & -0.33 & 0.39 & -0.37 \\
\hline 0.072 & 0.01 & 0.14 & -0.01 & -0.25 & 0.28 & -0.14 \\
\hline
\end{tabular}

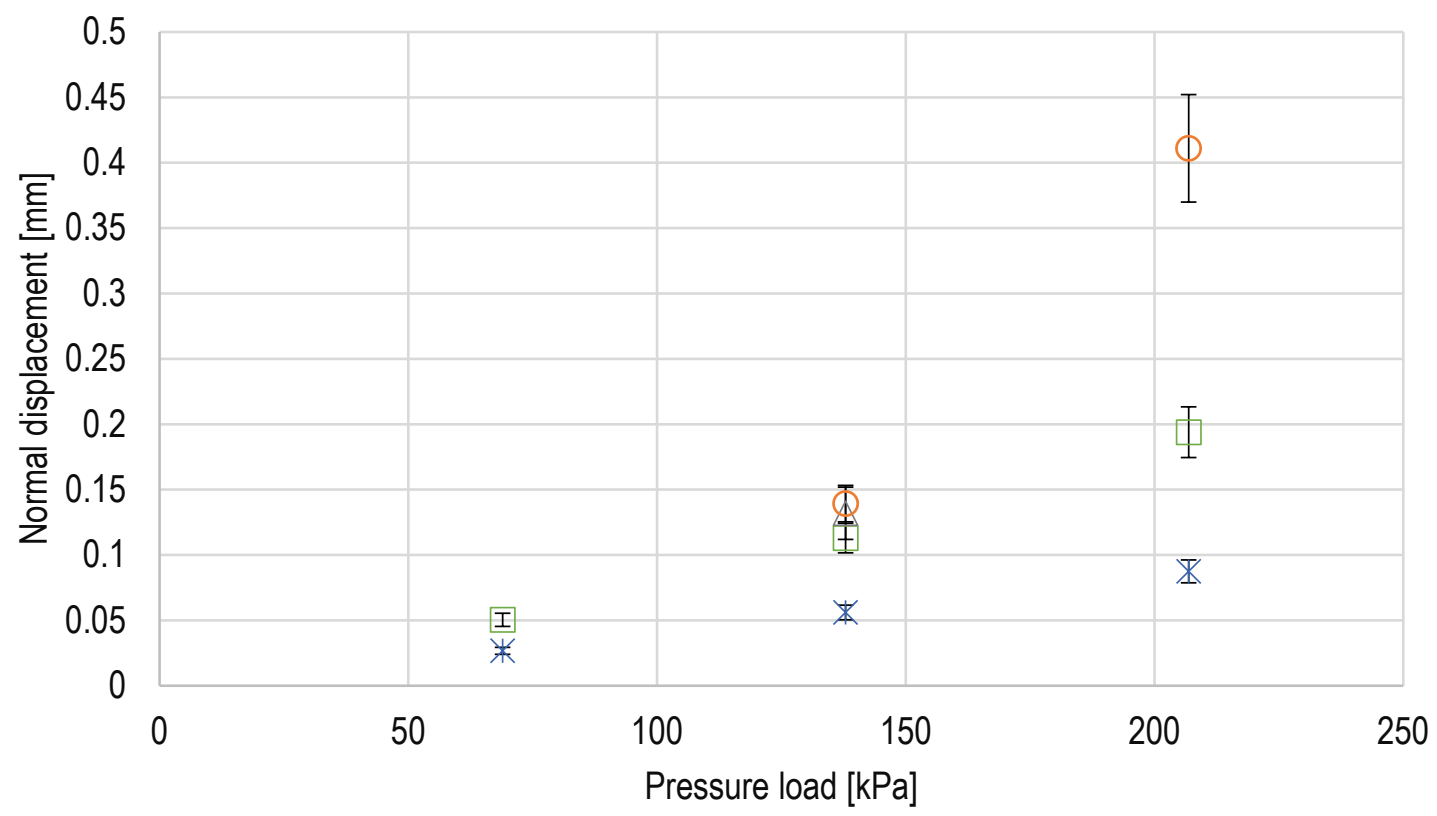

$* \# 5$ - every $1 / 4$ in tab and edge $\square \# 5$ - every $1 / 4$ in tab

$\triangle \# 5$ - every $1 / 8$ in tab $\quad \bigcirc \# 5$ - every other $1 / 4$ in tab

Figure D. 1. Digitized plot: normal displacement of points on the midspan of the plate in function of the pressure load for tests with varying edge constraints (see Figure 5.12) 
(a)

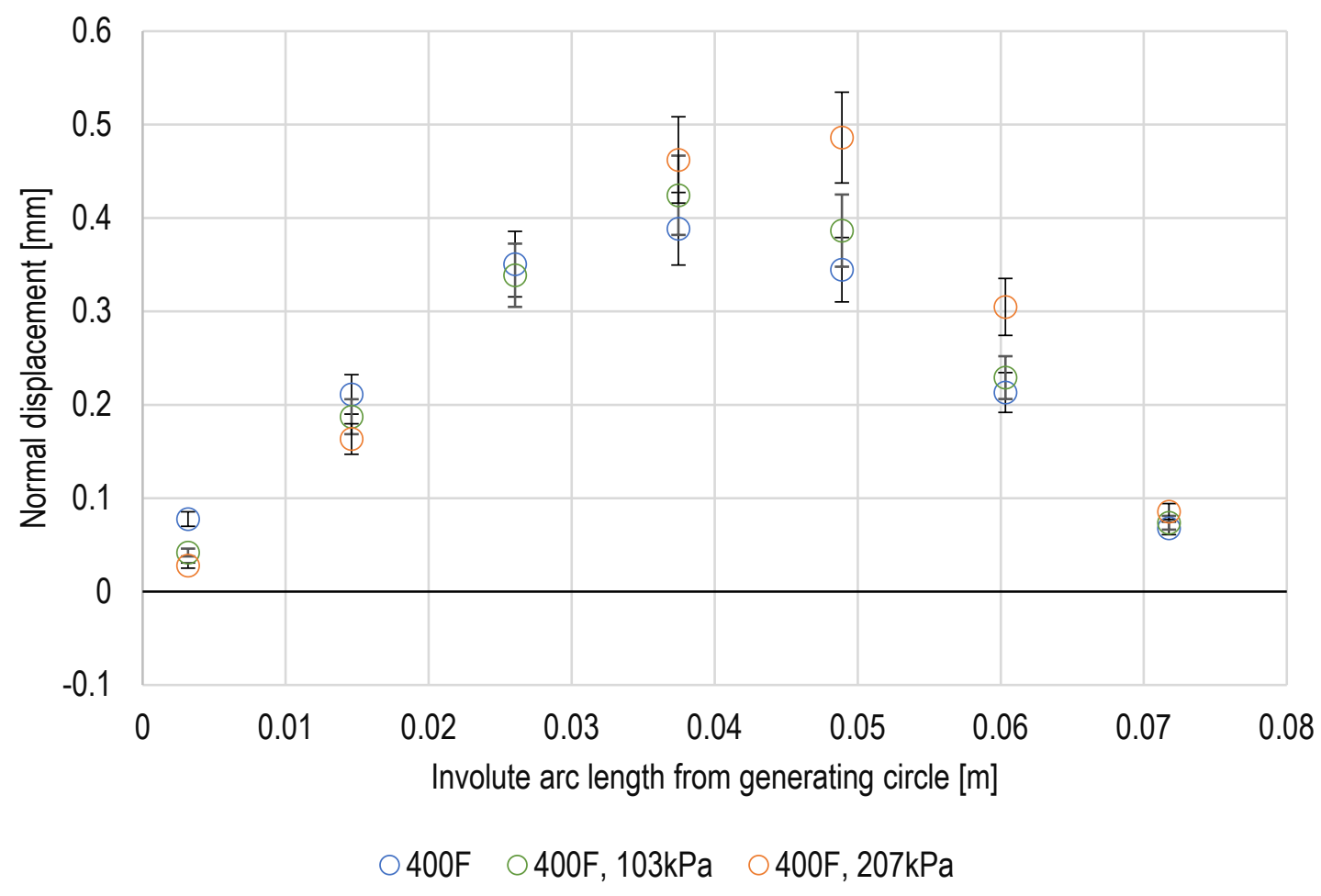

(b)

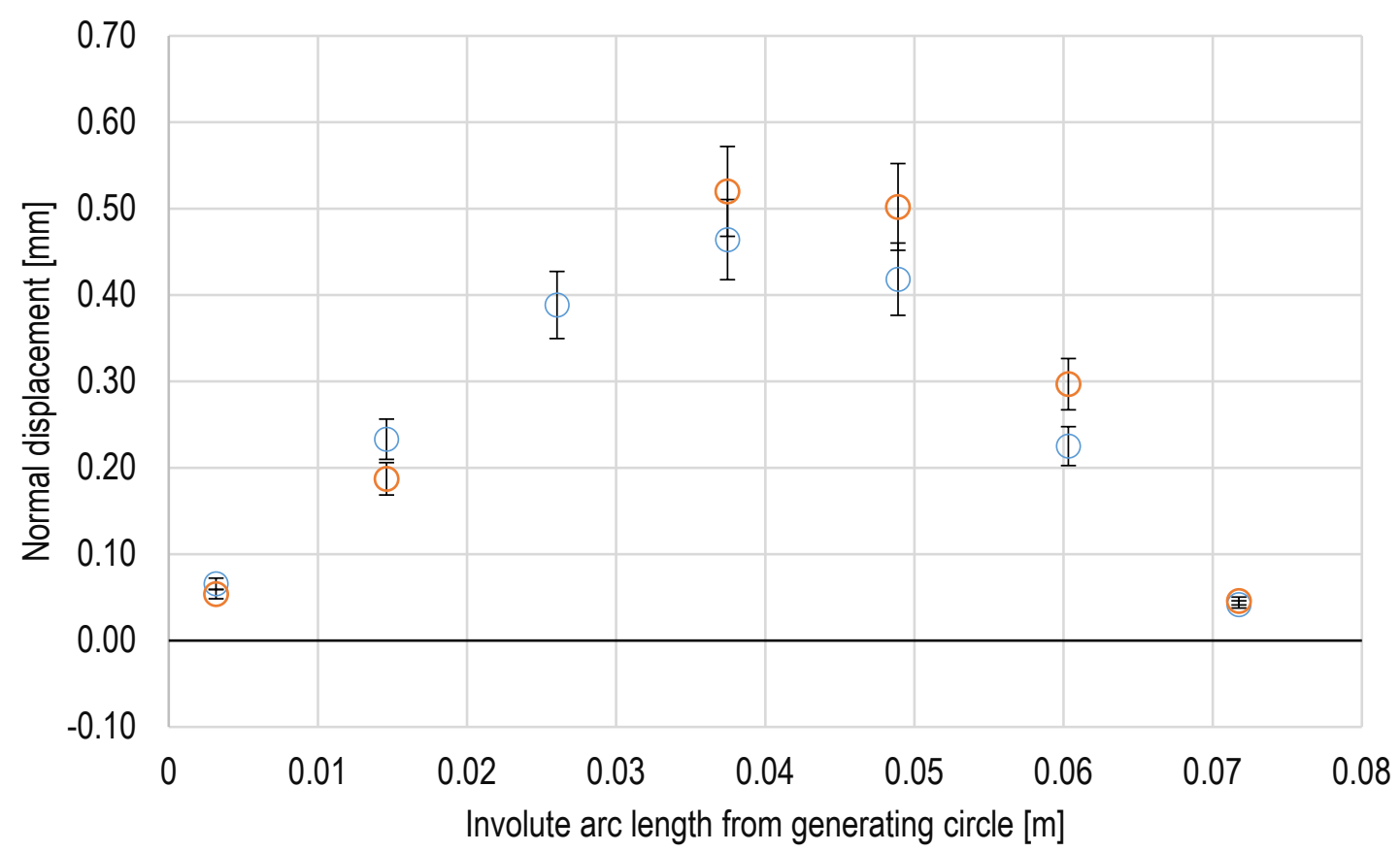

-400F $\bigcirc 400 \mathrm{~F}, 207 \mathrm{kPa}$

Figure D. 2. Digitized plot: normal displacements of the midspan of a plate under thermal and mechanical loads (a) without sealant, (b) with sealant (see Figure 5.13) 
(a)

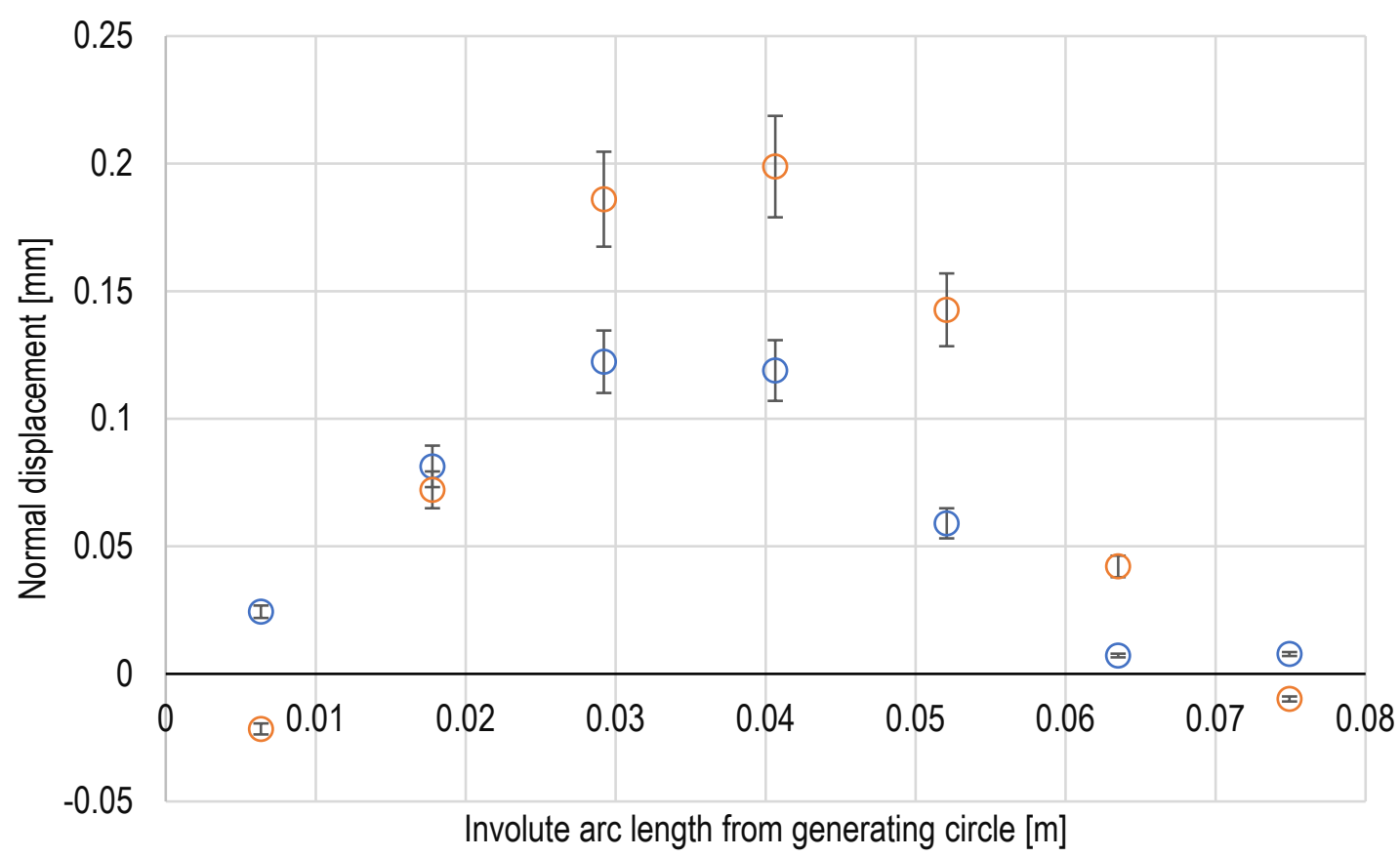

$\circ X=0 \quad X=0.6096 m$

(b)

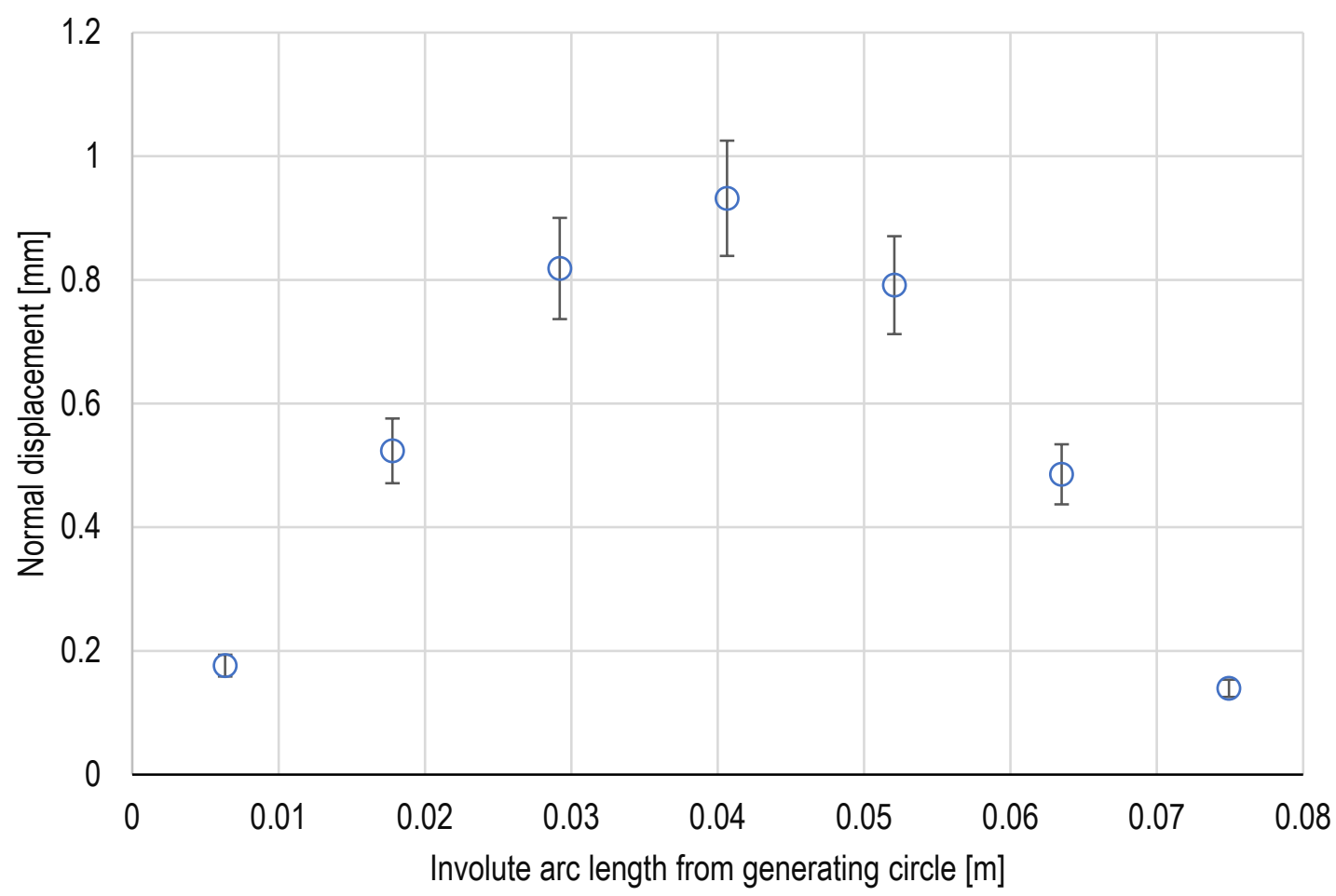

Figure D. 3. Digitized plot: normal displacements of the (a) ends and (b) midspan of a plate clamped in a solid Invar base (see Figure 5.11) 
(a)

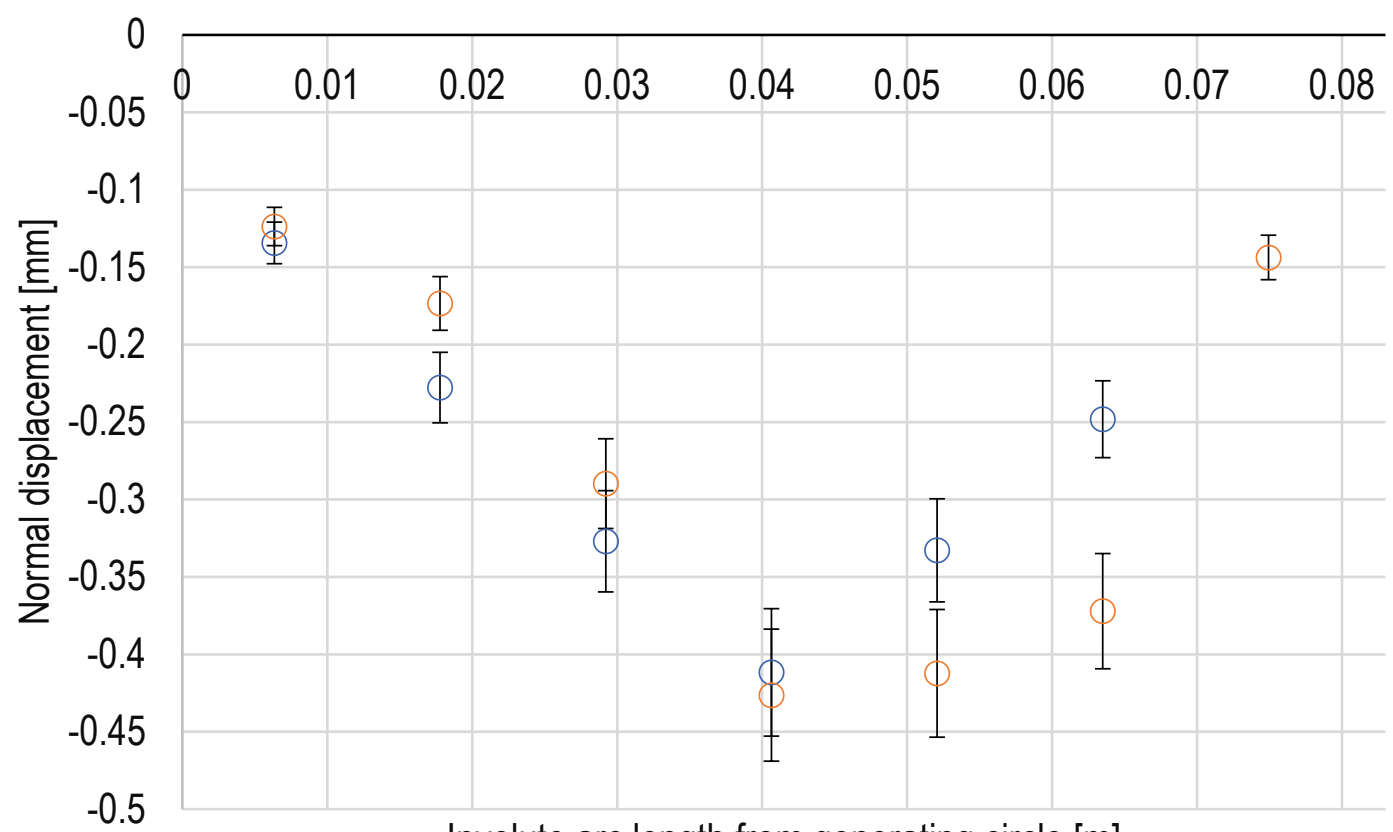

Involute arc length from generating circle [m]

$$
\bigcirc X=0 m \quad \bigcirc X=0.6096 m
$$

(b)

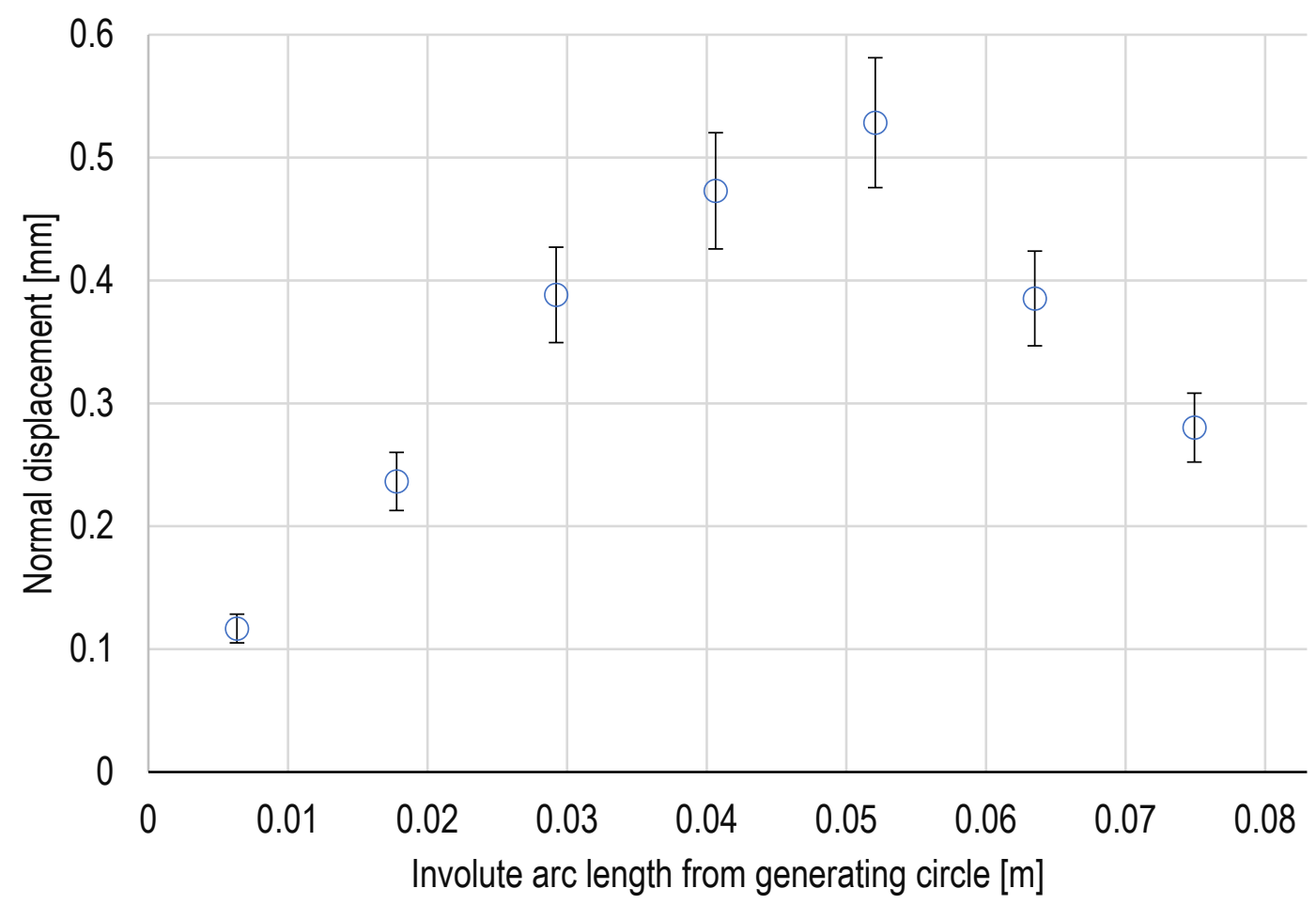

Figure D. 4. Digitized plot: normal displacements of the (a) ends and (b) midspan of a plate clamped in a split Invar base under temperature load (see Figure 5.11) 



\section{Argonne $\mathbf{A}$}

\section{Nuclear Science and Engineering Division}

Argonne National Laboratory

9700 South Cass Avenue, Bldg. 208

Argonne, IL 60439

www.anl.gov 